NOVEL SUPPORTS FOR COAL LIQUEFACTION CATALYSTS

By

Henıy W. Haynes, Jr.

January 1992

Work Performed Under Contract No. FG22-88PC88942

For

U.S. Department of Energy

Pittsburgh Energy Technology Center

Pittsburgh, Pennsylvania

By

University of Wyoming

Laramie, Wyoming 


\section{DISCLAIMER}

This report was prepared as an account of work sponsored by an agency of the United States Government. Neither the United States Government nor any agency thereof, nor any of their employees, makes any warranty, express or implied, or assumes any legal liability or responsibility for the accuracy, completeness, or usefulness of any information, apparatus, product, or process disclosed, or represents that its use would not infringe privately owned rights. Reference herein to any specific commercial product, process, or service by trade name, trademark, manufacturer, or otherwise does not necessarily constitute or imply its endorsement, recommendation, or favoring by the United States Government or any agency thereof. The views and opinions of authors ex. pressed herein do not necessarily state or reflect those of the United States Government or any agency thereof.

This report has been reproduced directly from the best available copy.

Available to DOE and DOE contractors from the Office of Scientific and Technical Information, P.O. Box 62, Oak Ridge, TN 37831; prices available from (615)576-8401, FTS 626-8401.

Available to the public from the National Technical Information Service, U. S. Department of Commerce, 5285 Port Royal Rd., Springfield, VA 22161. 
$\mathrm{DOE} / \mathrm{PC} / 88942-12$

DE92 011506

\section{NOVEL SUPPORTS FOR COAL LIQUEFACTION CATALYSTS}

By

Henry W. Haynes, Jr.

January 1992

Work Performed Under Contract No. DE-FG22-88PC88942

For

U.S. Department of Energy

Pittsburgh Energy Technology Center

Pittsburgh, Pennsylvania

By

University of Wyoming

Laramie, Wyoming 


\title{
NOVEL SUPPORTS FOR COAL LIQUEFACTION CATALYSTS
}

DOE/PC/88942-12

\author{
Henry W. Haynes, Jr.
}

\begin{abstract}
This research is divided into three parts: 1. Evaluation of Alkaline-Earth-Promoted CoMo/Alumina Catalysts in a Bench Scale Hydrotreater, 2. Development of a Novel Catalytic Coal Liquefaction Microreactor (CCLM) Unit, and 3. Evaluation of Novel Catalyst Preparations for Direct Coal Liquefaction.

The bench scale hydrotreating results demonstrated that hydrogenation activity could be maintained and at the same time coke formation could be reduced by adding calcium and magnesium to an otherwise finished CoMo/Alumina hydrotreating catalyst. Calcium was more effective. It was also shown by the temperature programmed desorption of $t$ butylamine that calcium and barium were effective in eliminating acid sites. Magnesium and beryllium were less effective. Thus, coking of the catalysts seemed to correlate with catalyst acidity while hydrogenation was unaffected. Hydrodenitrogenation was, however, affested adversely by the incorporation of alkaline earth metals into the composition.

The design and construction of the CCLM unit proceeded through three stages: 1 . cold model studies, 2. hydrotreating studies, and finally 3. coal liquefaction studies. This unit employs a novel ebullated bed microreactor which charges only five grams of catalyst. An optimum impeller design was identified during the cold model work, and correlations
\end{abstract}


were developed for characterizing the state of ebullation. High internal recycle rates insure that the reactor is perfectly mixed. A kinetics evaluation of the hydrotreating of a raw creosote oil demonstrated the capabilities of the unit for hydrotreating work. Thermal reactions were minimal, and no attrition of the catalyst was experienced. Operation of the unit in the coal liquefaction mode required that a coal paste syringe pump be installed. Early problems were experienced due to plugging of the inlet and outlet ports; but these were eliminated by directing cooling air on the fittings. After a limited process variable study, a set of operating conditions was identified for catalyst screening purposes.

An external layer of material, approximately $20 \mu \mathrm{m}$ in thickness, was observed on a used catalyst that had processed ARCO Black Thunder coal for ten days. This material was rich in calcium and sulfur consistent with the high calcium content of the coal ash. Attempts to regenerate this catalyst by combustion were not successful and the evidence suggests that this layer is easily sintered, thus blocking access to the interior of the particle.

Only limited catalyst screening was conducted prior to the termination of the grant period, and only preliminary results can be reported. A calcium modified CoMo/Alumina catalyst did not appear to offer any significant improvements over the unmodified catalyst. This suggests that a major contributor to the deactivation may be something other than coking. Perhaps the formation of a relatively impermeable "rind" on the external surface of the catalyst as described in the previous paragraph is a factor. A commercial zeolite containing residuum processing catalyst provided by Idemitsu, Inc., was also tested. 
I. INTRODUCTION $\ldots \ldots \ldots \ldots \ldots \ldots \ldots \ldots \ldots \ldots \ldots \ldots \ldots \ldots \ldots \ldots \ldots$

II. EVALUATION OF ALKALINE-EARTH-PROMOTED CoMo/ALUMINA CATALYSTS IN A BENCH SCALE HYDROTREATER . . . . . . . . 5

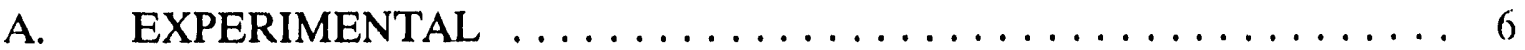

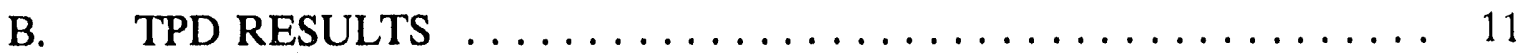
C. HYDROTREATING RESULTS $\ldots \ldots \ldots \ldots \ldots \ldots \ldots \ldots \ldots \ldots \ldots$

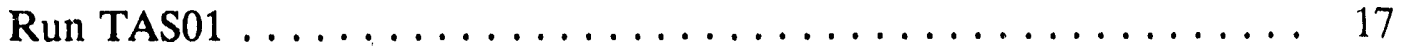

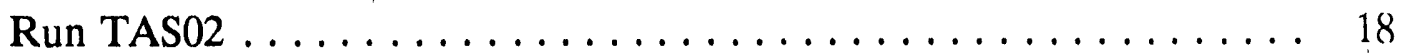
Run TASO3 ........................... 18

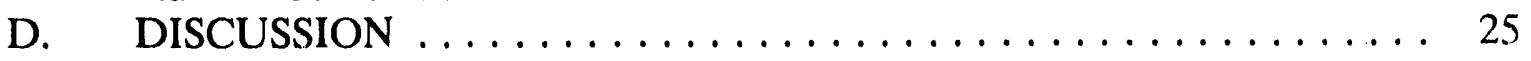
E. CONCLUSIONS ........................ 28

III. DEVELOPMENT OF A NOVEL CATALYTIC COAL LIQUEFACTION MICROREACTOR $($ CCLM) UNIT . . . . . . . . . . . . . . . 29

A. REACTOR COLD MODEL STUDIES $\ldots \ldots \ldots \ldots \ldots \ldots \ldots, 32$

1. Impeller Performance $\ldots \ldots \ldots \ldots \ldots \ldots \ldots \ldots \ldots, 36$

2. Dimensionless Cor elations $\ldots \ldots \ldots \ldots \ldots \ldots \ldots \ldots \ldots 41$

3. Internal Recycle Rates $\ldots \ldots \ldots \ldots \ldots \ldots \ldots \ldots \ldots \ldots$

4. Conclusions ......................... 57

B. HYDROTREATING STUDIES $\ldots \ldots \ldots \ldots \ldots \ldots \ldots \ldots \ldots$

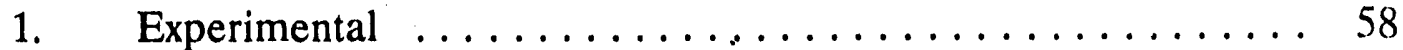

2. Results ........................... 64

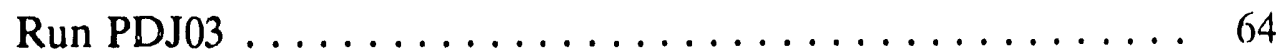

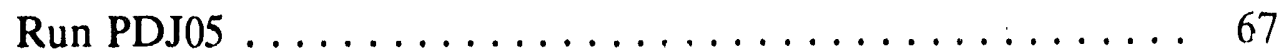

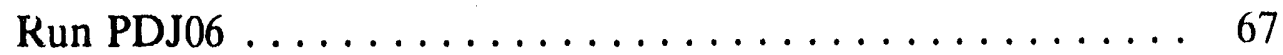

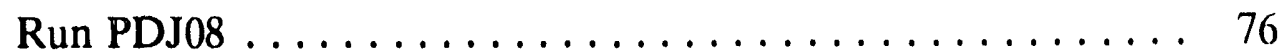

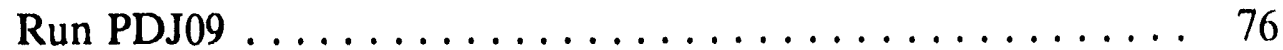

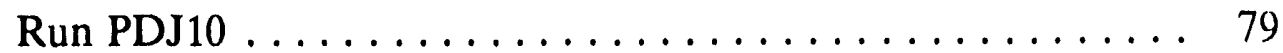

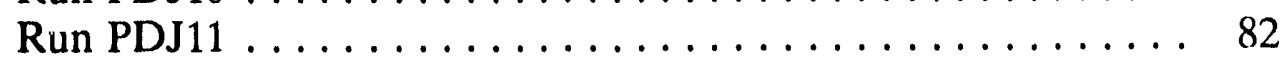

3. Analysis and Discussion .................. 82

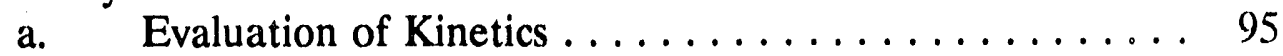

b. Catalyst Attrition ................... 100

c. Used Catalysts . . . . . . . . . . . . . . . . . . . . . . . . 104

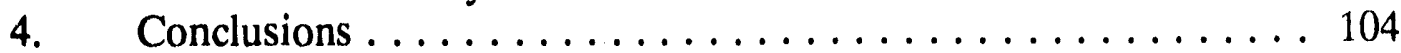

C. COAL LIQUEFACTION STUDIES $\ldots \ldots \ldots \ldots \ldots \ldots \ldots \ldots \ldots$

1. Experimental ......................... 107

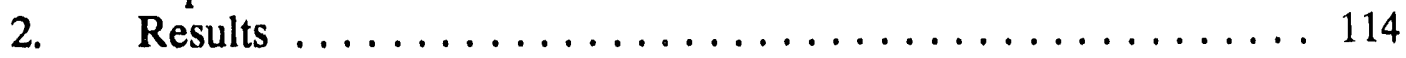

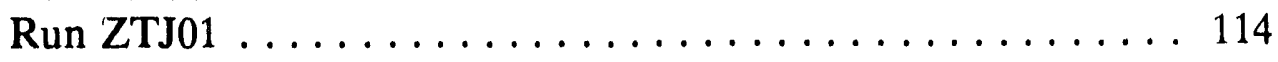




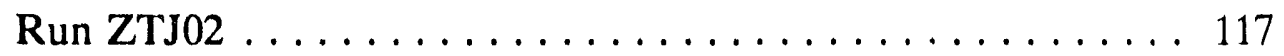

Run ZTJ03 ........................ 118

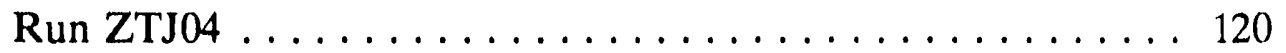

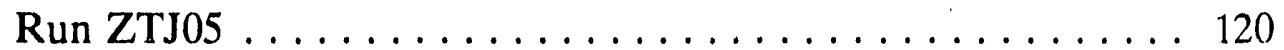

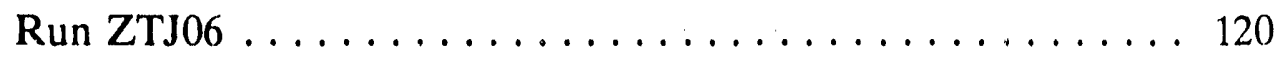

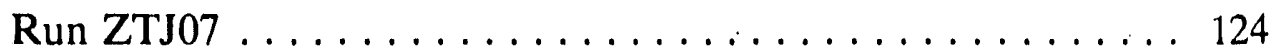

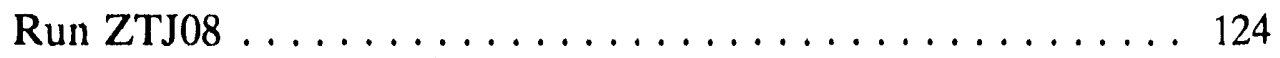

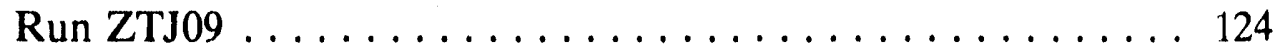

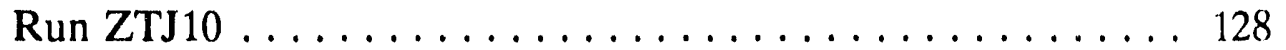

Run ZTJ11 ....................... 128

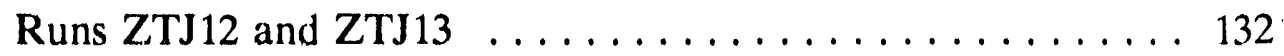

Run ZTJ14 ........................ 132

3. Analysis and Discussion ................... 132

4. Conclusions ........................... 159

IV. EVALUATION OF NOVEL CATALYST PREPARATIONS FOR DIRECT COAL LIQUEFACTION $\ldots \ldots \ldots \ldots \ldots \ldots \ldots \ldots \ldots \ldots \ldots \ldots \ldots$

A. Ca-MODIFIED AMOCAT-1A $\ldots \ldots \ldots \ldots \ldots \ldots \ldots \ldots \ldots 1$

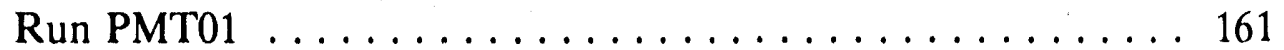

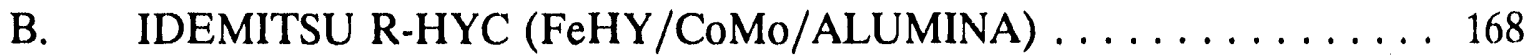

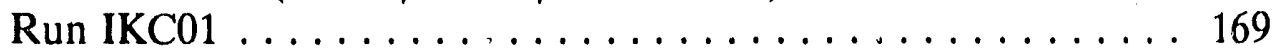

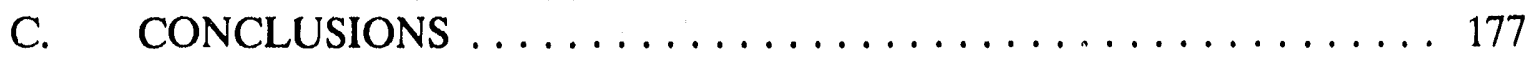

LITERATURE REFERENCES $\ldots \ldots \ldots \ldots \ldots \ldots \ldots \ldots \ldots \ldots \ldots$

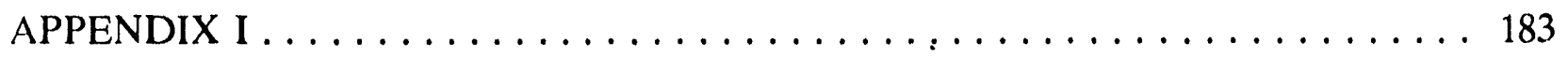

TEMPERATURE PROGRAMMED DESORPTION/CHEMISORPTION

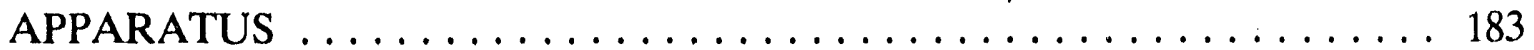

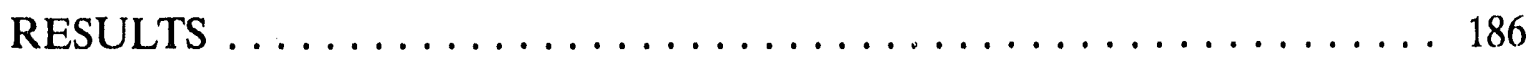




\section{INTRODUCTION}

Substantial improvements in direct coal liquefaction technology have been realized in recent years, and the effective utilization of heterogeneous catalysts has been a major factor in these improvements. The H-coal process (catalytic, single stage) demonstrated increased distillate yields and improved product quality by comparison to the SRC-II process (noncatalytic, single stage). The investigation of two stage processes began (or was renewed) in the eighties as it became evident that advantages could be realized by independently adjusting conditions in the first stage liquefaction reactor and the second stage hydrotreating reactor. Operations at Wilsonville in the Integrated Two-Stage Liquefaction (ITSL) thermal-catalytic mode produced further significant improvements in both distillate yields and product quality. The two reactors have now been close-coupled and catalyst has been added to the first stage with the result that distillate yields of the order of $70 \mathrm{wt} \%$ (maf basis) are typically realized with Illinois No. 6 coal (1).

It is clear that the addition of catalyst to the liquefaction reactor is advantageous, and it is not difficult to speculate as to why this is so. The insitu regeneration of hydrogen donor may be necessary to insure that free-radical coal fragments are quenched rapidly to prevent repolymerization $(2,3)$, and it has been shown that good hydrogen donor capacity is essential to reduce solvent adduction (4-6). It has been suggested that the catalyst may participate directly in the hydrogen transfer reactions between the hydrogen donor and the coal fragments (7). In view of these demonstrated process benefits it is important that we focus more attention to the development of catalysts specifically for coal liquefaction applications. 
Most researchers in direct coal liquefaction have employed "off the shelf" petroleum processing catalysts, and relatively little attention has been paid to the catalyst. In coal liquefaction the catalyst is subjected to very harsh environments. Temperatures tend to be much higher than in the closest commercial application in petroleum refining - residuum hydrodesulfurization. The feed is more aromatic, and metals and other coal ash components are present in great abundance. Not ouly is the catalyst in a much different environment as compared to petroleum processing, but the function of the catalyst is different. Simply put, the job of the coal liquefaction catalyst is to replenish hydrogen donor, i.e. to hydrogenate. It may not even be desirable to remove heteroatoms. Some evidence suggests that high nitrogen and oxygen contents are beneficial from the standpoint of solvent quality.

This research is devoted to the development of heterogeneous catalysts specifically for application to coal liquefaction. The number of such studies have been few, though particular note should be made of the very fine work at the Amoco Oil Company $(8,9)$ in the mid- and late seventies. These researchers found pore structure to be the single most important factor in designing a coal liquefaction catalyst. Many other investigators have tested a variety of catalyst preparations for coal liquefaction efficacy in batch autoclave reactors. Studies of this type date all the way back to prewar Germany (10). Unfortunately the amount of information that can be gained from batch autoclave studies is severely limited. Perhaps one can obtain a measure of initial activity from such experiments, but any inferences regarding the suitability of a catalyst for process applic $\mathrm{c}_{\mathrm{i}: \mathrm{i}} \cdots$, ns may be misleading. Indeed, experience in processing petroleum streams has shown that initial activity and activity maintenance are often inversely related. 
The reason that so much prior work has been conducted in batch reactors is undoubtedly due to the experimental difficulties that arise when one attempts to operate a continuous unit at the laboratory scale. A major effort during the present investigation was thus devoted to the development of a continuous Catalytic Coal Liquefaction Microreactor (CCLM). This unit possesses several truly unique features. Most notable is the reactor which operates in a liquid fluidized or "ebullated" bed state. The catalyst charge is only five grams, typically, which makes it ideal for catalyst screening. Small batches of catalyst can be prepared for testing. Although not demonstrated in the present report, the reactor should provide an excellent means of evaluating coal liquefaction kinetics. Internal recycle ratios typically exceed $1000 / 1$ making the reactor essentially gradientless. Another unique feature of the unit is the manner in which coal is introduced into the reactor. The pumping of coal slurry at rates of the order of $10 \mathrm{~cm}^{3} / \mathrm{hr}$ is not feasible using currently available components. This problem was solved by introducing the coal as a paste, i.e. by extruding the paste into the inlet line to the reactor.

As the development of the continuous coal liquefaction unit progressed, a parallel study was undertaken to prepare, characterize, and evaluate a series of alkaline earth prowinoted CoMo/Alumina catalysts. These preparations were first evaluated in a bench scale hydrotreater using a coal derived liquid as the feedstock. Toward the end of the project some similar preparations were tested in the coal liquefaction unit. This report is therefore divided into three sections:

- Evaluation of Alkaline-Earth-Promoted CoMo/Alumina Catalysts in a Bench Scale Hydrotreater

- Development of a Novel Catalytic Coal Liquefaction Microreactor 
- Evaluation of Novel Catalyst Preparations for Direct Coal Liquefaction This project is ongoing. Now that the Catalytic Coal Liquefaction Microreactor is operational, our attention is again directed towards the preparation and testing of novel coal liquefaction catalysts. Prior work in our laboratory has identified several attractive candidates for further testing under actual coal liquefaction conditions. 


\section{EVALUATION OF ALKALINE-EARTH-PROMOTED CoMo/ALUMINA CATA- LYSTS IN A BENCH SCALE HYDROTREATER}

The promotion of $\mathrm{Co}($ or $\mathrm{Ni}) \mathrm{Mo} /$ Alumina catalysts with percentage quantities of alkali or alkaline earth metals has been proposed as a means of reducing carbon formation on catalysts subjected to a high coking environment $(11,12,13)$. Most investigators report a loss of activity to accompany the incorporation of these components into the catalyst formulation (14-18). The presence of alkali serves to inhibit the reduction of molybdenum to the $\mathrm{Mo}^{4+}$ oxidation state, and the original octahedral coordination of $\mathrm{Mo}^{6+}$ is transformed into a tetrahedral coordination (19-22). Similar results are reported for alkaline earth promoted catalysts (23). However, the manner in which the alkali or alkaline earth is introduced into the composition, and the relative amount of promotor to active metal appear to be important factors. Activity losses are minimized if alkali is added after the active metals $(17,24)$. Furthermore, $O^{\prime} Y$ oung has shown that reducibility is not significantly altered by comparison to the alkali free catalyst provided that the alkali-molybdenum atomic ratio is less than unity (25). It is probably also significant that O'Young's preparations involved the addition of alkali components to an otherwise finished catalyst.

An carlier contribution from our group describes a study in which a sodium promoted nickel molybdate catalyst was compared with the untreated catalyst while hydrotreating a coal-derived liquid (26). In terms of hydrogenation activity, the treated and untreated catalysts were essentially equivalent. Both possessed excellent activity and this activity was well maintained over the 400 hour run duration. Carbon deposition on the used catalyst was substantially reduced by the sodium treatment. The incorporation of sodium into the catalyst did, however, reduce the hydrodenitrogenation activity. The present study was 
undertaken to ascertain whether similar effects could be realized by promotion with the alkaline earth metals. We also present the results of catalyst acidity measurements to aid in the interpretation of reaction data for both alkali and alkaline earth promoted catalysts.

\section{A. EXPERIMENTAL}

Catalyst deactivation runs were conducted in the bench scale trickle bed hydrotreater of Figure 1. Briefly, the reactor consists of a 0.402 in. i.d. type 316 stainless-steel tube with a 0.125 in. o.d. thermocouple well extending through the bed along the axis. The reactor was charged with approximately $3 \mathrm{~g}$ of catalyst (1/16 in. extrusions) diluted with $6-7 \mathrm{~g}$ of quartz chips (10 - 30 mesh) sufficient to extend the bed length to 6 in. A jacket surrounding the reactor tube allowed the injection of air to cool hot spots in the bed. The reactor-jacket assembly was positioned near the center of a 22 in. tubular furnace. With this arrangement

the temperature spread was typically 5 or $6^{\circ} \mathrm{C}$. Liquid feed and hydrogen passed cocurrently in down flow through the bed. The liquid product was collected in high pressure accumulators and the gas product was monitored via a wet test meter and collected in butyl rubber gas bags for analysis. Prior to a run the catalyst was presulfided with a $5 \mathrm{wt} \%$ $\mathrm{CS}_{2} /$ cyclohexane mixture following a standard temperature program which culminated in a two hour hold at $440^{\circ} \mathrm{C}$.

At this scale of operation it is difficult to obtain reliable kinetics information due principally to the low liquid mass velocities characteristic of such systems $(27,28)$. One should therefore not attach too much significance to the absolute values of the reported rate constants. Rather it is the relative values of the rate constants that are significant. The system has proven to be a reliable catalyst screening tool. Replicate runs with identical 


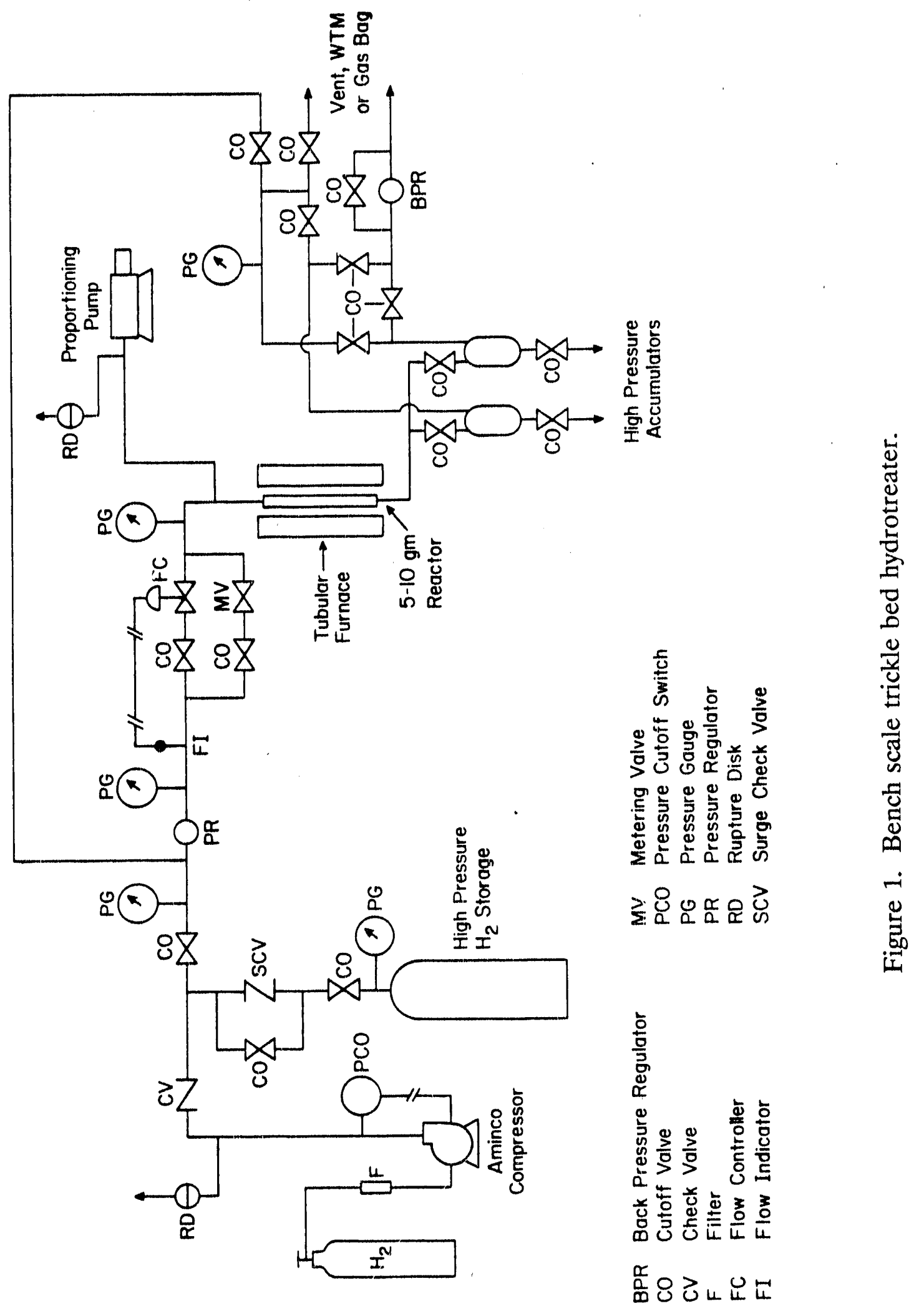


catalyst charges have demonstrated that the data are reproducible (29). Deactivation run conditions were chosen such that differences in activity level are readily observed.

Acid sites characterization was by the temperature programmed desorption (TPD) of tert-butylamine. (See Appendix I). From the TPD spectrum a relative acid density (RAD) was calculated by dividing the area under the high-temperature acid peak ( $\beta$-peak) by the BET surface area. This quantity is an indicator of the acid sites density when compared with other catalysts in the program. All catalysts were presulfided in $10 \% \mathrm{H}_{2} \mathrm{~S} / \mathrm{H}_{2}$ prior to the TPD experiment.

The catalyst selected for this investigation was a CoMo/Alumina catalyst (Amocat 1A) provided by the Amoco Oil Company. This catalyst was designed specifically for coal liquefaction applications as described in Amoco reports $(8,9)$. Properties of the catalyst are compiled in Table 1. The alkali and alkaline earth promoted catalysts were prepared from Amocat $1 \mathrm{~A}$ by incipient wetness impregnation with aqueous nitrates. Exceptions are the barium promoted catalysts which, because of solubility considerations, were prepared from aqueous nitrites. The nitrite was also employed in the sodium impregnations for consistency with earlier work (26). All catalysts, including the untreated catalyst, were calcined in flowing air at $450^{\circ} \mathrm{C}$ for four hours.

The feedstock was a mildly hydrogenated creosote oil $\left(560-835^{\circ} \mathrm{F}\right)$ spiked with 20 wt $\%$ ash free residuum material $\left(1050^{+{ }^{\circ}} \mathrm{F}\right)$ produced at the Advanced Coal Liquefaction Research Facility at Wilsonville, Alabama, during Run 247. Properties of the feedstock HCO1-R are compiled in Table 2. 
Table 1. Fresh Catalyst Properties

\begin{tabular}{|c|c|c|c|}
\hline & Amocat 1A & Mg-Promoted & Ca-Promoted \\
\hline $\mathrm{wt} \% \mathrm{MoO}_{3}$ (nominal) & 16 & 16 & 16 \\
\hline $\mathrm{wt} \% \mathrm{CoO}$ (nominal) & 3 & 3 & 3 \\
\hline $\mathrm{wt} \% \mathrm{MgO}$ & --- & 3.8 & $\cdots$ \\
\hline $\mathrm{wt} \% \mathrm{CaO}$ & --- & $\cdots$ & 5.3 \\
\hline BET Surface Area, $\mathrm{m}^{2} / \mathrm{g}$ & 167 & 144 & 135 \\
\hline Pore Volume ( $>60 \AA$ dia.), $\mathrm{cm}^{3} / \mathrm{g}$ & 0.71 & 0.69 & 0.69 \\
\hline Avg. Micropore Diameter, $\AA$ & 130 & 125 & 125 \\
\hline Avg. Macropore Diameter, $\AA$ & 4500 & 4500 & 4500 \\
\hline Relative Acid Density & 0.049 & 0.036 & 0 \\
\hline
\end{tabular}


Table 2. Feedstock Properties (HC01-R)

$\begin{array}{lc}\text { wt } \% \text { C } & 91.43 \\ \text { wt } \% \mathrm{H} & 6.84 \\ \text { wt } \% \mathrm{~S} & 0.20 \\ \text { wt } \% \mathrm{~N} & 0.68 \\ \text { wt } \% \text { O (BD) } & 0.85 \\ \text { wt \% Asphaltene } & 12 \\ \text { wt\% Preasphaltene } & 4 \\ \text { Sp. Gr. (60/60 F) } & 1.1232\end{array}$


BET surface areas were calculated from the nitrogen adsorption isotherm at liquid nitrogen temperature. Pore size distributions were obtained by mercury porosimetry. Prior to characterization, all used catalysts were extracted in tetrahydrofuran (THF) for 24 hours and dried under vacuum at $100^{\circ} \mathrm{C}$ for 48 hours. The used THF extracted catalysts were analyzed for carbon-hydrogen content in a combustion tube apparatus.

\section{B. TPD RESULTS}

The acidity of CoMo/Alumina catalysts arises from two sources. The support, pure $\gamma$-alumina, possesses a wide distribution of Lewis acid sites (30-34). When molybdenum is added to the alumina support and calcined, Brönsted acidity appears (30-33,35,36). Less information is available for the sulfide state. Hou and Wise (37) observed acid sites on molybdenum sulfide and found that surface acidity was enhanced in the presence of hydrogen sulfide. Lipsch and Schuit have postulated that the interaction of $\mathrm{H}_{2}$ with $\mathrm{MoS}_{2}$ results in the formation of SH groups which are acidic in the Brönsted sense (38). Boorman and coworkers (39) failed to detect evidence of Brönsted acidity in an IR study of sulfided CoMo/Alumina catalysts that had been subjected to fluoride treatment. Yet these catalysts were active for cumene dealkylation and cyclohexane isomerization, reactions known to proceed on protonic sites. In our own investigations using the TPD of t-butylamine (33) we observe a wide flat spectrum on pure $\gamma$-alumina. The addition of molybdenum gives rise to a relatively sharp high temperature peak. Sulfiding reduces, but does not eliminate this peak. Promotion with Co or Ni does not appear to greatly alter the acidic properties of Mo/alumina. 
A series of catalysts was prepared by loading the Amocat $1 \mathrm{~A}$ with percentage quantities of $\mathrm{Li}, \mathrm{Na}, \mathrm{K}, \mathrm{Be}, \mathrm{Mg}, \mathrm{Ca}$ and $\mathrm{Ba}$. These were then subjected to analysis by the TPD of $t$-butylamine. Prior to the analysis the catalysts were sulfided in $10 \% \mathrm{H}_{2} \mathrm{~S} / 90 \% \mathrm{H}_{2}$. TPD spectra for the Na promoted catalysts are presented in Figure 2. As observed earlier by Baker $(26,33)$ the increased loadings of $\mathrm{Na}$ gradually neutralize the acidity. Acidity is completely eliminated at a $\mathrm{Na} / \mathrm{Mo}$ mole ratio of 1.2 . Similar results were observed with $\mathrm{Li}$ and $\mathrm{K}$ promoted catalysts. The Relative Acid Density (RAD), which is obtained by dividing the high temperature peak area by the BET surface area, is plotted in Figure 3 for all three promotor metals. The effect is much the same in all three cases.

The Mg promoted catalyst preparations were subjected to TPD analysis next, and the results are shown in Figure 4. Unlike the alkalis, promotion with $\mathrm{Mg}$ does not completely eliminate the acid peak. Similar results were observed with $\mathrm{Be}$. Ca on the otherhand, behaves much as the alkali metals, Figure 5, and the same is true for $\mathrm{Ba}$. Relative acid densities for all four alkaline earths are plotted in Figure 6. Additional samples of $\mathrm{Ca}$ loaded catalysts were prepared and tested to locate the point at which the high temperature peak is eliminated. This occurs at a loading of about $\mathrm{Ca} / \mathrm{Mo}=0.9$ mole ratio.

Because of these observed differences in acidity, the Mg- and Ca-promoted catalysts were selected for further study in the hydrotreating unit. The Ca-promoted catalyst contained $5.3 \mathrm{wt} \% \mathrm{CaO}$ and the Mg-promoted catalyst contained $3.8 \mathrm{wt} \% \mathrm{MgO}$. Both weight percentages correspond to a loading of 0.9 mole of alkaline earth $/ \mathrm{mole}$ of molybdenum. Properties of the promoted catalysts are also listed in Table 1. Cumulative 


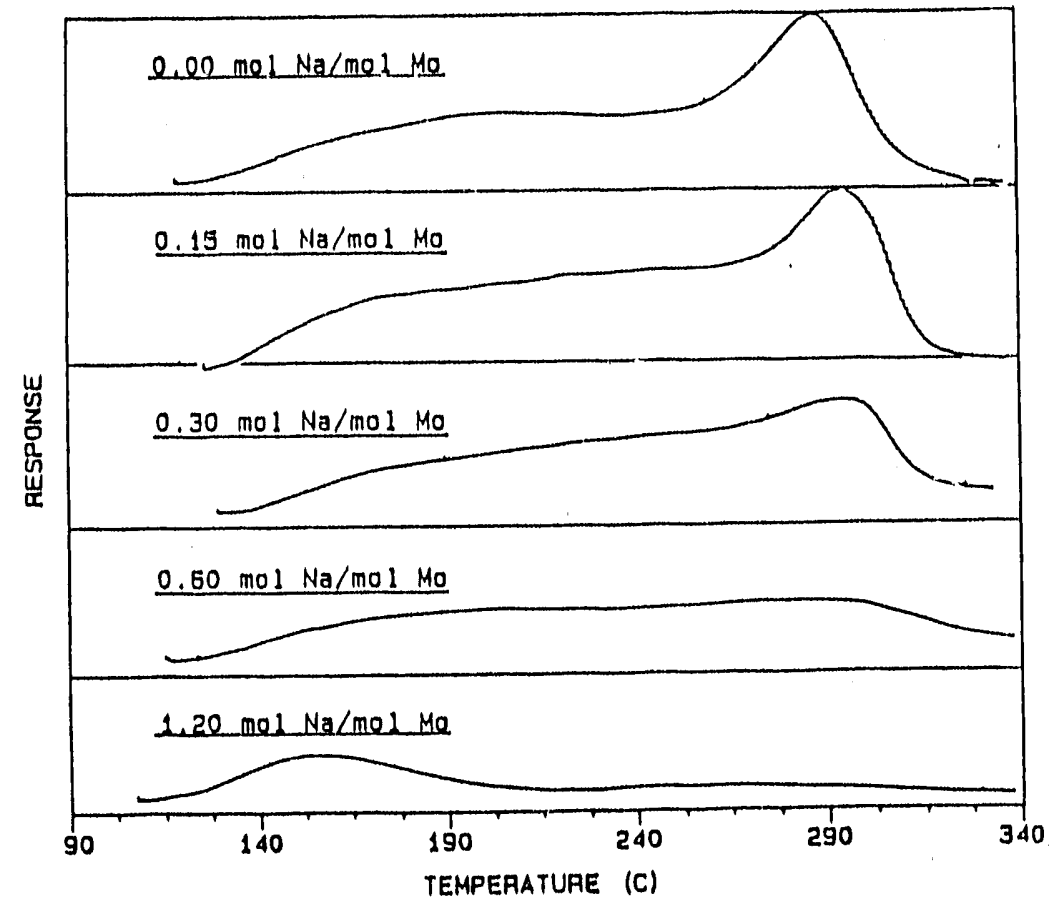

Figure 2. Effect of sodium loading on the TPD spectra of Amocat 1A.

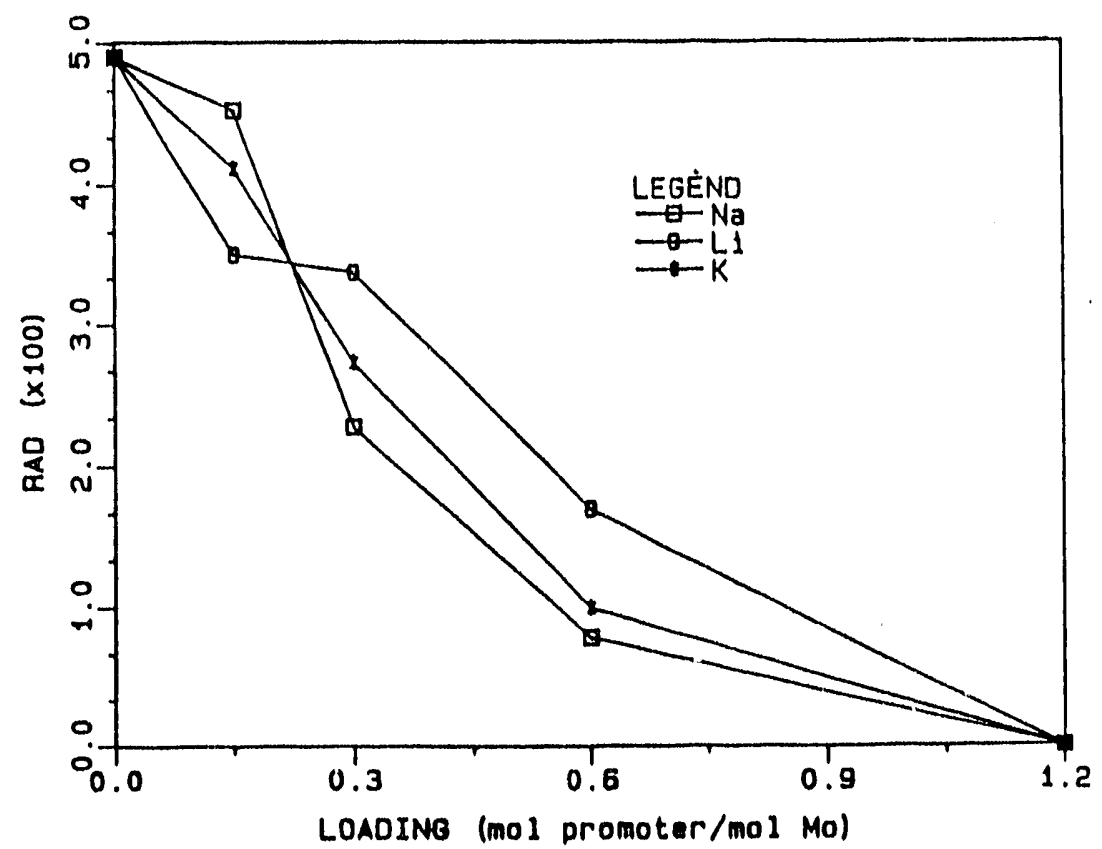

Figure 3. RAD values versus loading of alkali metals. 


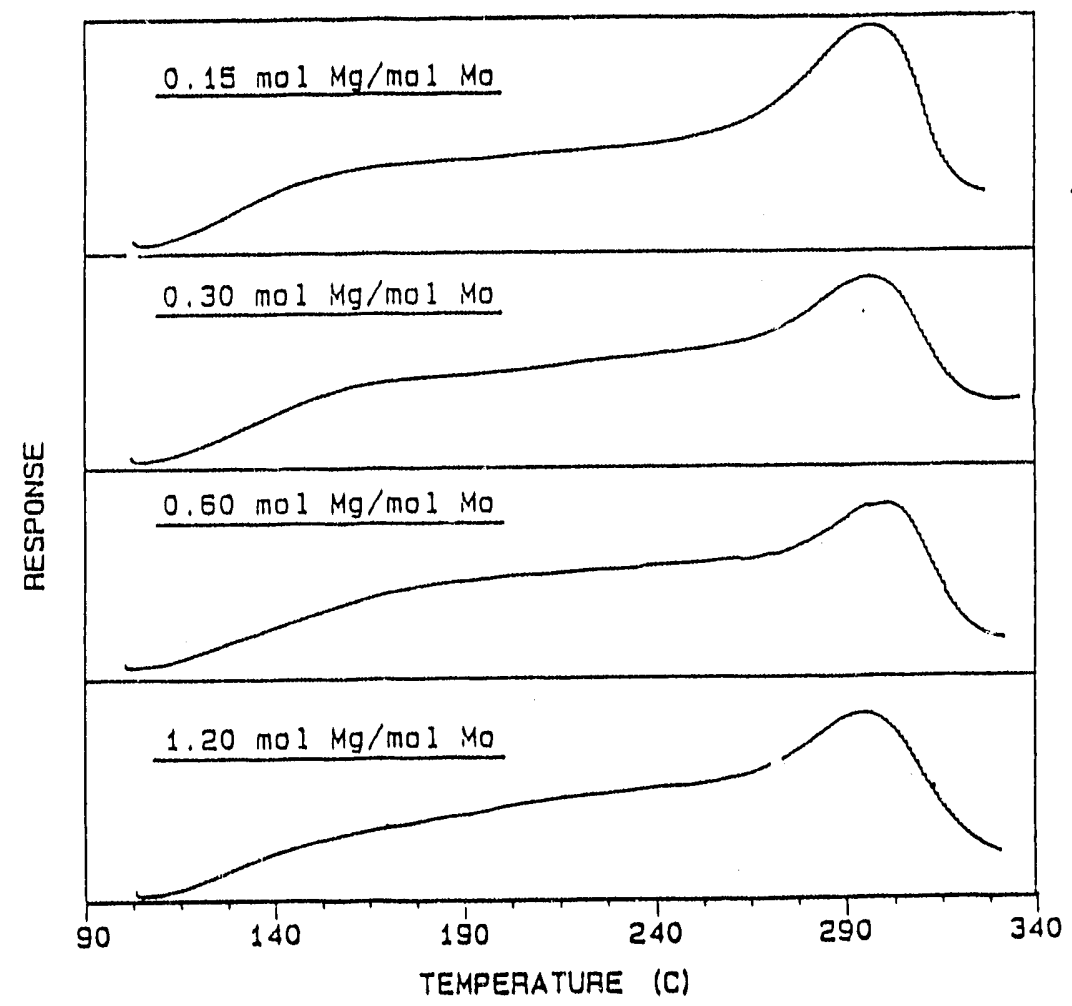

Figure 4. Effect of magnesium loading on the TPD spectra of Amocat 1A.

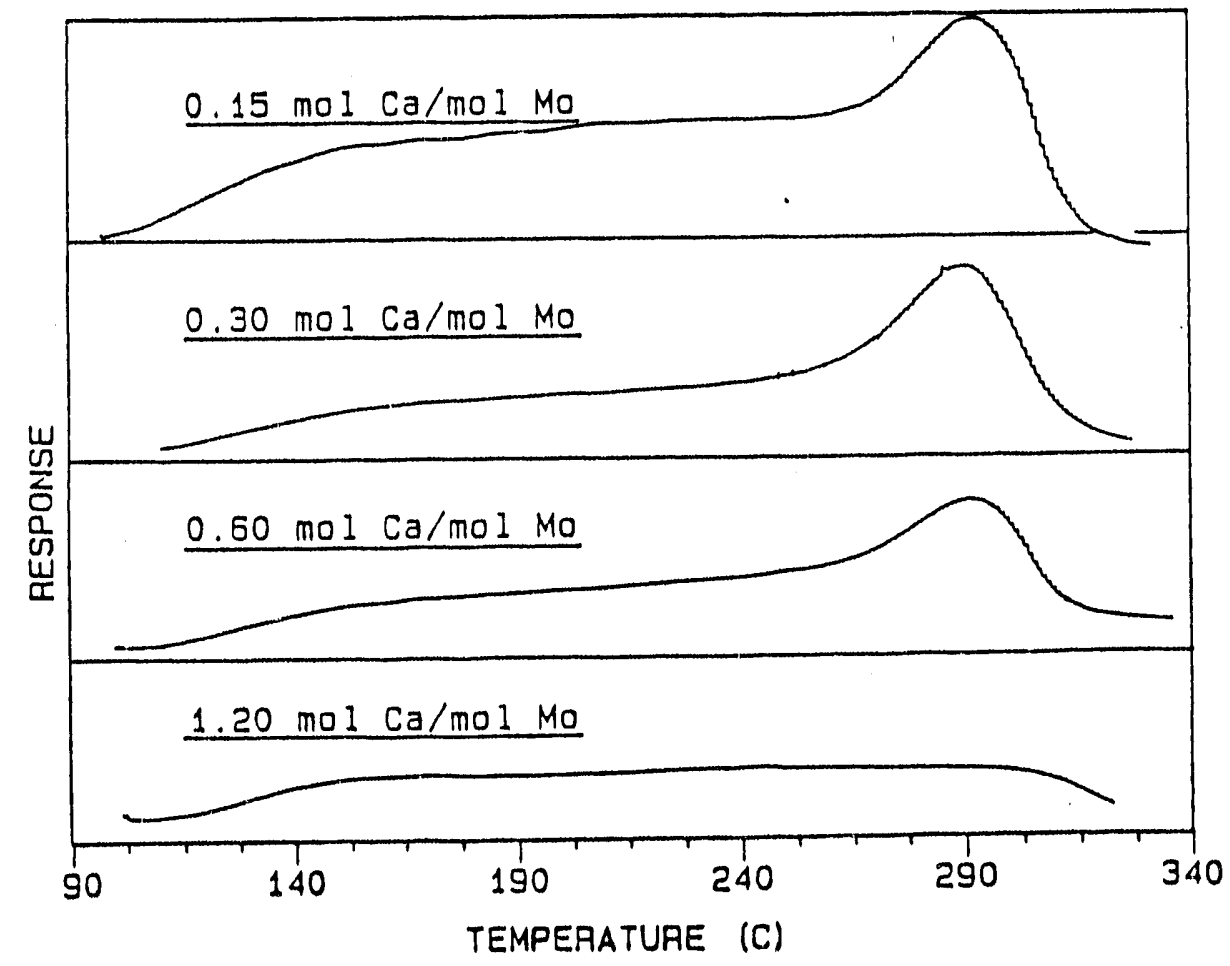

Figure 5. Effect of calcium loading on the TPD spectra of Amocat 1A. 


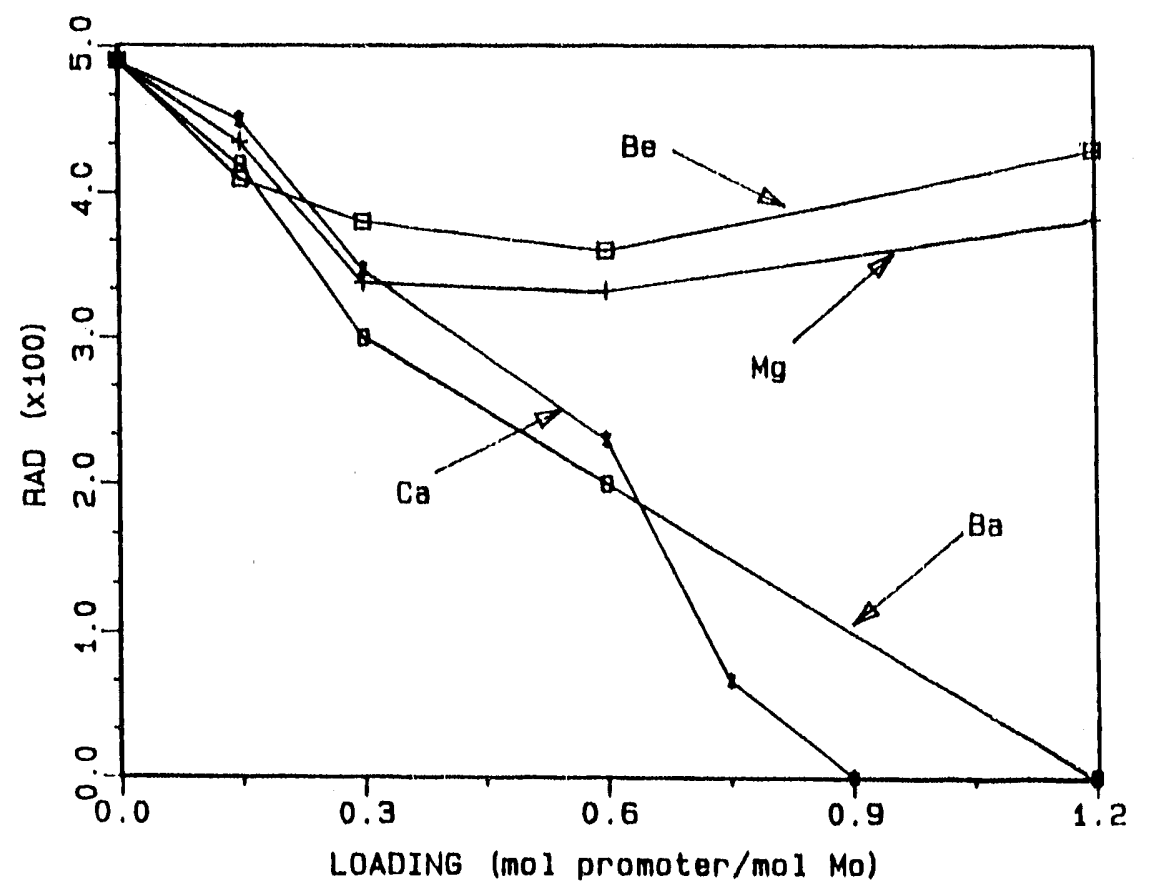

Figure 6. RAD values versus loading of alkaline earth metals.

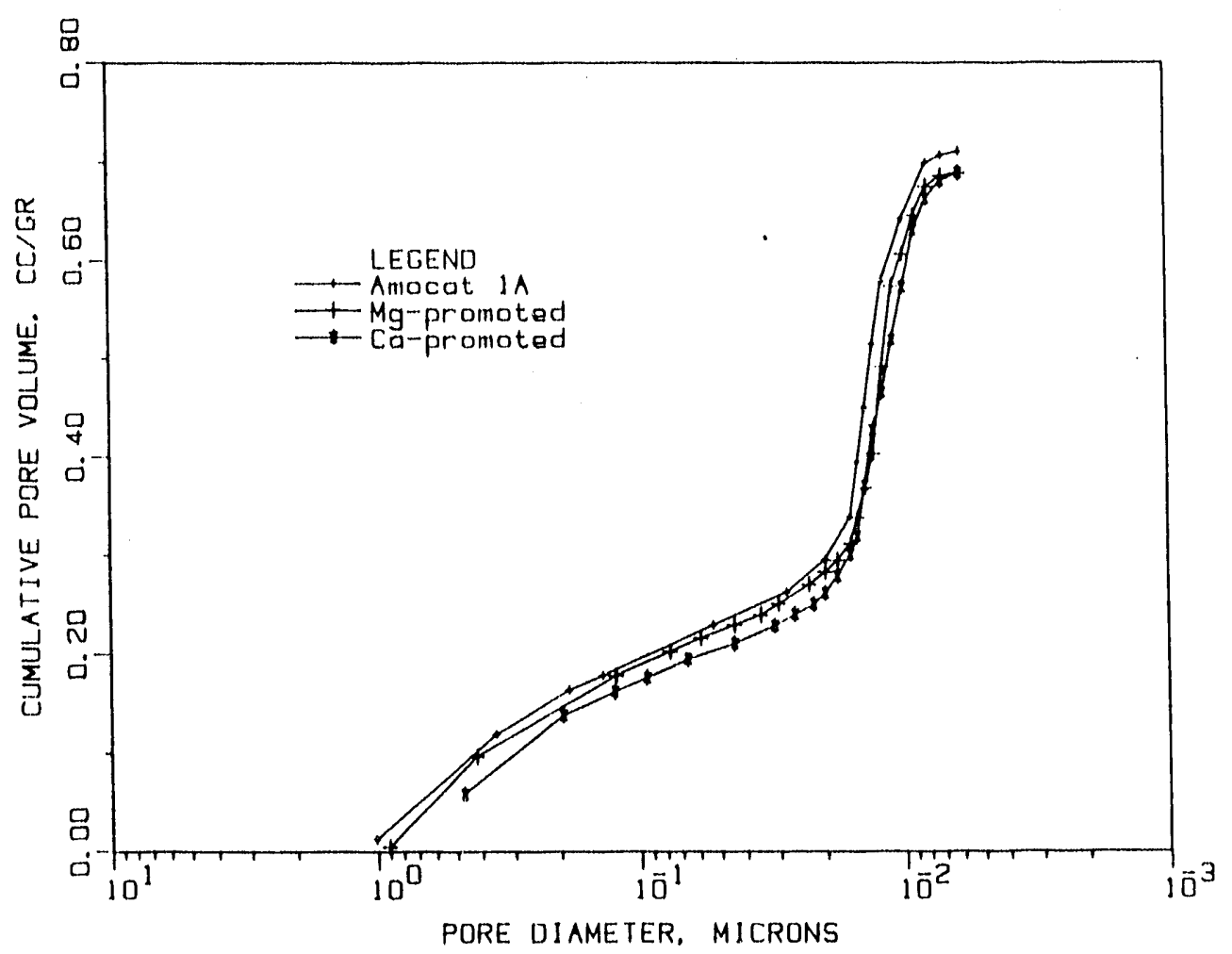

Figure 7. Cumulative pore size distributions for fresh catalysts. 
pore size distributions are plotted in Figure 7. Though some reduction in surface area is evident with the promoted catalysts, the pore structures are not seriously altered.

\section{HYDROTREATING RESULTS}

In many cases it was necessary to make small corrections for deviations from the target temperature. The first step was to calculate an "Effective Isothermal Temperature", $T_{E}$, which we define as the temperature (assumed constant) which gives the same convers' on as observed. The EIT is calculated from an integration over the measured axial temperature profile according to the relation:

$$
\exp \left(-E_{d} / R T_{E}\right)=\frac{1}{L} \int_{0}^{L} \exp \left(-E_{d} / R T\right) d z
$$

For typical axial temperature variations of only a few degrees, this calculation is insensitive to values of the activation energy. All calculations were therefore based on a value of $E_{a}$ $=10 \mathrm{kcal} / \mathrm{mole}$. The second step was to correct the observed rate constant, $k_{\text {obs }}$, to the target temperature, $\mathrm{T}$, using the Arrhenius relation:

$$
k=k_{o b s} \exp \left[-\frac{E_{a}}{R}\left(\frac{1}{T}-\frac{1}{T_{E}}\right)\right]
$$

From an earlier process variable study (40) the activation energy for hydrogen uptake was taken as $E_{a}=3500 \mathrm{cal} / \mathrm{mole}$. A literature value of $E_{a}=14800 \mathrm{cal} / \mathrm{mole}(41)$ was assumed for the hydrodenitrogenation kinetics.

Rate constants for hydrodenitrogenation were calculated from the relation: 


$$
k_{N}=-\frac{1}{\tau_{w}} \ln \left(\frac{N}{N_{F}}\right)
$$

Where $\tau_{w}$ is the weight hourly space time and $N$ is the weight percent nitrogen in the liquid product. The F-subscripted quantity refers to the feed. Equation (3) is based on the assumption of first order irreversible kinetics. Hydrogen uptake is reversible, so the HYD rate constant was calculated for the first order, reversible expression:

$$
k_{H}=-\frac{1}{\tau_{k}} \ln \left(\frac{H_{E}-H}{H_{E}-H_{F}}\right)
$$

where $H$ is the weight percent hydrogen in the product. On the basis of earlier work (40), the equilibrium hydrogen content was taken as $\boldsymbol{H}_{\boldsymbol{E}}=9.035 \mathrm{wt} \%$. Meaningful hydrodesulfurization results could not be obtained because conversion levels often approached $100 \%$.

The hydrotreating runs were assigned the designations TAS1, TAS2 and TAS3, respectively, for the $\mathrm{Ca}-\mathrm{Mg}$ - and unpromoted catalysts. Deactivation runs were conducted while maintaining conditions constant at $\mathrm{P}=2000 \mathrm{psig}, \mathrm{T}=825^{\circ} \mathrm{F}\left(440^{\circ} \mathrm{C}\right), \mathrm{WHSV}=3$ and $\mathrm{H}_{2}$ treat rate $=5500 \mathrm{SCF} / \mathrm{bbl}$. These conditions, while severe by hydrotreating standards, are not out of line when compared to coal liquefaction conditions. All three runs were targeted for 10 days or 250 hours of continuous operation.

\section{Run TAS01:}

Operability was good during this run with the Ca-promoted catalyst. A minor upset occurred between the third and fourth yield periods when a valve on the high pressure hydrogen storage tank developed a leak. As a consequence the reactor pressure dropped 
to 1940 psi and hydrogen flow ceased for about 3 to 4 hours. The leaking valve was repaired and the run was continued without further problems.

The effective isothermal temperatures ranged from $439.4^{\circ} \mathrm{C}$ to $441.4^{\circ} \mathrm{C}$, very close to the target of $440^{\circ} \mathrm{C}$. Pressures (except for the problem mentioned in the previous paragraph) ranged from 1980 to 2040 psi. Carbon material balances ranged from about 90 to 99 percent. Run summaries are presented in Table 3. Elemental analyses of liquid products from the 5th, 7th and 9th balance periods were not obtained in order to save on analytical costs.

\section{Run TAS02:}

The Mg-promoted catalyst was investigated during Run TAS02. Operability was excellent from beginning to end. The effective isothermal temperatures ranged from $440.2^{\circ} \mathrm{C}$ to $440.6^{\circ} \mathrm{C}$ and pressures were right on target (between 1995 psi and 2005 psi). Carbon balances were again somewhat low. The Run Summaries are compiled in Table 4. As indicated in this table, some elemental analyses were not performed.

\section{Run TAS03:}

Several upsets were experienced during this run with the unpromoted Amocat $1 \mathrm{~A}$ catalyst. At the beginning of the run as the temperature profile was being adjusted, a short power outage left the reactor at temperature under flowing hydrogen without feed flow. This situation went uncorrected for less than one hour. Because of the short duration of this mishap, it was decided to continue the run. An additional upset was experienced while ending the 9 th balance period. A valve was accidentally opened to a nonpressurized 


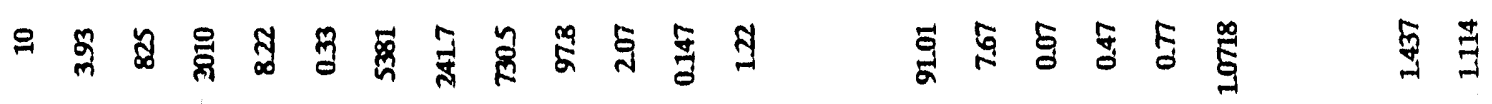

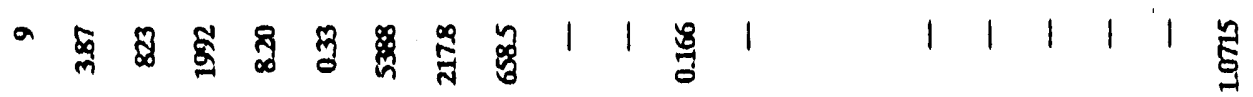

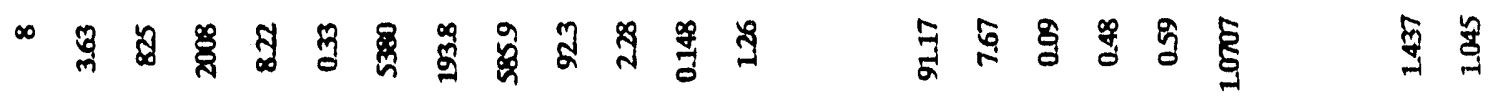

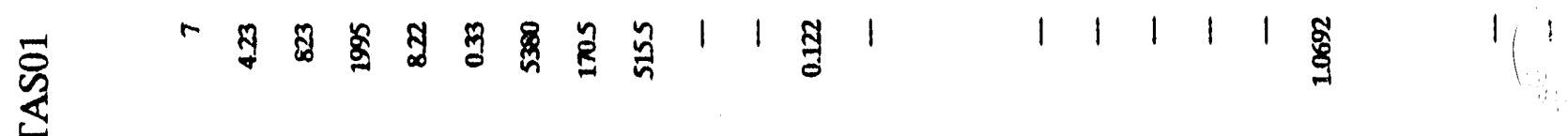

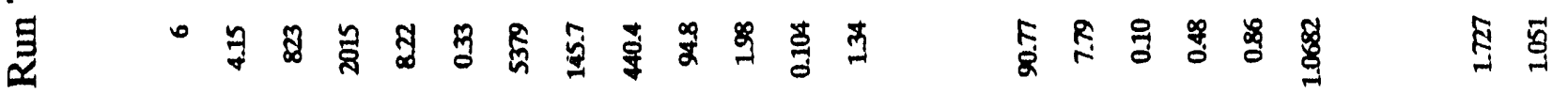

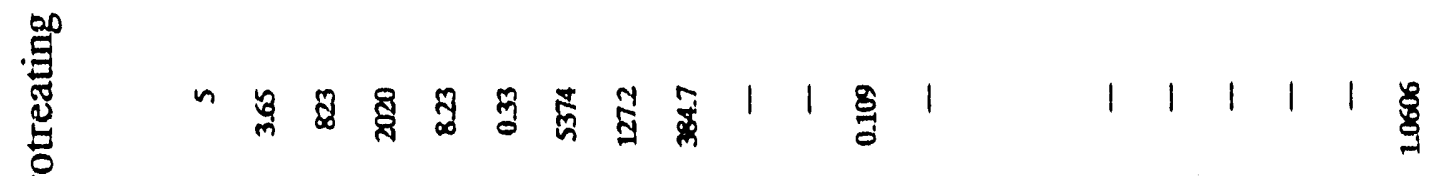

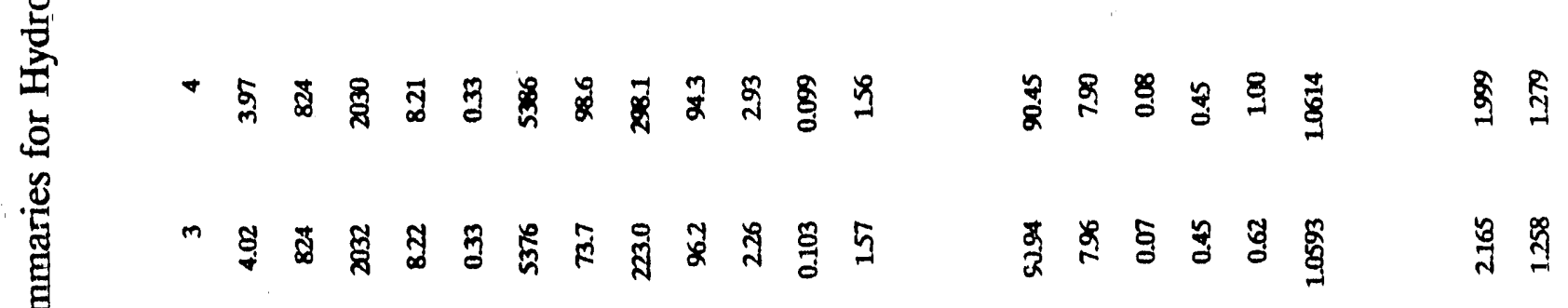

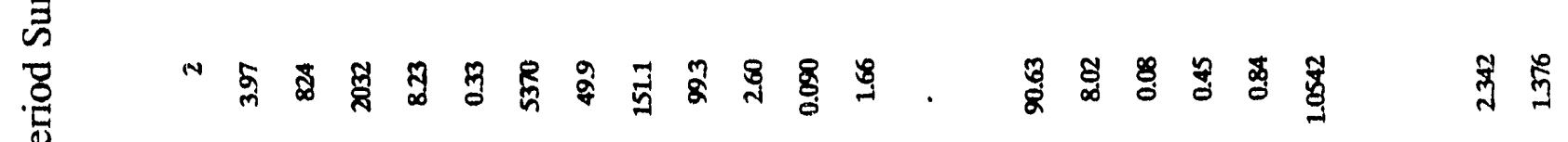

$$
\begin{aligned}
& \dot{m}
\end{aligned}
$$

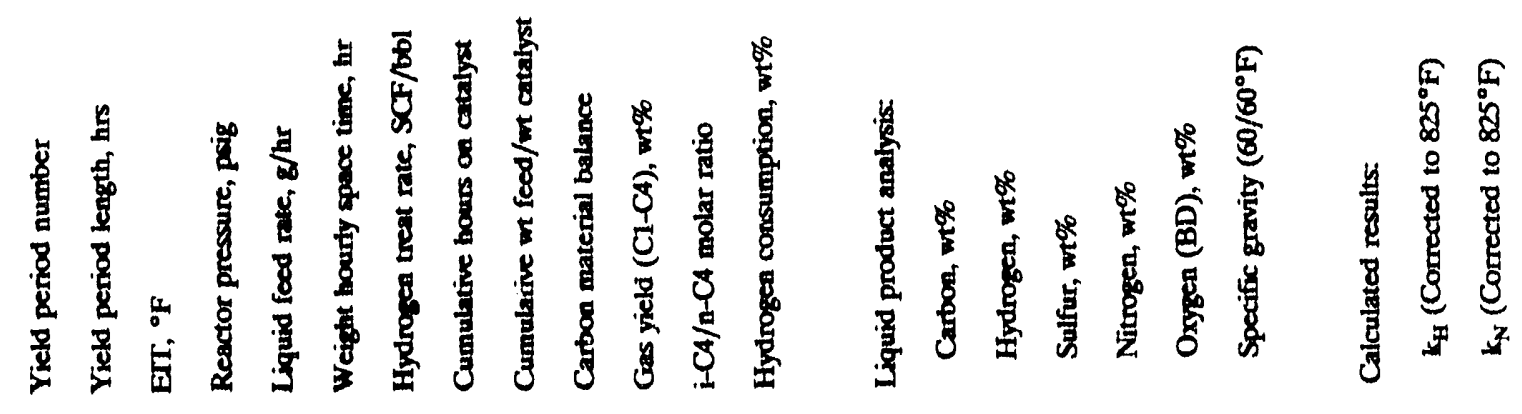




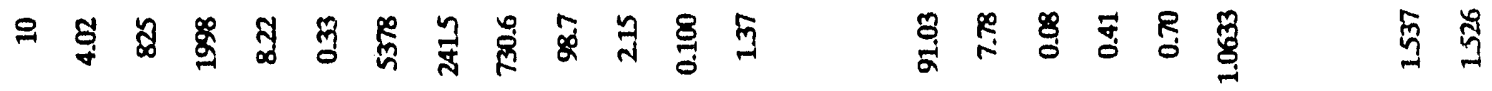

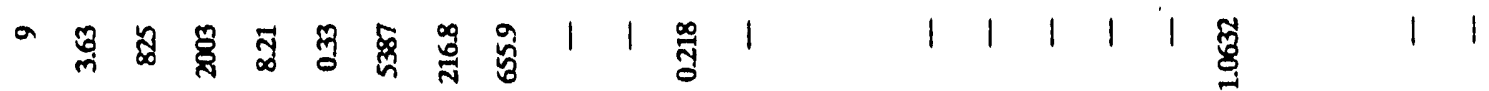

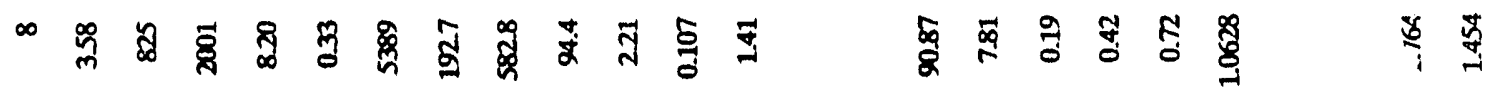

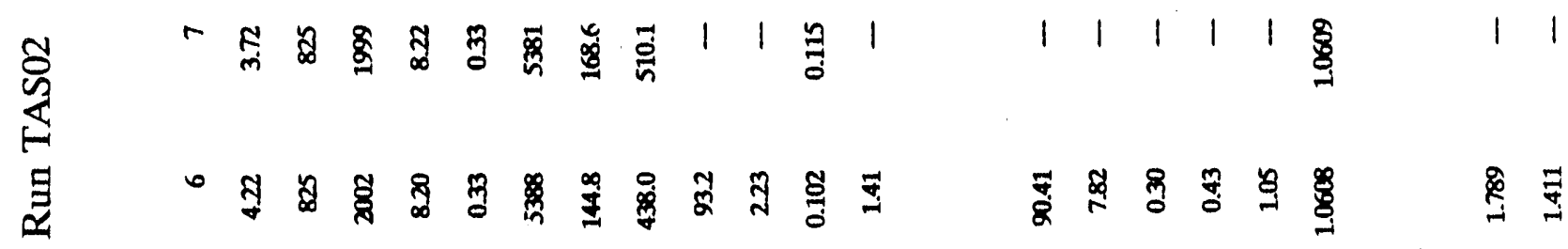

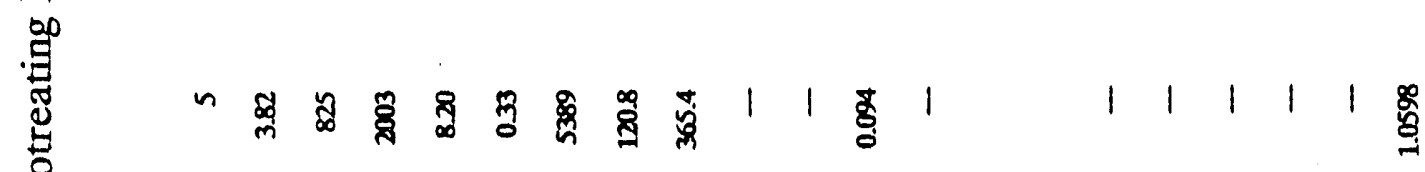

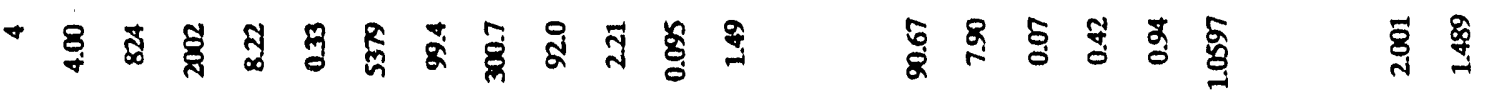

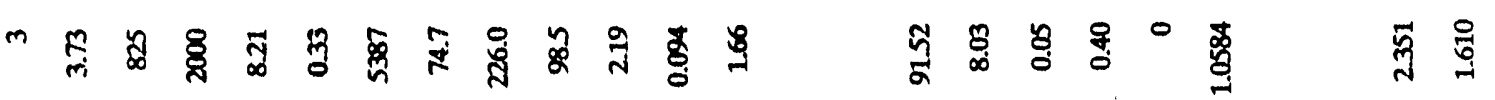

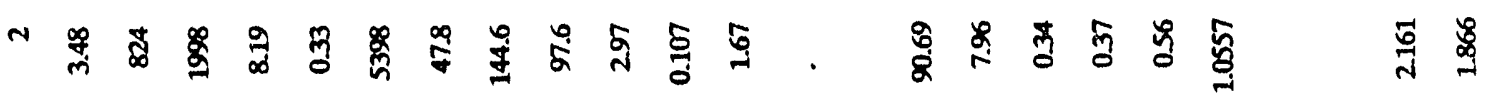

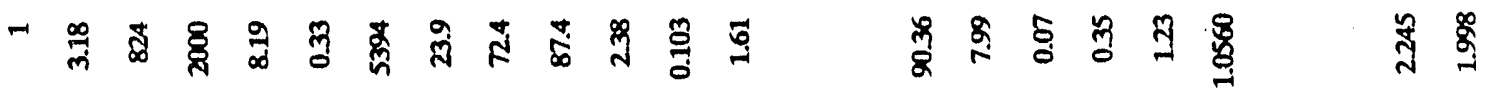

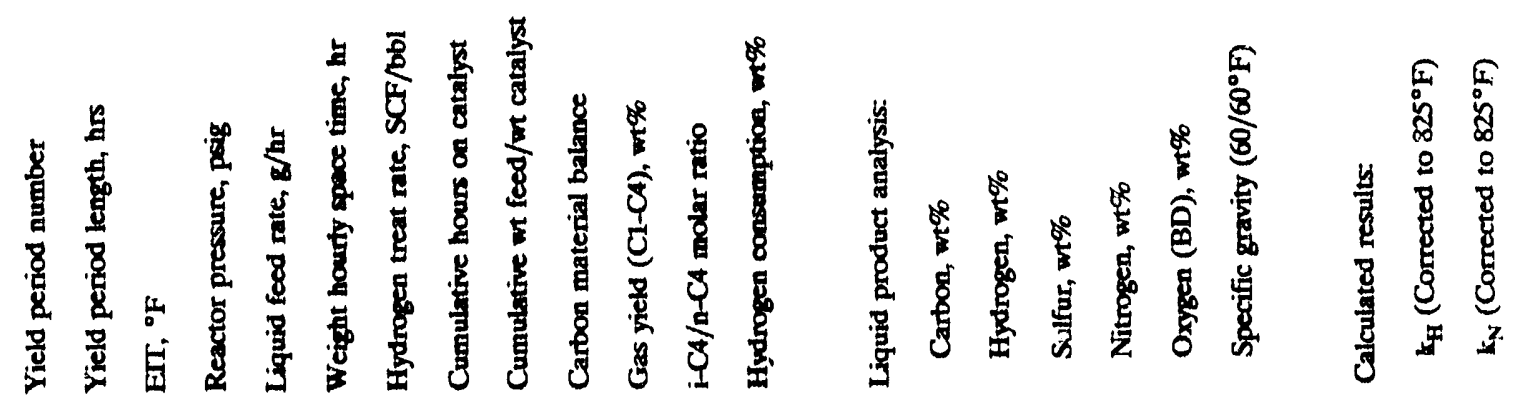


accumulatol: causing the reactor pressure to drop quickly to $1000 \mathrm{psi}$. The 9 th balance period was canceled, the reactor was broughı back to $2000 \mathrm{psi}$ and the run was continued for the final 10th day before it was terminated.

The TAS03 yield period summaries are presented in Table 5. Effective isothermal temperatures ranged between 439.4 and $441.0^{\circ} \mathrm{C}$, pressures varied from 1980 to $2015 \mathrm{psi}$. As with the previous runs, the carbon material balances were slightly low, but within acceptable limits.

Hydrogen uptake deactivation curves for the three catalysts are plotted in Figure 8. While there may have been some loss in initial activity due to the addition of promotor metals, it seems clear that the hydrogenation activities are essentially equivalent after a catalyst service of about 100 units. Similar results were observed in a previous study of sodium promoted catalysts $(26,33)$. In contrast, the hydrodenitrogenation activities are significantly lowered by the incorporation of alkaline earth metals into the catalyst, Figure 9. An upset was experienced prior to the last balance period during the run with unpromoted catalyst, hence the dashed line.

The used catalysts were subjected to X-ray analysis, and spectra for both the untreated and the Mg-treated catalysts contained small peaks corresponding to $\mathrm{Co}_{9} \mathrm{~S}_{8}$, Figure 10. This is consistent with recent work reported by Amoco workers who observed evidence of cobalt sintering in used Amocat 1A catalysts from coal liquefaction experiments. Electron microprobe revealed the presence of $5-10 \mu \mathrm{m}$ regions of locally high cobalt sulfide concentrations dispersed throughout the extrudates (42). Interestingly, the $\mathrm{Co}_{9} \mathrm{~S}_{8}$ 


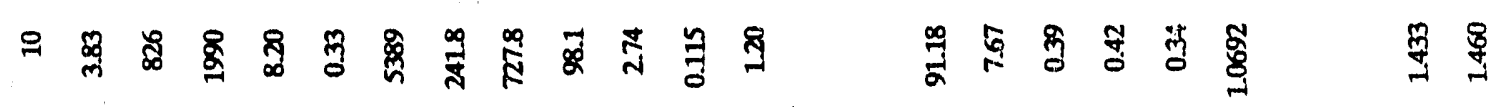

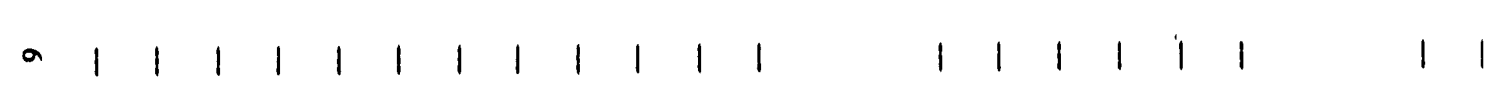

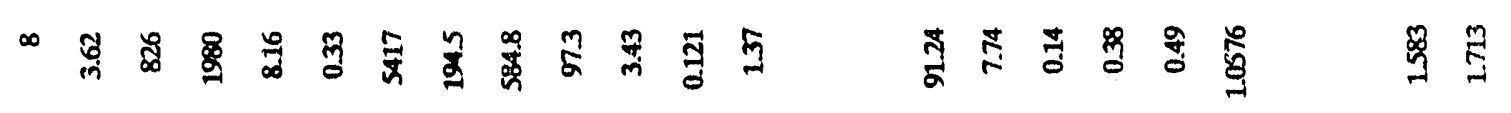

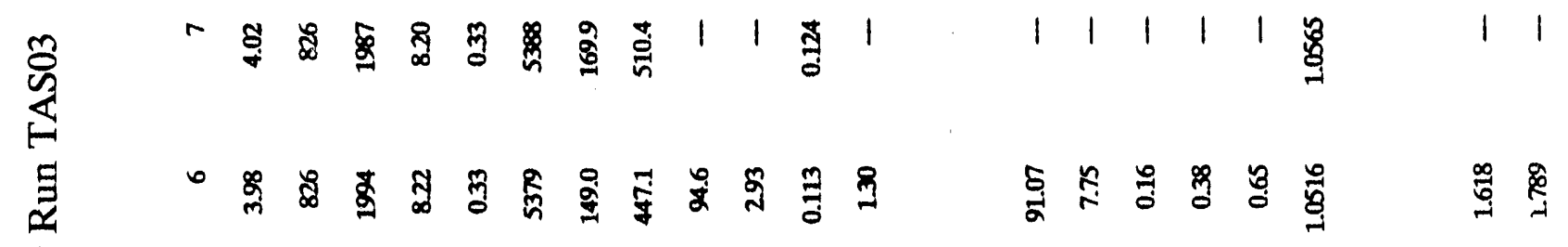

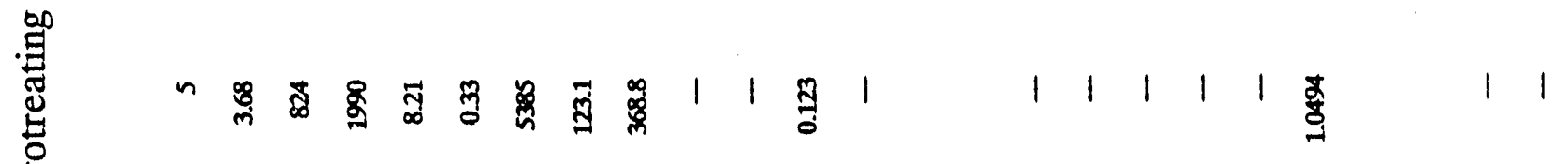

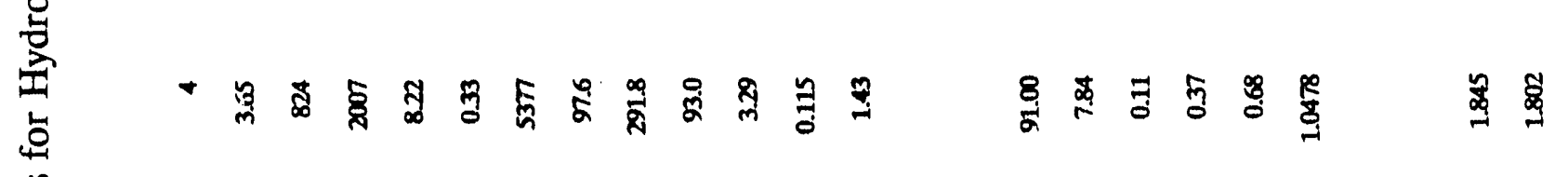

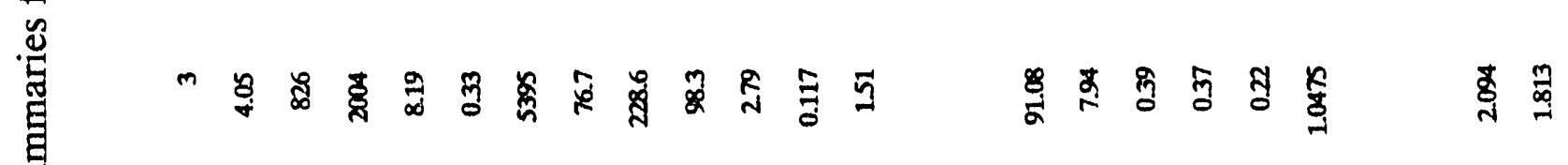

$$
\begin{aligned}
& \text { 窝 }
\end{aligned}
$$

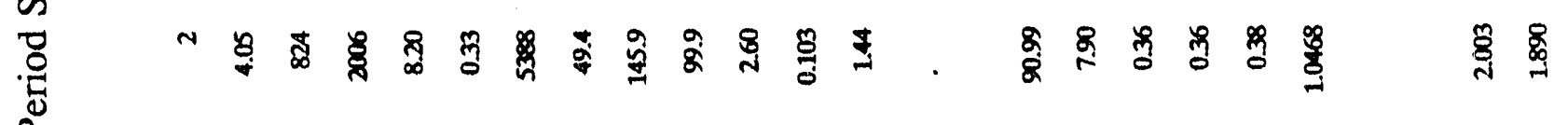

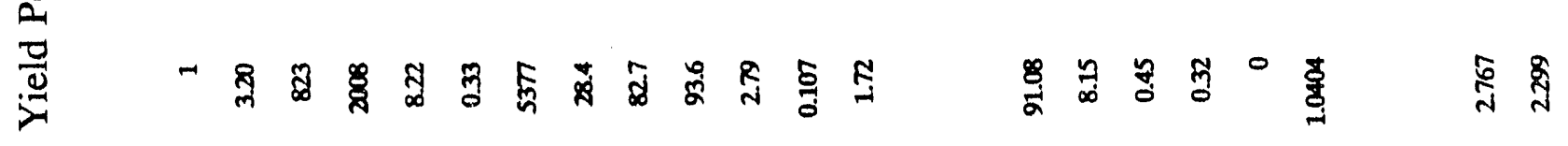

$$
\begin{aligned}
& \text { 望 }
\end{aligned}
$$

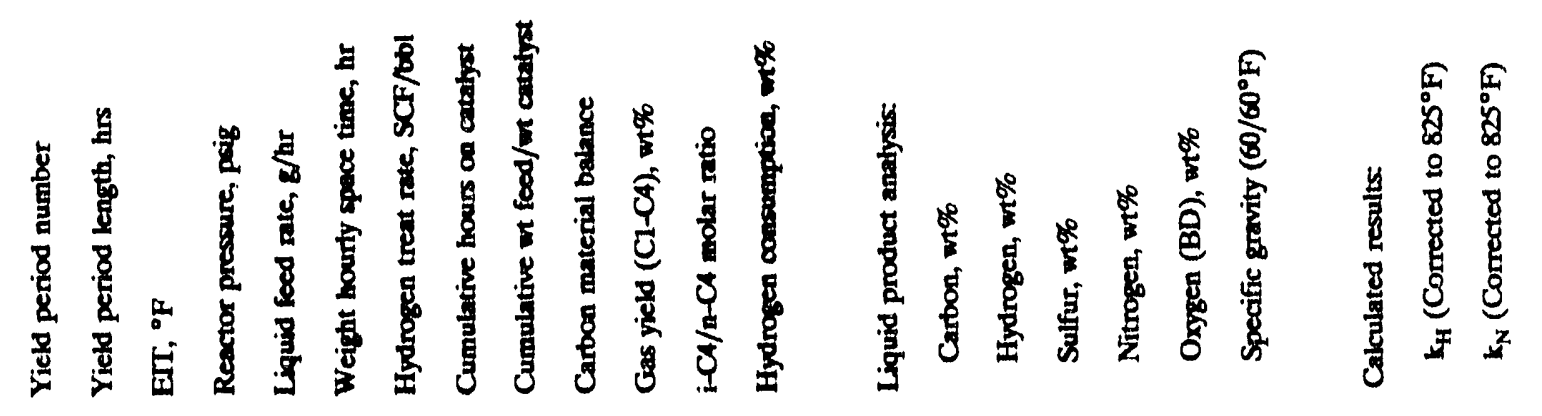




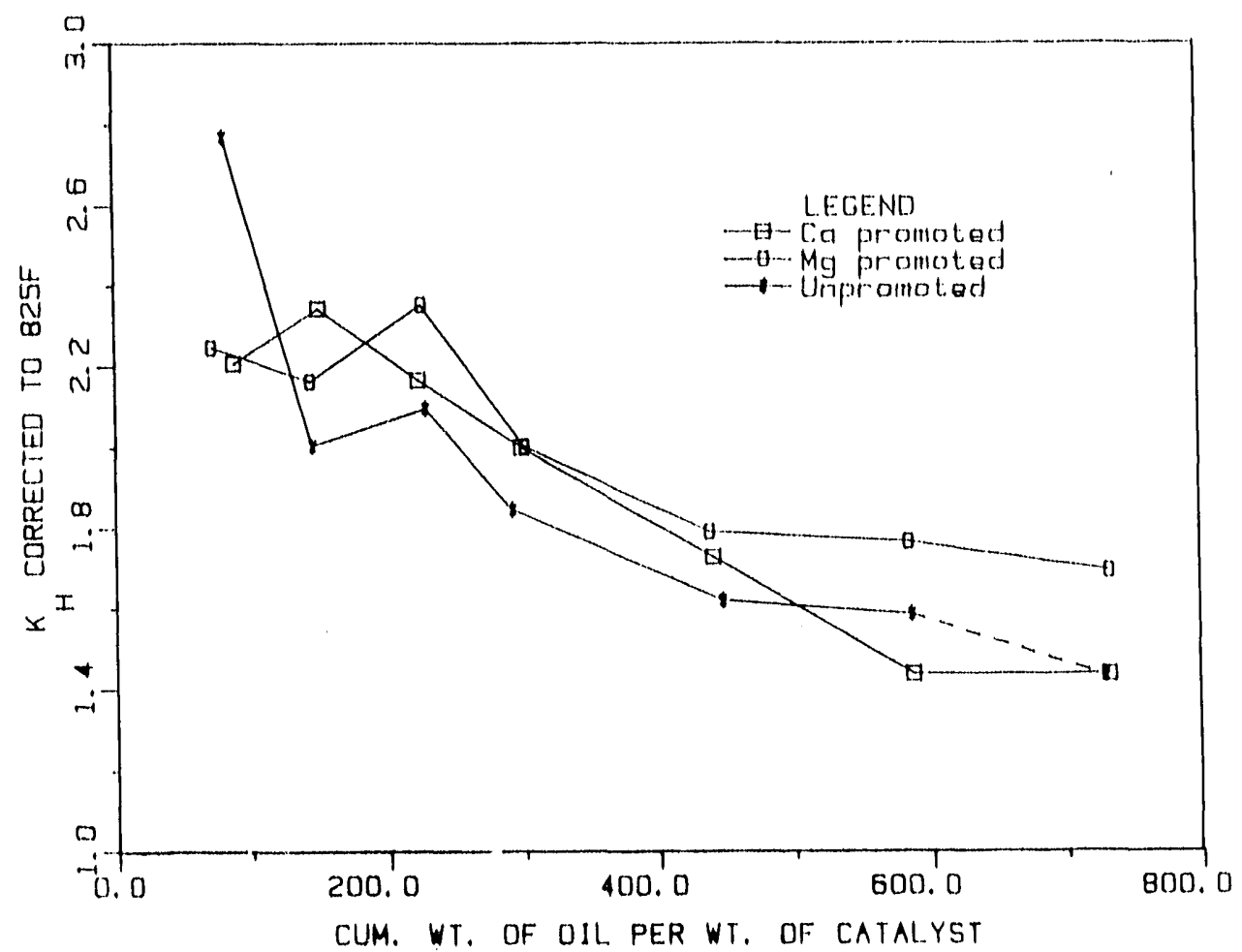

Figure 8. Deactivation curves for hydrogen uptake (HYD).

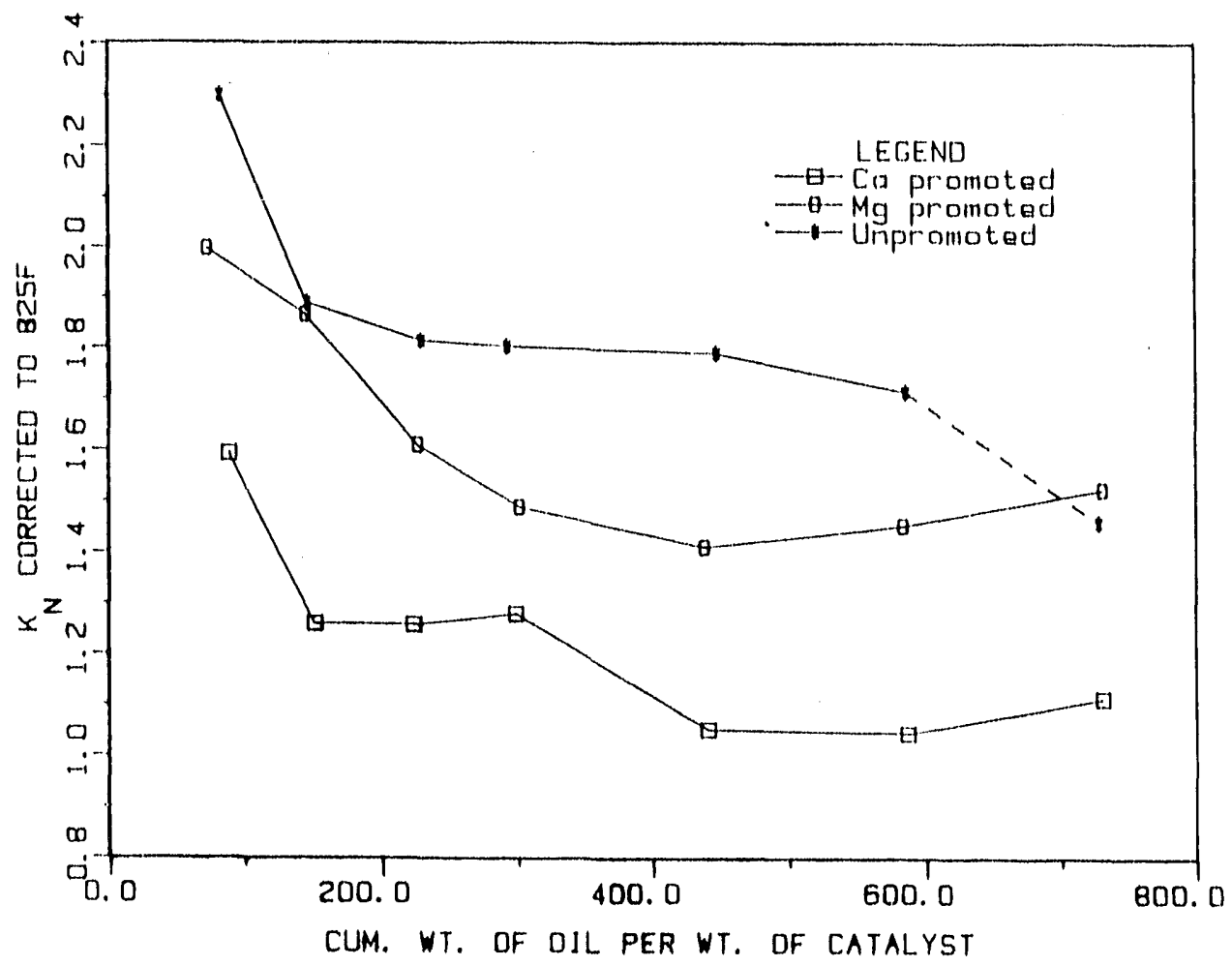

Figure 9. Deactivation curves for hydrodenitrogenation (HDN). 


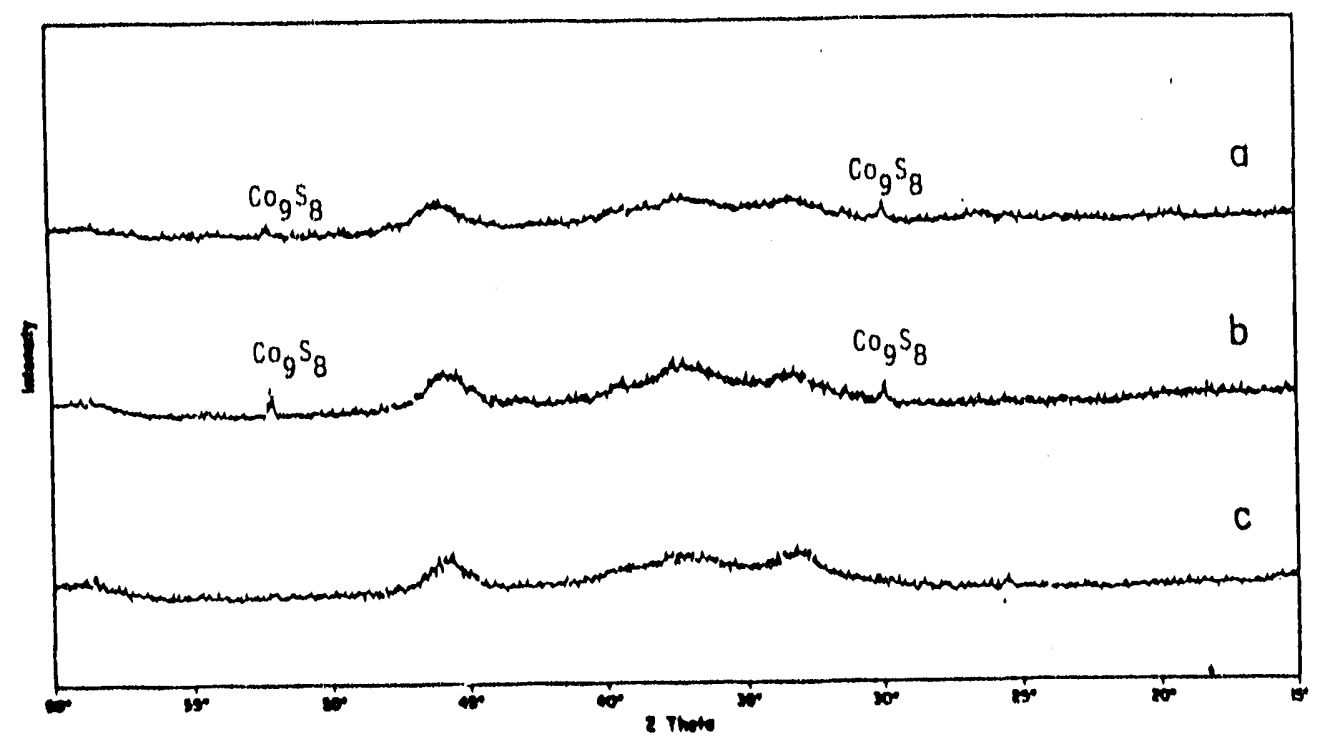

Figure 10. X-ray diffraction patterns of used catalysts from runs: a) TAS03, b) TAS02 and c) TASO1.

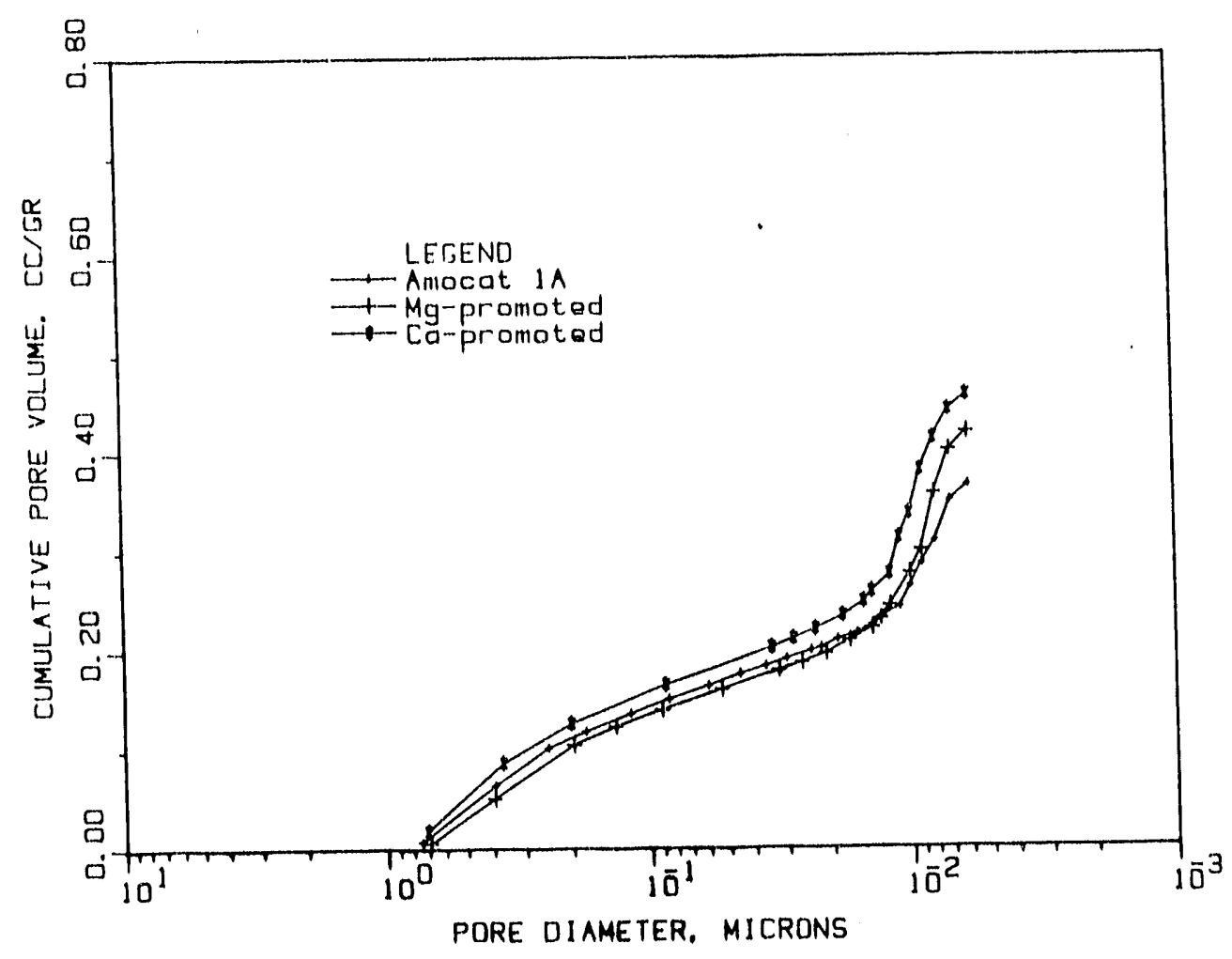

Figure 11. Cumulative pore size distributions for used catalysts. 
peaks were absent from the X-ray pattern of our used Ca-treated catalyst. Only the broad peaks associated with $\boldsymbol{\gamma}$-alumina were observed.

Properties of the used THF extracted catalysts are compiled in Table 6. By comparison with the fresh catalyst values of Table 1, it is apparent that a modest reduction in surface area has occurred with the greatest reduction being for the untreated catalyst. The loss in pore volume is more substantial with the pore volume reduction ranging from $33 \%$ for the Ca-promoted catalyst to $49 \%$ for the unpromoted catalyst. This is also evident from a comparison of cumulative pore size distributions plotted in Figures 7 and 11. Perhaps the most interesting information in Table 6 is the carbon deposition data. Promotion with alkaline earth metals does serve to reduce coke deposition, and calcium promotion is more effective than magnesium promotion.

\section{DISCUSSION}

A comparison of results for the calcium promoted catalyst with earlier results for a sodium promoted catalyst (26) reveals some strong similarities. Catalyst acidity as measured by the TPD of tert-butylamine can be completely extinguished by either component. Hydrogenation activities after the first few hours on stream are practically unaffected by either component, although there may be some reduction in initial activity when $\mathrm{Na}$ or $\mathrm{Ca}$ are added to the catalyst formulation. Both components act to lower the activity for hydrodenitrogenation, and both serve to reduce coke deposition.

The reduction in hydrodenitrogenation activity that accompanies the incorporation of alkaline earth metals into the catalyst appears to be related to catalyst acidity. The most acidic catalyst, i.e. the unpromoted catalyst, possesses the highest hydrodenitrogenation 
Table 6. Used Catalyst Properties

BET Surface Area, $\mathrm{m}^{2} / \mathrm{g}$
Pore Volume (>60 A dia.), cc/g
Avg. Micropore Diameter, $\AA$
Avg. Macropore Diameter, $\AA$
Relative Acid Density, $\mathrm{m}^{-2}$
Wt $\%$ Carbon
Wt $\%$ Hydrogen

Amocat 1A Mg-Promoted Ca-Promoted 137 137 118

0.36

0.41

0.46

100

100

100

4000

4100

4100

0.020

0.014

0

17.2

13.2

9.80

1.34

1.01

1.03 
activity; whereas, the least acidic Ca-promoted catalyst exhibits the lowest activity. The Mgpromoted catalyst lies in between these extremes with regard to both acid site density and hydrodenitrogenation activity. It thus appears that acid sites are essential for good hydrodenitrogenation activity presumably because they provide preferential adsorption sites for basic nitrogen species. Acid sites are evidently not essential for good hydrogeuation activity, however.

Carbon deposition also appears to correlate with catalyst acidity, Table 6. Higher coke levels are observed on the more acidic catalysts. Kageyama and coworkers report a similar trend (11). They also found the nitrogen content of coke deposits to be reduced for a Ca-promoted catalyst. These findings tend to support the popular hypothesis that basic nitrogen compounds are mainly responsible for coke formation.

The results of this study are broadly consistent with recent results reported by Shimada and coworkers (17). These investigators also observed that doping with $\mathrm{Ca}$ and Mg served to reduce both coke level and hydrodenitrogenation activity. Consistent with previous results for sodium promoted catalysts (24) they find that activity losses are reduced by adding the alkaline earth metal as a last step in the preparation, i.e. after the active metals have been added. Somewhat contrary to our findings is their observation that hydrogenation activity is also reduced by the alkaline earth treatment. However, it may be important to note that this conclusion is based on the hydrogenation of a model compound in a batch reactor. Their results thus reflect initial activity levels. As noted above, our initial hydrogenation activity appears to be higher for the unpromoted catalyst, but this advantage soon disappears. 
Our results for both alkali (26) and alkaline earth promoted hydrotreating catalysts have been explained in a rather straightforward manner in terms of catalyst acidity. However, in a study of hydrotreating catalysts prepared on different support materials (43), we report findings that appear somewhat contradictory of the present results. In particular we observe a trend of decreasing coke formation with increasing RAD. This may be due to the fact that characterization of catalyst acidity by TPD of t-butylamine is far from complete. In particular, our analysis provides little or no information regarding the strength (44) or type (Brönsted or Lewis) of acidity. These factors may be expected to effect both coking tendency and hydrodenitrogenation activity levels.

\section{E. CONCLUSIONS}

The promotion of an otherwise finished CoMo/Alumina hydrotreating catalyst with percentage quantities of alkaline earth metals offers an effective means of reducing coking tendency while maintaining a high hydrogenation activity. The treatment does have an adverse affect on hydrodenitrogenation activity. Alkali and alkaline earth promotion may therefore be beneficial in applications such as coal liquefaction where the primary function of the catalyst is to hydrogenate and the reaction environment is conducive to coking.

The performance of these catalysts appears to be simply related to catalyst acidity as evaluated by the TPD of tert-butylamine. 


\section{DEVELOPMENT OF A NOVEL CATALYTIC COAL LIQUEFACTION MICRO- REACTOR (CCLM) UNIT}

Hydrotreating studies such as the one described in the previous section have identified a number of prospects for an improved coal liquefaction catalyst. However, a major deficiency of such studies is that the catalyst is not tested under actual coal liquefaction conditions. To illustrate, some typical hydrotreating results from earlier work in our laboratory (43) are plotted in Figure 12. Despite the high severity conditions employed $\left(825^{\circ} \mathrm{F}, 2000 \mathrm{psi}\right.$, WHSV $\left.=3, \mathrm{HTR}=4500-5000 \mathrm{SCF} / \mathrm{bbl}\right)$, deactivation of the better catalysts is not that rapid. While certain of these catalysts exhibited a reduced coking tendency, any corresponding improvement in activity maintenance was not recognized because the standard commercial catalysts performed remarkably well in this environment. Because of the hydrogen deficient nature of the coal liquefaction mixture, and also because of the presence of coal ash components, it is probable that these same catalysts would not perform as well in a coal liquefaction application. Accordingly we embarked upon a project to develop a continuous coal liquefaction unit that will operate at the microscale and thereby permit the evaluation of relatively small batches of catalyst of the order of five grams.

A novel feature of this unit is the reactor. Several types of continuous flow laboratory reactors have seen service in multiphase (Gas/Liquid/Solid) applications such as coal liquefaction. Mahoney, et al., describe a spinning basket configuration in which the catalyst is contained in an annular basket attached to a rotating shaft (45). Baffles inside, above and below the basket direct fluid through the basket. In another design described by Mahoney, the annular catalyst basket is fixed and the impeller is designed to circulate fluid 


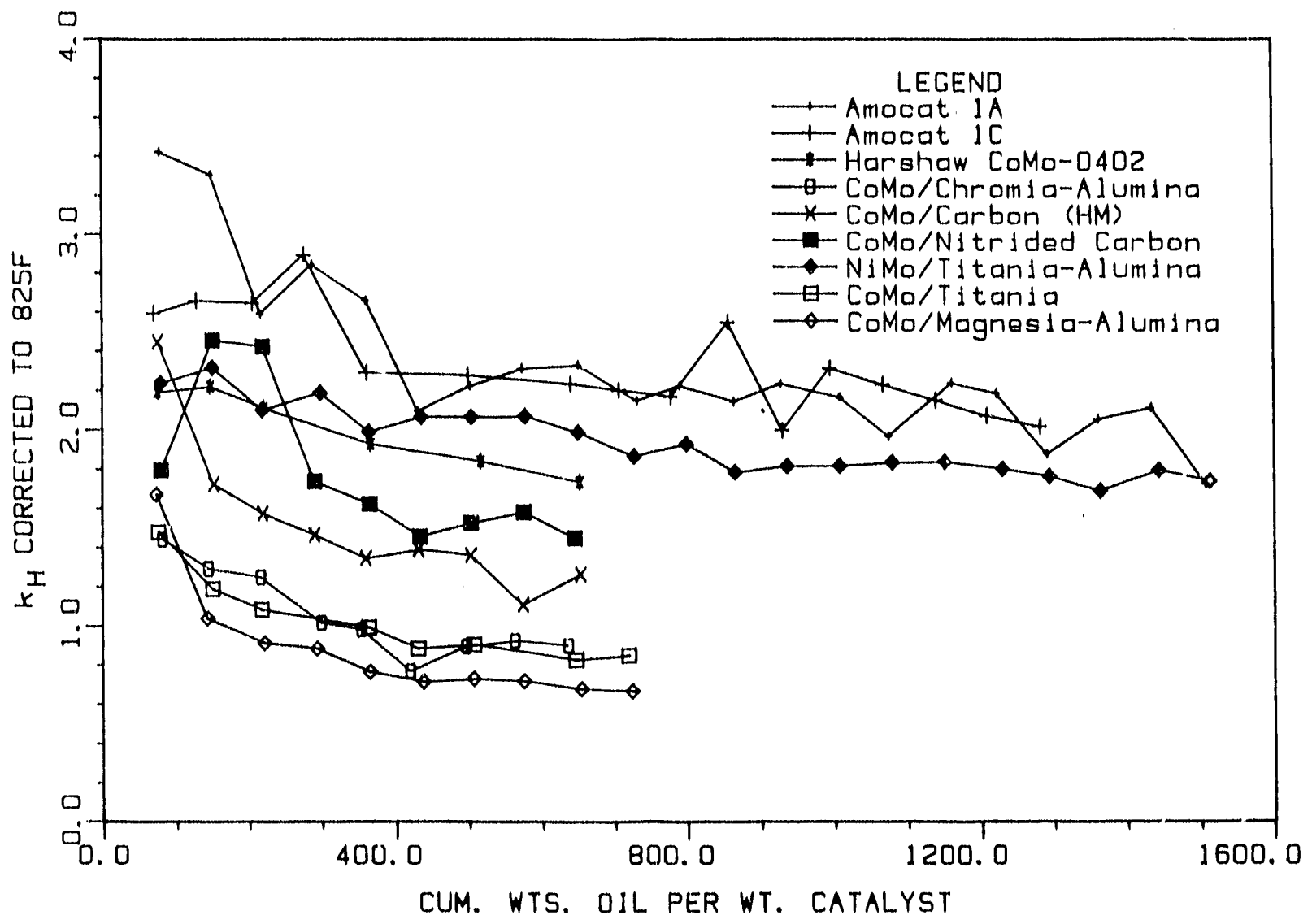

Figure 12. Deactivation curves for hydrogen uptake (HYD) for a variety of catalyst preparations (43). 
radially through the basket (46). Autoclave Engineers, Inc., Erie, Pennsylvania, markets reactor internals corresponding to both of these configurations and several others as well. These are described in their Bulletin 1200.

A potential problem with any reactor design that employs fixed or stationary beds of catalyst in a coal liquefaction application is the buildup of ash, metals and carbonaceous residue on the external surface of the particles. In severe cases the particles may become cemented to one another, but in any case this buildup is likely to lead to a premature deactivation of the catalyst. Such deposits have been reported on spend SYNTHOIL catalysts (47), and on used catalysts from a bench scale coal liquefaction unit (8). The hydrotreatment of heavy coal derived liquids can also give rise to external carbonaceous deposits when benzene (or toluene) insolubles are present $(11,48)$. In all these cases the catalyst was contained in stationary beds. To the authors' knowledge, no such fouling of the catalyst has been observed on spent catalysts from H-coal or from the Wilsonville operation where the hydrotreatment is done in liquid fluidized "ebullated" beds. In the ebullated bed, constant agitation and movement of the catalyst particles is claimed to reduce and perhaps even eliminate this mode of deactivation.

We therefore chose an ebullated bed reactor design for continuous coal liquefaction unit. The development of the unit proceeded through three stages: 1. reactor cold model studies, 2. hydrotreating studies and finally 3. coal liquefaction studies. The results from these three phases of the investigation will be discussed in turn. 


\section{A. REACTOR COLD MODEL STUDIES}

The laboratory liquid fluidized hrol microreactor consists of a cylindrical catalyst basket having an impermeable wall and wire screen ends (30 x 30 mesh type 316 SS wire cloth) positioned in the bottom of a $100 \mathrm{cc}$ stirred autoclave. An impeller situated just above the basket circulates fluid down through the annular space between the basket and the vessel wall and up through the center of the catalyst bed where the catalyst particles are fluidized. The reactor inlet is from the bottom through a hole drilled along the axis. Both liquid and gaseous reactants are introduced at this point. The products exit through a drawoff tube whose length can be adjusted to control liquid depth. A drawing of the reactor is provided in Figure 13. In the cold model study, the vessel and the catalyst basket were constructed of Plexiglas.

A drawing of the basket assembly is presented in Figure 14. The basket is held in place by 3 spring clips welded at $120^{\circ}$ spacings. Removal of the basket is accomplished by inserting a tool in holes drilled through the top of the spring clips. Access to the catalyst is by removal of the snap ring and wire screen at either end of the basket. Two impeller designs were investigated. The radial flow impeller is depicted in Figure 15. Fluid enters at the hub and is diructed outward (radially) by the four inclined blades as in a centrifugal pump. The blade angle is measured from the tangent. The arrangement is such that the only exit from the impeller is downward through the annular space between the basket and the vessel wall. A drawing of the axial flow impeller is provided in Figure 16. Four blades rotate in the annular space between the impeller body and the vessel wall. Entrance to the impeller is from above. The blade angle is measured from the vertical. 


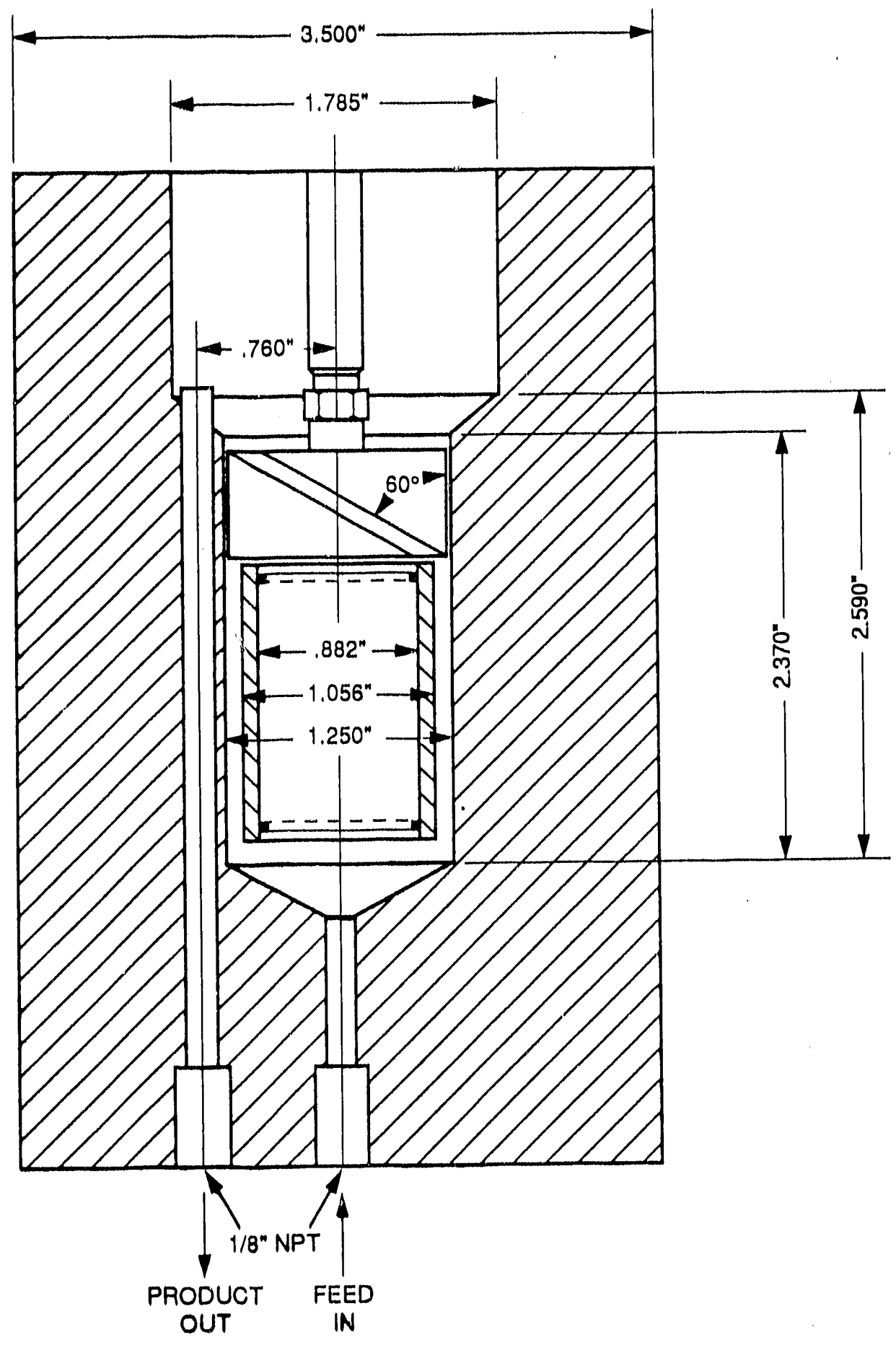

Figure 13. Ebullated bed reactor assembly. 

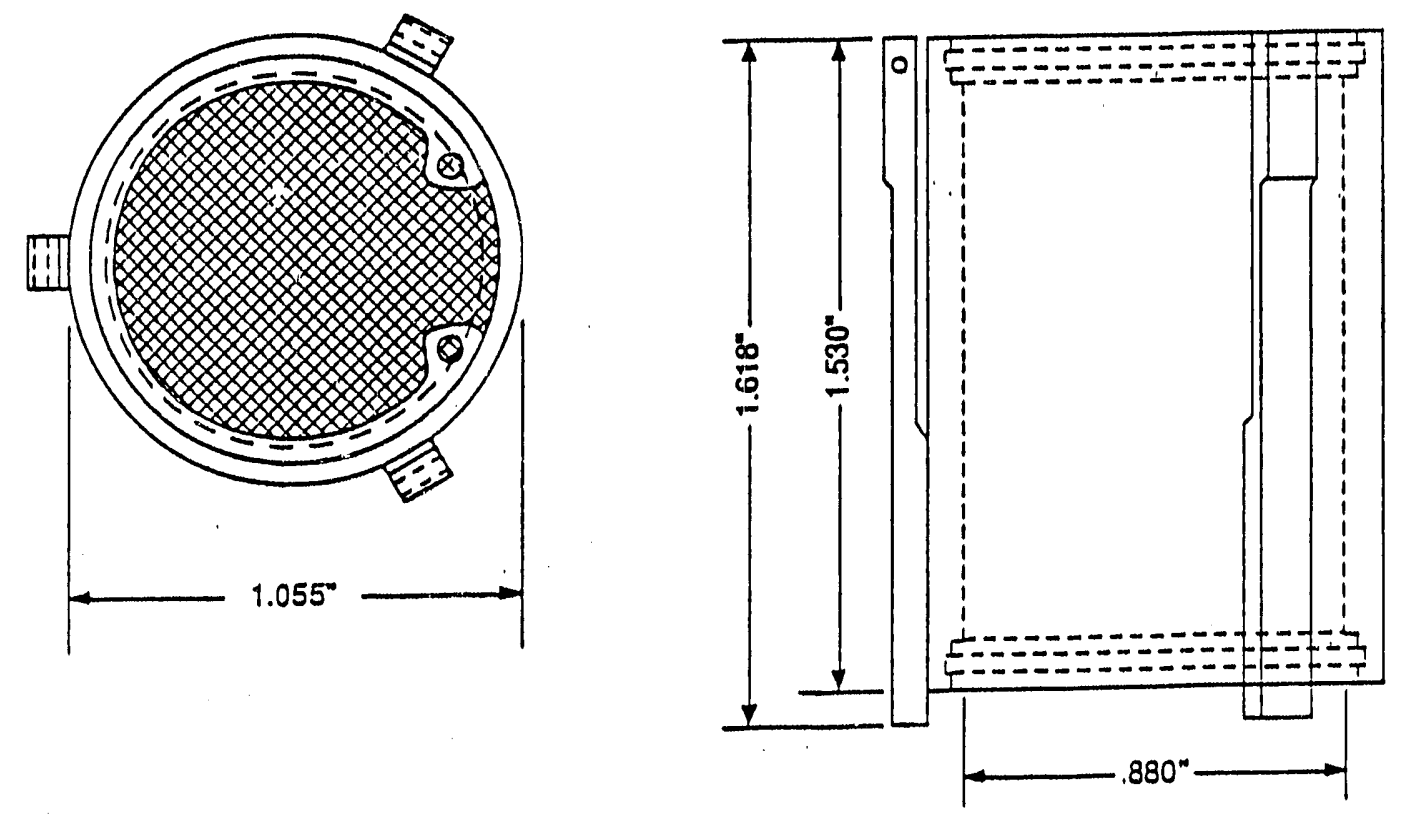

Figure 14. Catalyst basket assembly.
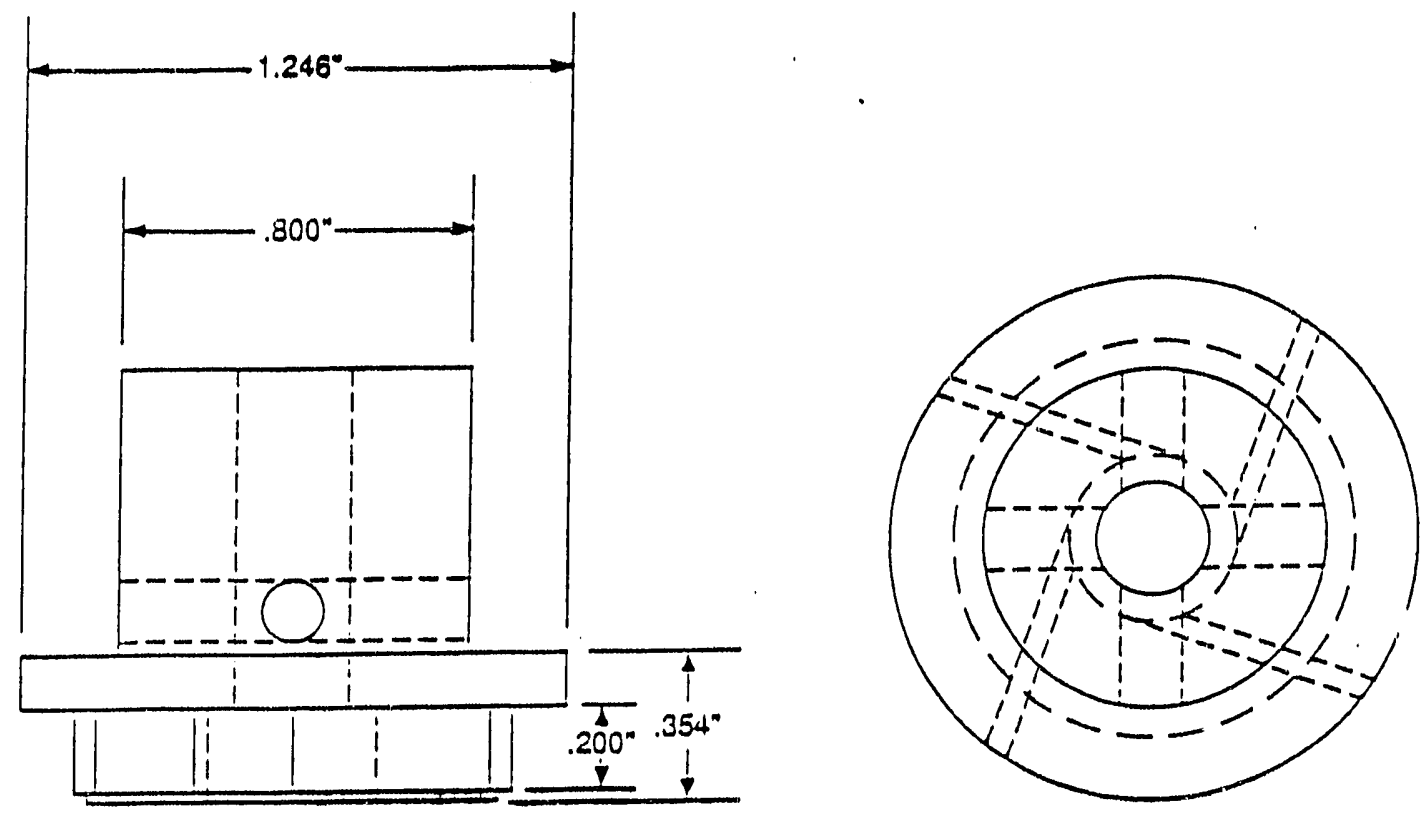

Figure 15. Radial flow impeller, $20^{\circ}$ blade angle. 

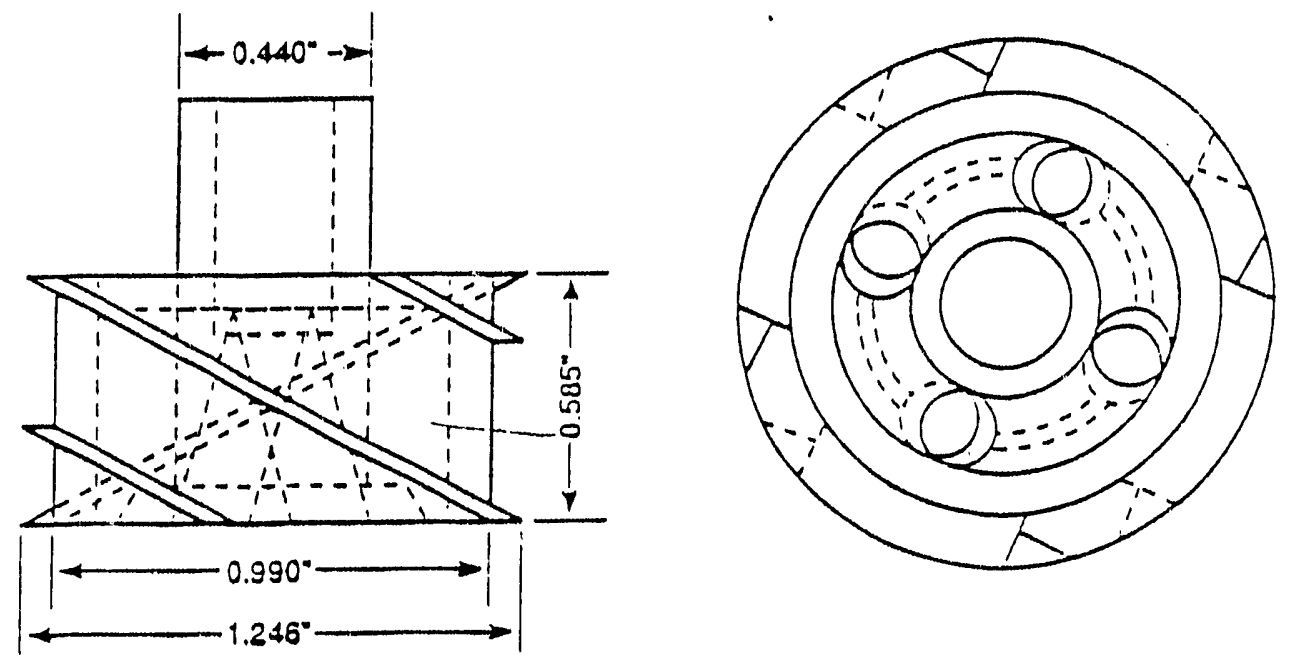

Figure 16. Axial flow impeller, $60^{\circ}$ blade angle. 
A series of photographs illustrating liquid fluidized bed performance at increasing stirrer speeds is presented in Figure 17. In this experiment the solid particles were catalyst particles (Amocat 1A, 1/16" extrusions) and the liquid was water. The impeller was of radial flow design with a blade angel of $20^{\circ}$. At the lowest stirrer speed of $320 \mathrm{rpm}$ (upper left hand) the bed is not fluidized although visual inspection reveals a very slight movement of particles. At the next highest speed of $615 \mathrm{rpm}$ (upper right hand) the bed is expanded considerably and visual inspection reveals a clear state of fluidization. At $910 \mathrm{rpm}$ (lower left hand) the bed is further expanded, and visual inspection reveals a highly agitated state. Particles are beginning to adhere to the upper screen of the basket. At the highest stirrer speed in the sequence, $1205 \mathrm{rpm}$, many particles adhere to the top screen and the lower part of the bed remains fluidized and highly agitated.

Note is made of the fact that for this particular series of photographs the catalyst charge is smaller than usual. In actual hydrotreating and coal liquefaction experiments the catalyst basket is about three quarters full.

\section{Impeller Performance:}

Impeller design is critical to performance and several variations were tested. For Liquid/Solid fluidization excellent results were obtained with both the radial flow and the axial flow designs. Radial flow impellers having $45^{\circ}, 30^{\circ}$ and $20^{\circ}$ blade angles were tested. The larger blade angles produce excessive cavitation in the impeller and thus the most effective radial flow impeller was the one having a $20^{\circ}$ blade angle. An impeller having curved blades v/as tested, but performance was not improved by comparison to a similar impeller having straight blades. Consideration of ease of construction favors straight blades. 

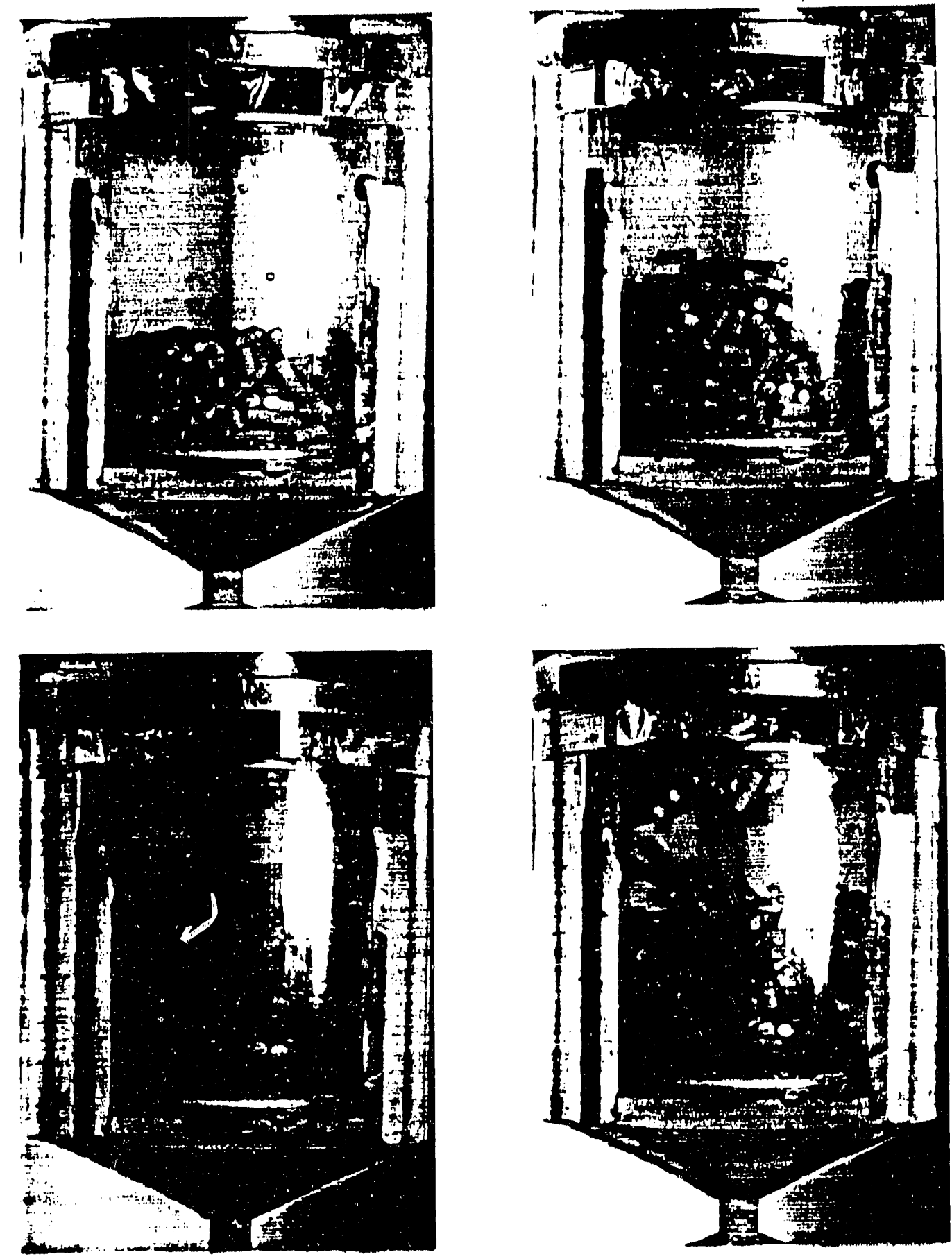

Figure 17. Liquid fluidized bed performance, $20^{\circ}$ radial flow impeller, $1 / 16$ inch Arnocat $1 \mathrm{~A}$ extrusions in water. 
Experiments with Gas/Liquid/Solid systems using the radial flow impeller were not successful. Gas tends to accumulate in the impeller resulting in a loss of circulation. Many different impeller configurations were investigated in an effort to eliminate this problem. Blade width was increased, and weep holes were drilled at various positions in an attempt to dissipate the gas. Nothing was successful. It became apparent that the radial flow design could not be made to work in this application.

The axial flow impeller was found to give excellent results for Gas/Liquid/Solid systems and results roughly equivalent to that of the radial design for Liquid/Solid systems. Axial flow impellers having blade angles of $30^{\circ}, 45^{\circ}$ and $60^{\circ}$ were tested and their performance is compared with that of the most successful $\left(20^{\circ}\right.$ blade angle) radial flow impeller in Figure 18. Here the system is $1 / 16$ inch catalyst extrudates in water, and no gas is flowing. Bed height is plotted versus stirrer speed, and the two horizontal lines locate the initial unexpanded bed height and the top screen. Of the axial flow impellers, the one with a $60^{\circ}$ blade angle is able to expand the bed at lower. stirrer speeds. The performance is very close to that of the radial flow impeller. Similar results were observed with other particles and fluids. In all cases the $60^{\circ}$ blade angle impeller outperformed the axial flow impellers with smaller blade angle.

The effect of gas flow is seen in Figure 19 where bed height is again plotted versus stirrer speed. The $6 \mathrm{~mm}$ diameter glass beads are fluidized in air/water using the $60^{\circ}$ axial impeller. The introduction of air is somewhat detrimental to performance, but good fluidization is still obtained. Variations in liquid depth also affect the performance of the axial impeller. This is shown in Figure 20 where bed height is plotted versus stirrer speed 


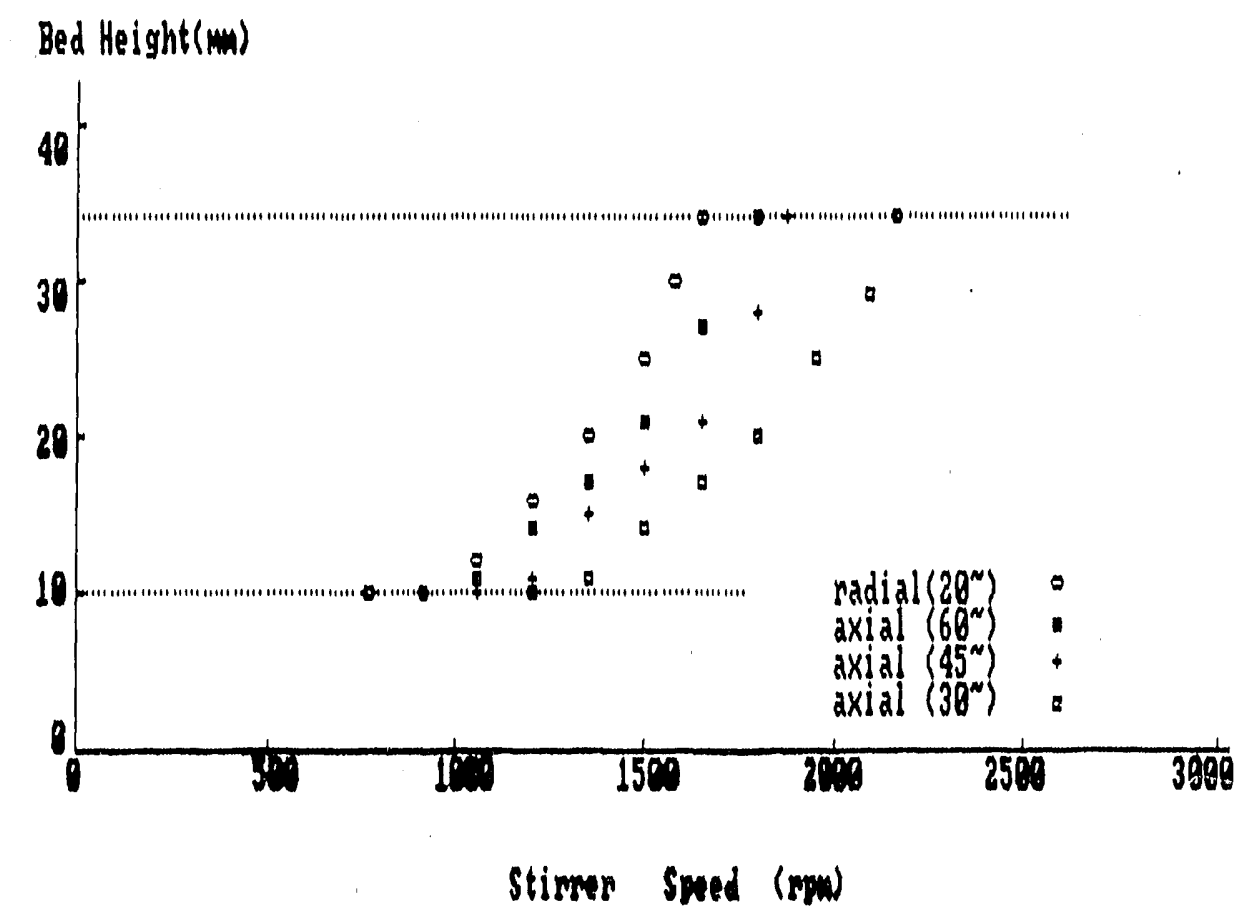

Figure 18. Liquid/solid fluidization for several impeller designs. Catalyst particles (1/16 inch dia. extrusions) in water (95 $\mathrm{mm}$ depth).

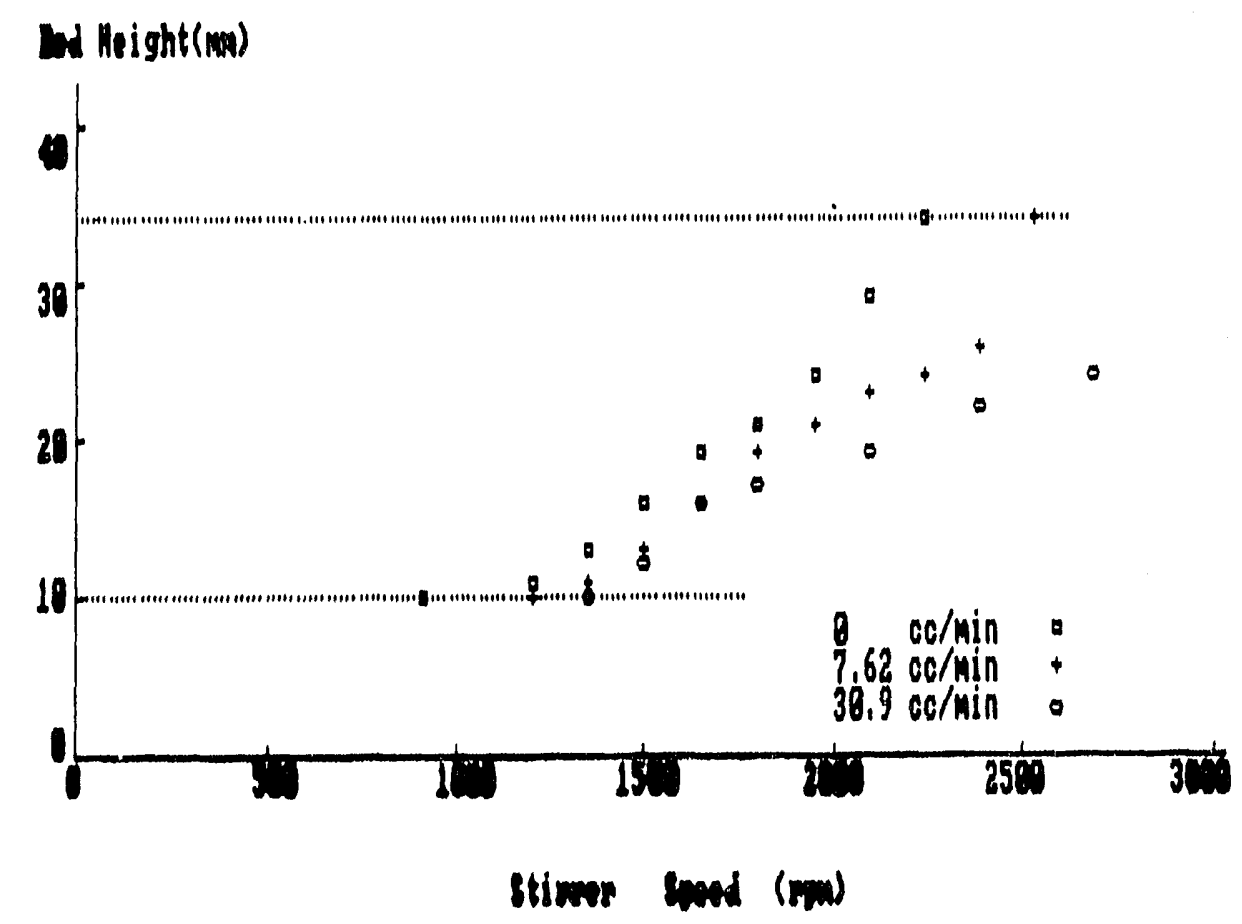

Figure 19. Effect of air flowrate on Gas/Liquid/Solid fluidization. Glass beads $(6 \mathrm{~mm}$ dia.) in water ( $95 \mathrm{~mm}$ depth), $60^{\circ}$ blade angle axial impeller. 


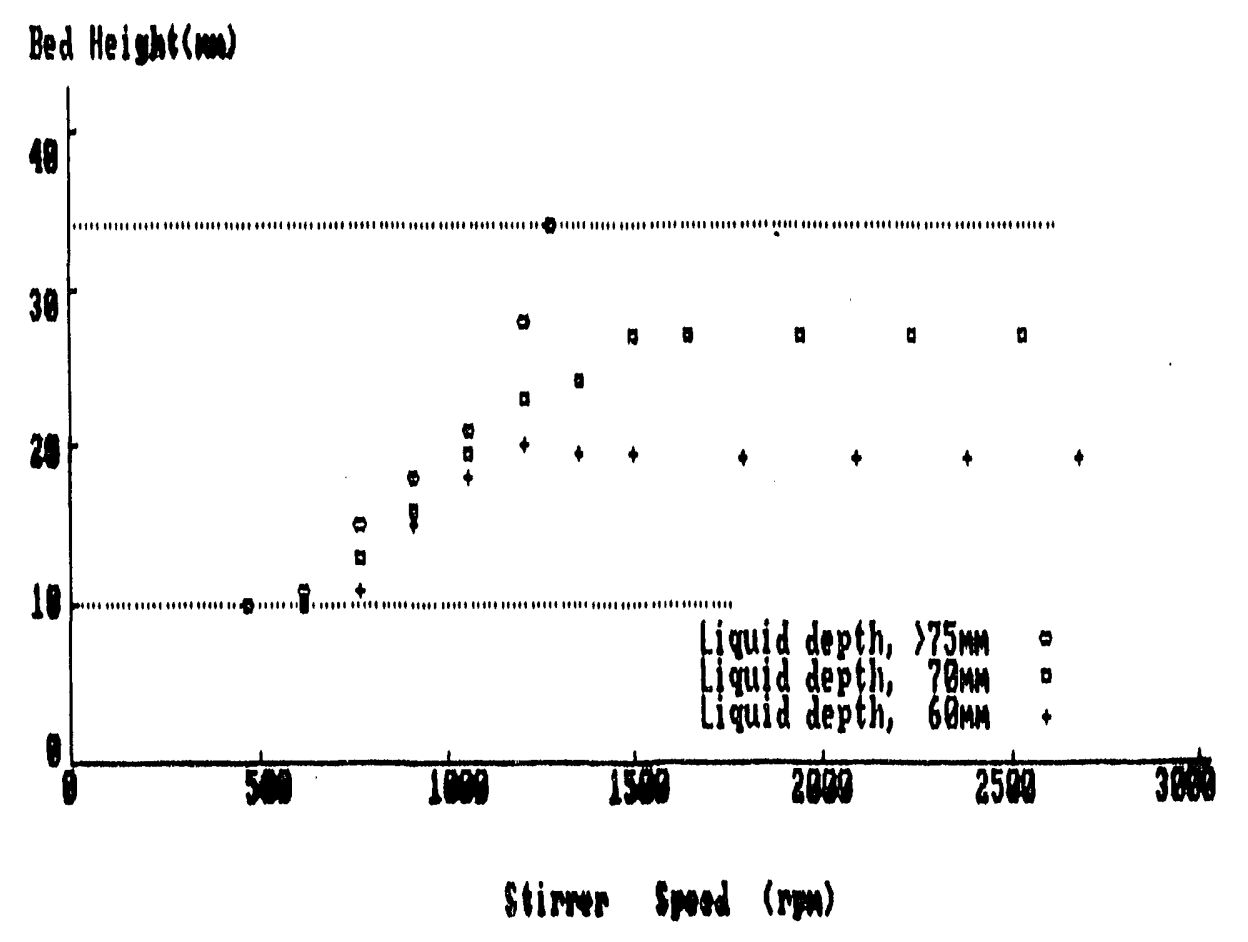

Figure 20. Effect of liquid depth on Liquid/Solid fluidization. Catalyst particles (1/16 inch dia. extrusions) in water. $45^{\circ}$ blade angle axial impeller. 
for several values of liquid depth (measured from the bottom of the reactor). Since fluid enters the impeller from above, good performance at high stirrer speeds requires that the depth be sufficient to prevent cavitation. Note that the effect of liquid depth is minimal at low stirrer speeds and the incipient fluidization velocity is hardly affected. The invariance of bed height at high stirrer speeds is not necessarily a negative result since the range of useful stirrer speeds is expanded due to the lack of particle carryover.

From observations with both impeller designs it has become clear why the axial flow design is superior for Gas/Liquid/Solid applications. With the radial flow design all gas must pass through the hub region where it comes into contact with the blades resulting in a loss of circulation. With the axial flow design, gas and liquid exit through holes drilled near the center of the impeller and gas separates above the impeller leaving only liquid to come into contact with the impeller blades.

\section{Dimensionless Correlations:}

Successful operation of the catalytic coal liquefaction microreactor requires that we be able to predict two critical stirrer speeds - the stirrer speed corresponding to incipient fluidization, $S_{1}$, and that corresponding to particle carryover, $S_{2}$. (In the latter case particles are retained by the upper screen.) Dimensionless correlations for these quantities were developed for both impeller designs from a study in which particle size, particle density, particle shape, fluid viscosity, fluid density and bed height (at rest) were varied. Glass and steel balls, and aluminum cylinders were fluidized in water, a polymer water solution, vegetable oil and motor oils of different viscosities. In the axial flow impeller experiments, 
gas density was varied by using air and helium. All experimentation was conducted at ambient conditions. See Tables 7 and 8 respectively for the radial and axial impeller results.

It is important to recognize that the cold model vessel and internals are identical in size and shape to the actual reactor. The correlations below are applicable only to this system. They are required because visual inspection of fluidization performance is not possible in the stainless steel reactor. These correlations are not intended for scale up, and indeed they are of little or no use for such purposes.

Barring a possible effect due to surface tension, dimensional analysis considerations indicate that the system can be analyzed in terms of 5 dimensionless groups which are taken to be:

$$
\begin{aligned}
& R e_{1}=\frac{S_{1} \rho_{l} d_{l}^{2}}{\mu_{l}}=\text { rotational Reynolds number } \\
& G a=\frac{d_{p}^{3}\left(\rho_{p}-\rho_{l}\right) \rho_{l} 8}{\mu_{l}^{2}}=\text { Galileo number } \\
& \left(\rho_{p}-\rho_{l}\right) / \rho_{l}=\text { buoyancy factor } \\
& d_{p} / d_{l}=\text { particle diameter factor } \\
& H_{b} / d_{l}=\text { bed height factor }
\end{aligned}
$$

The characteristic length was taken as the impeller diameter, $d_{i}=31.6 \mathrm{~mm}$. For the particle carryover correlation, a Reynolds number, $\operatorname{Re}_{2}$, is defined identical to the above definition, but with $S_{2}$ replacing $S_{1}$. 
Table 7. Liquid/Solid Fluidization Results for $20^{\circ}$ Radial Flow Impeller

\begin{tabular}{|c|c|c|c|c|c|c|c|c|}
\hline $\begin{array}{c}d_{1} \\
(\mathrm{~mm})\end{array}$ & $\begin{array}{c}\mathrm{H}_{\mathrm{b}} \\
(\mathrm{mm})\end{array}$ & $\begin{array}{c}d_{p} \\
(\mathrm{~mm})\end{array}$ & $\begin{array}{c}\mathrm{L}_{\mathrm{p}} \\
(\mathrm{mm})\end{array}$ & $\begin{array}{c}\rho_{p} \\
(\mathrm{~g} / \mathrm{cc})\end{array}$ & $\begin{array}{c}\rho_{1} \\
(\mathrm{~g} / \mathrm{cc})\end{array}$ & $\begin{array}{c}\mu_{t} \\
\text { (cp) }\end{array}$ & $\begin{array}{c}\mathrm{S}_{1} \\
(\mathrm{rpm})\end{array}$ & $\begin{array}{c}\mathrm{S}_{2} \\
(\mathrm{rpm})\end{array}$ \\
\hline 9.5 & 10 & 3. & -- & 2.569 & 1.0 & 1.006 & 910 & 1500 \\
\hline 9.5 & 10 & 4. & $\ldots$ & 2.569 & 1.0 & 1.006 & 1205 & 1648 \\
\hline 9.5 & 10 & 5. & .. & 2.569 & 1.0 & 1.006 & 1350 & 1943 \\
\hline 9.5 & 10 & 6. & $\ldots$ & 2.569 & 1.0 & 1.006 & 1500 & 2090 \\
\hline 9.5 & 10 & 3.10 & .. & 8.424 & 1.0 & 1.006 & 1795 & .. \\
\hline 9.5 & 10 & 4.67 & -. & 8.254 & 1.0 & 1.006 & 2238 & -. \\
\hline 9.5 & 6 & 4. & -. & 2.569 & 1.0 & 1.006 & 1058 & 1943 \\
\hline 9.5 & 20 & 4. & -. & 2.569 & 1.0 & 1.006 & 1058 & 1205 \\
\hline 9.5 & 5 & 3.10 & -- & 8.424 & 1.0 & 1.006 & 1795 & -. \\
\hline 9.5 & 10 & 3. & -- & 2.569 & 1.0 & 12. & 762 & 1058 \\
\hline 9.5 & 10 & 4. & $\cdots$ & 2.569 & 1.0 & 12. & 910 & 1264 \\
\hline 9.5 & 10 & 5. & -. & 2.569 & 1.0 & 12. & 1058 & 1352 \\
\hline 9.5 & 10 & 6. & -. & 2.569 & 1.0 & 12. & 1279 & 1649 \\
\hline 9.5 & 10 & 3.10 & -. & 8.424 & 1.0 & 12. & 1500 & 2533 \\
\hline 9.5 & 10 & 4.67 & -- & 8.254 & 1.0 & 12. & 1943 & -- \\
\hline 9.5 & 10 & 3. & -. & 2.569 & 0.867 & 120. & 674 & 969 \\
\hline 9.5 & 10 & 4. & -- & 2.569 & 0.867 & 120. & 836 & 1279 \\
\hline 9.5 & 10 & 5. & -- & 2.569 & 0.867 & 120. & 984 & 1426 \\
\hline 9.5 & 10 & 6. & -- & 2.569 & 0.867 & 120. & 1205 & 1500 \\
\hline 9.5 & 10 & 3.10 & -- & 8.424 & 0.867 & 120. & 1353 & 2380 \\
\hline 9.5 & 10 & 4.67 & .- & 8.254 & 0.867 & 120. & 1795 & -. \\
\hline 9.5 & 5 & 4. & -- & 2.569 & 0.867 & 120. & 763 & 1647 \\
\hline 9.5 & 24 & 4. & -- & 2.569 & 0.867 & 120. & 763 & 983 \\
\hline 9.5 & 5 & 3.10 & -- & 8.424 & 0.867 & 120. & 1350 & .. \\
\hline 9.5 & 10 & 2.32 & 2.416 & 2.70 & 1.0 & 1.006 & 763 & 1279 \\
\hline 9.5 & 10 & 2.32 & 6.950 & 2.70 & 1.0 & 1.006 & 910 & 1279 \\
\hline 9.5 & 10 & 3.17 & 3.859 & 2.70 & 1.0 & 1.006 & 984 & 1426 \\
\hline 9.5 & 10 & 3.17 & 6.360 & 2.70 & 1.0 & 1.006 & 1058 & 1500 \\
\hline 9.5 & 10 & 2.32 & 2.416 & 2.70 & 1.0 & 12. & 615 & 984 \\
\hline 9.5 & 10 & 2.32 & 6.950 & 2.70 & 1.0 & 12. & 726 & 1131 \\
\hline 9.5 & 10 & 3.17 & 3.859 & 2.70 & 1.0 & 12. & 763 & 1131 \\
\hline 9.5 & 10 & 3.17 & 6.360 & 2.70 & 1.0 & 12. & 836 & 1205 \\
\hline 9.5 & 10 & 2.32 & 2.416 & 2.70 & 0.867 & 120. & 541 & 984 \\
\hline 9.5 & 10 & 2.32 & 6.950 & 2.70 & 0.867 & 120. & 615 & 1058 \\
\hline 9.5 & 10 & 3.17 & 3.859 & 2.70 & 0.867 & 120. & 689 & 1131 \\
\hline 9.5 & 10 & 3.17 & 6.360 & 2.70 & 0.867 & 120. & 763 & 1205 \\
\hline
\end{tabular}




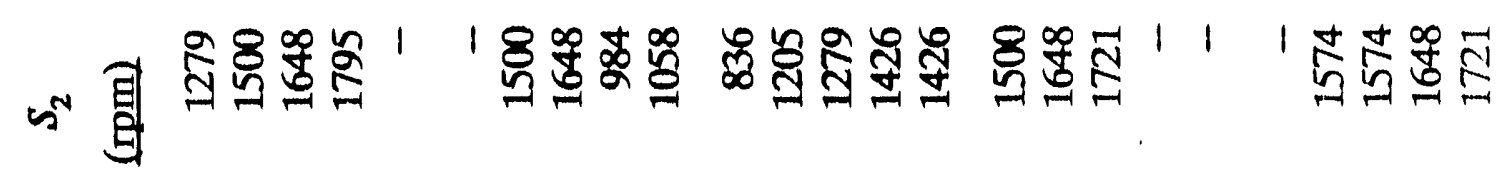

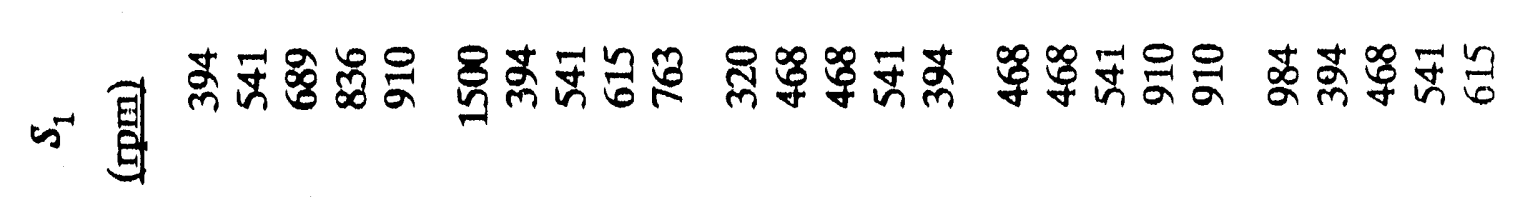

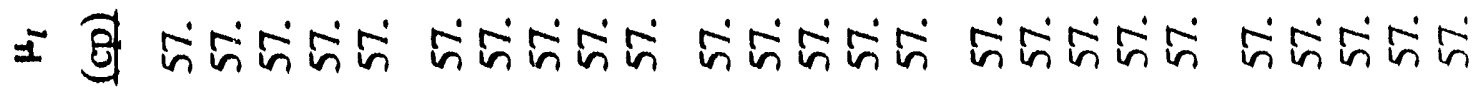

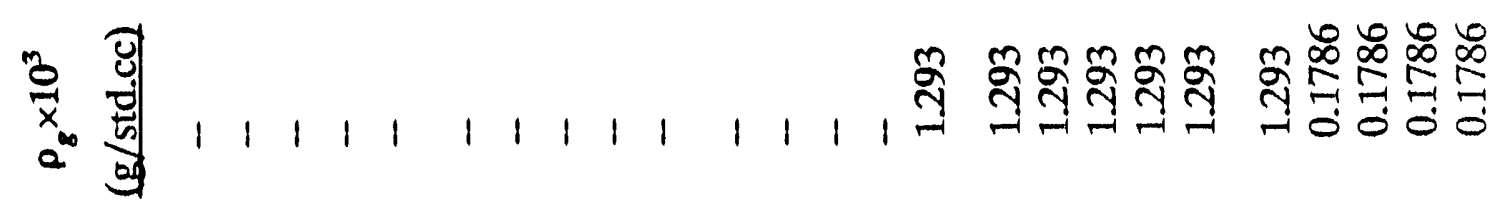

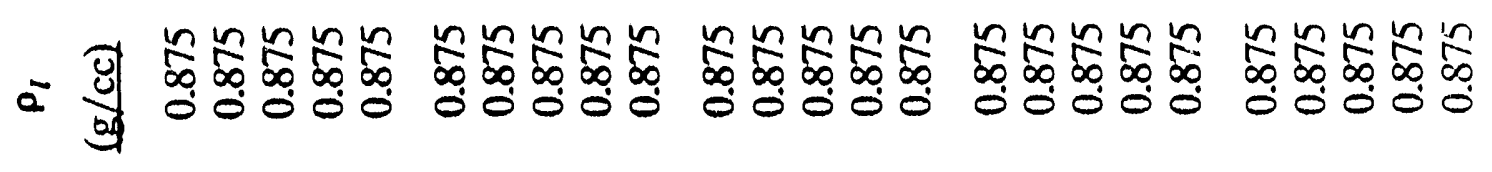

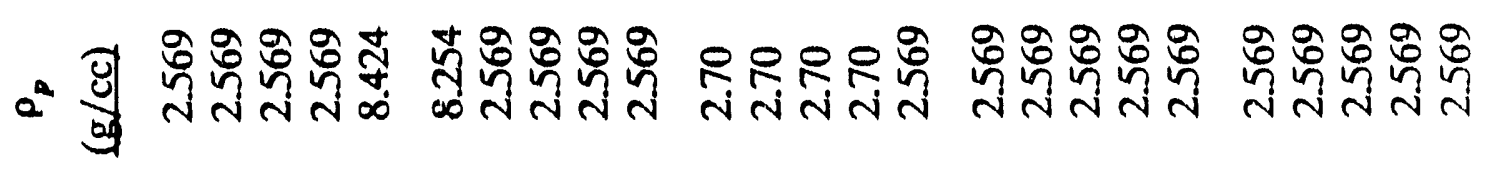

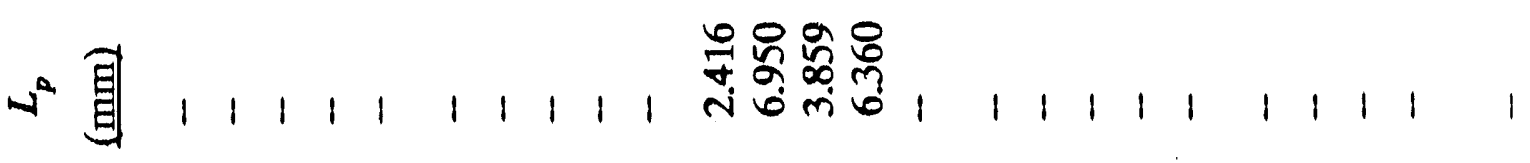

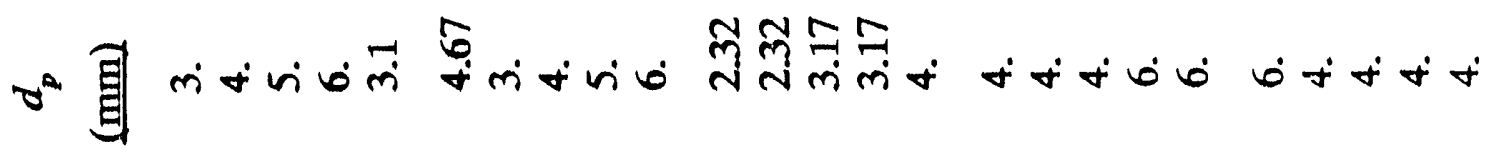

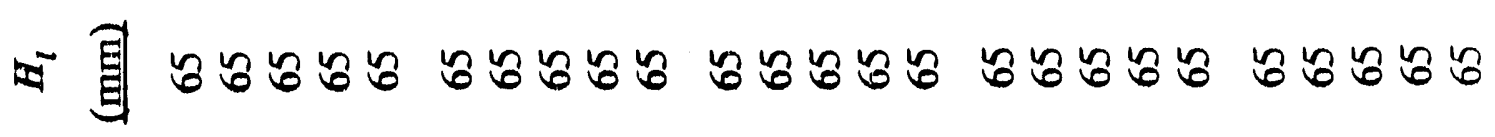

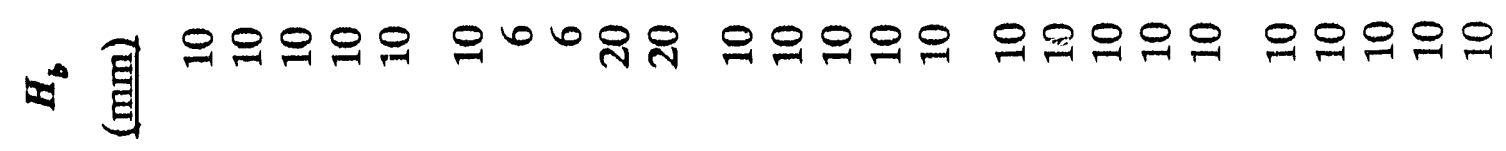

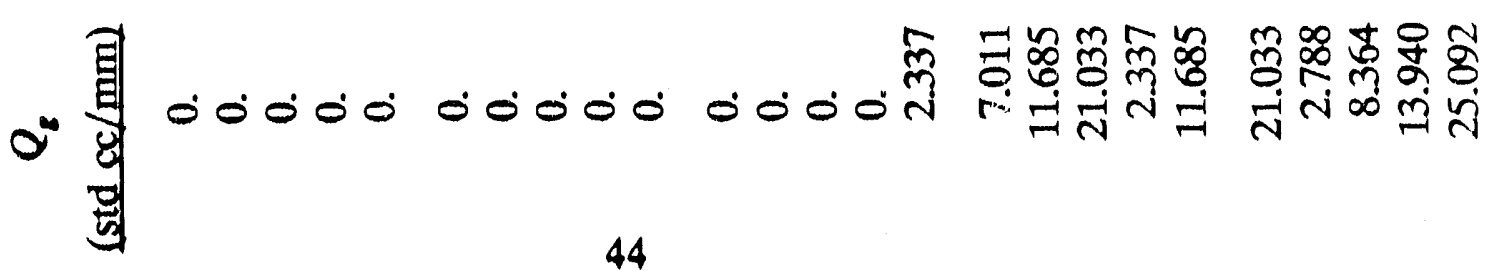


$\omega^{N}$ 慁

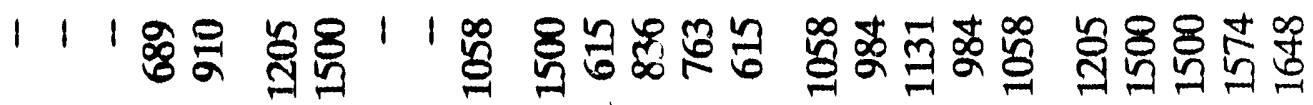

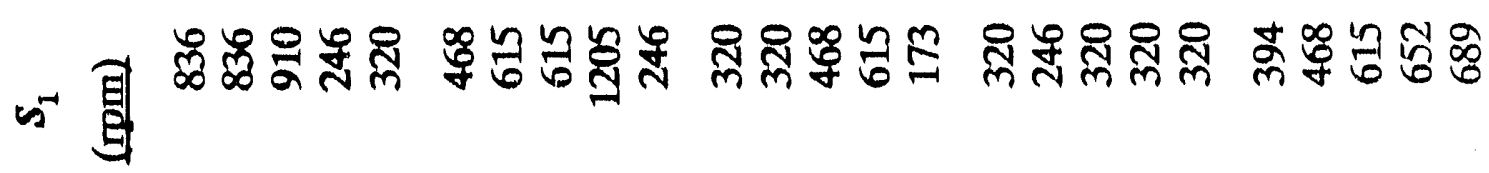

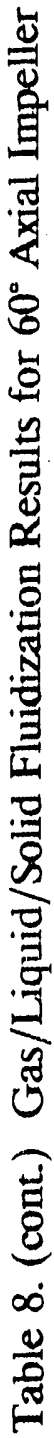

I 鳥

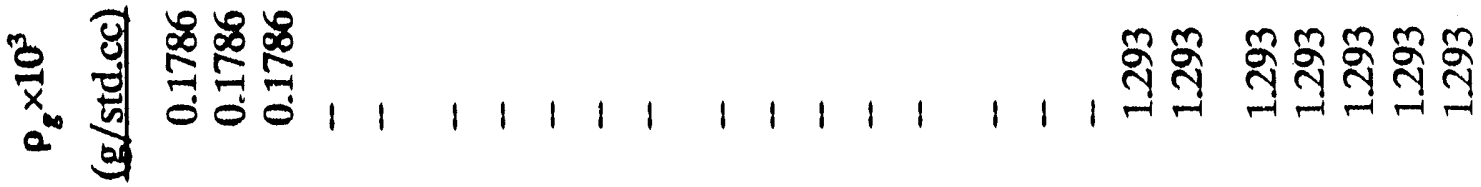

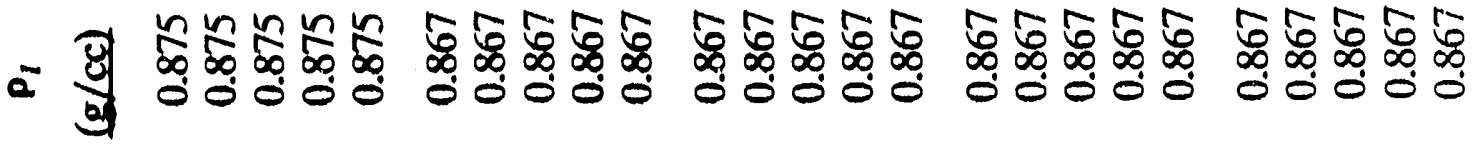

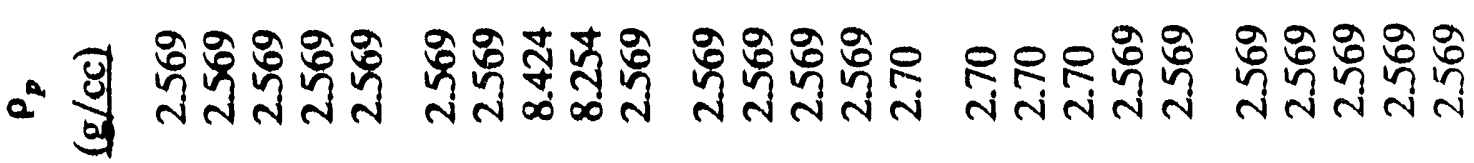

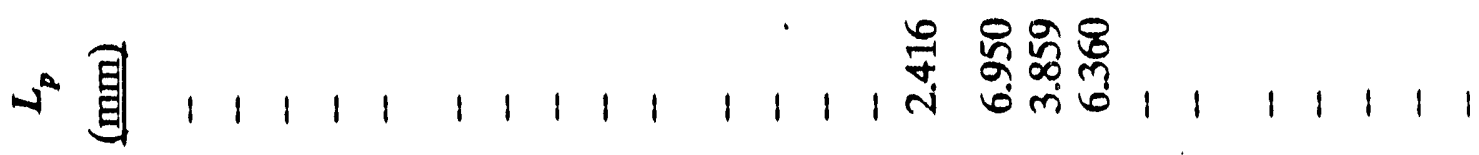

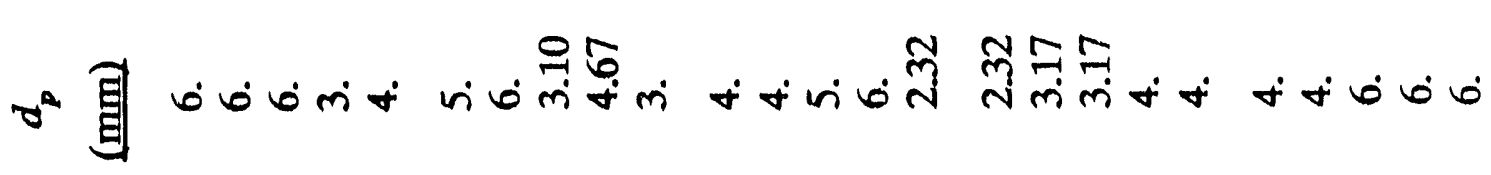

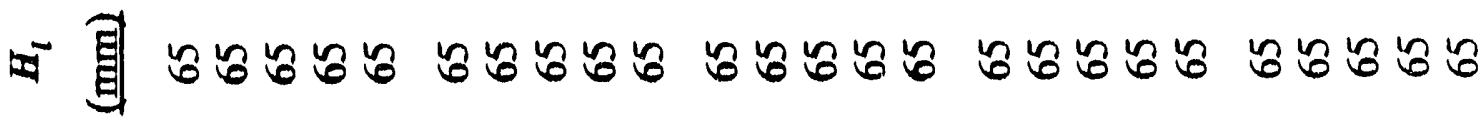

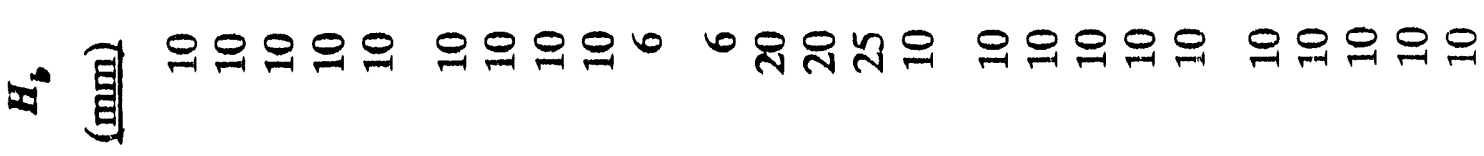

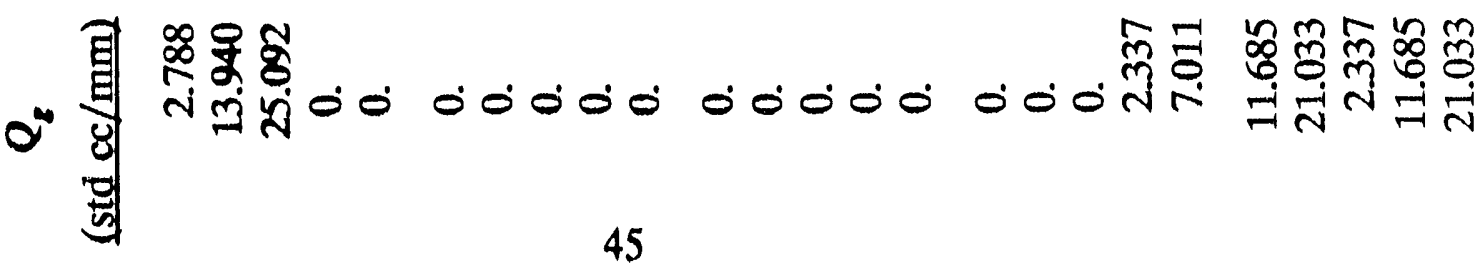




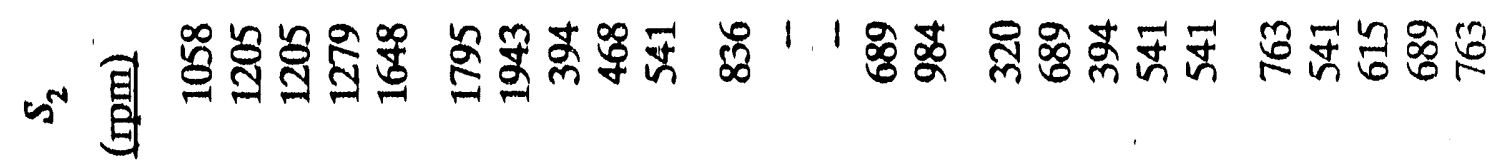

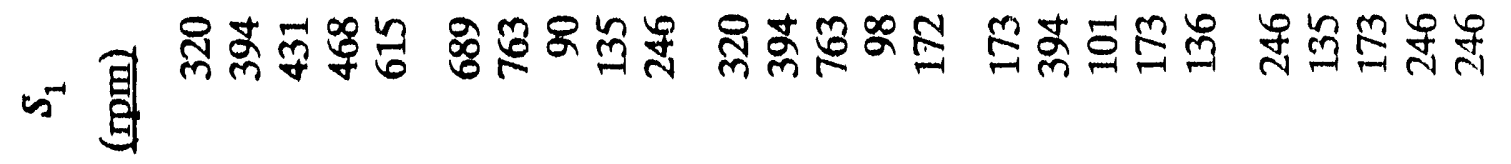

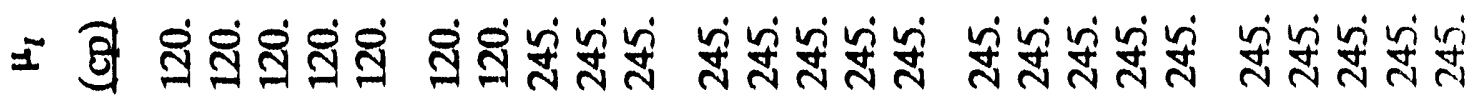

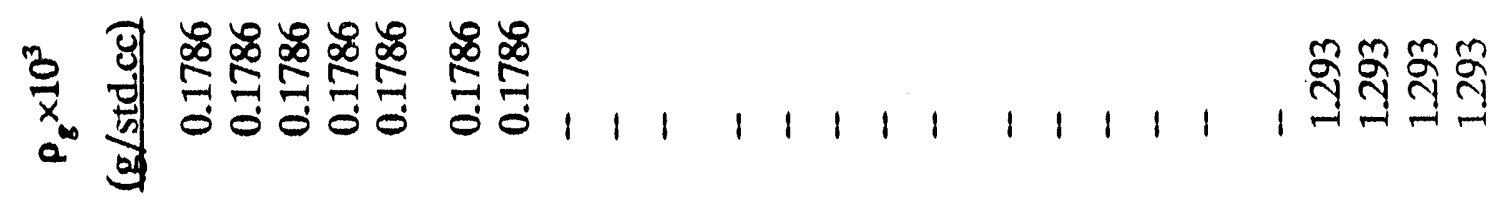

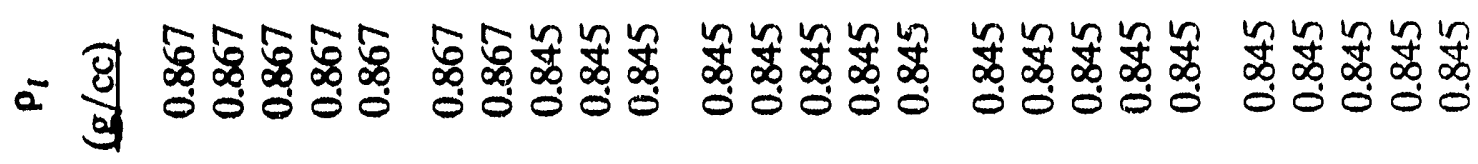

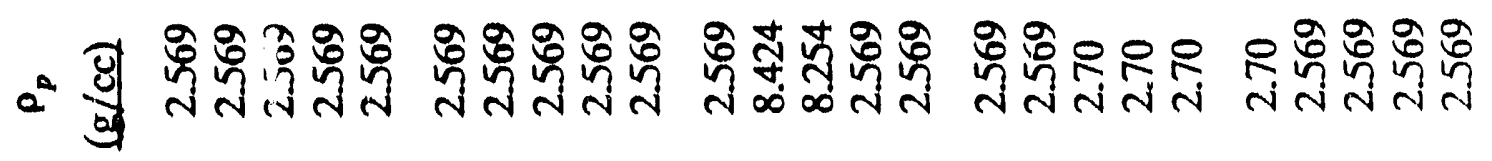

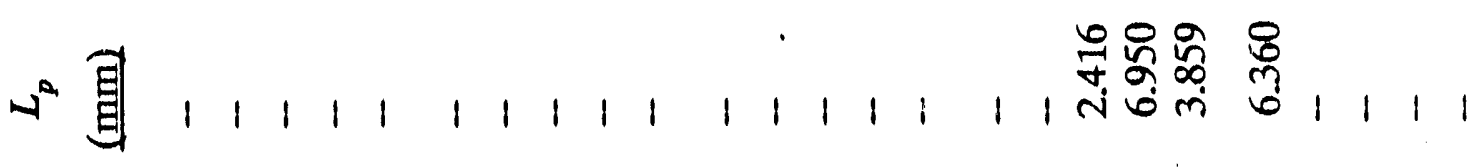

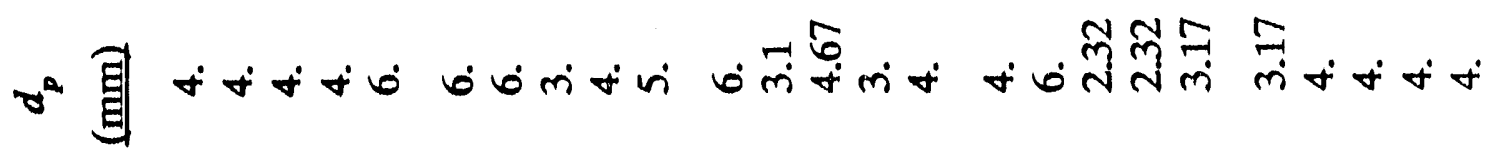

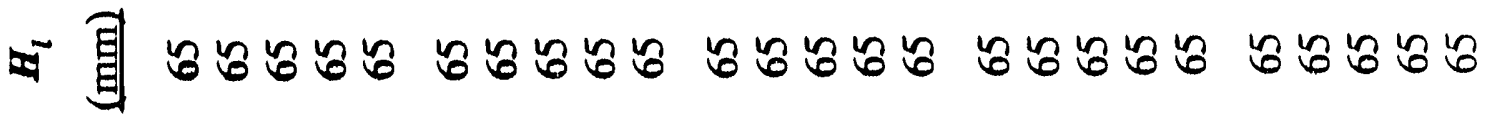

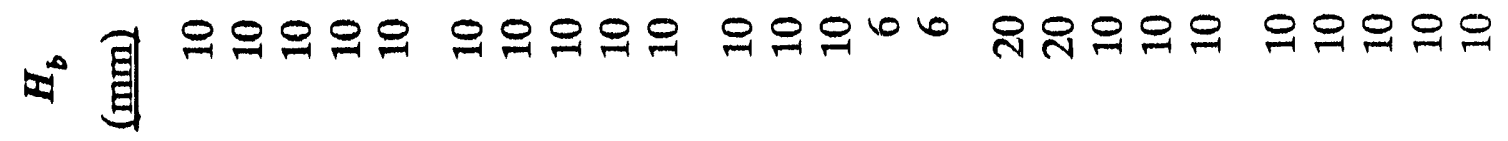

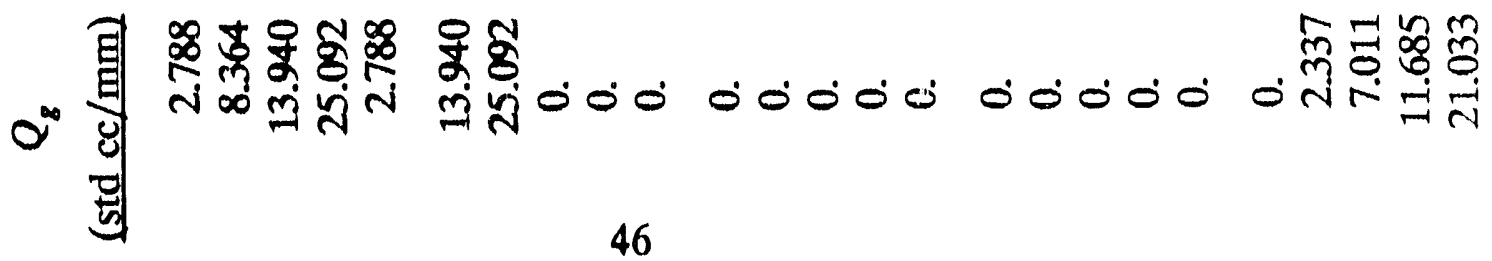




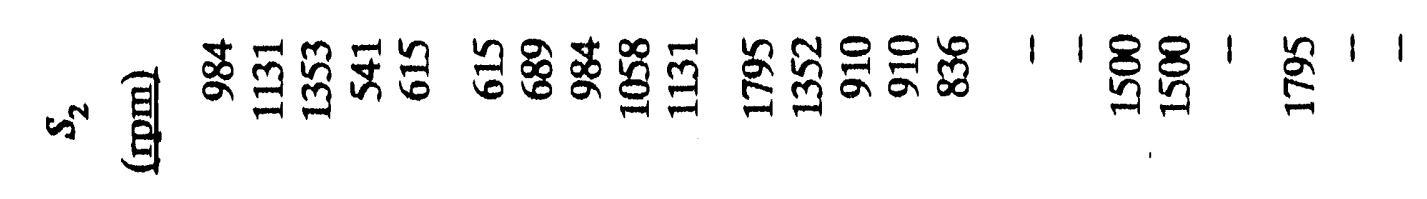

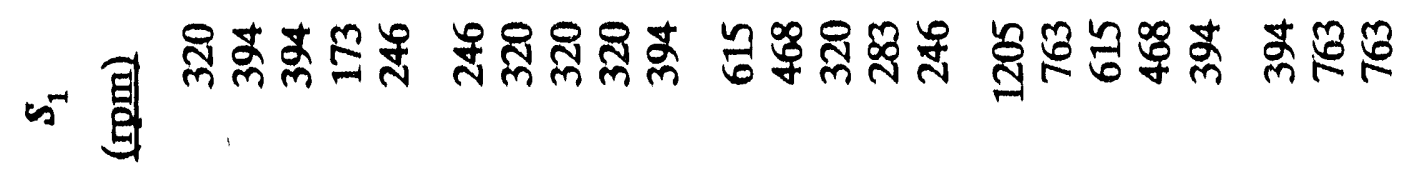

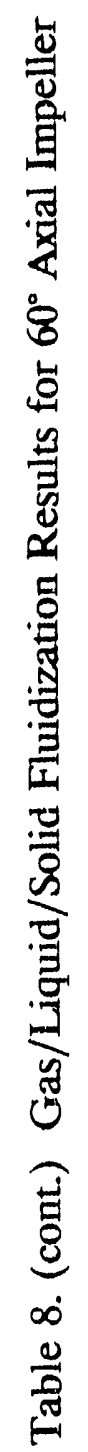

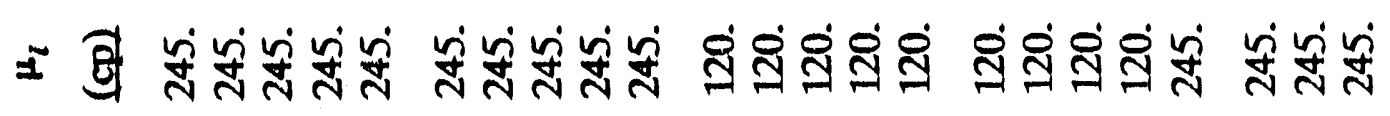

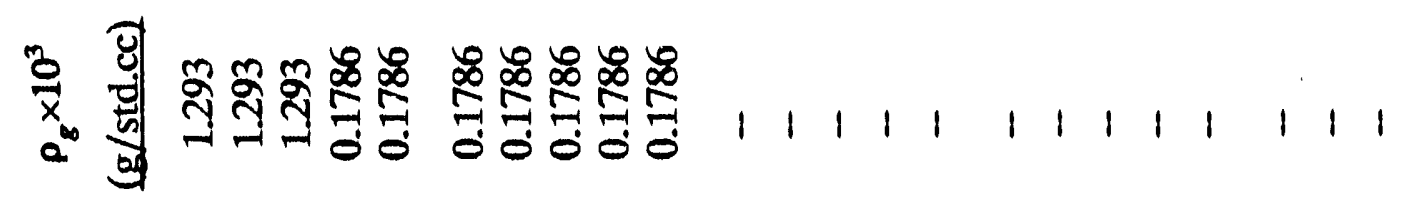

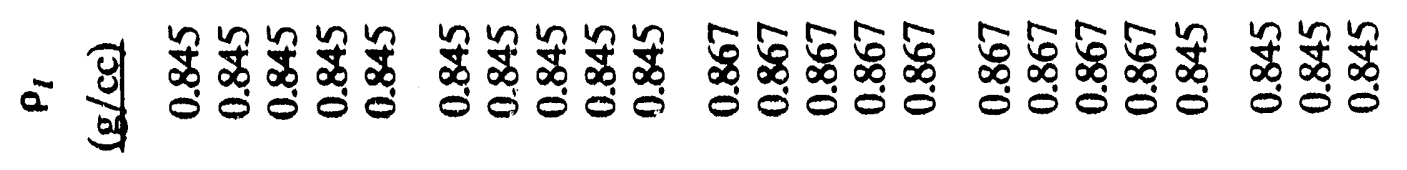

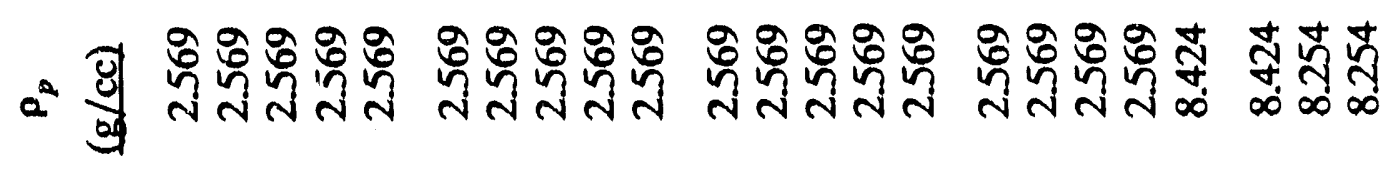

$\checkmark$ 每 11111111111111111111111111111

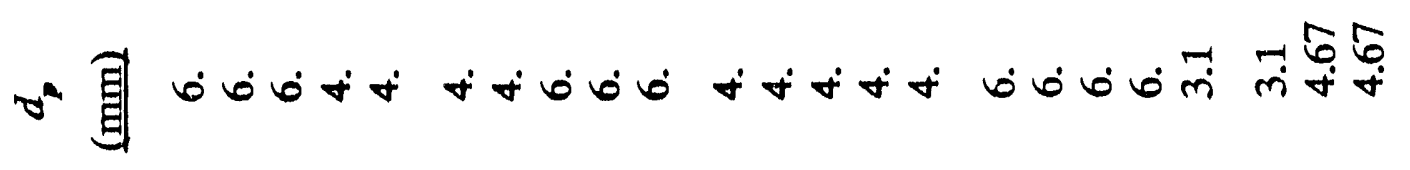

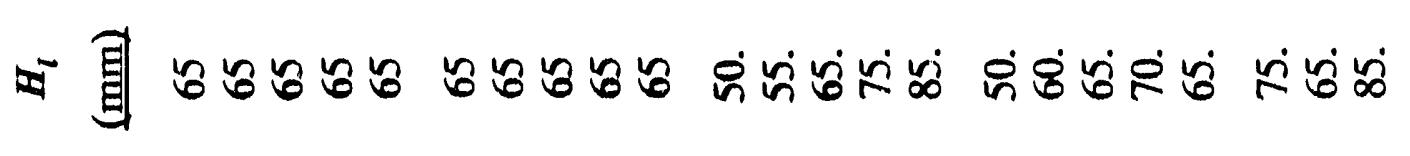

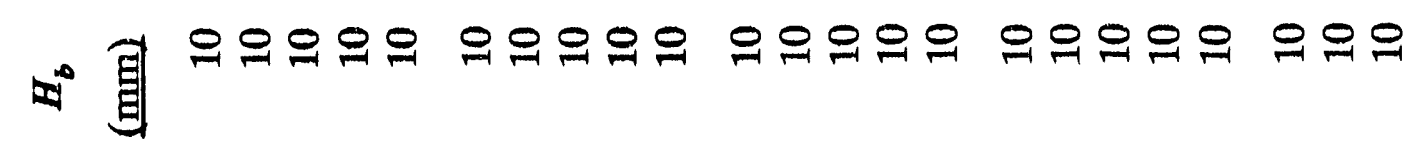

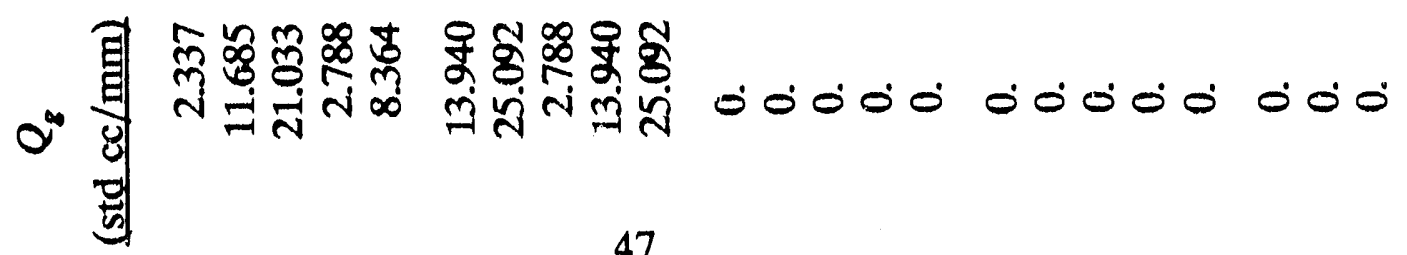


Following the recommendation of Song and coworkers (49), nonspherical particles were treated in terms of an equivalent spherical diameter, $d_{e}$, and a shape factor, $\phi_{s}$. For cylinders, the diameter of a sphere of equal volume is given by:

$$
d_{c}=\left(\frac{3}{2} d^{2} l\right)^{1 / 3}
$$

where $l$ and $d$ are respectively the length and diameter of the cylinder. The shape factor is defined as the ratio of the surface area of a sphere to that of a cylindrical particle of the same volume. Thus

and $d_{p}$ is given by:

$$
\phi_{s}=\frac{d_{c}^{2}}{d\left(\frac{d}{2}+l\right)}
$$

$$
d_{p}=d_{\iota} \phi_{,}
$$

The data were also analyzed with the shape factor set equal to unity. In all cases the use of a shape factor as defined by Eq. (6) significantly reduced the scatter about the regression line.

A power law model of the form:

$$
R e=b_{1} G a^{b_{4}}\left[\left(\rho_{p}-\rho_{l}\right) / \rho_{l}\right]^{b_{3}}\left(d_{l} \int d_{l}\right)^{b_{4}}\left(H_{\downarrow} \int d_{l}\right)^{b_{s}}
$$

was fit to the radial impeller ( $20^{\circ}$ blade angle) data for both $S_{1}$ and $S_{2}$ (36 points each) using a nonlinear regression program. For $S_{1}$, the stirrer speed at incipient fluidization, the effect of bed height was found to be negligible. The following correlation was obtained: 


$$
R e_{1}=1.937 G a^{0.537}\left[\left(p_{p}-p_{l}\right) / p_{l}\right]^{-0.104}\left(d_{p} \int d_{l}\right)^{-0.858}
$$

A parity plot of predictions from this equation is provided in Figure 21. Agreement between the predicted and experimental $S_{1}$ values is good. A correlation for the stirrer speed corresponding to particle carryover was similarly obtained by a nonlinear fit of Eq. (8) to the $S_{2}$ data. The regression equation is:

$$
\operatorname{Re}_{2}=1.224 G a^{0.540}\left(d, d d_{i}\right)^{-1.012}\left(H_{J} J d_{i}\right)^{-0.385}
$$

The buoyancy factor was found to be negligible (although a buoyancy term is contained in $G a)$, but it was necessary to include the bed height term. A parity plot of this correlation is presented in Figure 22. The particle carryover data are in good agreement with the predictions of Eq. (10).

For Gas/Liquid/Solid fluidization, dimensional analysis identifies a total of 8 dimensionless correlating variables. In addition to the groups identified previously we have:

$$
\begin{aligned}
& F r=\frac{Q_{8}^{2}}{d_{i}^{A} g d_{p}}=\text { Froude number } \\
& P_{d} / P_{l}=\text { gas density factor } \\
& \left(H_{l}-60\right) / d_{i}=\text { liquid height factor }\left(H_{l} \sim \text { mm }\right)
\end{aligned}
$$

As discussed earlier, nonspherical particles were treated in terms of an equivalent spherical diameter and a particle shape factor.

Nonlinear regression on a total of 94 data points provided the following correlation for $S_{1}$, the stirrer speed at incipient fluidization for the $60^{\circ}$ blade angle axial impeller: 


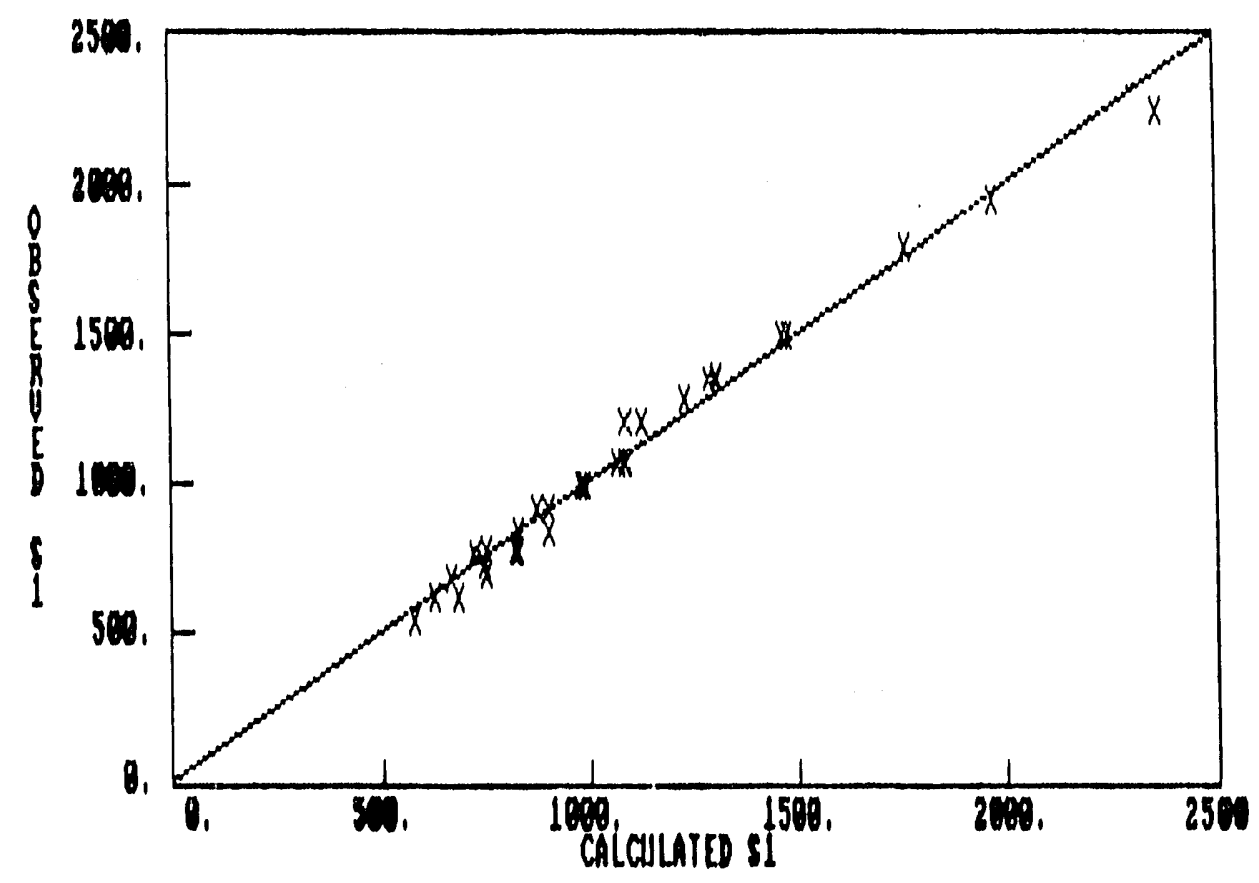

Figure 21. Parity plot for $S_{1}$ correlation, Eq. (9). $20^{\circ}$ radial flow impeller.

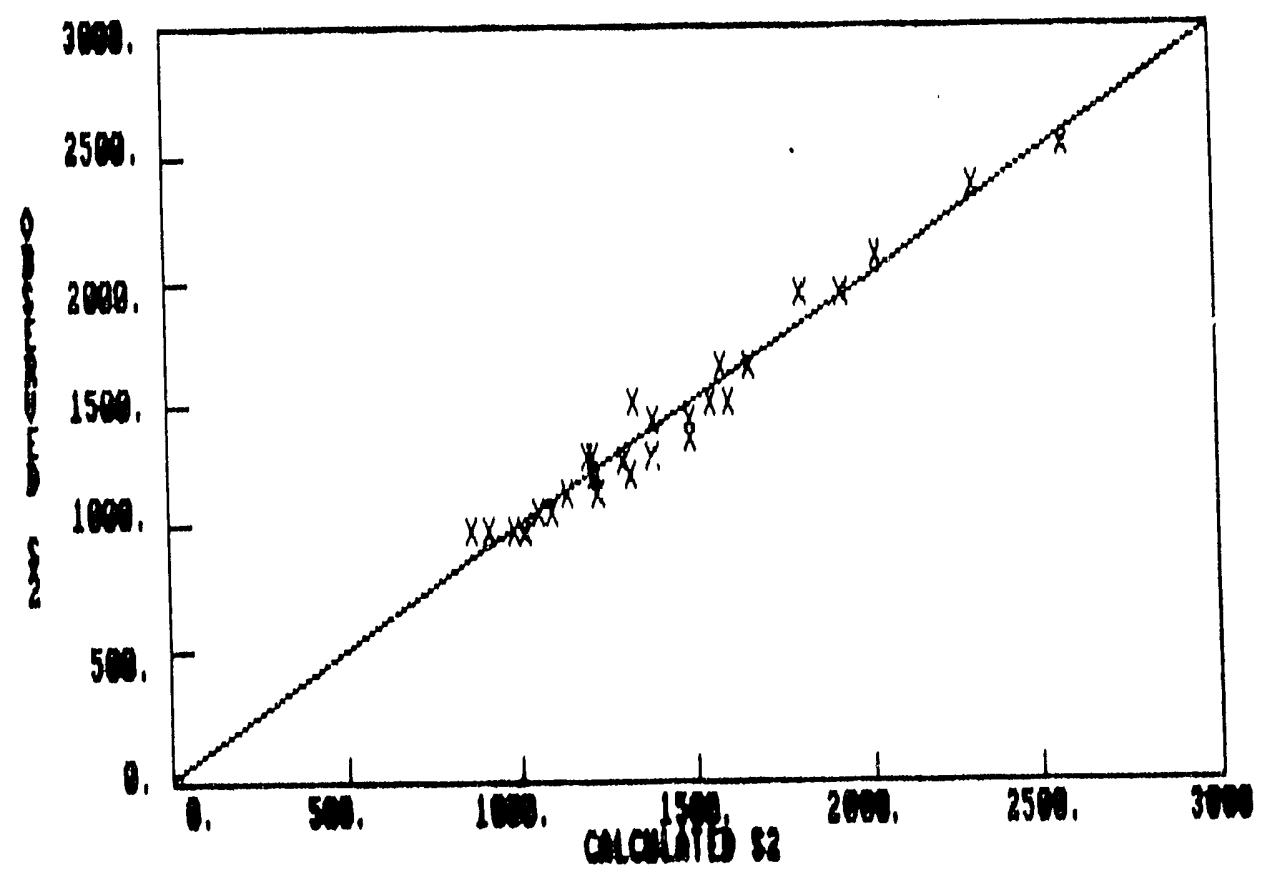

Figure 22. Parity plot for $S_{2}$ correlation, Eq. (10). $20^{\circ}$ radial flow impeller. 


$$
R e_{1}=0.202 G a^{0.72}\left(\frac{\rho_{p}-\rho_{l}}{\rho_{l}}\right)^{-0.120}\left(\frac{d_{p}}{d_{l}}\right)^{-1.045}\left[1+27.7 F r^{0.385}\right]
$$

Experimentally it was observed that neither gas density nor rest bed height nor liquid level had a significant effect on $S_{1}$. A parity plot for this correlation is presented in Figure 23. The correlation provides a satisfactory representation of the data.

Earlier we made note of the fact that for some situations, particle carryover may not be attainable at any stirrer speed with the axial flow impeller. The bed expands with increasing stirrer speed up to a point, and thereafter no further expansion of the bed is observed. This phenomenon is illustrated in Figure 20. At about the point corresponding to cessation of the bed expansion, cavitation was observed in the impeller blades. Experimentally it was not difficult to observe the onset of cavitation, and so a correlation was developed for the critical stirrer speed, $\boldsymbol{S}_{\mathbf{3}}$, at which cavitation is first observed. Thus we obtained:

$$
R e_{3}=2.05 G a^{0.522}\left(\frac{\rho_{p}-\rho_{l}}{\rho_{l}}\right)^{-0.507}\left(\frac{d_{p}}{d_{l}}\right)^{-1.577}\left(\frac{H_{i}-60}{d_{l}}\right)^{0.234}\left[1-31.2 F r^{0.361}\right]
$$

Note the positive dependence of $S_{3}$ (or $R_{3}$ ) on the liquid depth, $H_{l}$. Without sufficient liquid depth above the impeller, gas is sucked into the inlet and circulation is limited. This behavior is, however, quite unlike that observed with the radial flow impeller where circulation ceases when the blades come into contact with gas. A parity plot for the $S_{3}$ correlation is presented in Figure 24.

In many situations particle carryover is observed, and those data provided the following correlation for $S_{2}$ : 


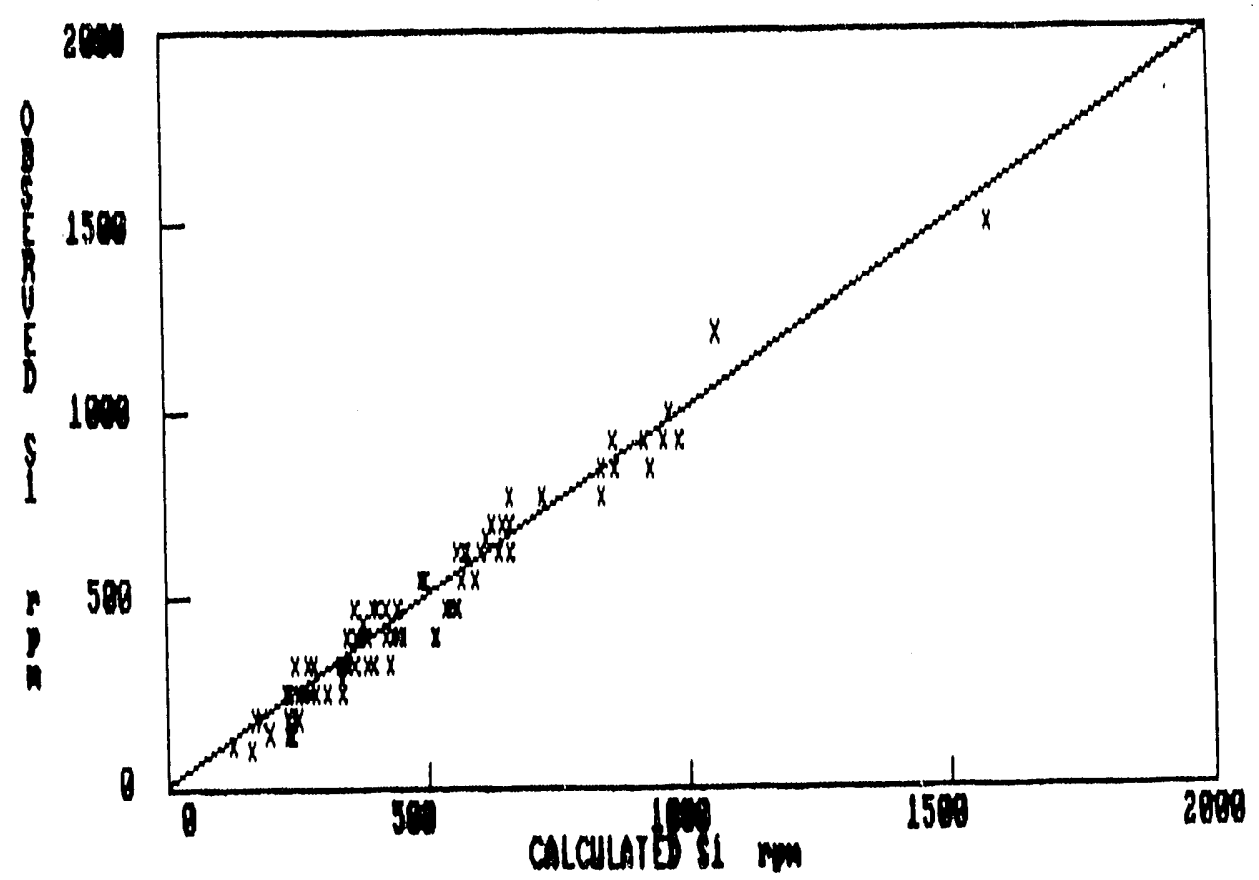

Figure 23. Parity plot for $S_{1}$ correlation, Eq. (11). $60^{\circ}$ axial flow impeller.

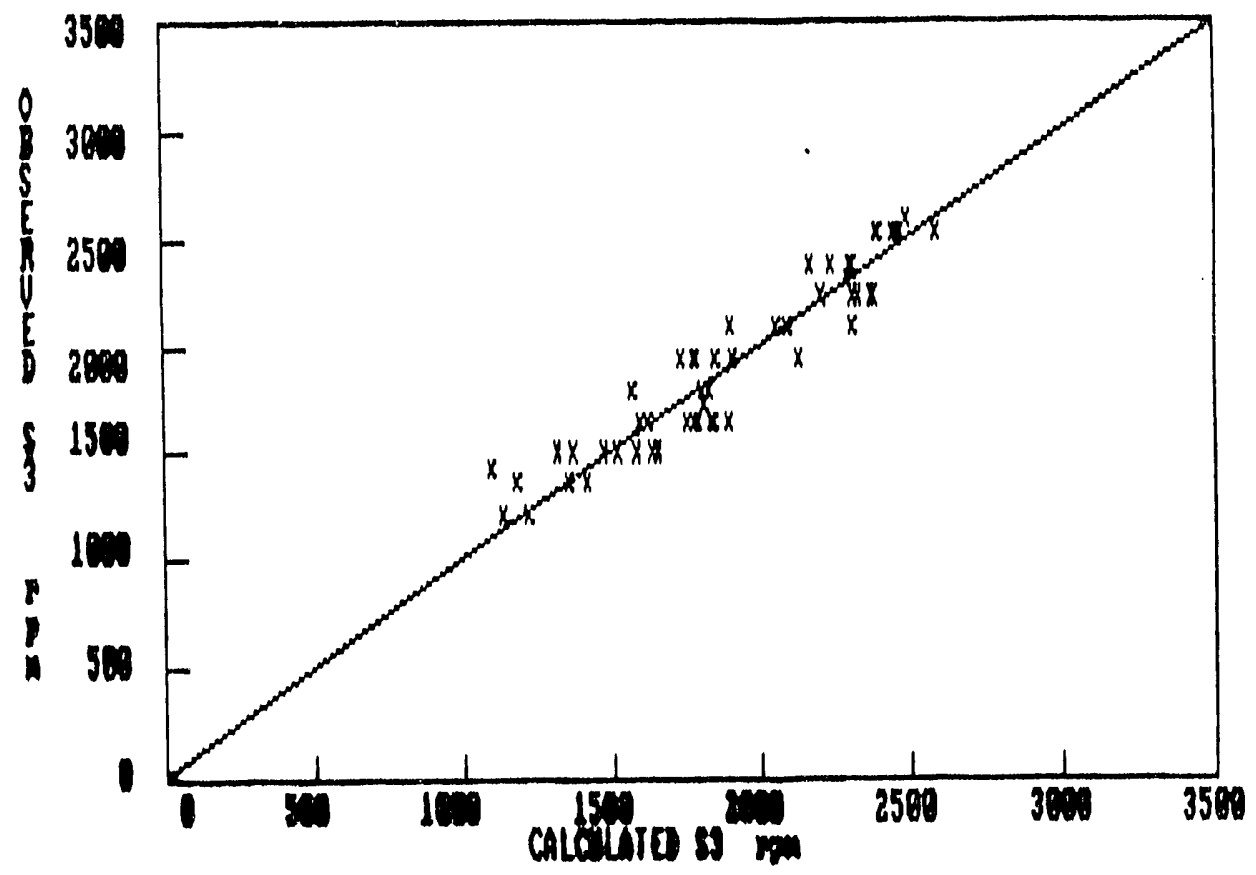

Figure 24. Parity plot for $S_{4}$ correlation, Eq. (12). $60^{\circ}$ axial flow impeller. 


$$
R e_{2}=0.1276 G a^{0.747}\left(\frac{d_{p}}{d_{i}}\right)^{-1.437}\left(\frac{H_{b}}{d_{i}}\right)^{-0.634}\left[1+10.26 F r^{0.275}\right]
$$

The parity plot is provided in Figure 25. The scatter about this correlation is a bit more extensive by comparison to the $S_{1}$ correlation. This is due in part to experimental difficulties in locating the point of particle entrainment.

The correlations for $S_{2}$ and $S_{3}$ can be used to predict whether or not particle carryover will occur. When the calculated value of $S_{3}$ is less than $S_{2}$, cavitation commences before the bed is expanded to the upper screen and particle carryover is not observed. If $S_{2}$ is less than $S_{3}$ the bed expands to the limit.

\section{Internal Recycle Rates:}

A third important feature of the reactor, namely the internal circulation rate, will now the addressed. The internal recycle ratio must be above a critical value to insure that the vessel may be treated as perfectly mixed in a reaction kinetics study. Estimates of the internal circulation rate at different stirrer speeds were calculated from observations of the stirrer speed at incipient fluidization. Only the $60^{\circ}$ blade angle axial flow impeller was treated because the performance of this impeller was superior by comparison to the many designs tested, and because this impeller was employed in subsequent hydrotreating and coal liquefaction studies.

Upon equating the drag force in a fixed bed of spheres (Ergun equation) to the displacement weight of the bed, the following equation is obtained for the incipient fluidization velocity: 


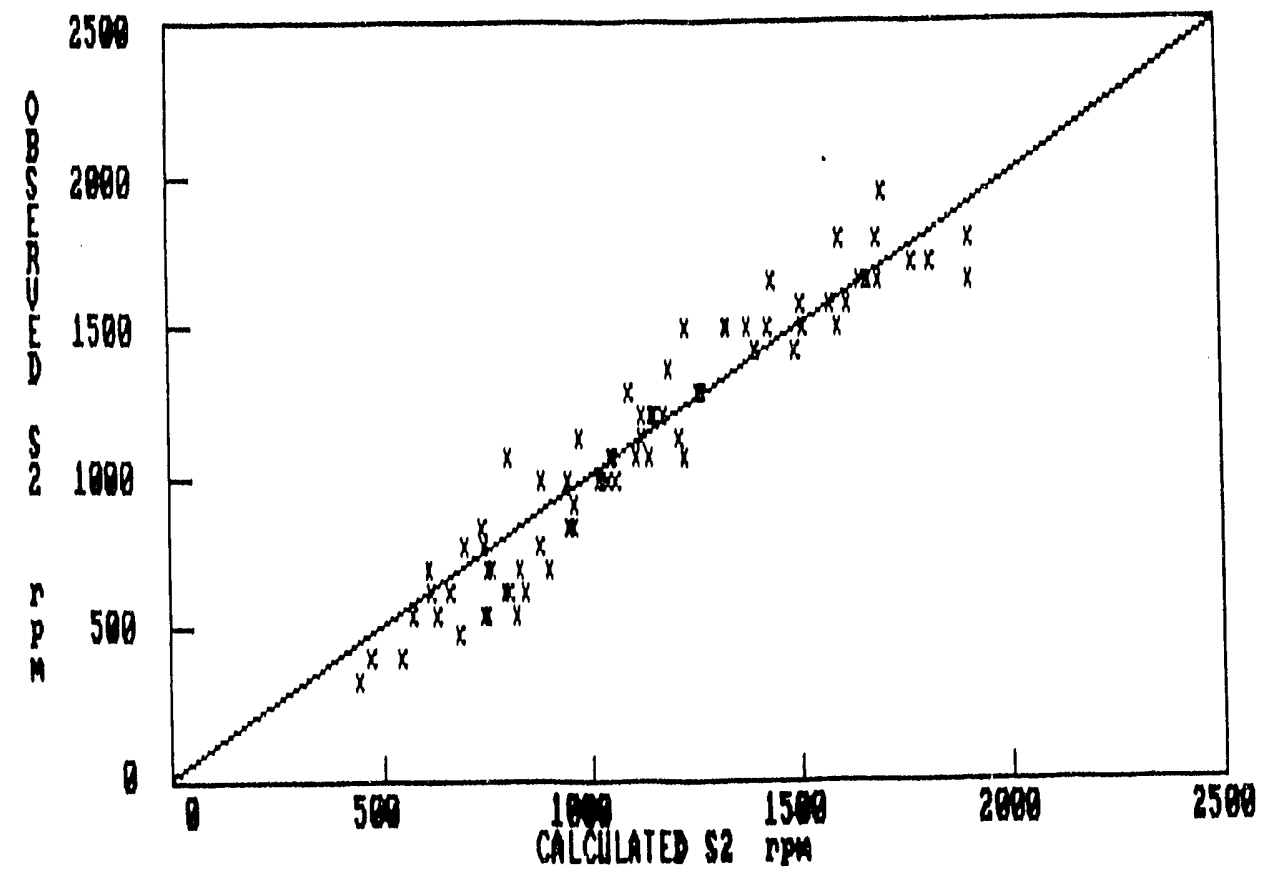

Figure 25. Parity plot for $S_{2}$ correlation, Eq. (13). $60^{\circ}$ axial flow impeller. 


$$
1.75 R e^{2}+150(1-e) R e-e^{3} G a=0
$$

where

$$
\operatorname{Re}=\frac{u \mu_{p} p_{l}}{\mu_{l}}
$$

is not to be confused with the rotational Reynolds number, and $u_{i}$ is the superficial velocity at incipient fluidization. In our calculations we have taken $\Theta=0.476$ for the porosity of a loose packing of spheres.

The stirrer speed at incipient fluidization, $S_{1}$, is observed experimentally for a given particle/fluid combination and the corresponding Reynolds No. is calculated from Eq. (14). The superficial incipient fluidization velocity is then calculated from Eq. (15), and multiplying by the bed cross-sectional area gives the liquid circulation rate. Liquid circulation rates calculated in this manner are plotted versus stirrer speed in Figure 26. All the data for different fluids and particles fall on the same curve. This figure would therefore appear to have predictive capabilities over the range of fluid and particle properties investigated.

Figure 26 provides a basis for a statement about the approach to perfect mixing or backmix behavior. For a five gram catalyst charge and a Weight Hourly Space Velocity (WHSV) of 2, the feedrate to the reactor will be approximately $10 \mathrm{cc} / \mathrm{hr}$. It is evident from the figure that the ratio of circulation rate to feedrate, i.e. the recycle ratio, will be of the order of thousands provided that the stirrer speed is above about $600 \mathrm{rpm}$. To provide perspective, consider a first order irreversible reaction taking place in a recycle reactor operating at the $90 \%$ conversion level. At a recycle ratio of $100 / 1$, the error introduced in 


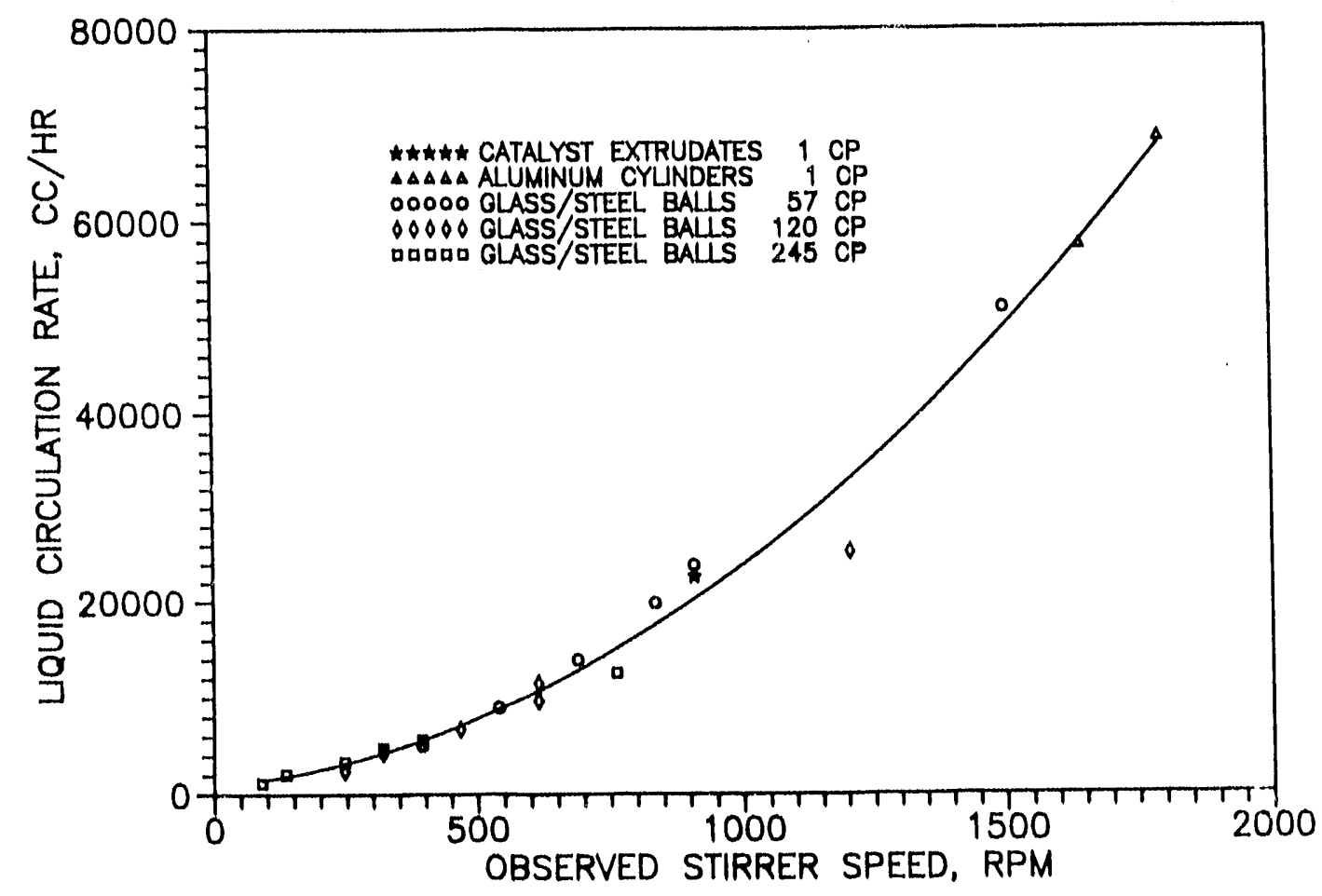

Figure 26. Liquid circulation rate versus stirrer speed. 
the calculated first order rate constant by assuming perfect mixing is only $4.4 \%$. At a $1000 / 1$ recycle ratio the error is reduced to less than $0.5 \%$. The errors are even less severe at lower conversion levels. Thus it would appear that the ebullated bed microreactor may be treated as a perfectly mixed reactor for practically all situations likely to be encountered.

\section{Conclusions:}

A study of many different impeller variations identified two designs of interest. A radial flow design performed well in liquid/solid applications but was unsuitable in gas/liquid/solid service. An axial flow design worked well in both applications. For the radial flow impeller, correlations were developed for 1) stirrer speed at incipient fluidization, $S_{1}$, and 2) stirrer speed at particle carryover, $S_{2}$. For the axial flow impeller, correlations were developed for 1) stirrer speed at incipient fluidization, $S_{1}, 2$ ) stirrer speed at particie carryover, $S_{2}$, and 3) stirrer speed corresponding to onset of cavitation, $S_{3}$. When $S_{2}>S_{3}$, bed expansion is limited. Under typical operating conditions internal circulation rates are of the order of thousands to one, so for all practical purposes the reactor may be considered perfectly mixed. The results reported herein are strictly limited to reactors identical in size and shape to the cold model, and to the range of physical properties investigated.

\section{B. HYDROTREATING STUDIES}

A considerable part of the development of the CCLM was conducted while the reactor operated as a hydrotreater. The feedstock for these studies was a raw creosote oil, and the catalyst was the same CoMo/alumina catalyst (Amocat 1A) described earlier, 
Section II-A and Table 1. No coal paste was fed to the unit during this phase of the investigation. This placed less burden on the operators of the unit who were just becoming familiar with its operation. It will become apparent during later discussion that considerable improvements in the operation of the unit were achieved during the hydrotreating studies.

\section{Experimental:}

The raw creosote oil was obtained from Allied Signal Chemical Company and carries their designation 24-CB. It is obtained from the high temperature carbonization of bituminous coal with further processing to remove excess crystalline salts. The initial boiling point is $400^{\circ} \mathrm{F}$ and $95 \%$ boils below $960^{\circ} \mathrm{F}$. A GC simulated distillation curve (ASTM D2887-73) is plotted in Figure 27. Elemental analyses are compiled in Table 9. The material is very deficient in hydrogen and consists mostly of two, three and four ring polynuclear aromatics.

A schematic of the experimental apparatus is provided in Figure 28. High pressure hydrogen is fed to the unit through a mass flow controller (Brooks mod. 5850 TRB). Liquid feedstock is introduced by a liquid chromatography pump (Eldex mod. 1003 with K-seal) from a feed tank sitting on an analytical pan balance which reads to 0.01 gram. The hydrogen and liquid feed streams are combined just prior to entering at the bottom of the

reactor, Figure 13. Product exits through the drawoff tube and is directed to either of two high pressure accumulators. Gas leaving the accumulator passes through a back pressure regulator, a Wet Test Meter (WTM), and is collected in a butyl rubber gas bag for analysis. At the termination of a balance period, the product stream is switched to the second accumulator so that the first accumulator can be depressured without disturbing the system. 


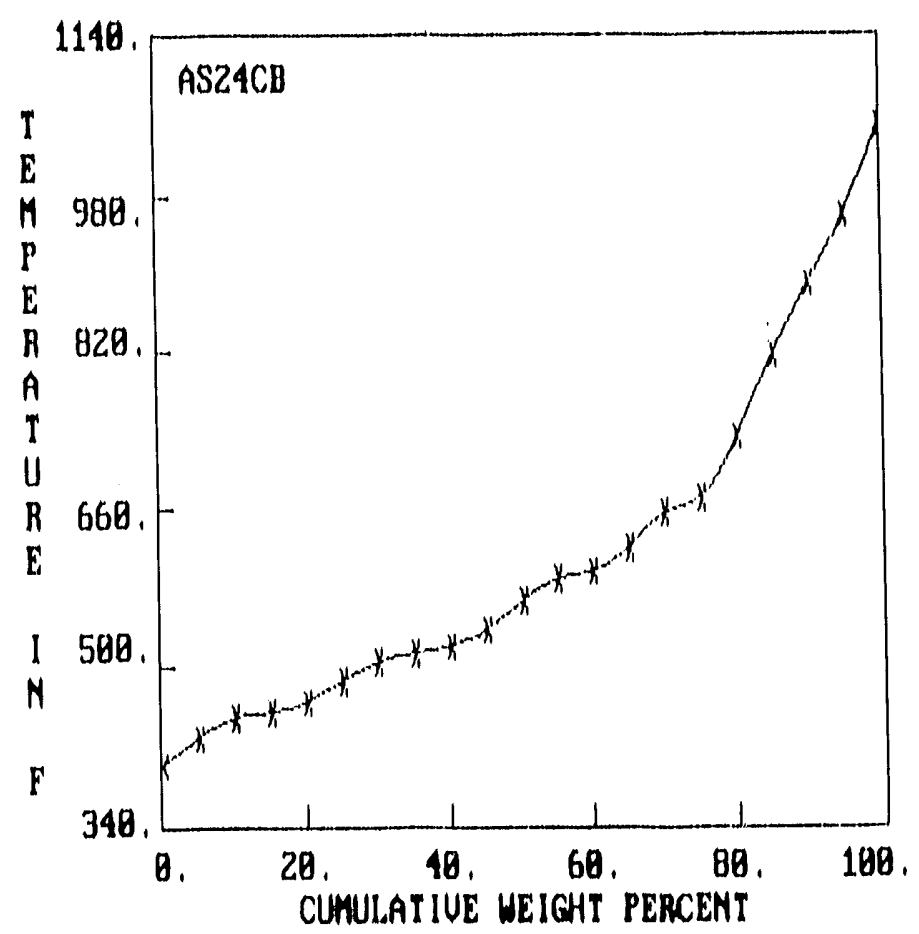

Figure 27. GC simulated distillation curve (ASTM D2887-73) for Allied Signal 24-CB creosote oil.

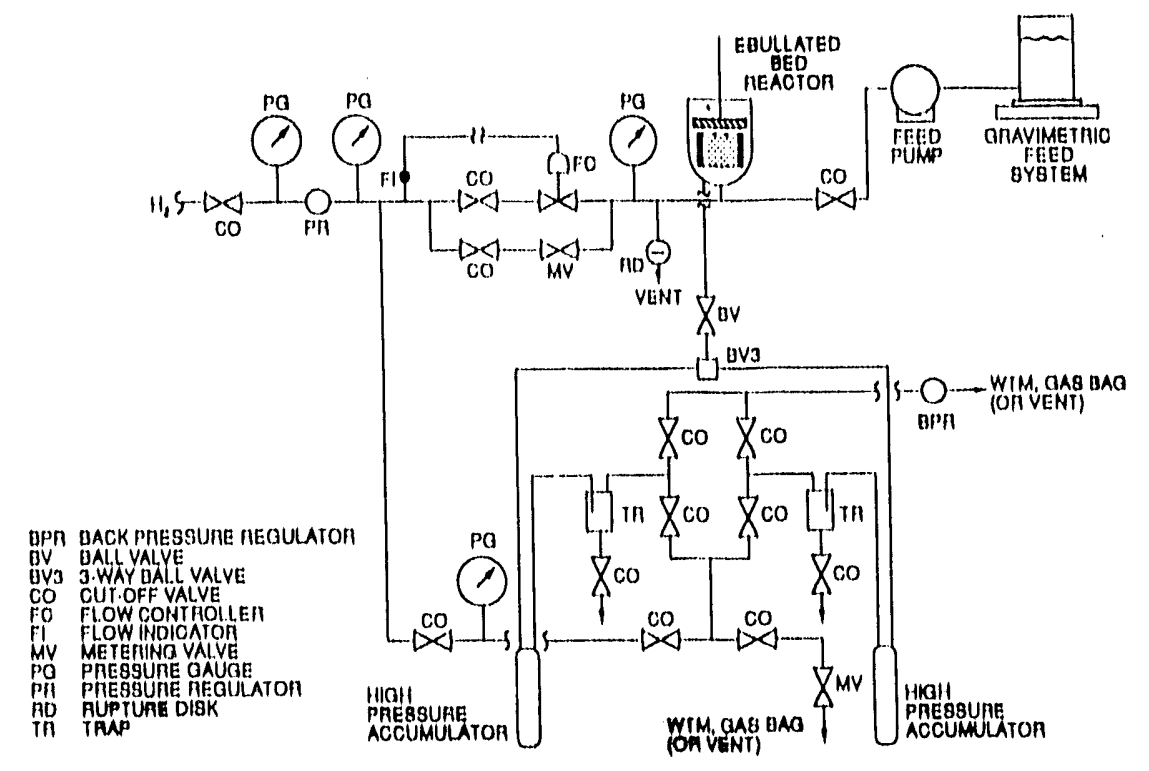

Figure 28. Catalytic Coal Liquefaction Microreactor unit configured for hydrotreating studies. 
Table 9. Elemental Analyses for Allied Chemical Raw Creosote Oll 24-CB

\begin{tabular}{lr} 
& $w+\%$ \\
\cline { 2 - 2 } $\mathrm{C}$ & 90.64 \\
$\mathrm{H}$ & 6.35 \\
$\mathrm{~N}$ & 1.00 \\
$\mathrm{O}$ & 1.38 \\
$\mathrm{~S}$ & 0.67 \\
\cline { 2 - 2 } & 100.0
\end{tabular}


All products .. gas and liquid -- are collected for the duration of the balance period, Including the gas in the accumulator at the end of the experiment.

Prior to charging the reactor, the catalyst was calcined in air at $500^{\circ} \mathrm{C}$ for 16 hours. Five grams was then loaded into the reactor and sulfided insitu according to the standard procedure of Table 10. This procedure is designed to allow sulfiding to be completed and the reactor to be brought to operating conditions in one working day, and it is roughly consistent with guidelines recommended by Hallie (50). Hallie, for example, points out that sulfiding with a liquid phase feedstock spiked with an organic sulfur component is to be preferred over the common laboratory procedure of sulfiding with an $\mathrm{H}_{2} \mathrm{~S} / \mathrm{H}_{2}$ mixture. The reasons for this are not stated, but it seems possible that the poor heat transfer characteristic of gas phase systems might lead to overheating of the catalysi during the exothermic sulfiding reaction. He also recommends that the sulfiding temperature should never exceed $300^{\circ} \mathrm{C}$, and the decomposition temperature for carbon disulfide is listed as $175^{\circ} \mathrm{C}$. A major difference between the procedure of Table 10 and the recommendations of Hallie is the heating rate. Hallie proposes that the heating rate should never exceed $10^{\circ} \mathrm{C} / \mathrm{hr}$. Again, no justification for this limit is given, but perhaps this is to prevent temperature excursions in industrial size reactors. Temperature control is excellent in our laboratory system, hence the much higher temperature programming rate. A typical temperature program history for our system is plotted in Figure 29.

Balance periods were typically conducted once a day. The product gas was analyzed immediately by gas chromatography (Carle AGC111-H refinery gas analyzer). The liquid 
Table 10. Catalyst Presulfiding Procedure

1. Prepare sulfiding feed consisting of $5 \mathrm{wt} \% \mathrm{CS}_{2}$ in heavy mineral oil.

2. Fill the reactor with sulfiding feed. Pressure the system to operating pressure and start pumping sulfiding feed at WHSV $=2$. Set the hydrogen flow at $5000 \mathrm{scf} / \mathrm{bbl}$.

3. Raise the temperature from ambient to $250^{\circ} \mathrm{C}$ at nominal $2^{\circ} \mathrm{C} / \mathrm{min}$. (Note: This is the temperature programmer setting. The actual reactor temperature will increase at a somewhat lower rate due to system lag.)

4. Hold the temperature at $250^{\circ} \mathrm{C}$ for two hours.

5. Switch to makeup solvent and program at nominal $2^{\circ} \mathrm{C} / \mathrm{min}$ to reaction temperature. 


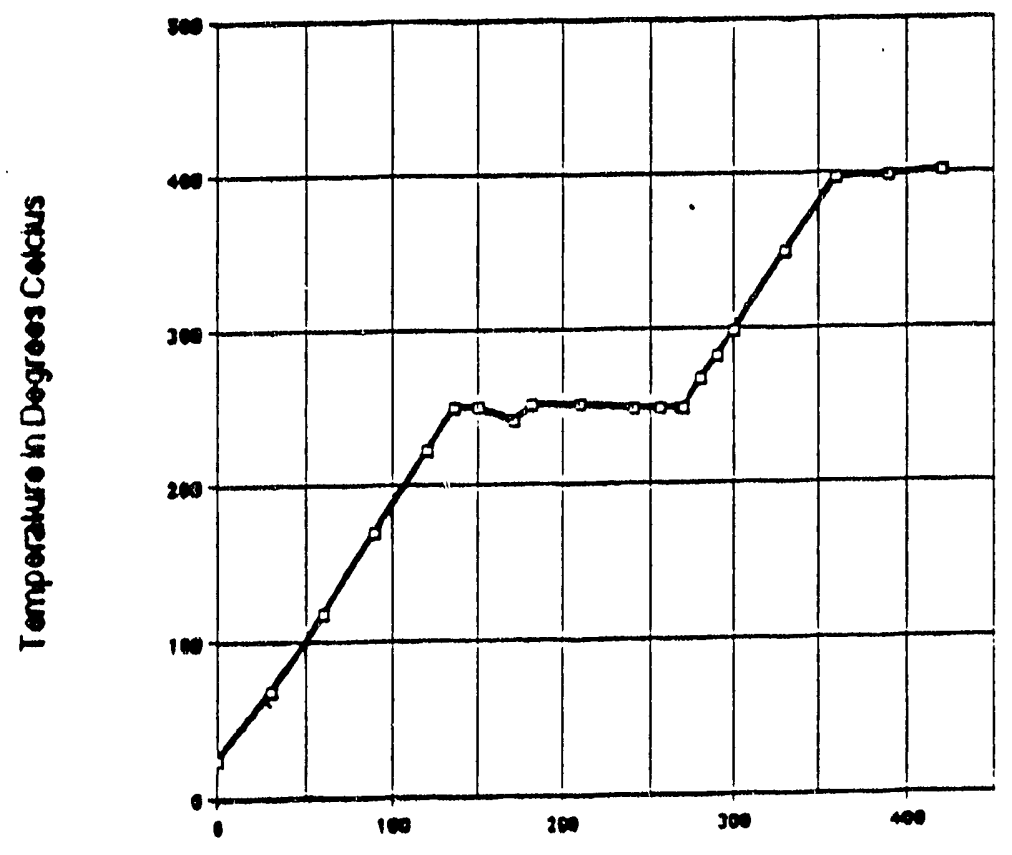

The from slart in Minules

Figure 29. Reactor temperature program, Run PDJ03. 
products were routinely analyzed for $\mathrm{C}, \mathrm{H}, \mathrm{N}$ and $\mathrm{S}$ by Amoco Oil Co., Naperville, IL. Specific gravities were measured in house by the pycnometer method.

\section{Results:}

Operational problems were experienced during the first two runs identified as Runs PDJ01 and PDJ02. In both cases the runs were terminated after a single balance period. No detailed analysis of the results was attempted.

\section{Run PDJ03:}

This was to have been a 10 day run at $\mathrm{T}=750^{\circ} \mathrm{F}, \mathrm{P}=2000 \mathrm{psig}$, WHSV $=2, \mathrm{H}_{2}$ Treat Rate $=5000 \mathrm{SCF} / \mathrm{BBL}$ and a stirrer speed of $1500 \mathrm{rpm}$. On the morning following the 8 th yield period, the rupture disk on the reactor blew forcing an abrupt termination of the run. The rupture disk blew for no apparent reason as the unit was operating smoothly. The cause is believed to be the high operating temperature of the reactor and the fact that a 316 SS rupture disk was in use. Autoclave Engineers recommends that a nickel alloy rupture disk be installed for high temperature service.

A run summary for the eight balance periods is provided in Table 11 . The carbon material balances tend to be a bit high for all yield periods, ranging from $100.7 \%$ to $106.7 \%$. During yield period no. 4 the hose leaving the WTM was pinched and the reading may have been affected. Also, due to a valve switching error some depressuring of the second high pressure accumulator occurred through the WTM. This may explain the high material balance. This may also have occurred to a lesser extent during yield period 5 . The consistently high material balances are suggestive of a small systematic error. 
Table 11

Run PDJ03, 5.0005 GMS Amocat 1A

Run Summary:

Yield Period No.

Yicld Period Length, HR

Average 'Temperature, $\mathbf{F}$

Average Temperature, $\mathrm{C}$

Average Pressure, PSIG

Liquid Feed Rate, GM/HR

Weight Ilourly Space Velocity

Weight Hourly Space Time

Hydrogen Treat Rate, L(SIP)/HR

Hydrogen Treat Rate, SCF/BBL

Stirrer Speed, rpm

Exit Gas Rate, I.SIP)/HR

Cumulative Hours on Catalyst

Cumulative Wt. Oil/Wt. Catalyst

Liquid Matcrial Balance, Wt\%

Carbon Material Balance, Wt\%

Overall Material Balance, Wt\%

1
6.0
750
399.0
2030
9.55
1.91
.524
8.17
5210
1500
4.58
20.5
42.5
101.04
100.7
100.0

2

6.0

749

398.6

2020

10.12

2.02

.494

8.17

4920

1500

4.86

44.5

91.6

105.2

104.3

103.8
3

6.0

750

399.0

2010

10.27

2.05

.487

8.17

4850

1500

4.8

68.6

140.5

103.0

102.4

102.1
$4 \cdot 5$

$6.0-6.0$

$\begin{array}{rr}750 & 750 \\ 398.7 & 3990\end{array}$

$2000 \quad 2010$

$9.85 \quad 10.25$

$1.97 \quad 2.05$

$\begin{array}{lr}.508 & .488 \\ 8.17 & 8.17\end{array}$

$5050 \quad 4860$

$1500 \quad 1500$

$6.03 \quad 5.98$

$92.6 \quad 116.6$

$190.3 \quad 239.0$

$107.5 \quad 102.7$

$106.7 \quad 102.3$

$107.8 \quad 103.3$

Liquid Product Analysis:

Wt\% Carbon

WI\% Ilydrogen

WI\% Sulfur

Wt\% Nitrogen

Wi\% Oxygen

Spccific Gravity $(60 / 60)$
(FEED)

90.57

6.38

.745

.923

1.38

1.0921
89.63
9.81

.021

.17

.369

.9719

Corrected Yields Based on Liquid Feed:

Carbon Monoxide, Wt\%

Carbon Dioxide, Wt\%

Ammonia, Wt\%

Ifydrogen Sulfide, Wt\%

Water, Wt\%

Ilydrocarbon Gases (C1 - (A), Wt\%

Liquids (CS+), Wt\%

Hydrogen Consumption, Wi\% (analysis)

Hydrogen Consumption, WI\% (gas phase)

Corrected Conversions:

$\%$ Hydrodesulfurization

$\%$ Hydrodenitrogenation

$\%$ Ilydrodeoxygenation

Corrected Reaction Rates:

Sulfur Removal, GM/HR/GM

Nitrogen Removal, GM/HR/GM

Oxygen Removal, GM/HR/GM

llydrogen Uptake, GM/HR/GM

Gas Make, GM/HR/GM (xE-3)
.9775

89.66
9.65
.018
.204
.468
.976

89.49
9.6
0

0

.903

1.026

100.4

3.66

2.58
66.0 
Table 11 (continued)

Run PDJ03, 5.0005 GMS Amocat 1A

Run Summary:

Yield Period No.

Yicld Period Length, HR

Average Temperature, $F$

Average Temperature, $\mathrm{C}$

Avcrage Pressure, PSIG

Liquid Feed Rate, GM/HR

Weight Hourly Space Velocity

Weight Hourly Space Time

Hydrogen Treat Rate, L(STP)/HR

Hydrogen Treat Rate, SCF/BBL

Stirrer Speed, rpm

Exit Gas Rate, L(STP)/HR

Cumulative Hours on Catalyst

Cumulative Wt. Oil/Wt. Catalyst

Liquid Material Balance, Wi\%

Carbon Material Balance, Wt\%

Overall Material Balance, Wt\%

$\begin{array}{ccc}6 & 7 & 8 \\ 6.0 & 6.0 & 6.0 \\ 750 & 750 & 750 \\ 399.1 & 398.8 & 399.0 \\ 2010 & 2000 & 2010 \\ 10.17 & 10.2 & 10.25 \\ 2.03 & 2.04 & 2.05 \\ .492 & .49 & .488 \\ 8.17 & 8.17 & 8.17 \\ 4900 & 4880 & 4860 \\ 1500 & 1500 & 1500 \\ 4.58 & 4.78 & 4.82 \\ 140.6 & 164.6 & 188.6 \\ 288.1 & 337.5 & 386.9 \\ 103.9 & 104.1 & 102.8 \\ 103.2 & 103.4 & 102.2 \\ 102.7 & 102.7 & 101.9\end{array}$

Liquid Product Analysis:

(FEED)

Wt\% Carbon

W:\% Hydrogen

W:\% Sulfur

90.57

6.38

.745

.923

1.38

Wt\% Oxygen

Sprecific Gravity $(60 / 60)$

$\begin{array}{ccc}89.58 & 89.63 & 89.63 \\ 9.59 & 9.51 & 9.57 \\ .013 & .015 & .015 \\ .179 & .187 & .212 \\ .638 & .658 & .573 \\ .9768 & .9773 & .9782\end{array}$

Corrected Yields Based on Liquid Feed:

Carbon Monoxide, Wt\%

Carbon Dioxide, Wt\%

Ammonia, Wt\%

Hydrogen Sulfide, Wt\%

Watcr, Wi\%

Hydrocarbon Gases (C1 - C4), Wt\%

Liquids (CS +), Wt\%

Hydrogen Consumption, Wt\% (analysis)

Hydrogen Consumption, Wt\% (gas phase)

Corrected Conversions:

\% Hydrodesulfurization

\% Hydrodenitrogenation

\% Hydrodeoxygenation

98.2

80.5

53.5

98.0

79.6

98.0

76.9

$52.0 \quad 58.2$

Corrected Reaction Rates:

Sulfur Removal, GM/HR/GM

Nitrogen Removal, GM/HR/GM

Oxygen Removal, GM/HR/GM

Ilydrogen Uptake, GM/HR/GM

Gas Make, GM/HR/GM (xE-3)

$\begin{array}{llr}1.488 & 1.489 & 1.496 \\ 1.509 & 1.498 & 1.454 \\ 1.5 & 1.465 & 1.647 \\ 6.66 & 6.508 & 6.658 \\ 9.886 & 9.726 & 10.542\end{array}$




\section{Run PDJ05:}

Run PDJ05 was a short thermal run in which the standard five gram catalyst charge was replaced with an equal volume of glass beads. The three balance periods were at the base operating conditions of $\mathrm{T}=750^{\circ} \mathrm{F}, \mathrm{P}=2000 \mathrm{psig}, \mathrm{H}_{2}$ Treat Rate $=5000 \mathrm{SCF} / \mathrm{BBL}$ and a stirrer speed of $1500 \mathrm{rpm}$. The liquid feedrate was a nominal $10 \mathrm{gms} / \mathrm{hr}$ corresponding to the catalytic run at WHSV $=2$. A summary of results is provided in Table 12. Material balances were excellent for all three balance periods. The negative HDN conversion reported for yield period no. 1 is a consequence of the small amount of thermal HDN at these conditions, and uncertainty in the analytical results.

\section{Run PDJ06:}

This was an extensive, 30-day process variable study in which conditions were varied over the range: $700^{\circ} \mathrm{F} \leq \mathrm{T} \leq 800^{\circ} \mathrm{F}, 1 \leq \mathrm{WHSV} \leq 4,1500$ psig $<\mathrm{P}<2500 \mathrm{psig}$. Base run conditions $\left(\mathrm{T}=750^{\circ} \mathrm{F}, \mathrm{P}=2000 \mathrm{psi}, \mathrm{WHSV}=2, \mathrm{H}_{2}\right.$ Treat Rate $\left.=5000 \mathrm{SCF} / \mathrm{BBL}\right)$ were repeated periodically to maintain a check on catalyst activity. The run summary is provided in Table 13.

Material balances were good except for yield period nos. 5, 6, 7, 13, 18 and 29 where the material balances tended to be high $(\approx 110 \%)$. In the first four cases, the unit was operating at the lowest flowrate and a slight disturbance in the balance would have the greatest effect on the feed reading. These disturbances were unavoidable when the high

pressure accumulators were drained or disassembled. (See later discussion for a modification to the unit which appears to have greatly reduced this problem.) There were no unusual observations during yield period no. 18 that might explain the high material 
Table 12

Run PDJ05, Thermal Run

Run Summary:

Yicld Period No.

Yicld Pcriod length, HR

Average 'Temperature, $\mathrm{F}$

Average Temperature, $\mathrm{C}$

Average Pressure, PSIG

liquid reed Rate, GM/HR

Weight Hourly Space Velocity

Weight Hourly Space Time

Hydrogen Treat Rate, L(SIP)/HR

Ilydrogen 'Treat Rate, SCF/BBL

Stirrer Speed, RPM

1.xit Gas Rate, L.SIP)/HR

Cumulative Hours on Catalyst

Cumulative WI. Oil/Wt. Catalyst

Liquid Material Balance, WI\%

Carbon Matcrial Balance, $W t \%$

Overall Material Balance, Wi\%

$\begin{array}{ccc}1 & 2 & 3 \\ 5.0 & 5.0 & 5.0 \\ 750 & 750 & 750 \\ 399.0 & 399.0 & 308.8 \\ 2010 & 2020 & 2010 \\ 10.36 & 10.54 & 10.44 \\ 2.07 & 2.11 & 2.09 \\ .483 & .475 & .48 \\ 8.18 & 8.18 & 8.18 \\ 4810 & 4730 & 4780 \\ 1500 & 1500 & 1500 \\ 8.71 & 8.55 & 8.8 \\ 26.5 & 50.5 & 74.5 \\ 55.3 & 106.4 & 156.2 \\ 99.9 & 98.1 & 98.8 \\ 100.1 & 98.4 & 99.3 \\ 100.0 & 98.4 & 99.3\end{array}$

Liquid Product Analysis:

WI\% Carbon

(FEED)

90.57

90.72

90.93

Wi\% Ilydrogen

90.64

6.76

6.67

.745

Wt\% Nitrogen

Wt\% Oxygen

Specific Gravity $(60 / 60)$

1.0921

1.02

1.0773

Corrected Yields Based on Liquid Feed:

Carbon Monoxide, Wi\%

Carbon Dioxide, WI\%

0 .

$-.153$

Ammonia, Wt\%

llydrogen Sulfide, Wt\%

Waler, Wi\%

llydrocarbon Gases (C1 - C4), Wt\%

Liquids (CS+), Wt\%

Hydrogen Consumption, Wt\% (analysis)

Hydrogen Consumption, Wt\% (gas phase)

$\begin{array}{ll}0 & 0 \\ 0 & 0 \\ .018 & .045 \\ .156 & .157 \\ .42 & .535 \\ .128 & .127 \\ 99.7 & 99.5 \\ .45 & .36 \\ .49 & .43\end{array}$

Corrected Conversions:

$\%$ Hydrodesulfurization

\% Ilydrodenitrogenation

Corrected Reaction Rates:

Sulfur Removal, GM/HR/GM $\times 10^{2}$

Nitrogen Removal, GM/HR/GM $\times 10^{2}$

Oxygen Removal, GM/HR/GM $\times 10^{2}$

Hydrogen Uptake, GM/HR/GM $\times 10^{2}$

Gas Make, GM/HR/GM $\times 10^{3}$

$\begin{array}{rc}.309 & .309 \\ .032 & .077 \\ .785 & .99 \\ 0.828 & 0.601 \\ 2.694 & 2.645\end{array}$


Table 13

Run PDJ06, 5.0026 gms Amocat 1A

Run Summary:

Yield Period No.

Yield Period Length, IIR

Average Temperature, $F$

Average Temperature, $\mathrm{C}$

Average Pressure, PSIG

Liquid Feed Rate, GM/HR

Weight Hourly Space Velocity

Weight Hourly Space Time

Hydrogen Treat Rate, L(SIP)/HR

Hydrogen Treat Rate, SCF/BBL

Stirrer Speed, RPM

Exit Gas Rate, L(STP)/HR

Cumulative Hours on Catalyst

Cumulative Wt. OIl/Wt. Catalyst

Liquid Material Balance, Wt\%

Carbon Material Balance, Wt\%

Overall Material Balance, Wt\%

1
5.0
750
399.0
2010
11.9
2.38
.42
8.18
4190
1500
4.77
22.0
44.2
104.7
103.4
102.9

2
5.0
750
399.0
2040
12.84
2.57
.39
8.18
3880
1500
4.66
46.0
99.4
103.5
101.6
101.4

3
5.0
748
398.0
2030
10.14
2.03
.493
8.18
4920
1500
5.78
70.0
149.6
105.8
104.3
104.9

$\begin{array}{cc}4 & 5 \\ 5.0 & 7.0 \\ 749 & 750 \\ 398.5 & 399.0 \\ 2020 & 2030 \\ 9.86 & 4.71 \\ 1.97 & .94 \\ .507 & 1.061 \\ 8.18 & 7.34 \\ 5060 & 9490 \\ 1500 & 1500 \\ 5.69 & 5.32 \\ 94.0 & 119.0 \\ 196.7 & 224.6 \\ 104.4 & 113.5 \\ 103.4 & 111.4 \\ 103.6 & 109.5\end{array}$

Liquid Product Analysis:

Wi\% Carbon

Wt\% Hydrogen

Wi\% Sulfur

Wi\% Nitrogen

Wi\% Oxygen

Specific Gravity (60/60)

$\begin{array}{cc}89.19 & 88.75 \\ 9.37 & 9.3 \\ .044 & .12 \\ .2 & .2 \\ 1.196 & 1.63 \\ .9802 & .9874\end{array}$

88.92
9.54
.046
.15
1.344
.9754

$\begin{array}{cc}89.36 & 88.22 \\ 9.64 & 10.46 \\ .018 & .036 \\ .17 & .07 \\ .812 & 1.214 \\ .9728 & .9424\end{array}$

Corrected Yields Based on Liquid Feed:

Carbon Monoxide, Wt\%

Carbon Dioxide, Wt\%

Ammonia, Wt\%

Hydrogen Sulfide, Wi\%

Watcr, Wi\%

Hydrocarbon Gases (C1 - C4), Wt\%

Liquids (CS +), Wt\%

Hydrogen Consumption, Wt\% (analysis)

Hydrogen Consumption, Wt\% (gas phase)

$\begin{array}{lc}0 & 0 \\ 0 & 0 \\ .876 & .874 \\ .745 & .662 \\ .19 & -.315 \\ .329 & .221 \\ 101.3 & 101.9 \\ 3.4 & 3.3 \\ 3.84 & 3.49\end{array}$

0
0
.937
.742
.019
.446
101.5
3.61
2.83

0

Corrected Conversions:

$\%$ Hydrodesulfurization

$\%$ Hydrodenitrogenation

Corrected Reaction Rates:

Sulfur Removal, GM/HR/GM $\times 10^{2}$ Nitrogen Removal, GM/HR/GM $\times 10^{2}$ Oxygen Removal, GM/HR/GM $\times 10^{2}$ Hydrogen Uptake, GM/HR/GM $\times 10^{2}$ Gas Make, GM/HR/GM $\times 10^{3}$

$\begin{array}{rr}1.666 & 1.599 \\ 1.713 & 1.845 \\ .402 & -.719 \\ 7.560 & 8.059 \\ 7.831 & 5.684\end{array}$

$\begin{array}{rlr}1.416 & 1.433 & .668 \\ 1.562 & 1.48 & .802 \\ .033 & 1.105 & .134 \\ 6.881 & 6.798 & 4.195 \\ 9.048 & 9.023 & 7.597\end{array}$


Table 13 (continued)

Run PDJ06, 5.0026 gms Amocat 1A

Run Summary:

Yield P'eriod No.

Yield Period Length, IIR

Average Temperature, $F$

Average Temperature, $\mathrm{C}$

Average Pressure, PSIG

l.lquild I'ced Rate, GM/HR

Weight Hourly Space Velocity

Weight Hourly Space Time

Hydrogen Treat Rate, LSIP)/HR

Hydrogen Treat Rate, SCF/BBL

Stirrer Speed, RPM

Exit Gas Rate, L.(STP)/HR

Cumulative Hours on Catalyst

Cunulative Wt. Oil/Wt. Catalyst

Liquid Material Balance, Wi\%

Carbon Material Balance, Wt\%

Overall Material Balance, W:\%

$\begin{array}{cc}6 & 7 \\ 7.0 & 7.0 \\ 754 & 752 \\ 401.0 & 400.0 \\ 2020 & 2020 \\ 4.97 & 5.11 \\ .99 & 1.02 \\ 1.006 & .978 \\ 7.34 & 7.34 \\ 9000 & 8740 \\ 1500 & 1500 \\ 5.49 & 5.34 \\ 143 & 167 \\ 248.3 & 273.9 \\ 110.8 & 109.2 \\ 109.1 & 107.9 \\ 108.1 & 107.2\end{array}$

8

3.0
749

398.5

2020

15.0

3,0

.334

9.81

3980

1500

7.11

189

352.2

103.0

101.6

102.2

88.43

(FEED)

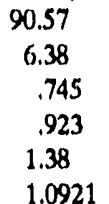

10.479

.018

.06

1.012

.9427

88.73
10.489
.038
0.08
.662
.9457

89.02

9.06

.11

.27

.9925

$\begin{array}{cc}90.1 & 89.35 \\ 8.81 & 9.44 \\ 0.065 & .051 \\ .33 & .21 \\ .695 & .949 \\ 1.0023 & .9795\end{array}$

Corrected Yields Based on Liquid Peed:

Carbon Monoxide, Wt\%

Carbon Dioxide, Wt\%

Ammonia, Wi\%

Hydrogen Sulfide, Wt\%

Water, Wi\%

Hydrocarton Gases (C1 - C4), Wt\%

liquids $(\mathrm{CS}+)$, Wt\%

Hydrogen Consumption, Wi\% (analysis)

Hydrogen Consumption, Wt\% (gas phase)

$\begin{array}{cc}0 & 0 \\ 0 & 0 \\ 1.048 & 1.023 \\ .773 & .751 \\ .397 & .8 \\ .989 & 1.011 \\ 101.5 & 101.2 \\ 4.74 & 4.75 \\ 5.55 & 5.24\end{array}$
0
0
.673
$-.204$
.413
101.4
3.05
2.35

$\begin{array}{cc}0 & 0 \\ 0 & 0 \\ .72 & .864 \\ .723 & .737 \\ .769 & .477 \\ .304 & .636 \\ 100.3 & 100.8 \\ 2.77 & 3.52 \\ 2.39 & 3.23\end{array}$

Corrected Conversions:

\% Ilydrodesulfurization

$\%$ Hydrodenitrogenation

$\%$ Hydrodeoxygenation

Corrected Reaction Rates:

Sulfur Removal, GM/HR/GM $\times 10^{2}$ Nitrogen Removal, GM/HR/GM $\times 10^{2}$ Oxygen Removal, GM/HR/GM $\times 10^{2}$ Hydrogen Uptake, GM/HR/GM $\times 10^{2}$ Gas Make, GM/HR/GM $\times 10^{3}$

$$
\begin{aligned}
& 1.9 \\
& 1.946 \\
& -.543 \\
& 8.674 \\
& 12.375
\end{aligned}
$$

$\begin{array}{rr}2.755 & 1.362 \\ 2.397 & 1.396 \\ 2.769 & .831 \\ 10.202 & 6.422 \\ 12.329 & 12.487\end{array}$


Table 13 (continued)

Run PDJ06, 5.0026 gms Amocat 1A

Run Summary:

Yicld Period No.

Ylald Period Length, HR

Average Temperature, $P$

Average Temperature, $\mathrm{C}$

Average Pressure, PSIC

Liquid Feed Rate, GM/HR

Wolght Hourly Space Volocity

Woight Hourly Space Time

Hydrogen Treat Rate, L(STP)/HR

Ilydrogen Treat Rate, SCF/BBL

Stirrer Speed, RPM

Exil Gas Rate, L(STP)/HR

Cumulative Hours on Catalyst

Cumulative Wt. Oil/Wt. Catalyst

Liquid Matcrial Balance, Wt\%

Carbon Material Balance, Wt\%

Overall Matertal Balance, Wi\%

$\begin{array}{ccccc}11 & 12 & 13 & 14 & 15 \\ 5.0 & 7.0 & 7.0 & 3.0 & 3.0 \\ 750 & 703 & 705 & 702 & 701 \\ 399.0 & 373.0 & 374.0 & 372.0 & 371.5 \\ 2020 & 2030 & 2030 & 2020 & 2030 \\ 9.84 & 5.39 & 5.19 & 15.53 & 20.67 \\ 1.97 & 1.08 & 1.04 & 3.11 & 4.13 \\ .508 & .929 & .965 & .322 & .242 \\ 8.18 & 7.34 & 7.34 & 9.81 & 13.12 \\ 5070 & 8300 & 8620 & 3850 & 3870 \\ 1500 & 1500 & 1500 & 1500 & 1500 \\ 5.85 & 6.19 & 6.2 & 9.54 & 11.92 \\ 262.0 & 287.0 & 311.0 & 333.0 & 357.0 \\ 549.9 & 579.9 & 605.7 & 666.2 & 762.6 \\ 106.5 & 103.9 & 108.9 & 102.4 & 101.0 \\ 106.1 & 103.0 & 107.8 & 102.2 & 98.4 \\ 106.3 & 103.8 & 107.6 & 103.0 & 99.4\end{array}$

Liquid Product Analysis:

WI\% Carbon

WI\% Hydrogen

WI\% Sulfur

Wi\% Nitrogen

Wi\% Oxygen

Specific Gravity $(60 / 60)$

$\begin{array}{cc}89.72 & 89.66 \\ 9.5 & 9.58 \\ .037 & .021 \\ .22 & .2 \\ .523 & .539 \\ .9788 & .9809\end{array}$

89.54

Corrected Yields Based on Liquid Feed:

Carbon Monoxide, WI\%

Carbon Dioxide, Wi\%

Ammonla, Wi\%

Ilydrogen Sulfide, Wt\%

Water, Wt\%

Hydrocarbon Gases (C1 - C4), WI\%

Liquids (C5t), Wt\%

Ilydrogen Consumption, Wt\% (analysis)

Ilydrogen Consumption, Wt\% (gas phase)

0.
0
.876
.769
.942
.167
100.9
3.63
2.66

0
0
.864
.77
.837
.147
101.0
3.64
3.54

Corrected Conversions:

$\%$ Hydrodesulfurization

\% Hydrodenitrogenation

$\%$ Ilydrodeoxygenation

Corrected Reaction Rates:

Sulfur Removal, GM/HR/GM $\times 10^{2}$ Nitrogen Removal, GM/HR/GM $\times 10^{2}$ Oxygen Removal, GM/HR/GM $\times 10^{2}$ Hydrogen Uptake, $\mathrm{GM} / \mathrm{HR} / \mathrm{GM} \times 10^{2}$ Gas Make, GM/HR/GM $\times 10^{3}$ 
Table 13 (continued)

Run PDJ06, 5.0026 gms Amocat 1A

Run Summary:

Yietd Period No.

Yicld Period Longth, IIR

Average 'I'cmperature, I'

Average 'T'emperature, $C$ :

Average Pressure, PSic

I.iquid lieod Rato, GM/IIR

Woight Ilourly Spaco Velocity

Weight Ilourly Spaco 'Time

Ilydrogen Treat Rate, L(SIT)/IIR

Ilydrogen 'Ireat Rate, SCP/BIBL

Sitirer Speed, RMP

I'xil Gas Ralo, L,(STP)/HR

C'umulative Hours on Catalyst

Cumulative Wt. Oll/Wt, Catalyst

licyuid Maturial Balance, WI\%

Carbon Material Balance, $W_{t} \%$

Overall Material Balance, Wi\%

$\begin{array}{ccccc}16 & 17 & 18 & 19 & 20 \\ 5.0 & 5.0 & 5,0 & 5.0 & 7.0 \\ 700 & 750 & 775 & 801 & 801 \\ 371.0 & 399.0 & 413.0 & 427.0 & 427.0 \\ 2020 & 2010 & 2030 & 2020 & 2020 \\ 10.5 & 10.12 & 10.06 & 10.12 & 5.27 \\ 2.1 & 2.02 & 2.01 & 2.02 & 1.05 \\ .476 & .494 & .497 & .494 & .2941) \\ 8.18 & 8.18 & 8.18 & 8.18 & 7.34 \\ 4750 & 49.30 & 4 \% 60 & 4930 & 8480 \\ 1500 & 1500 & 1500 & 1500 & 1500 \\ 6.77 & 5.69 & 5.38 & 5.5 & 5.19 \\ 382.0 & 406.0 & 430,0 & 454.0 & 479.0 \\ 818.0 & 867.2 & 915.7 & 963.9 & 992.4 \\ 100.9 & 102.4 & 111.6 & 100.6 & 98.7 \\ 96.9 & 101.5 & 111.3 & 101.1 & 1(00.1 \\ 99.2 & 101.6 & 110.3 & 101.1 & 100.2\end{array}$

L.icuild Product Analysis:

WI\% Cartion

(IULUD)

9.57
6.38

WI\% Ilydrogen

6.38
.745

.923

ogen

1.38

Specific Gravity $(60 / 60)$

1.0921

88.69
8.7
.26
.4
1.95
1.0088

89.43
9.33
.044
.25
.946
.9813

89.65
9.49
.052
.2
.608
.9705

$\begin{array}{cc}89.42 & 88.54 \\ 9.22 & 10.09 \\ .031 & .027 \\ .18 & .07 \\ 1.149 & 1.273 \\ .96 .55 & .9299\end{array}$

Corrected Yields Based on Liquid Feed

Carbon Monoxide, Wi\%

Carbon Dloxide, WI\%

Ammonia, Wi\%

Ilydrogen Sulfide, Wi\%

Water, Wt\%

Ilydrocarbon Gases (Cl - CA), WI\%

l.iquids (CS+), Wt\%

llydrogen Consumption, Wi\% (analysis)

Ilydrogen Consumption, Wt\% (gas phase)

0
0

.625

.51

$-.686$

.089

102.0

2.58

2.29

64.4

55.8

$-44.2$

94.0

72.7

30.9

93.0
78.3

55.8

95.9

80.6

17.1

96,4

92.5

9.0

Corrected Reaction Rates:

Sulfur Removal, GM/HR/GM $\times 10^{2}$ Nitrogen Removal, GM/HR/GM $\times 10^{2}$ Oxygen Removal, GM/IIR/GM $\times 10^{2}$ Ilydrogen Uptake, GM/HR/GM $\times 10^{2}$ Gas Make, GM/HR/GM $\times 10^{3}$ 
Table 13 (continued)

Run PDJ06, 5.0026 gms Amocat 1A

Run Sumnary;

Ylold Period No,

Yleld Poriod Longth, IIK

Average 'I'emperature, I'

Average 'Tomperature, $\mathrm{C}$

Average Pressure, PSICH

L.lquid liced Rato, GM/HR

Woight Hourly Space Velocity

Woight Hourly Space Time

Ilydrogen T'reat Rato, L(SI'P)/IIR

Ilydrogen 'Treat Rate, SCH/BBBL.

Silirrer Speed, RPM

IXxit Clas Ratc, L(SIP)/HR

Cumulative Hours on Catalyst

Cumulative Wt. Oll/Wt. Catalyst

1.lquld Material Balance, Wt\%

Carbon Material Balanco, Wi\%

Overall Matcrial Balance, Wi\%

$\begin{array}{cc}21 & 22 \\ 7.0 & 3.0 \\ 801 & 801 \\ 427.0 & 427.0 \\ 2010 & 2010 \\ 5.21 & 15.23 \\ 1.04 & 3.05 \\ .959 & .328 \\ 7.34 & 9.81 \\ 8580 & 3920 \\ 1500 & 1500 \\ 5.34 & 6.96 \\ 503.0 & 525.0 \\ 1018.2 & 1077.9 \\ 99.5 & 101.3 \\ 100.4 & 102.1 \\ 100.6 & 102.3\end{array}$

23
5.0
752
400.0
2020
10.06
2.01
.497
8.18
4960
1500
5.92
550.0
1129.9
102.4
102.3
102.1

$\begin{array}{rc}24 & 25 \\ 5.0 & 3.0 \\ 752 & 754 \\ 400.0 & 401.0 \\ 1.520 & 1510 \\ 11.12 & 16.4 \\ 2.22 & 3.28 \\ .45 & .305 \\ 8.18 & 9.81 \\ 4480 & 3640 \\ 1500 & 1500 \\ 6.1 & 7.64 \\ 574.0 & 597.0 \\ 1180.3 & 1251.1 \\ 98.0 & 98.8 \\ 97.8 & 99.3 \\ 98.0 & 99.5\end{array}$

L.iquid Product Analysls:

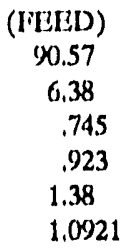

88.15
9.98
.029
0.08
1.761
.9325

90.1
8.83
.04
.29
.74
.9897

89.99
9.02
.053
.29
.647
.9906

$\begin{array}{cc}89.89 & 90.67 \\ 8.57 & 8.19 \\ .053 & .066 \\ .32 & .48 \\ 1.167 & .524 \\ 1.0031 & 1.022\end{array}$

Corrected Ylelds Based on Liquid Ireed:

Carbon Monoxide, Wi\%

Cartion Dioxide, WI\%

Anımonia, Wi\%

Ilydrogen Sulfide, Wi\%

Water, Wi\%

Ilydrocarbon Gases (Cl - C4), Wt\%

Liquids (CSt), Wt\%

Hydrogen Consumption, Wt\% (analysis)

Ilydrogen Consumption, Wt\% (gas phase)

0
0

0
1.025

$0^{\circ}$

Corrected Conversions:

$\%$ Ilydrodesulfurization

\%) llydrodenitrogenation

Corrected Reaction Rates:

Sulfur Removal, GM/HR/GM $\times 10^{2}$ Nitrogen Removal, GM/IIR/GM $\times 10^{2}$ Oxygen Removal, GM/HR/GM $\times 10^{2}$ Ilydrogen Uptake, GM/HR/GM $\times 10^{2}$ Gas Make, GM/HR/GM $\times 10^{3}$

$\begin{array}{cr}.747 & 2.148 \\ .879 & 1.933 \\ . .38 & 1.967 \\ 4.519 & 8.204 \\ 42.083 & 45.466\end{array}$

$$
\begin{array}{r}
1.538 \\
1.338 \\
.467 \\
5.187
\end{array}
$$$$
12.63
$$ 
Table 13 (continued)

\section{Run PDJ06, 5.0026 gms Amocat 1A}

Run Summary:

Ylakd Purlod No.

Ylald Porlod Length, IIR

Average 'l'emperature, it

Average 'I'emperature, C

Averago Pressuro, PSIO

l.lyuld lioed Rate, GM/HR

Weight Ilourly Spaco Velocity

Weight Ilourly Space 'Time

Ilydrogen 'Ireat Rate, L(STP)/IIR

llydrogen 'I'reat Rate, SCI'/BHL

Stirrer Speed, RPM

Lxil Cus Rate, L(SIT)/HR

Cumulative llours on Catalyst

Cumulative Wt. Oll/Wt, Catalyst

liculd Materlal Balance, Wi\%

Carbon Material Balance, Wt\%

Overall Muterial Balance, Wt\%

$\begin{array}{cccc}26 & 27 & 29 & 30 \\ 5.0 & 3.0 & 5.0 & 5.0 \\ 752 & 750 & 750 & 750 \\ 400,0 & 399,0 & 399,0 & 399,0 \\ 2510 & 2510 & 2030 & 2030 \\ 9.64 & 14.83 & 9.84 & 9.82 \\ 1.93 & 2.97 & 1.97 & 1.96 \\ .519 & .337 & .508 & .509 \\ 8.18 & 9.81 & 8.18 & 8.18 \\ 5170 & 4030 & 5070 & 5080 \\ 1.500 & 1500 & 1500 & 1500 \\ 5.69 & 7.57 & 6.0 & 6.51 \\ 622.0 & 645.0 & 694.0 & 718.0 \\ 1301.5 & 1368.1 & 1468.6 & 1517.1 \\ 105.2 & 106.1 & 117.4 & 103.6 \\ 103.5 & 105.5 & 117.0 & 103.2 \\ 102.8 & 105.0 & 114.8 & 103.3\end{array}$

Liquid Product Analysis:

WI\% Carbon

Wi\% llydrogen

Wi\% Sulfur

WI\% Nitrogen

Wi\% Oxygen

Specific Gravity $(60 / 60)$
88.74

9.38

.158

.26

1.462

.9847

$\begin{array}{cc}89.9 & 89.91 \\ 8.88 & 8.78 \\ .051 & .042 \\ .33 & .31 \\ .839 & .958 \\ .9971 & .999\end{array}$

Correcled Yields Based on Liquid leed:

Carbon Monoxlde, Wt\%

Carton Dloxide, Wi\%

Ammonia, Wi\%

Hydrogen Sulfide, Wi\%

Watcr, Wi\%

IIydrocarbon Gases (C1 - C4), Wt\%

liquids (CS+), Wi\%

llydrogen Consumption, Wt\% (analysis)

Ilydrogon Consumption, Wt\% (gas phase)

Corrected Conversions:

$\%$ Hydrodesulfurization

\% llydrodenitrogenation

\% Ilydrodeoxygenation

0.

Corrected Reaction Rates:

Sulfur Removal, GM/IIR/GM $\times 10^{2}$ Nitrogen Removal, GM/HR/GM $\times 10^{2}$ Oxygen Removal, GM/IIR/GM $\times 10^{2}$ Ilydrogen Uptake, GM/IIR/GM $\times 10^{2}$ (jas Make, GM/HR/GM $\times 10^{3}$ 
balance. During yield period no. 28 the ball valve at the reactor exit began leaking and product was diverted to the yield period accumulator prior to switching the valve. No workup of this yield period was attempted. The problem persisted but to a much lesser degree during yield period no. 29 , and this factor is probably responsible for the high material balance.

A negative HDO is reported for several balance periods (e.g. yield period no. 2, 15, 16, etc.). Since the oxygen content of the liquid product is calculated by difference, no significance is attached to these observations. No attempt will be made to work up the HDO data.

Operability was generally good through the completion of yield period no. 23. At this point the pressure was reduced to $1500 \mathrm{psi}$ and fluctuations in the temperature were observed. We believe that this was due to partial vaporization of the reactor contents to the point that the impeller was no longer immersed. Circulation therefore ceased. The run was terminated voluntarily after the $30^{\text {th }}$ yield period. However, rather than the normal shutdown procedure of cutting the heater while maintaining flow of both gas and liquid, the reactor was operated in the batch mode for several hours. The unit was maintained at reaction temperature and the liquid feed was cut out. Hydrogen flow was reduced to a minimum. The idea was to measure the equilibrium hydrogen content for use in subsequent data analysis. Instead we vaporized most of the reactor contents, and only a few cubic centimeters of a heavy oil remained in the bottom of the reactor.

Upon inspection of the reactor basket after opening the vessel, it was observed that the bottom screen was nearly plugged. Circulation would certainly be hindered with the 
basket in this state. It is possible that the screen may have plugged during the batch reactor period when the liquid level dropped below the impeller. However, as mentioned in the previous paragraph a similar loss of circulation was also experienced after yield period no. 23. Alternatively, the screen deposits could be due to a gradual accumulation for the entire course of the run. Similar deposits were not observed in the previous shorter duration run (Run PDJ03).

\section{Run PDJ08:}

Run PDJ08 was an approximately 10 day run at base conditions $\left(\mathrm{T}=750^{\circ} \mathrm{F}, \mathrm{P}=\right.$ $2000 \mathrm{psi}, \mathrm{WHSV}=2, \mathrm{H}_{2}$ Treat Rate $=5000 \mathrm{SCF} / \mathrm{BBL}$ ). During this run the basket screen size was increased from the standard $30 \times 30$ (0.013 in. wire dia., $0.020 \mathrm{in}$. aperture) to 16 $x 16$ (0.018 in. wire dia., 0.045 in aperture). No plugging of the screen was evident at run termination. Run summaries for the ten balance periods of Run PDJ08 are compiled in Table 14. The overall material balances are acceptable, ranging from a low of $94.2 \%$ to a high of $104.4 \%$.

\section{Run PDJ09:}

Run PDJ09 was a thermal run in which the five gram catalyst charge was replaced with an equivalent volume of $3 \mathrm{~mm}$ glass beads. Temperature, Weight Hourly Space Velocity $^{1}$ and Hydrogen Treat Rate were varied over the nominal range: $700 \mathrm{~F} \leq \mathrm{T} \leq 800$ F, $1 \leq$ WHSV $\leq 4$ and $4000 \mathrm{SCF} / \mathrm{BBL} \leq \mathrm{HTR} \leq 8500 \mathrm{SCF} / \mathrm{BBL}$. Pressure was held

\footnotetext{
1 Based on the standard five gram catalyst charge.
} 
Table 14

Run PDJ08, 5.0046 GMS Amocat 1A

Run Summary:

Yicld Period No.

Yield Period Length, HR

Average Temperature, $\mathrm{F}$

Average Temperature, $\mathrm{C}$

Average Pressure, PSIG

Liquid Feed Rate, GM/HR

Weight Hourly Space Velocity

Weight Hourly Space Time

Hydrogen Treat Rate, L(STP)/HR

Hydrogen Treat Rate, SCF/BBL

Stirrer Speed, rpm

Exit Gas Rate, L(STP)/HR

Cumulative Hours on Catalyst

Cumulative Wt. Oil/Wt. Catalyst

Liquid Material Balance, Wt\%

Carbon Material Balance, Wt\%

Overall Material Balance, Wt\%

$\begin{array}{cc}1 & 2 \\ 4.0 & 4.0 \\ 739 & 746 \\ 393.0 & 396.5 \\ 2020 & 2010 \\ 10.23 & 10.67 \\ 2.04 & 2.13 \\ .489 & .469 \\ 8.18 & 8.18 \\ 4870 & 4670 \\ 1500 & 1500 \\ 4.83 & 4.84 \\ 20.0 & 45.0 \\ 39.7 & 90.5 \\ 101.1 & 96.5 \\ 100.6 & 96.1 \\ 100.7 & 97.0\end{array}$

3

$$
749
$$

398.3

2010

10.42

2.08

.48

8.18

4780

1500

4.51

68.5

138.2

101.1

100.5

100.4

(FEED)

$\begin{array}{lc} & \\ & \text { (FEED) } \\ & 90.6 \\ & 6.35 \\ & .673 \\ & 1.001 \\ & 1.379 \\ & 1.0921\end{array}$

Wt \% Carbon

Wt\% Hydrogen

Wt\% Sulfur

Wt\% Nitrogen

Wi\% Oxygen

Specific Gravity $(60 / 60)$

Corrected Yields Based on Liquid Feed:

Carbon Monoxide, Wt\%

Carbon Dioxide, Wt\%

Ammonia, Wt\%

Hydrogen Sulfide, Wt\%

Water, Wt\%

Hydrocarbon Gases (C1 - C4), Wt\%

Liquids (CSt), Wt\%

llydrogen Consumption, Wt\% (analysis)

Hydrogen Consumption, Wt\% (gas phase)

Corrected Conversions:

$\%$ Hydrodesulfurization

$\%$ Hydrodenitrogenation

$\%$ Hydrodeoxygenation

Corrected Reaction Rates:

Sulfur Removal, GM/HR/GM $\times 10^{2}$

Nitrogen Removal, GM/HR/GM $\times 10^{2}$ Oxygen Removal, GM/HR/GM $\times 10^{2}$ Hydrogen Uptake, GM/HR/GM x $10^{2}$ Gas Make, GM/HR/GM $\times 10^{3}$

1.823

6.805

8.81
96.2

79.9

72.7
83.5

78.9

62.8

$\begin{array}{ll}89.49 & 89.73 \\ 9.56 & 9.56 \\ 0.047 & 0.065 \\ 0.210 & 0.190 \\ 0.693 & 0.455 \\ 0.9764 & 0.9783\end{array}$

\section{0}

.96

597

.975

.535

100.6

3.68

3.83
0
0

.985

.646

1.039

.666

$100.7 \quad 100.4$

$3.7 \quad 3.72$

$3.09 \quad 2.03$

$92.9 \quad 90.3$

$\begin{array}{ll}78.9 & 80.9\end{array}$

$49.4 \quad 66.9$

$\begin{array}{lrrl}1.38 & 1.171 & 1.293 & 1.318 \\ 1.706 & 1.644 & 1.632 & 1.756 \\ 2.14 & 1.804 & 1.409 & 2.0 \\ 7.222 & 7.011 & 7.042 & 7.353 \\ 11.345 & 11.138 & 11.654 & 14.445\end{array}$


Table 14 (continued)

Run PDJ08, 5.0046 GMS Amocat 1A

Run Summary:

Yield Period No.

Y'ield Period Length, HR

Average Temperature, $\mathbf{F}$

Average Temperature, $\mathrm{C}$

Average Pressure, PSIG

L.iquid Feed Rate, GM/HR

Weight Hourly Space Velocity

Weight Hourly Space Time

Hydrogen Treat Rate, L(STP)/HR

Ilydrogen Treat Rate, SCF/BBL

Stirrer Speed, rpm

Exit Gas Rate, L(STP)/HR

Cumulative Hours on Catalyst

Cumulative Wt. Oil/Wt. Catalyst

Liquid Material Balance, Wt\%

Carbon Material Balance, Wi\%

Overall Material Balance, Wt\%

$\begin{array}{ccccc}6 & 7 & 8 & 9 & 10 \\ 4.0 & 4.0 & 4.0 & 4.0 & 4.0 \\ 749 & 751 & 746 & 750 & 750 \\ 398.3 & 399.7 & 396.5 & 399.0 & 399.0 \\ 2010 & 2020 & 2030 & 2020 & 2010 \\ 10.02 & 9.92 & 10.15 & 10.17 & 9.75 \\ 2.0 & 1.98 & 2.03 & 2.03 & 1.95 \\ .499 & .504 & .493 & .492 & .513 \\ 8.18 & 8.18 & 8.18 & 8.18 & 8.18 \\ 4970 & 5020 & 4910 & 4900 & 5110 \\ 1500 & 1500 & 1500 & 1500 & 1500 \\ 4.88 & 4.74 & 4.86 & 5.18 & 5.13 \\ 141.0 & 165.0 & 188.5 & 213.0 & 236.5 \\ 281.9 & 330.0 & 377.5 & 426.7 & 471.3 \\ 105.9 & 100.9 & 101.3 & 100.3 & 101.3 \\ 105.0 & 100.0 & 100.6 & 99.9 & 100.9 \\ 104.4 & 100.2 & 100.7 & 100.4 & 101.3\end{array}$

Liquid Product Analysis:

Wi\% Carbon

WI\% Hydrogen

Wt\% Sulfur

Wt\% Nitrogen

Wt\% oxygen

Specific Gravity $(60 / 60)$

89.30
9.52
0.019
0.210
0.951
0.9782

Corrected Yields Based on Liquid Feed:

Carbon Monoxide, Wt\%

Carbon Dioxide, Wt\%

Ammonia, Wt\%

Hydrogen Sulfide, Wt\%

Water, Wt\%

Hydrocarbon Gases (C1 - C4), Wi\%

I.iquids (CS+), W:\%

Hydrogen Consumption, Wt\% (analysis)

Hydrogen Consumption, Wt\% (gas phase)

Corrected Conversions:

\% Hydrodesulfurization

$\%$ Hydrodenitrogenation

\% Hydrodeoxygenation

Corrected Reaction Rates:

Sulfur Removal, GM/HR/GM $\times 10^{2}$ Nitrogen Removal, GM/HR/GM $\times 10^{2}$ Oxygen Removal, GM/HR/GM $\times 10^{2}$ Hydrogen Uptake, GM/HR/GM $\times 10^{2}$ Gas Make, GM/HR/GM $\times 10^{3}$

$\begin{array}{cc}0 & 0 . \\ 0 & 0 \\ .947 & .959 \\ .677 & .695 \\ .424 & .474 \\ .609 & .711 \\ 100.8 & 100.8 \\ 3.49 & 3.67 \\ 3.94 & 3.51\end{array}$

0
0
.947
.693
.601
.606
100.7
3.53
3.42

$\begin{array}{cc}0 & 0 \\ 0 & 0 \\ .948 & .924 \\ .664 & .701 \\ .952 & .912 \\ .76 & .719 \\ 100.4 & 100.4 \\ 3.68 & 3.67 \\ 3.12 & 3.17\end{array}$

94.6

77.8

27.3

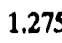

1.56

.755

6.472

12.197

\section{1}

78.8

30.5

97.0
77.9
38.7


1.323
1.58
1.083
6.605
12.298

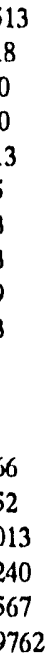


constant at a nominal 2000 psig. No operability problems were encountered during the course of the run.

Just prior to Run PDJ09 the stainless-steel lines connecting the feedtank to the Eldex pump inlet were replaced with $1 / 8$ inch flexible teflon tubes. The new arrangement places less tension on the feed-tank balance. It was believed that this might result in a more accurate monitoring of the feedrate. Although the material balances of the previous run PDJ08 were quite good, the material balances obtained in some of the earlier runs were poor by comparison.

The PDJ09 run summary is presented in Table 15 . The overall material balances were excellent during this run, ranging from about $98 \%$ to $102 \%$. The replacement of the feedtank lines appears to have resulted in much improved material balances.

One set of numbers looks peculiar, namely the negative hydrogen consumption calculated from the gas analysis. We believe this to have resulted from a small leak through the three-way ball valve separating the two high pressure accumulators. As the yield period accumulator was depressured through the wet test meter and into the gas bag, some gas (mostly hydrogen) may have leaked from the second accumulator which was still under

pressure. The valve was tightened at the run termination to prevent similar problems in subsequent runs.

\section{Run PDJ10:}

At the termination of Run PDJ06 it was discovered that the catalyst basket screen was partially plugged. Since it was not possible to identify the cause of plugging, we could not discount the possibility that the deposit could have accumulated gradually over the 
Table 15

Run PDJ09, 3 mm Glass Beads

Run Summary:

Yicld Period No.

Yicld Period Length, HR

Average Temperature, $F$

Average Temperature, $\mathrm{C}$

Average Pressure, PSIG

liquid Feed Rate, GM/HR

Weight Hourly Space Velocity

Weight Hourly Space Time

Ilydrogen Treat Rate, I.(STP)/IIR

Ilydrogen Treat Rate, SCF/BBL

Stirrer Speed, rpm

Iixit Gas Rate, L(STP)/HR

Cumulative Hours on Catalyst

Cumulative Wt. Oil/Wt. Catalyst

liquid Material Balance, Wt\%

Carbon Matcrial Balance, Wt\%

Overall Material Balance, Wt\%

$\begin{array}{cc}1 & 2 \\ 4.0 & 4.0 \\ 747 & 747 \\ 397.2 & 397.3 \\ 2010 & 2010 \\ 9.42 & 9.6 \\ 1.88 & 1.92 \\ .531 & .521 \\ 8.18 & 8.18 \\ 5290 & 5190 \\ 1500 & 1500 \\ 8.66 & 9.26 \\ 24.2 & 48.7 \\ 46.1 & 93.4 \\ 100.1 & 101.5 \\ 110.0 & 101.8 \\ 100.7 & 102.7\end{array}$

\section{3}

6.0

754

401.0

2020

5.2

1.04

.963

7.33

8590

1500

7.66

73.3

124.4

97.7

98.1

99.8
45

2.0

751

399.2

2000

20.3

4.06

.247

13.11

3930

1500

15.81

119.8

227.1

100.4

100.7

102.0

Liquid Product Analysis:

W $1 \%$ Carbon

(FEED)

90.6

Wt\% Hydrogen

90.47

90.79

6.72

0.470

1.090

0.930

1.001

1.379

Wi\% Oxygen

Specific Gravity $(60 / 60)$
6.67
0.380

0.820

1.660

1.0784
90.55

6.99

0.410

0.910

1.240

1.0696
90.80

6.61

0.530

0.830

1.230

1.0812

Corrected Yields Based on Liquid Feed:

Carbon Monoxide, Wt\%

Carbon Dioxide, Wt\%

Ammonia, Wt\%

Ilydrogen Sulfide, Wt\%

Water, Wt\%

llydrocarbon Gases (C1 - C4), WI\%

Liquids $(\mathrm{CS}+)$, Wt\%

Hydrogen Consumption, Wt\% (analysis)

llydrogen Consumption, Wt\% (gas phase)

0

0

Corrected Conversions:

\% Hydrodesulfurization

\% Hydrodenitrogenation

\% Hydrodeoxygenation

43.5

Corrected Reaction Rates:

Sulfur Removal, GM/HR/GM $\times 10^{2}$ Nitrogen Removal, GM/HR/GM $\times 10^{2}$ Oxygen Removal, GM/HR/GM $\times 10^{2}$ Hydrogen Uptake, GM/HR/GM $\times 10^{2}$ Gas Make, GM/HR/GM $\times 10^{3}$

30.4
-8.6
32.8



.392
-.165
.868
.743
2.781

$\begin{array}{cr}.551 & .392 \\ .339 & -.165 \\ . .53 & .868 \\ .674 & .743 \\ 2.404 & 2.781\end{array}$

.275
.098
.15
.665
5.84

.277
.194
.32
.713
6.456


Table 15 (continued)

Run PDJ09, 3 mm Glass Beads

Run Summary:

Yield Period No.

Yield Period Lengih, HKS.

Average Temperaluris:

Average Temperaluate

Average Pressure, Harci

Liquid Feed Rate, GSH/HR

Weight Hourly Space Velocity

Weight Hourly Space Time

Hydrogen Treat Rate, L(STP)/HR

Ilydrogen Treat Rate, SCF/BBL

Stirrer Speed, rpm

Exit Gas Rate, L(STP)/HR

Cumulative Hours on Catalyst

Cumulative Wt. Oil/Wt. Catalyst

Liquid Material Balance, Wt\%

Carbon Material Balance, Wt\%

Overall Material Balance, Wt\%

$\begin{array}{ccc}6 & 7 & 8 \\ 4.5 & 4.0 & 4.0 \\ 700 & 797 & 750 \\ 371.3 & 425.0 & 399.0 \\ 2020 & 2010 & 2010 \\ 10.07 & 10.08 & 10.13 \\ 2.01 & 2.01 & 2.02 \\ .497 & .497 & .494 \\ 8.18 & 8.18 & 8.18 \\ 4950 & 4940 & 4920 \\ 1500 & 1500 & 1500 \\ 9.65 & 8.91 & 8.7 \\ 146.5 & 168.8 & 192.3 \\ 283.1 & 327.9 & 375.5 \\ 100.6 & 99.0 & 99.7 \\ 100.6 & 100.1 & 100 \\ 101.8 & 101.2 & 101\end{array}$

Liquid Product Analysis:

WI\% Carbon

WI\% Hydrogen

Wt\% Sulfur

Wt\% Nitrogen

Wi\% Oxygen

Specific Gravity $(60 / 60)$

$\begin{array}{lll}90.60 & 90.80 & 90.83 \\ 6.62 & 6.84 & 6.77 \\ 0.540 & 0.390 & 0.450 \\ 1.080 & 0.860 & 0.870 \\ 1.160 & 1.110 & 1.080 \\ 1.0822 & 1.0686 & 1.0764\end{array}$

Corrected Yields Based on Liquid Feed:

Carbon Monoxide, Wt\%

Carbon Dioxide, Wt\%

Ammonia, Wt\%

Hydrogen Sulfide, Wt\%

Water, Wt\%

Hydrocarbon Gases (C1 - C4), Wt\%

Liquids $(\mathrm{CS}+)$, Wt\%

Hydrogen Consumption, Wt\% (analysis)

Hydrogen Consumption, Wt\% (gas phase)

$\begin{array}{ll}0 & 0 \\ 0 & 0\end{array}$

Corrected Conversions:

$\%$ Hydrodesulfurization

Corrected Reaction Rates:

Sulfur Removal, GM/HR/GM $\times 10^{2}$ Nitrogen Removal, GM/HR/GM $\times 10^{2}$ Oxygen Removal, GM/HR/GM $\times 10^{2}$ Hydrogen Uptake, GM/HR/GM $\times 10^{2}$ Gas Make, GM/HR/GM $\times 10^{3}$

$\begin{array}{crr}.267 & .578 & .456 \\ -.16 & .302 & .274 \\ .441 & .566 & .618 \\ .549 & 1.304 & .946 \\ 0.0 & 20.335 & 7.303\end{array}$


entire duration of the run. Because of this uncertainty, a second process variable study, Run PDJ10, was undertaken. Results from this run, which consisted of twenty-two balance periods, are presented in Table 16.

The experiment with the larger screen size, Run PDJ08, resulted in a small catalyst loss and consequently, a slightly smaller screen $(18 \times 18,0.017 \mathrm{in.}$ wire dia., $0.0386 \mathrm{in}$. aperture) was installed in the catalyst basket prior to Run PDJ10. Also, care was taken to remove any fines from the catalyst charge by screening. Failure to do this may have resulted in the minor catalyst loss experienced during Run PDJ08.

No operability problems were experienced during Run PDJ10. Upon referring to Table 16, it is apparent that the material balances were excellent. The total material balances were all within $\pm 2 \%$. Catalyst recovery at run termination was good $(99.94 \%)$.

\section{Run PDJ11:}

The purpose of the final hydrotreating run, Run PDJ11, was to investigate the effect of stirrer speed on performance. Run conditions were held constant at $2000 \mathrm{psi}, 750^{\circ} \mathrm{F}$, WHSV $=2$ and $\mathrm{H}_{2}$ Treat Rate $=7500 \mathrm{SCF} / \mathrm{BBL}$. The stirrer speed was varied from 320 to $1795 \mathrm{rpm}$. To save on analytical costs, the products were only submitted for $\mathrm{C} / \mathrm{H}$ analysis. The run summary is presented in Table 17.

\section{Analysis and Discussion:}

A comparison of the total material balances from Runs PDJ06 and PDJ10 is presented in Figure 30. The earlier PDJ06 data were obtained prior to the feedtank lines 
Table 16

Run PDJ10, 5.0029 GMS Amocat 1A

Run Summary:

Yiclu Period No.

Yield Period Length, IIR

Average 'Temperature, $\mathrm{p}$

$\Lambda v e$ rage 'T'mperature, $\mathrm{C}$

Average Pressure, PSIG

Likuld lieed Rate, GM/HR

Weight Ilourly Space Velocity

Weight Hourly Space Time

Ilydrogen 'Treat Rate, L(STP)/HR

Ilydrogen Treat Rate, SCP/BBL

Stirrer Specd, rpm

Exll Gas Rate, I.(STP)/HR

Cumulative Hours on Catalyst

Cumulative WI. Oil/Wt, Catalyst

Liquid Material Balance, Wi\%

Carbon Material Balance, Wt\%

Overall Material Balance, Wt\%

$\begin{array}{cc}1 & 2 \\ 4.0 & 4.0 \\ 750 & 747 \\ 399.0 & 397.0 \\ 2000 & 2000 \\ 10.02 & 10.05 \\ 2.00 & 2.01 \\ 0.499 & 0.498 \\ 8.18 & 8.18 \\ 4970 & 4960 \\ 120.5 & 1205 \\ 4.49 & 4.52 \\ 20.3 & 45.3 \\ 39.9 & 89.3 \\ 103.8 & 103.2 \\ 102.5 & 102.0 \\ 101.3 & 101.0\end{array}$

\section{3}

4.0

750

399.0

2000

10.11

2.02

0.495

8.18

4920

1205

4.57

68.3

134.8

103.1

101.9

101.0

$\begin{array}{cc}4 & 5 \\ 4.0 & 6.0 \\ 748 & 752 \\ 397.8 & 400.2 \\ 2000 & 2000 \\ 10.49 & 5.42 \\ 2.10 & 1.08 \\ 0.477 & 0.924 \\ 8.18 & 7.33 \\ 4750 & 8250 \\ 1205 & 1205 \\ 4.62 & 4.44 \\ 92.3 & 117.3 \\ 182.7 & 212.0 \\ 102.7 & 103.5 \\ 101.8 & 101.9 \\ 100.9 & 100.2\end{array}$

Liguld Product Analysis:

(FEED)

WI\% Carbon

Wi\% Ilydrogen

Wi\% Sulfur

90.6

6.35

.673

1.001

W $1 \%$ Nitrogen

Wi\% Oxygen

Specific Gravity $(60 / 60)$

Corrected Yields Based on Liquid Poed:

Carbon Monoxide, WI\%

Carbon Dioxide, Wt\%

Ammonia, Wi\%

Ilydrogen Sulfide, Wi\%

Waler, W1\%

Ilydrocarbon Gases (C1 - C4), Wt\%

Liquids (CS+), Wt\%

Ilydrogen Consumption, Wt\% (analyvis)

IJydrogen Consumption, Wt\% (gas phase)

Corrected Conversions:

$\%$ Hydrodesulfurization

\% Hydrodenitrogenation

\% Hydrocicoxysenation

Corrected Reaction Rates:

Sulfur Removal, GM/HR/GM $\times 10^{2}$

Nitrogen Removal, GM/HR/GM $\times 10^{2}$

Oxygen Removal, GM/HR/GM $\times 10^{2}$

Hydrogen Uptake, GM/HR/GM $\times 10^{2}$

Gas Make, GM/HR/GM $\times 10^{3}$
1.043

$-0.318$

2.762

6.792

6.862
1.313

1.601

0.657

6.646

$6.7 \% 0$
0.951

1.602

1.104

6.708

7.018

$\begin{array}{ll}89.17 & 89.27 \\ 9.54 & 9.47 \\ 0.150 & 0.019 \\ 1.144 & 0.201 \\ 0.000 & 1.040 \\ 0.9747 & 0.9783\end{array}$

89.29

9.48

0.200

0.206

0.824

0.9765

0

0

$-.193$

554

1.553

101.3

3.56

4.42

77.5

$-15,8$

100.0

97.1

79.7

23.7

0 .

.969

.695

.368

.338

101.2

3.56

4.41

0

.963

5

.615

.347

101.2

3.59

4.29

69.9

79.2

39.6

96.0

75.7

35.7

89.54

9.34

0.027

0.241

0.852

0.9820

88.65

10.16

0.015

0.073

1.102

0.9444
97.7

92.6

18.8
1.354

1.589

1.091

6.614

8.024 
Table 16 (continued)

Run PDJ10, 5.0029 GMS Amocat 1A

Run Summary:

Yiclu Period No.

Yicld Period length, HR

Average Temperature, $I$

Average Temperature, $\mathrm{C}$

Average Pressure, PSIG

1.iquid Fecd Rate, GM/HR

Weight Ilourly Space Velocity

Weight Hourly Space Time

Hydrogen Treat Rate, L(STP)/HR

Hydrogen Treat Rate, SCF/BIBL

Stirrer Speed, rpm

Vxit Gas Rate, L(STP)/HR

Cumulative Hours on Catalyst

Cunulative Wt. Oll/Wt. Catalyst

Liquid Material Balance, WI\%

Carbon Material Balance, Wt\%

Overall Material Balance, WI\%

$\begin{array}{ccccc}6 & 7 & 8 & 9 & 10 \\ 6.0 & 5.5 & 3.0 & 2.0 & 4.0 \\ 751 & 751 & 747 & 747 & 750 \\ 399.6 & 399.3 & 397.3 & 397.3 & 398.8 \\ 2000 & 2000 & 2000 & 2000 & 2000 \\ 5.20 & 5.26 & 15.30 & 20.51 & 10.28 \\ 1.04 & 1.05 & 3.06 & 4.10 & 2.06 \\ 0.962 & 0.952 & 0.327 & 0.244 & 0.487 \\ 7.33 & 7.33 & 9.8 & 13.11 & 8.18 \\ 8590 & 8500 & 3900 & 3890 & 4840 \\ 1205 & 1205 & 1205 & 1205 & 1205 \\ 4.42 & 4.18 & 5.72 & 8.52 & 4.76 \\ 141.3 & 164.6 & 187.8 & 212.3 & 236.3 \\ 237.0 & 261.1 & 326.4 & 424.5 & 475.6 \\ 105.1 & 103.9 & 102.9 & 101.9 & 102.0 \\ 103.0 & 102.5 & 102.0 & 101.6 & 100.8 \\ 100.8 & 100.3 & 101.3 & 100.9 & 99.7\end{array}$

Licquid Product Analysis:

Wi\% Carbon

(IFED)

W $1 \%$ Hydrogen

WI\% Sulfur

$10.23 \quad 10.22$

WI\% Nitrogen

0.011

10.22
0.031

0.079

WI\% Oxygen

1.001

Specific Gravity $(60 / 60)$

1.0921

Corrected Yields Based on Liquid Feed:

Carbon Monoxide, Wt\%

Carbon Dioxide, Wt\%

Ammonia, Wt\%

llydrogen Sulfide, Wt\%

Water, Wi\%

Hydrocarbon Gases (C1 - C4), Wt\%

l.iquids (CS+), Wt\%

Ilydrogen Consumption, WI\% (analysis)

Ilydrogen Consumption, WI\% (gas phase)

0.9485

0.9978

0.9839

Corrected Conversions:

\% Hydrodesulfurization

$\%$ Hydrodenitrogenation

$\%$ llydrodeoxygenation

98.3

91.9

$-4.3$

Corrected Reaction Rates:

Sulfur Renoval, GM/HR/GM $\times 10^{2}$

Nitrogen Removal, GM/HR/GM $\times 10^{2}$

Oxygen Removal, GM/HR/GM $\times 10^{2}$

Ilydrogen Uptake, GM/HR/GM $\times 10^{2}$

Gas Make, $\mathrm{GM} / \mathrm{HR} / \mathrm{GM} \times 10^{3}$

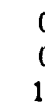

0

1.119

.703
.066

.71

102.0

4.47

6.36

0.

1.123

.682

.648

.633

101.4

4.46

6.46

u

.793

.34

.559

.299

100.9

2.88

3.35

0

0.765

.655

0.531

.249

100.4

2.57

3.09

0

0.921

.619

0.105

.446

101.2

3.27

4.40

5.3
2.3
1.7

0.674
0.970
0.605
4.355
6.651

47.5

91.6

62.9

86.6

65.2

36.0

34.2

75.7

6.8

$\begin{array}{rr}0.688 & 0.674 \\ 0.957 & 0.970 \\ -0.061 & 0.605 \\ 4.405 & 4.355 \\ 7.379 & 6.651\end{array}$

1.198

1.557

0.192

6.304

9.166 
Table 16 (continued)

Run PDJ10, 5.0029 GMS Amocat 1A

Run Summaryi

Yleld Period No.

Yield Period length, HR

Average Temperature, $F$

Average Temperature, $\mathrm{C}$

Avorage Pressure, PSIG

Liquid Feed Rate, GM/IIR

Weight Hourly Space Velocity

Weight Hourly Space Time

Hydrogen Treat Rate, L(STP)/HR

Hydrogen Treat Rate, SCF/BBL

Stirrer Speed, rpm

Ixxit Gas Rate, L(STP)/HR

Cumulative Hours on Catalyst

Cumulative Wt. Oll/Wt. Catalyst

Liquild Material Balance, Wi\%

Carbon Material Balance, Wi\%

Overall Material Balance, WI\%

11
4.0
750
399.0
2000
10.29
2.06
0.486
8.18
4840
1205
4.82
260.3
524.5
102.6
101.6
100.8

12
6.0
702
372.0
2000
5.29
1.06
0.945
7.33
8440
1205
5.08
284.8
552.4
104.5
102.8
101.0

' 13

14

15

6.0
702

372.0

2000

5.22

1.04

0,959

7.33

8560

1205

5.26

309.3

577.8

102.8

102.0

100.6

Liquid Product Analysis:

Wt\% Carben

Wt\% Hydrogen

(FEED)

Wi\% Sulfur

0.228

Wi\% Oxyoen

Specific Gravity $(60 / 60)$

$\begin{array}{cc}89.78 & 90.27 \\ 8.15 & 7.83 \\ 0.067 & 0.093 \\ 0.538 & 0.550 \\ 1.465 & 1.257 \\ 1.0221 & 1.0326\end{array}$

Corrected Yields Based on Liquid Peed:

Carbon Monoxide, Wt\%

Carbon Dioxide, Wt\%

Ammonia, Wi\%

Ilydrogen Sulfide, Wt\%

Water, Wt\%

Ilydrocarbon Gases (Cl - CA), Wt\%

Liquids (CS+), Wt\%

Hydrogen Consumption, Wt\% (analysis)

Hydrogen Consumption, Wt\% (gas phase)

$$
\begin{aligned}
& 0 \\
& 0
\end{aligned}
$$

100.9

3.28

3.98
0 .
.935
.676
$-.022$
101.7
3.4
4.85
0
.946
.656
.868
100,8
3.41
4.54

0
0

0

$.557 \quad 0.546$

.643

$-.11$

100.9

2.57

91.8

77.7

90.0

45.8

$-7.1$

86.1

44.9

71.8
23.8

76.8

55.9

0.132

.082

100.3

1.67

1.59

\% Ilydrodeoxygenation

Corrected Reaction Rates:

Sulfur Removal, GM/HR/GM $\times 10^{2}$ Nitrogen Removal, GM/HR/GM $\times 10^{2}$ Oxygen Removal, GM/HR/GM $\times 10^{2}$ Hydrogen Uptake, GM/HR/GM $\times 10^{2}$ Gas Make, GM/HR/GM $\times 10^{3}$

$\begin{array}{rr}1.824 & 2.379 \\ 1.381 & 1.843 \\ -0.296 & 0.487 \\ 5.693 & 6.257 \\ 2.175 & 3.372\end{array}$


Table 16 (continued)

Run PDJ10, 5.0029 GMS Amocat 1A

Run Summary:

Yield Period No.

Yiuld Period Length, IIR

Avorage 'I'emperature, I'

Average 'I'emperature, $\mathrm{C}$

Average Pressure, PSIC

licquid lieed Rate, GM/HR

Weight Hourly Space Velocity

Weight Hourly Space 'Time

llydrogen 'I'reat Rate, L(STP)/HR

Hydrogen 'Treat Rate, SCF/BBL

Stlirer Speed, rpm

lixit Clas Rate, L,(SIP)/HR

Cumulative Hours on Catalyst

Cunulative Wt. Oll/Wt, Catalyst

Liquidl Matcrial Balance, Wi\%

Carbon Material Balance, $W t \%$

Overall Material Balance, Wi\%

$\begin{array}{ccccc}16 & 17 & 18 & 19 & 20 \\ 4.0 & 4.0 & 4.0 & 4.0 & 4.0 \\ 698 & 750 & 775 & 831 & 774 \\ 370.0 & 399.1 & 412.6 & 444.0 & 412.0 \\ 2010 & 2000 & 1990 & 2000 & 2000 \\ 10.16 & 10.30 & 10,40 & 10.29 & 11.99 \\ 2.03 & 2.06 & 2.08 & 2.06 & 2.40 \\ 0.493 & 0.486 & 0.481 & 0.486 & 0.417 \\ 8.18 & 8.18 & 8.18 & 12.33 & 12.33 \\ 4900 & 4840 & 4790 & 7300 & 6260 \\ 1205 & 1205 & 1205 & 1205 & 1205 \\ 5.93 & 5.01 & 4.65 & 8.28 & 6.14 \\ 404.3 & 428.3 & 453.3 & 476.3 & 500.3 \\ 884.0 & 932.6 & 983.5 & 1030.2 & 10 \% 9.7 \\ 101.8 & 102.3 & 102.4 & 99.2 & 101.2 \\ 100.6 & 101.7 & 102.7 & 102.9 & 101.8 \\ 100.1 & 101.0 & 101.9 & 102.1 & 99.6\end{array}$

l.iquid Product Analyss:

Wi\% Carbon

Wi\% Hydrogen

Wi \% Sulfur

WI\% Nitrogen

WI\% Oxygen

Specific Gravity $(60 / 60)$

89.59

9.16

0.028

0.240

0.010

0.450

1.610

1.0122

0.982

0.9804

89.77

9.35

0.027

0.221

0.632

0.9712

Corrected Yields Based on Liquld Feed:

liquuids (CS+), Wt\%
Cart nonoxide, Wi\%

Ca, ., Dioxide, Wi\%

Ammonia, Wi\%

Hydrogen Sulfide, Wi\%

Watcr, Wt\%

Ilydrocarton Gases (C1 - CA), Wi\%

Ilydrogen Consumption, WI\% (analysis)

llydrogen Consumption, WI\% (gas phase)

0

0.663

0.704

$-0.281$

.107

101.2

2.39

2.77

98.5

54.5

$\cdot 18,1$

\% Ilydrodenitrogenation

\% Hydrodeoxygenation

Corrected Reaction Rates:

Sulfur Removal, GM/HR/GM $\times 10^{2}$

Nitrogen Removal, GM/HR/GM $\times 10^{2}$

Oxygen Removal, GM/HR/GM $\times 10^{2}$

Ilydrogen Uptake, GM/IIR/GM $\times 10^{2}$

Gas Make, GM/1IR/GM $\times 1\left(r^{3}\right.$
1.345

1.107

$-0.507$

4.563

2.177
0 .

0.923

.685

0.442

.673

100.5

3.24

3.79

95.8

75.9

28.4
0
0

, 949

.686

.844

1.373

99.7

3.56

4.02

96,0

78.0

54.3

$\begin{array}{ll}90.08 & 90.34 \\ 9.74 & 8.86 \\ 0.020 & 0.038 \\ 0.104 & 0.317 \\ 0.056 & 0.445 \\ 0.9390 & 0.9907\end{array}$

0.9907

0

0.834

0.675

1,055

1.063

99.4

2.99

$\begin{array}{ll}4.42 & 2.99 \\ 4.66 & 5.19\end{array}$

$97.1 \quad 94.4$

$90.0 \quad 68.5$

$96.1 \quad 67.9$

$\begin{array}{rr}1.327 & 1.342 \\ 1.563 & 1.621 \\ 0.807 & 1.557 \\ 6.186 & 6.778 \\ 13.855 & 28.525\end{array}$

1.344

1.522

$1.851 \quad 1.643$

$2.725 \quad 2.240$

$8.265 \quad 6.431$

$\% 6.822 \quad 25.47$ 
Table 16 (continued)

Run PDJ10, 5.0029 GMS Amocat 1A

Run Summary:

Yicld Porlod No.

Yiald Poriod Longth, HR

Average 'Temperature, $\mathrm{F}$

Average Temperature, $C$

Averago Pressure, PSIC

Liquild Feed Rate, GM/HR

Weight Hourly Space Volocity

Welght Hourly Space Time

Ilydrogen 'Treat Rato, L(STP)/HR

Hydrogen Treat Ratc, SCF/BHL

Stirrer Speed, rpm

Ixit Clas Rale, L(SIP)/HR

Cumulative Hours on Catalyst

Cumulative Wt, Oil/Wt, Catalyst

Llquid Malerial Balance, WI\%

Cartoon Materlal Balance, Wi\%

Overall Material Balance, WI\%

$\begin{array}{cc}21 & 22 \\ 4.0 & 4.0 \\ 753 & 752 \\ 400.6 & 400.0 \\ 2000 & 2000 \\ 10.27 & 10.27 \\ 2.05 & 2.05 \\ 0.487 & 0.487 \\ 8.18 & 8.18 \\ 4850 & 4850 \\ 1205 & 1205 \\ 5.17 & 5.21 \\ 524.3 & 548.3 \\ 1151.9 & 1200.9 \\ 101.0 & 101.8 \\ 100.7 & 100.9 \\ 100.3 & 100.4\end{array}$

Llquid Product Analysis:

Wi\% Carbon
Wi\% Hydrogen
Wi\% Sulfur
Wi\% Nitrogen
Wi\% Oxygen
Specific Gravity $(60 / 60)$

(FEED)

90.6
6.35
.673
1.001
1.379
1.0921

$\begin{array}{cl}89.75 & 89.28 \\ 8.96 & 8.96 \\ 0.096 & 0.150 \\ 0.327 & 0.317 \\ 0.867 & 1.293 \\ 0.9901 & 0.9912\end{array}$

Corrected Yields Based on Liquid Feed:

Carbon Monoxide, Wt\%

Cartion Dloxide, Wt\%

Ammonia, Wt\%

Hydrogen Sulfide, Wi\%

Water, Wi\%

IIydrocarton Gases (C1 - C4), W1\%

l.qquids (CS+), Wt\%

Ilydrogen Consumption, WI\% (analysis)

Ilydrogen Consumption, W1\% (gas phame)

$\begin{array}{cc}0 & 0 \\ 0 & 0 \\ .818 & .828 \\ .613 & .554 \\ .574 & .084 \\ .723 & .653 \\ 100.3 & 100.9 \\ 3.04 & 3.02 \\ 3.37 & 3.43\end{array}$

Corrected Conversions:

$\%$ Hydrodesulfurization

$\%$ Hydrodenitrogenation

85.7

67.2

36,9

$\%$ Ilydrodeoxygenation

Corrected Reaction Rates:

Sulfur Removal, GM/HR/GM $\times 10^{2}$ Nitrogen Removal, GM/HR/GM $\times 10^{2}$ Oxygen P.emoval, GM/HR/GM $\times 10^{2}$ Ilydrogen Uptake, GM/HR/GM $\times 10^{2}$ Gas Make, GM/HR/GM $\times 10^{3}$

$\begin{array}{rr}1.183 & 1.070 \\ 1.381 & 1.397 \\ 1.046 & 0.153 \\ 5.738 & 5.816 \\ 14.852 & 13.409\end{array}$


Table 17

Run PDJ11, 50049 GMS Amocat 1A

Run Summary:

Y'icld l'ariod No.

Ylald Period Length, IIR

Average 'T'omperature, $\mathrm{f}$

Average Temperature, $\mathrm{C}$

Average Pressure, PSIC

l.lquid freed Rate, GM/IIR

Welght Hourly Space Velocity

Welght Hourly Space 'Time

llydrogen 'Treat Rate, L,(STP)/HR

Ilydrogen 'Treat Rate, SCP/BBL

Siltrer Speed, rpm

Lxit Gas Rate, L(STP)/HR

Cumulative Hours on Catalyst

C'umulative Wt. OlI/Wt, Catalys

1.lyuid Maicrial Balance, Wi\%

Cartion Material Balance, Wt\%

Overall Material Balance', Wt\%

$\begin{array}{rr}1 & \\ 4.0 & 4.0 \\ 748 & 749 \\ 398.0 & 398.6 \\ 2000 & 2010\end{array}$

$2+3$

$4.0 \quad 4.0$

$749 \quad 748$

$398.6 \quad 398,0$

$2010 \quad 2000$

$\begin{array}{lll}10.51 & 10.27 & 10.22\end{array}$

$\begin{array}{lll}2.1 & 2.05 & 2.04\end{array}$

$\begin{array}{lll}476 & 487\end{array}$

8.18

4740

.487
8.18

4850

1205

4.53

42.9

85.4

102

101.3

98.7

1205

4.64

66.9

134.1

103.1

102.7

99.6

8.18

4870

1205

4.9

90,9

182.3

102.9

101.9

99.7

$4 \cdot 5$

$4,0=4,0$

$745 \quad 748$

$3 \% 60$

$2000 \quad 2010$

$10.19 \quad 10.18$

$2.04 \quad 2.03$

$.491 \quad .492$

$8.18 \quad 8.18$

$4890 \quad 4900$

$1205 \quad 910$

$4.78 \quad 4.81$

$114.9 \quad 138.9$

$230.4 \quad 278.5$

$102.9 \quad 102.3$

$\$ 02.1 \quad 101.8$

$99.7 \quad 99,3$

L.lquild Product Analyses:

WI\% Carton

WI\% Ilydrogen

Specilic Gravity $(60 / 60)$

(FELD)

Corrected Yields Based on Liquid Feed:

Carbon Monoxide, Wi\%

Carbon Dioxide, Wi\%

Ilydrocarton Gases (C1 - CA), Wt\%

liquids $(C S+)$, Wt\%

Ilydrogen Consumption, Wt\% (gas phase)

0

0

.392

100.8

3.86

0
0
.39
100.4
3.83
0
0
101

3.56

$\begin{array}{cc}0 & 0 \\ 0 & 0 \\ .358 & .424 \\ 100.8 & 100.6 \\ 3.59 & 3.51\end{array}$

7,075

8.228

6.782

6.813

6.726

7.294

0.765

8.01

7.655

8.63

- Does not include $\mathrm{HN}_{3}, \mathrm{H}_{2} \mathrm{~S}$ and $\mathrm{H}_{2} \mathrm{O}$ in exit gas. 
Table 17 (continued)

Run PDJ11, 5.0049 GMS Amocat 1A

Run Summary:

Yleld Porlod No.

Yicld Porlod Longth, IIR

Ave rago 'I'emperature, I'

Averago Tomperature, $\mathrm{C}$

Average Pressure, PSIC

I.lquild Foed Rate, GM/IIR

Welght Hourly Space Velocity

Welghi Hourly Spaco 'Timo

Ilydrogen Treat Rate, L(STP)/IIR

Ilydrogen 'I'reat Rate, SCF/BBL.

Stirrer Speed, rpm

13xit Gas Rato, I.(STP)/HR

Cumulative Hours on Catalyst

Cumulative Wt. Oll/Wt. Catalyst

Liquid Malcrial Balance, Wi\%

Carbon Material Balance, WI\%

Overall Matcrial Balance', WI\%

$\begin{array}{cc}6 & 7 \\ 4.0 & 4.0 \\ 750 & 748 \\ 399.0 & 398.0 \\ 2000 & 2000 \\ 10.31 & 10.28 \\ 2.06 & 2.05 \\ .486 & .467 \\ 8.18 & 8.18 \\ 4830 & 4850 \\ 615 & 320 \\ 4.71 & 5.08 \\ 162.9 & 186.9 \\ 321.9 & 370.2 \\ 103.1 & 102.9 \\ 102.6 & 102 \\ 99.8 & 100\end{array}$

8
4.0
750
399.0
2010
10.15
2.03
.493
8.18
4910
1205
1.83
210.9
418.4
102.2
101.5
99

$\begin{array}{cc}9 & 10 \\ 4.0 & 4.0 \\ 749 & 749 \\ 398.4 & 398.5 \\ 2010 & 2000 \\ 10.24 & 10.32 \\ 2.05 & 2.06 \\ .489 & .485 \\ 8.18 & 8.18 \\ 4860 & 4830 \\ 1500 & 1795 \\ 4.93 & 4.89 \\ 234.9 & 258.9 \\ 466.4 & 513.9 \\ 100.3 & 102.9 \\ 99.7 & 102.2 \\ 97.7 & 99.9\end{array}$

Liquild Product Analyses:

Wi\% Carbon

WI\% Hydrogen

Specific Gravity (60/60)

Corrected Yiolds Based on Liquild Feed:

Cartion Monoxide, Wt\%

Carbon Dioxide, WI\%

Ilydrocarbon Gases (C1 - C4), Wi\%

L lquids (CS+), Wi\%

Ilydrogen Consumption, Wt \% (gas phase)

$\begin{array}{cc}0 & 0 \\ 0 & 0 \\ .417 & .49 \\ 100.5 & 100.8 \\ 3.66 & 3.34\end{array}$

0
0
.481
100.6
3.69

0
0
.525
100.6

100.6

9.33

Corrected Reaction Rates:

Ilydrogen Uptake, GM/IIR/GM (XE2)

Gas Make, GM/HR/GM (xIB3)

- Does not include $\mathrm{HN}_{3}, \mathrm{H}_{2} \mathrm{~S}$ and $\mathrm{H}_{2} \mathrm{O}$ in exit gas. 


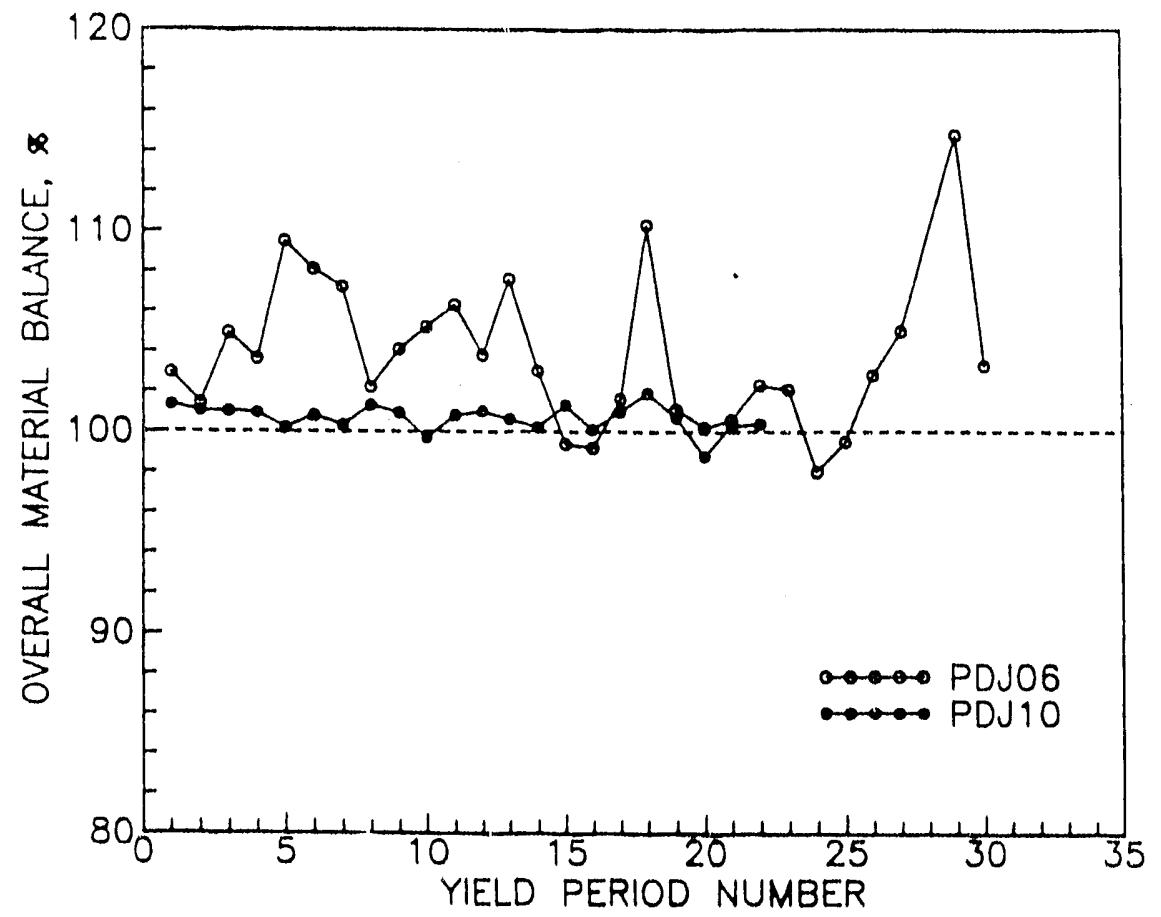

Figure 30. Total material balances before (Run PDJ06) and after (Run PDJ10) modifications to feedtank transfer lines. 
replacement; whereas, the PDJ10 data were collected afterwards. The improved material balances due to this modification are clearly evident.

The objective of the thermal runs, Runs PDJ05 and PDJ09, was to ascertain the extent to which non-catalytic reactions may contribute to the overall (i.e. observed) reactions. Total liquid holdup in the reactor with internals in place, but in the absence of catalyst is $58.9 \mathrm{~cm}^{3}$. A five gram catalyst charge displaces only about $5.7 \mathrm{~cm}^{3}$ leaving a substantial volume where thermal reactions might occur. Four separate samples of the feedstock were analyzed at various times during the study for $\mathrm{C}, \mathrm{H}, \mathrm{N}$ and $\mathrm{S}$. The results of these analyses are compiled in Table 18. Analyses for the entire slate of products from the thermal runs are presented in Table 19.

The first question to be addressed is whether the thermal reaction product compositions differ significantly from the feed composition. Stated more precisely, we take as our null hypothesis that the two samples are identical and test the alternative that the product composition is lower in $\mathrm{N}$ or $\mathrm{S}$ (or higher in. $\mathrm{H}$ ). The appropriate statistical test, a one-sided t-test, compares the difference between means assuming the variances to be unknown and equal. The results of this test are presented in Table 20. For nitrogen the calculated value of $t$ lies below the critical $t_{\text {crit }}$ and we cannot reject the nul! hypothesis. We may assume that thermal reactions do not contribute significantly to the overall HDN reaction. However, the null hypothesis is rejected for the $\mathbf{S}$ and $\mathbf{H}$ analyses, i.e., thermal reactions do contribute to the observed HDS and HYD reactions.

Because the extent of the thermal reaction data is very limited, it is not possible to develop reliable kinetics models for the thermal reactions. Fortunately the thermal HYD 
Table 18

\section{Results of Replicate Feed Analyses}

(All wt\%)

Nitrogen

0.943

0.902

1.020

1.140

Sulfur
0.61
0.88
0.60
0.60

Sulfur

.88

0.60
Hydrogen

6.44

6.32

6.34

6.29
Carbon

90.42

90.70

90.70

90.75

Table 19

Thermal Products Analyses

(All wt\%)

\begin{tabular}{rcccc}
\multicolumn{1}{l}{ Run-YP } & Nitrogen & Sulfur & Hydrogen & Carbon \\
PDJ05-01 & 1.05 & 0.58 & 6.71 & 90.64 \\
02 & 0.91 & 0.60 & 6.76 & 90.72 \\
03 & 0.89 & 0.60 & 6.67 & 90.93 \\
PDJ09-01 & 0.82 & 0.38 & 6.67 & 90.47 \\
02 & 1.09 & 0.47 & 6.72 & 90.79 \\
03 & 0.91 & 0.41 & 6.89 & 90.55 \\
04 & 0.82 & 0.41 & 6.94 & 90.75 \\
05 & 0.83 & 0.53 & 6.61 & 90.80 \\
06 & 1.08 & 0.54 & 6.62 & 90.60 \\
07 & 0.86 & 0.39 & 6.84 & 90.80 \\
08 & 0.87 & 0.45 & 6.77 & 90.83
\end{tabular}


Table 20

Test of Null Hypothesis that Composition of Feed and Products is Identical

\begin{tabular}{lrr}
\multicolumn{1}{c}{ Component } & $\frac{1}{1.328}$ & \\
Nitrogen & 3.177 & significant \\
Sulfur & 6.838 & significant \\
Hydrogen & & \\
& &
\end{tabular}


rate is small by comparison to the catalytic rate at a given set of conditions. Only a crude kinetics model is therefore needed to correct for thermal HYD reactions. A regression on the combined PDJ05 and PDJ09 data provided the following expression for the thermal HYD rate:

$$
R_{H Y D, T}=474 \exp \left(-\frac{7482}{T}\right)(12.5-H)
$$

Here $\mathrm{T}$ is in $\mathrm{K}, \mathrm{H}$ is the wt\% hydrogen in the products, and $\mathrm{R}_{\mathrm{HYD}, \mathrm{T}}$ is the thermal reaction rate in $\mathrm{gm} / \mathrm{hr}$. (Pressure was not varied during this study, and all data were obtained at 2000 psig.)

For the HYD reactions, the thermal reaction calculated from Eq. (16) is simply subtracted from the observed HYD reaction and this difference is taken as the catalytic HYD reaction. As justification for this simple procedure, we note that the correction amounts to only $5-10 \%$ of the observed HYD rate. No correction was made to the observed HDN rates.

Utilization of the correlations developed in Section III-A-2 for various critical stirrer speeds assumes a knowledge of the fluid viscosity. The viscosity of the raw creosote oil feedstock was measured in a rolling ball viscometer over a range of temperatures from ambient to $250^{\circ} \mathrm{F}$, and these values were extrapolated to reaction conditions using the modified Doolittle equation (51). At $750^{\circ} \mathrm{F}$, for example, the viscosity of raw creosote oil is estimated to be $1.29 \mathrm{cp}$. Inserting this value into the correlation for the stirrer speed at incipient fluidization, Eq. (11) gives a value of $S_{1}=817 \mathrm{rpm}$. Furthermore, the correlations 
predict that the bed can be expanded to the top of the basket, and the stirrer speed at which this occurs, $S_{2}$, was calculated to be $1345 \mathrm{rpm}$.

On this basis an intermediate value of $1205 \mathrm{rpm}$ would appear to be a good choice. However, due to the uncertainty in the extrapolated viscosities it was deemed advisable to conduct a brief study of the effect of stirrer speed on the observed reactor rates. Figure 31 is a plot of HYD rates at base operating conditions $\left(2000 \mathrm{psig}, 750^{\circ} \mathrm{F}\right.$, WHSV $=2, \mathrm{H}_{2}$ Treat Rate $=7500 \mathrm{SCF} / \mathrm{BBL}$ ) as stirrer speed is varied. The lower curve, which exhibits an apparent optimum, has not been corrected for catalyst deactivation. When this correction is made, i.e. when all data are corrected to a common "catalyst service" of 200 grams of oil processed per gram of catalyst, the upper curve results. There is clearly no significant effect of stirrer speed above about $1000 \mathrm{rpm}$. All subsequent data were obtained at a stirrer speed of $1205 \mathrm{rpm}$.

\section{a. Evaluation of Kinetics}

The HDN and HYD kinetics were derived from a process variable study in which temperature and weight hourly space velocity were varied over the ranges $700^{\circ} \mathrm{F} \leq \mathrm{T} \leq$ $830^{\circ} \mathrm{F}$ and $1 \leq$ WHSV $\leq 4$, Run PDJ10. Hydrogen treat rates were adjusted to insure that the gas phase product was $>95 \%$ hydrogen. Pressure was maintained constant at 2000 psig. Runs at base conditions were repeated periodically to maintain a check on catalyst activity. The Run PDJ10 data were selected in preference to Run PDJ06 because of higher quality, Figure 30.

The HIJN data were fit to the empirical model: 


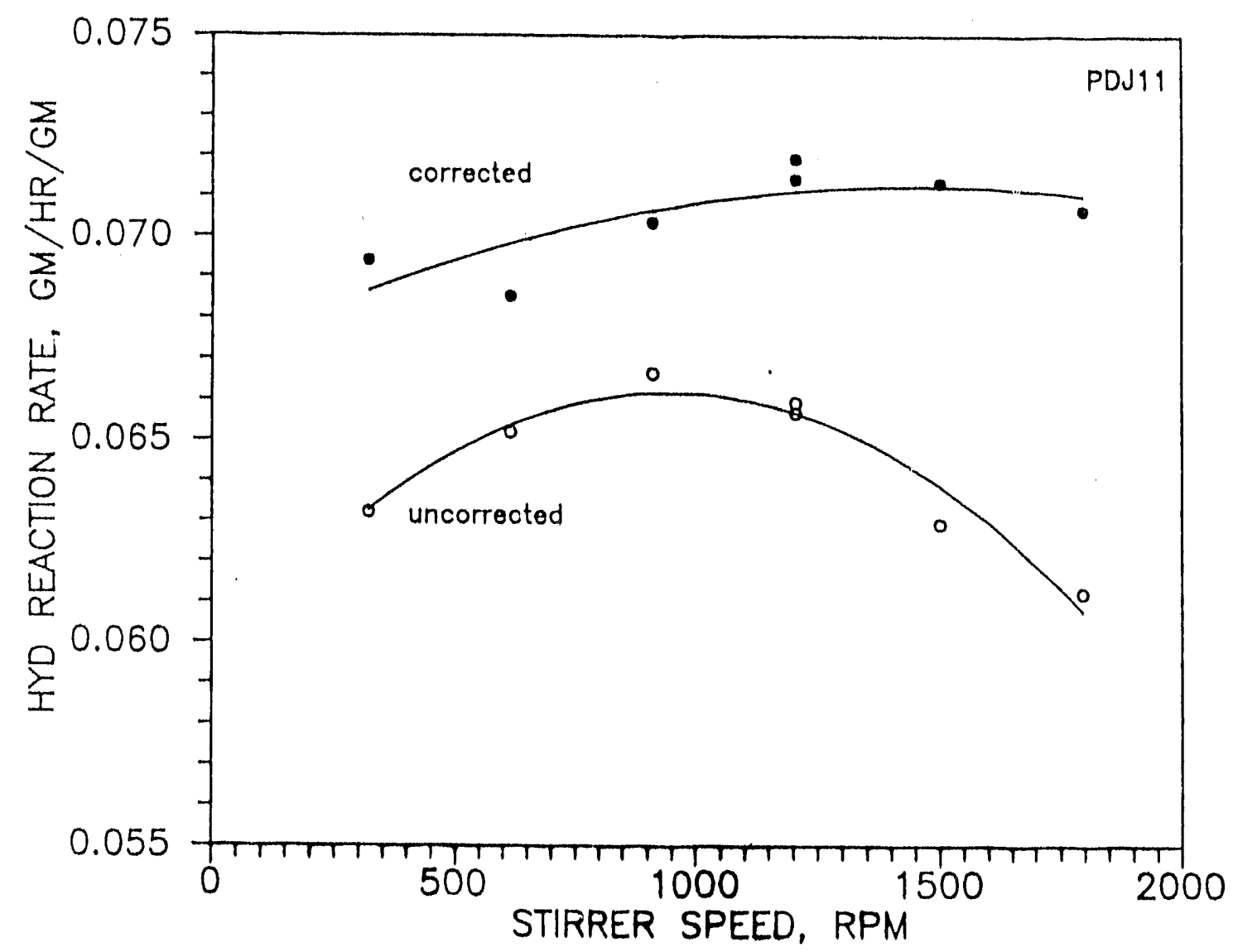

Figure 31. Effect of stirrer speed on hydrogen uptake (HYD) rate. 


$$
\begin{aligned}
& R_{H D N}=\theta_{N} k_{N} N^{N_{N}} \\
& \theta_{N}=e^{-\alpha_{N}(x-200)} \\
& k_{N}=k_{N_{0}} e^{-r_{N} / d x}
\end{aligned}
$$

by nonlinear regression. In these equations $\mathbf{N}$ is the wt\% nitrogen in the products, $\theta_{N}$ is a correction for catalyst deactivation and $\mathrm{X}$ is the catalyst service. Thus $\theta_{N}$ is unity when 200 weights of oil have been processed per weight of catalyst. The best fit parameters are:

$$
\begin{aligned}
& n_{N}=0.54 \\
& E_{N}=16550 \\
& k_{N_{0}}=9100 \\
& \alpha_{N}=4.0 \times 10^{-4}
\end{aligned}
$$

with $\mathbf{R}_{\mathrm{HDN}}$ in $\mathrm{gm} / \mathrm{hr} / \mathrm{gm}$ and $\mathrm{T}$ in kelvins.

A parity plot for this regression is presented in Figure 32. The model adequately describes the data. The HDN deactivation factor is plotted vs. catalyst service in Figure 33. The solid line is calculated from the regression parameters, and the points are the data at base run conditions. Since the catalyst is deactivating, all data are corrected to a common catalyst service of $X=200$ on the kinetics plot, Figure 34. Again, the solid lines are calculated from the overall regression and are not drawn through individual groups of points on the figure. The data are well described by the power law model. The Arrhenius plot for HDN is presented in Figure 35.

The HYD kinetics analysis is similar; however, allowance must be made for the fact that hydrogenation reactions are reversible. The hydrogen uptake data were fit to the following model: 


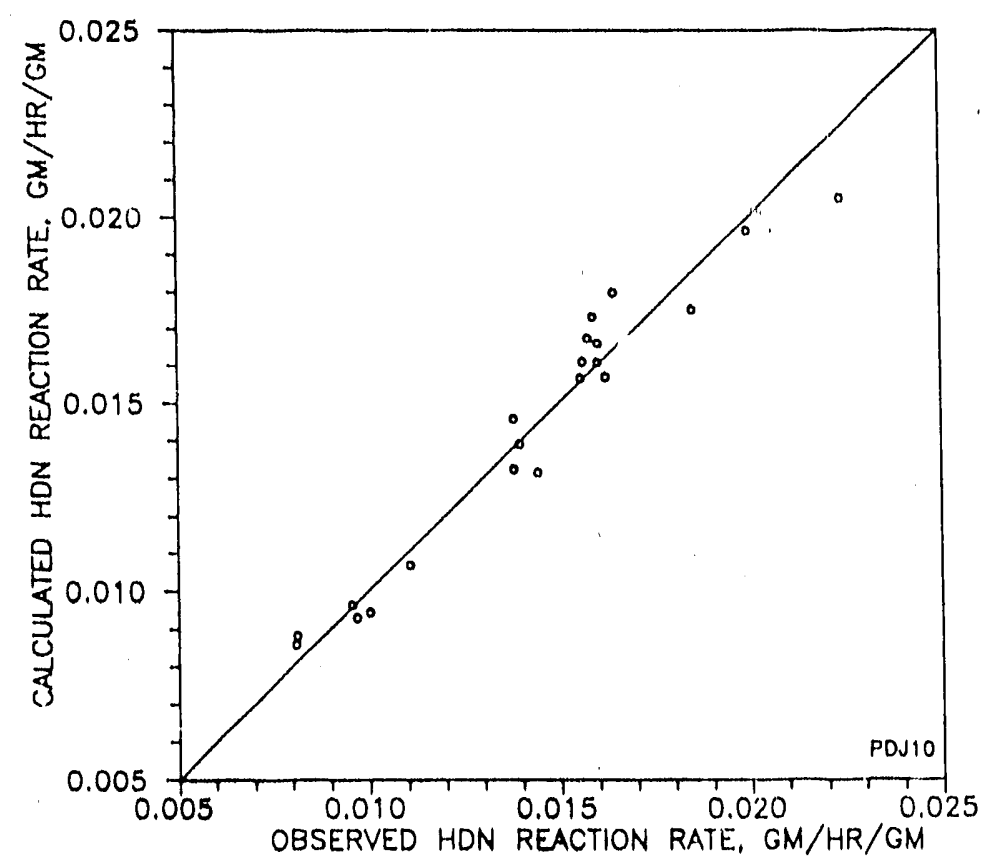

Figure 32. Parity plot for HDN kinetics model, Eqs. (17) - (19).

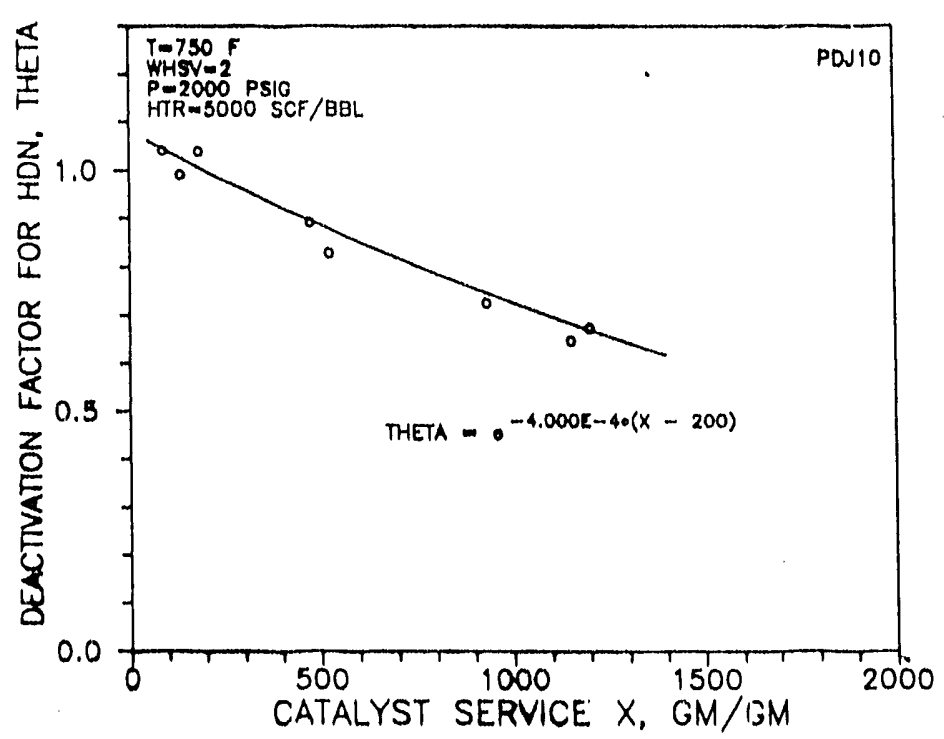

Figure 33. Deactivation function for HDN. Points are at base conditions: $\mathbf{P}=2000 \mathrm{psig}$, $\mathrm{T}=750^{\circ} \mathrm{F}, \mathrm{WHSV}=2, \mathrm{HTR}=5000 \mathrm{SCF} / \mathrm{BBL}$. 


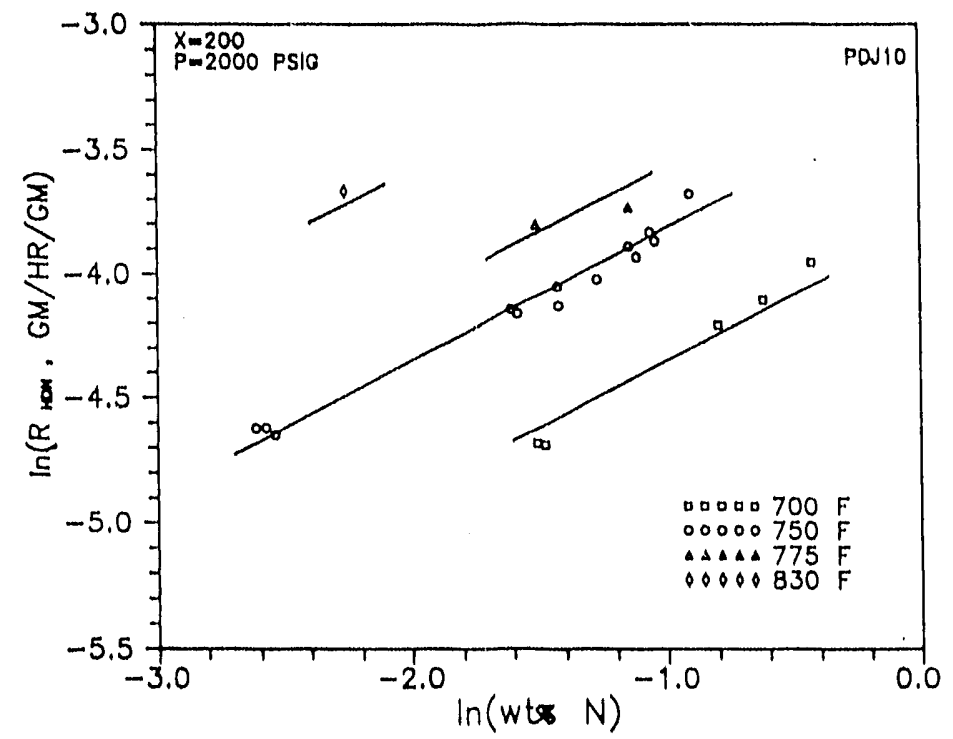

Figure 34. Kinetics plot for HDN. All data are corrected to a catalyst service of $200 \mathrm{cum}$. gm oil/gm catalyst.

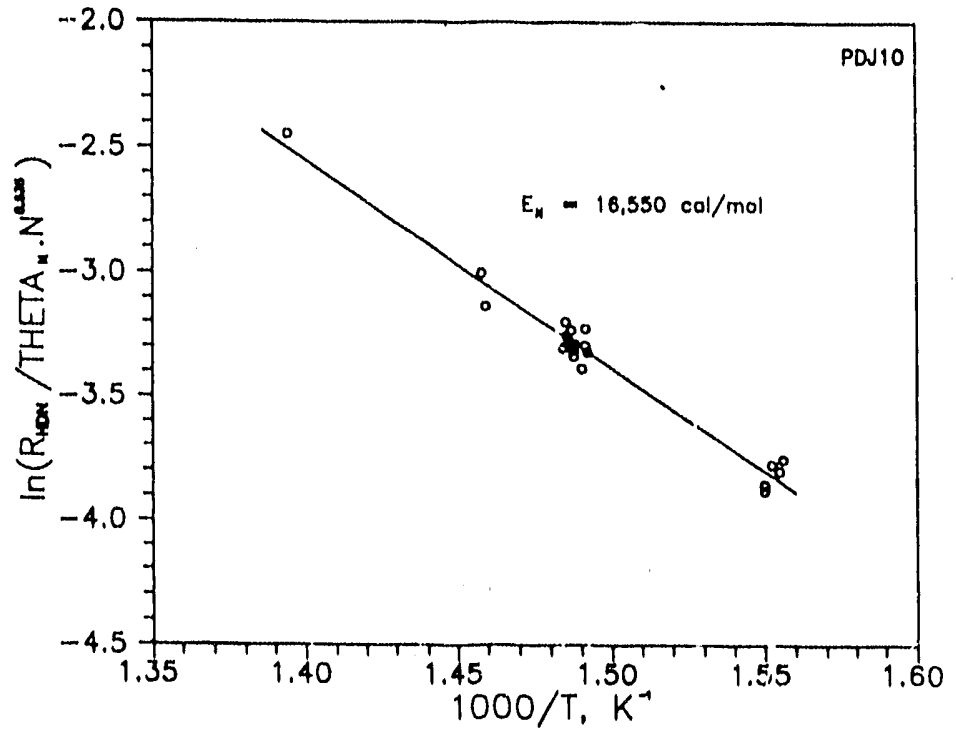

Figure 35. Arrhenius plot for HDN. All data are corrected to a catalyst service of 200 cum. gm oil/gm catalyst. 


$$
\begin{gathered}
R_{H Y D}=\theta_{H} k_{H}\left(H_{E}-H\right)^{n_{H}} \\
\ln H_{E}=A+B / T \\
\theta_{H}=e^{-\alpha_{H}(X-200)} \\
k_{H}=k_{H_{\odot}} e^{-E_{H} / A T}
\end{gathered}
$$

with the result:

$$
\begin{aligned}
n_{H} & =1.64 \\
A & =1.991 \\
B & =354 \\
E_{H} & =20690 \\
k_{H_{\odot}} & =57700 \\
\alpha_{H} & =4.28 \times 10^{-4}
\end{aligned}
$$

where $R_{\text {IIYD }}$ is in $\mathrm{gm} / \mathrm{hr} / \mathrm{gm}$ and $\mathrm{T}$ is in kelvins. A parity plot for the regression model is presented in Figure 36. Again, the fit is quite good. The additional complexity introduced by Eq. (21) is required to fit the higher temperature data. The fit is not acceptable if the temperature dependence of $\mathrm{H}_{\mathrm{E}}$ is neglected. The HYD deactivation function, kinetics plot and Arrhenius plot are presented in Figures 37, 38 and 39 respectively.

\section{b. Catalyst Attrition:}

A question of major concern is whether the agitation might result in catalyst attrition and loss. Table 21 summarizes the catalyst loss data for all our hydrotreating runs. In each case the used catalyst was extracted in THF, dried, and a portion was fired in a muffle furnace. From the recorded weights, the percent catalyst recovery relative to the charge of fresh calcined catalyst was calculated and listed in the table. Except for Run PDJ08, 


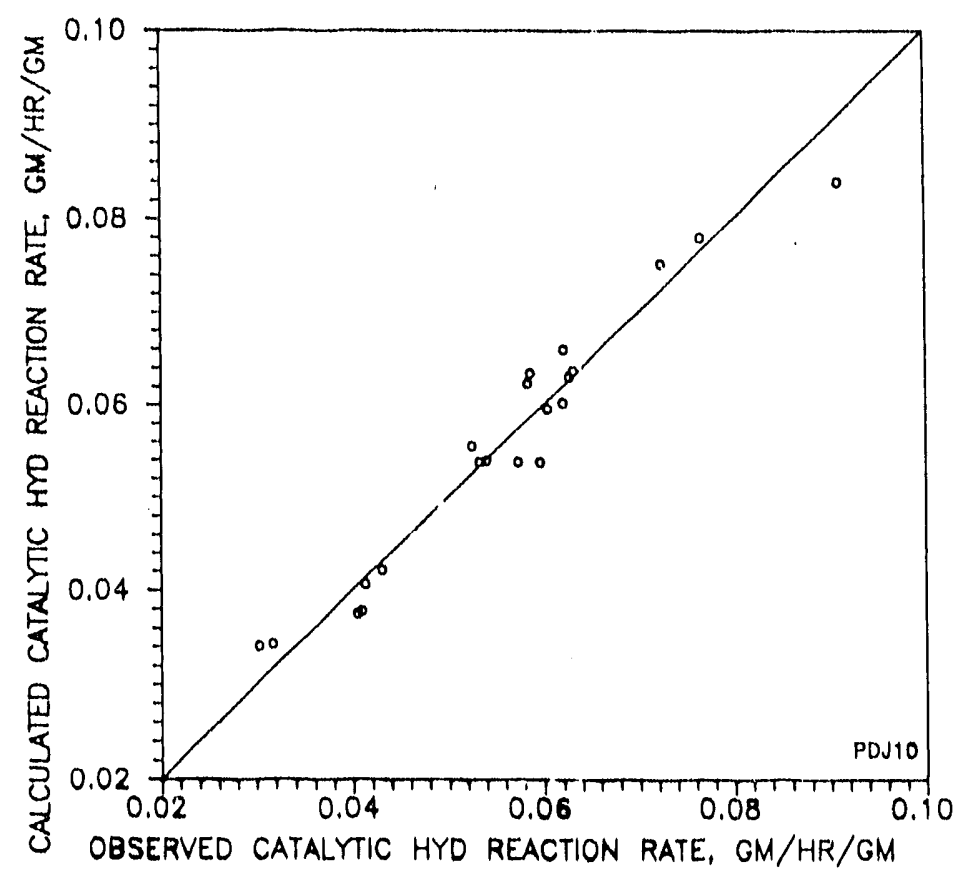

Figure 36. Parity plot for HYD kinetics model, Eqs. (20) - (23).

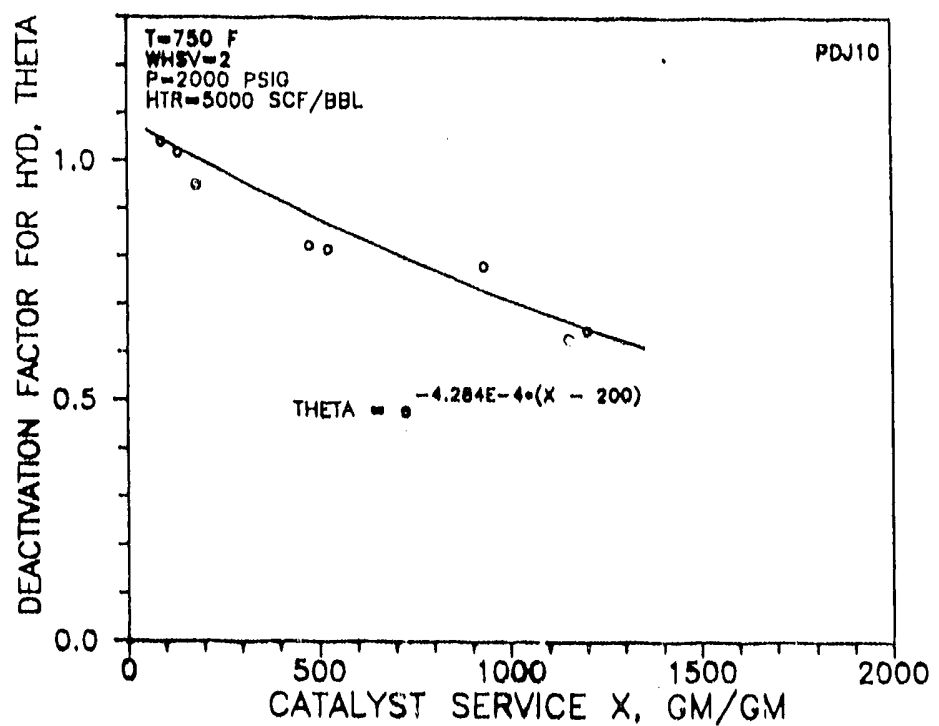

Figure 37. Deactivation function for HYD. Points are at base conditions: $P=2000$ psig, $\mathrm{T}=750^{\circ} \mathrm{F}, \mathrm{WHSV}=2, \mathrm{HTR}=5000 \mathrm{SCF} / \mathrm{BBL}$. 


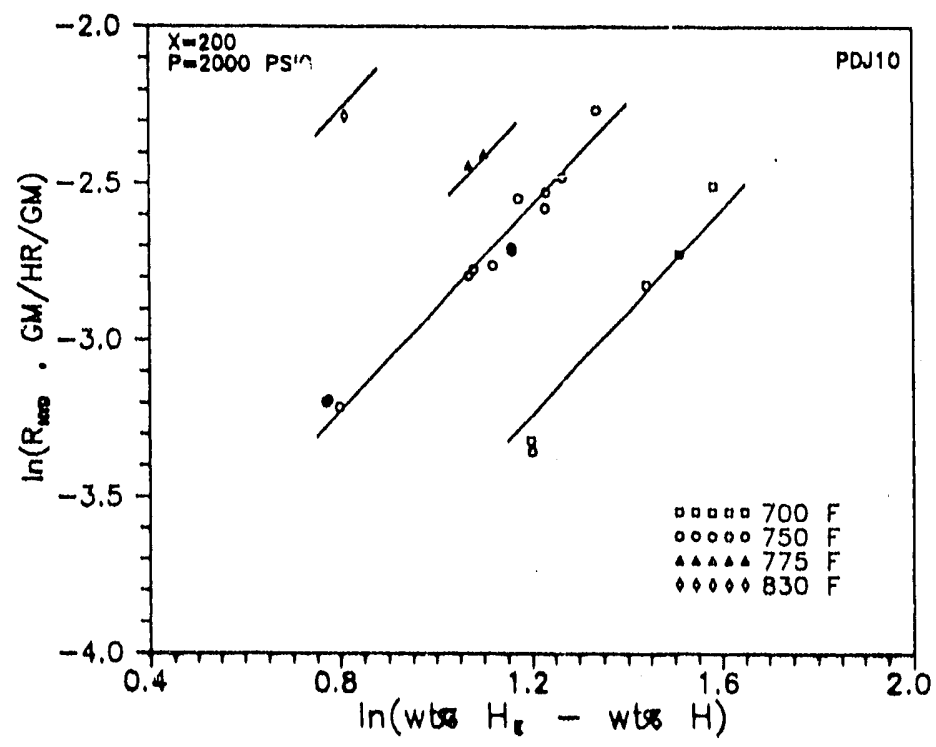

Figure 38. Kinetics plot for HYD. All data are corrected to a catalyst service of $200 \mathrm{cum}$. gm oil/gm catalyst.

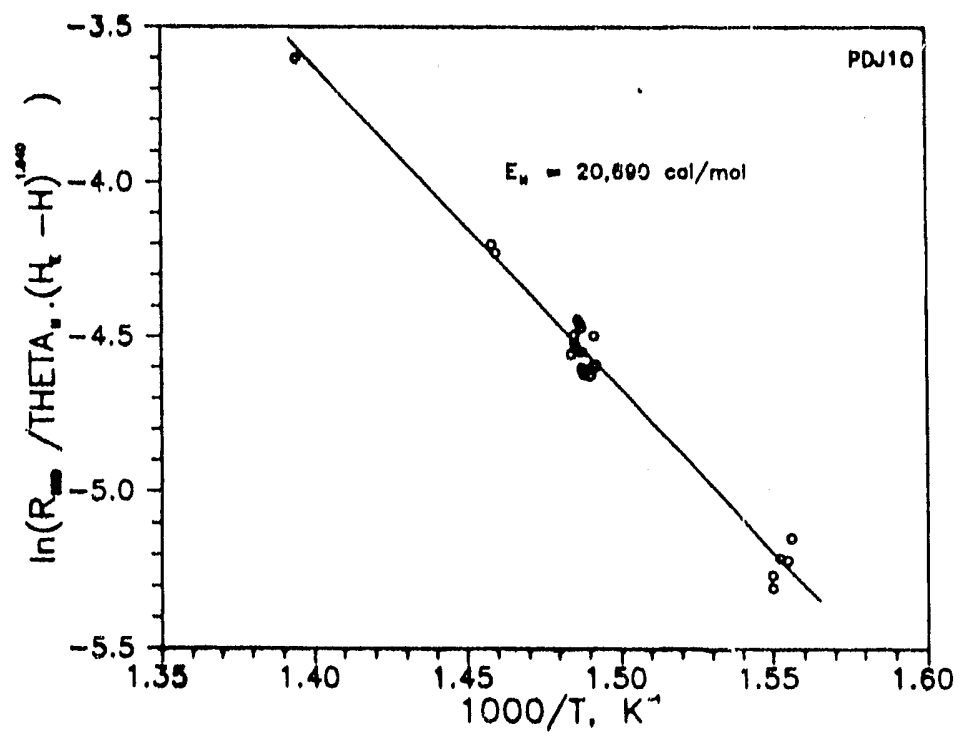

Figure 39. Arrhenius plot for HYD. All data are corrected to a catalyst service of 200 cum. gm oil/gm catalyst. 


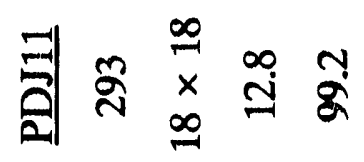

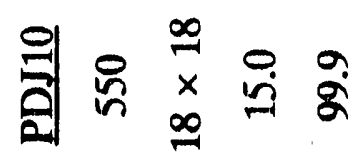

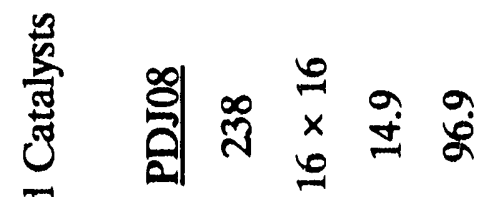

$$
\begin{aligned}
& \text { 岕 }
\end{aligned}
$$

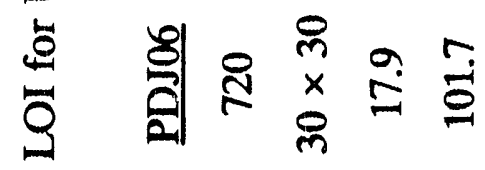

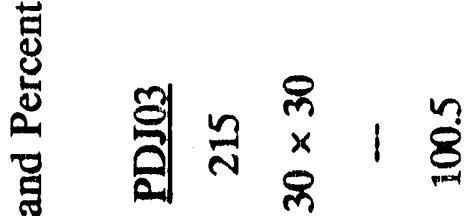

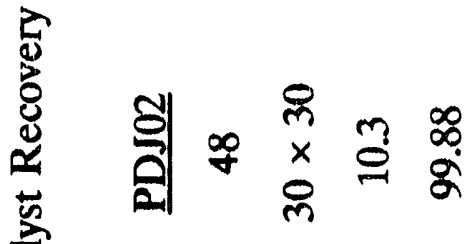

$$
\begin{aligned}
& \text { 离 }
\end{aligned}
$$

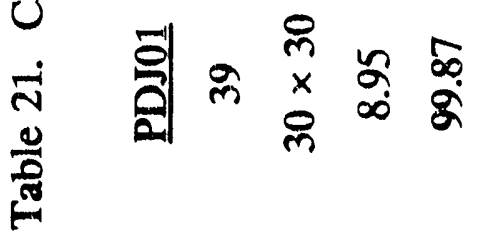

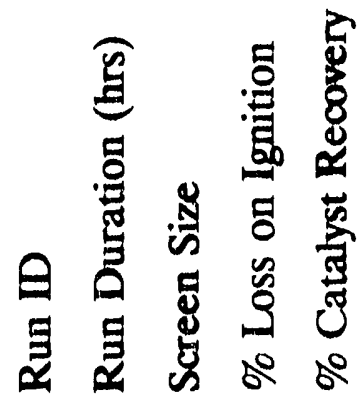


essentially $100 \%$ of the catalyst was recovered. The loss of catalyst observed for Run PDJ08 occurred when the basket screen size was increased, and the loss was probably due to our failure to screen fine particles of catalyst from the original charge rather than due to attrition. Thus catalyst attrition does not appear to be a problem with the Amocat $1 \mathrm{~A}$ catalysit.

\section{c. Used Catalysts:}

Elemental analyses of the THF extracted PDJ06, PDJ08 and PDJ10 catalysts are compiled in Table 22 . The coke deposits are clearly highly aromatic. This is also evident in the solid-state carbon-13 NMR spectrum for the used PDJ10 catalyst, Figure 40. The S/Mo atom ratio is consistent with fully sulfided $\mathrm{MoS}_{2}$.

\section{Conclusions:}

The ebullated bed microreactor provides an accurate and convenient means of evaluating hydrotreating kinetics at the laboratory scale. The reactor remained isothermal despite the large exothermic heat of reaction. Thus the advantages of the gradientless reactor are quite evident. Thermal reactions play a small but significant role in the HYD reactions. For HDN, thermal reactions could be ignored completely. Catalyst recovery was near $100 \%$ after as many as 30 days of continuous operation.

\section{COAL LIQUEFACTION STUDIES}

Additional modifications were required before introducing coal into the unit. At our scale of operation, the components required for pumping a coal slurry were unavailable. Accordingly we decided to inject coal into the unit as a coal paste with additional "makeup" 
Table 22. Analysis of Spent Catalysts

\begin{tabular}{lccc} 
Sample ID: & PDJ-06 & PDJ-08 & PDJ-10 \\
\hline Run Duration (hrs) & 720 & 238 & 550 \\
Carbon, wt.\% & 10.42 & 6.74 & 10.12 \\
Hydrogen, wt.\% & 0.89 & 0.58 & 1.03 \\
Nitrogen, wt.\% & 0.08 & 0.12 & 0.22 \\
Sulfur, wt.\% & 7.03 & 7.08 & 6.58 \\
H/C atom ratio & 1.02 & 1.03 & 1.21 \\
S/Mo atom ratio & 2.3 & 2.3 & 2.2
\end{tabular}




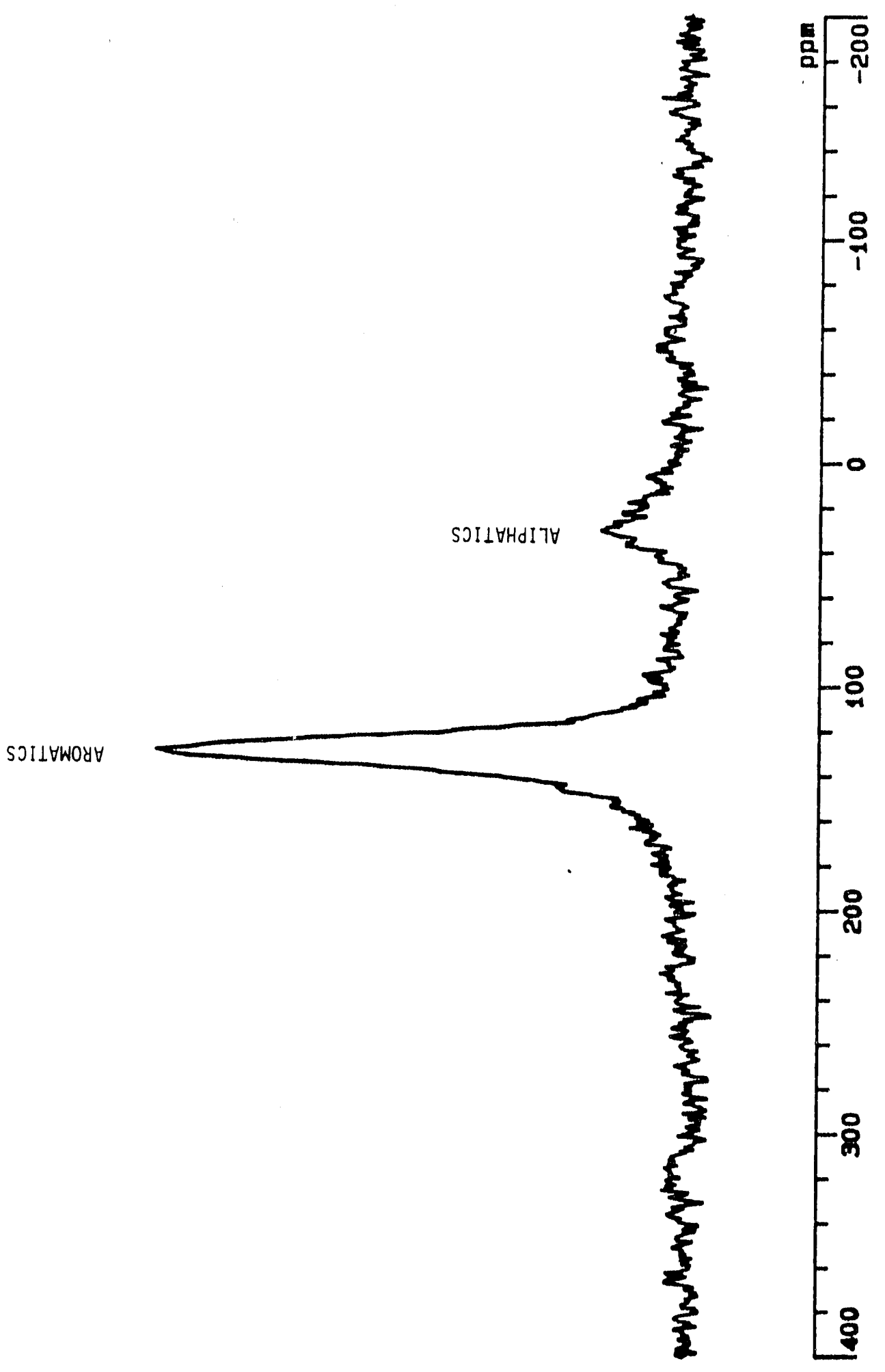

Figure 40. Solid state carbon-13 NMR spectrum for used PDJ10 catalyst. 
solvent provided separately. The purpose of the current (ZTJ) series of runs was to identify and correct any problems with the unit caused by the coal feedstock. A further objective was to identify a set of run conditions for subsequent deactivation studies.

\section{Experimental}

A schematic of the Catalytic Coal Liquefaction Microreactor is presented in Figure 41. This drawing is identical to the previous drawing of the Hydrotreating Unit, Figure 28, except that provision has been made for the introduction of coal paste via a high pressure syringe pump (ISCO Mod. LC-5000). The Isco pump head assembly was modified by installing a collar, Figure 42, at the outlet. The pressure transducer which normally screws into the top of the pump cylinder was removed, and the collar was inserted between the pump cylinder and the transducer. The collar serves two purposes: 1 . the paste is extruded through a larger, more gradual entrance, and 2. the pump can be filled without breaking lines to the reactor. (The transducer assembly is removed for filling, but the collar remains connecte-1 to the unit.) The operation of the pressure transducer is not affected by this modification.

An additional modification to the unit allows the product accumulators to be warmed slightly to facilitate product removal. An insulated enclosure was installed around the product accumulators, and heat was provided by a small electrical heater. However, at the base operating conditions that were ultimately established, the product flowed well without heating, so the modification was unnecessary.

The makeup solvent delivery system employs an Eldex Mod. A-30-S liquid chromatography pump and the feedrie is monitored gravimetrically. This system is the 


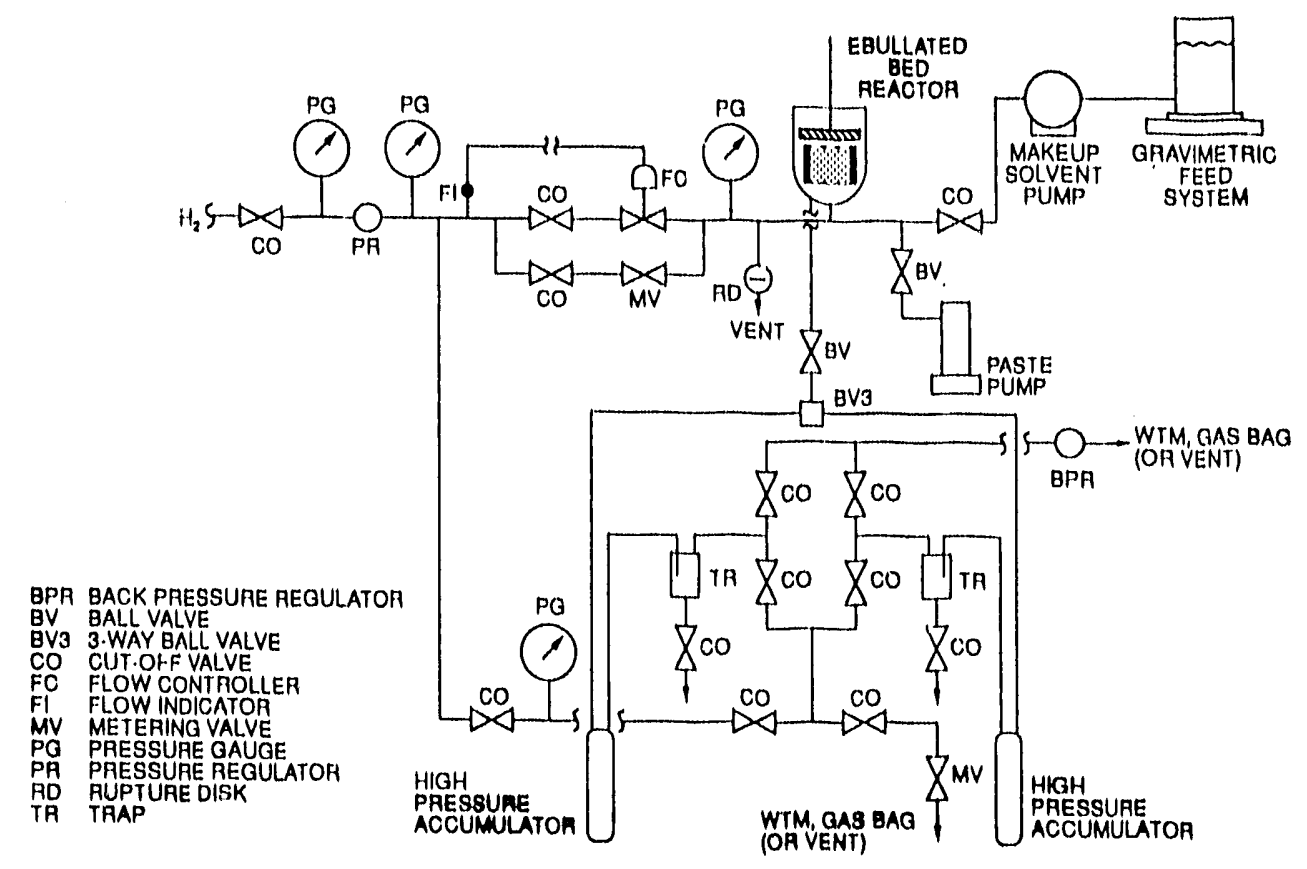

Figure 41. Catalytic Coal Liquefaction Microreactor Unit configured for coal liquefaction studies.

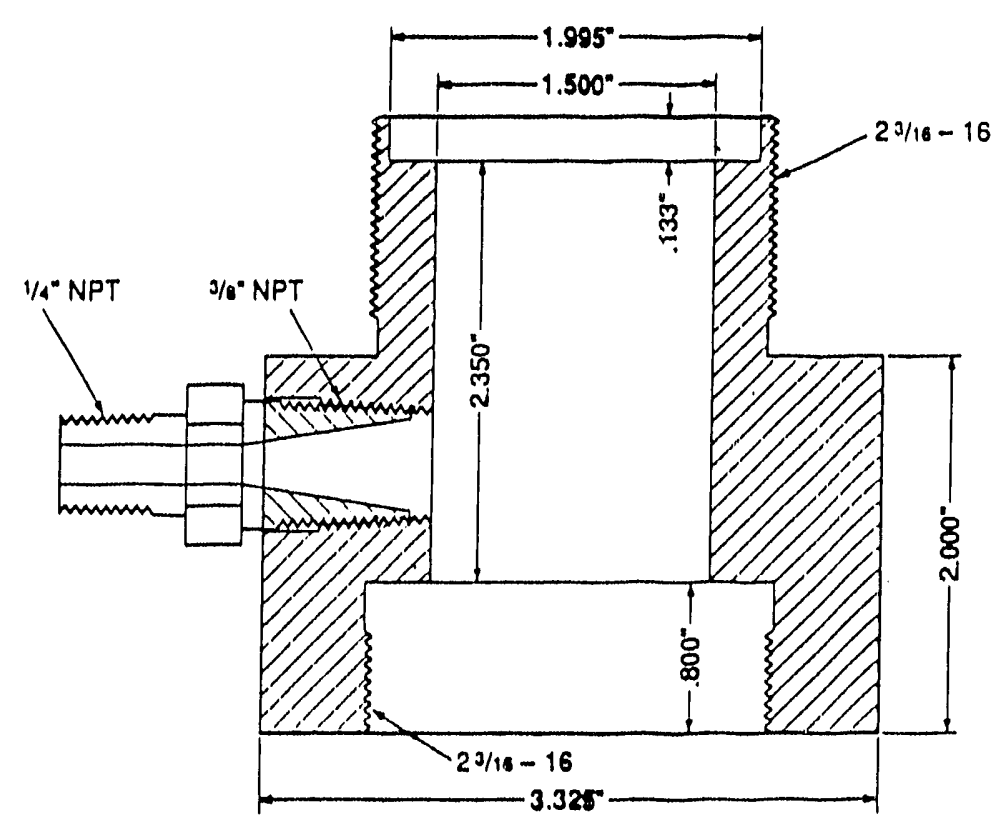

Figure 42. Coal paste pump collar. 
same as that employed in the hydrotreating studies and described in Section III-B-1. The hydrogen feed system is also identical to the hydrotreating configuration.

The coal paste used in these experiments consists of three components: 1. coal (as received) from Arco's Black Thunder Mine in the Powder River Basin, Wyoming, 2. deashed residuum material derived from this same coal at the Wilsonville, Alabama, facility and 3. Allied Signal 24-CB raw creosote oil. Preparation of the coal was conducted at the North Dakota Mining and Mineral Resources Research Institute under the direction of Dr. Curtis L. Knudsen with the consultation of Dr. Donald C. Cronauer of the Amoco Oil Company. The coal was ground on a 200 pound per hour Micro Pulveriser to pass $96 \%$ through 100 mesh screen. Dry ice was added during the process to exclude air, and the ground coal was stored under $\mathrm{CO}_{2}$. Proximate and ultimate analyses of the coal are provided in Table 23. An X-ray fluorescent analysis of the coal ash is reported in Table 24.

The solubility of the residuum was found to be $15.7 \%$ in cyclohexane, $99.9 \%$ in toluene and $100 \%$ in pyridine. The raw creosote oil is the same as that employed in the hydrotreating runs. Elemental analyses are compiled in Table 9, and a GC simulated distillation curve is presented in Figure 27.

The composition of the coal paste is listed in Table 25. Several methods of preparing the paste were tried. In the preferred procedure 1.5 parts by weight of the pulverized coal were mixed with 2.0 parts of creosote oil. One part of residuum was added with stirring and finally the remaining 1.5 parts of coal powder was combined with the mixture. In an alternative procedure, used only for the first four runs (ZTJ01 - ZTJ04), one part of residuum is mixed with two parts of creosote oil and the mixture is combined with an equal 
Table 23. Coal Proximate and Ultimate Analyses

\begin{tabular}{|c|c|c|c|}
\hline & $\begin{array}{c}\text { As Received } \\
(\%)\end{array}$ & $\begin{array}{c}\text { Moist Free } \\
(\%)\end{array}$ & $\begin{array}{l}\text { Moist/Ash } \\
\text { Free }(\%) \\
\end{array}$ \\
\hline \multicolumn{4}{|l|}{ Proximate Analysis } \\
\hline Moisture & 24.20 & N/A & N/A \\
\hline Volatile Matter & 33.72 & 44.51 & 47.50 \\
\hline Fixed Carbon & 37.29 & 49.19 & $52.49^{(a)}$ \\
\hline Ash & 4.78 & 6.31 & N/A \\
\hline \multicolumn{4}{|l|}{ Ultimate Analysis } \\
\hline Hydrogen & 6.66 & 5.24 & 5.59 \\
\hline Carbon & 53.20 & 70.22 & 74.95 \\
\hline Nitrogen & 0.69 & 0.91 & 0.97 \\
\hline Sulfur & 0.37 & 0.49 & 0.52 \\
\hline Oxygen & 34.28 & 16.81 & $17.95^{(\mathrm{a})}$ \\
\hline Ash & 4.78 & 6.31 & $\mathrm{~N} / \mathrm{A}$ \\
\hline
\end{tabular}

(a) By difference

Table 24. X-Ray Fluorescent Analysis of Coal Ash

\begin{tabular}{lrrr}
\multicolumn{1}{r}{ Oxide } & \% of Ash & \% $\mathrm{SO}_{3}$ Free \\
$\mathrm{SiO}_{2}$ & 25.50 & $31.3 \mathrm{~J}$ \\
$\mathrm{Al}_{2} \mathrm{O}_{3}$ & 16.50 & 20.30 \\
$\mathrm{Fe}_{2} \mathrm{O}_{3}$ & 4.70 & 5.80 \\
$\mathrm{TiO}_{2}$ & 1.60 & 2.00 \\
$\mathrm{P}_{2} \mathrm{O}_{5}$ & 1.70 & 2.10 \\
$\mathrm{CaO}$ & 24.40 & 30.00 \\
$\mathrm{MgO}$ & 5.90 & 7.20 \\
$\mathrm{Na}$ & 0.90 & 1.10 \\
$\mathrm{~K}_{2} \mathrm{O}$ & 0.10 & 0.10 \\
$\mathrm{SO}_{3}$ & 18.60 & 0.00 \\
Totals: & 99.90 & 99.90
\end{tabular}




\section{Table 25. Coal Paste Composition}

$\begin{array}{lr} & \underline{w t \%} \\ \text { coal }^{(1)} & 50.0 \\ \text { residuum }^{(2)} & 16.7 \\ \text { creosote oil } & \underline{33.3} \\ & 100.0\end{array}$

(1) As received. Contains $23.5 \%$ moisture (by drying at $104^{\circ} \mathrm{C}$ for 1 hour.

(2) Cyclohexane soluble $=15.71 \%$. Toluene soluble $=99.94 \%$. 
weight of coal. The mixture requires mild heating $\left(50^{\circ} \mathrm{C}\right.$ for $30 \mathrm{~min}$.) to obtain homogeneity. The paste prepared by either method does not settle or separate over a period of days or weeks and is readily extruded at room temperature.

Raw creosote oil was chosen as the makeup solvent and as a component of the coal paste because the hydrogen deficient nature of the resulting feedstock places a high demand on the catalyst. It is therefore easy to observe relatively small differences in catalyst activity.

The products workup consisted of forward sequential extraction first in c/clohexane, then in toluene and finally in pyridine. The entire product from the balance perioc: accumulator was washed into a beaker with cyclohexane. Further cyclohexane was added with stirring to bring the mixture to about $5 \mathrm{~cm}^{3}$ of cyclohexane per gram of slurry product. After allowing sufficient time for precipitation, the contents of the beaker were then poured through a dried and preweighed cellulose extraction thimble (single thickness, $43 \times 123 \mathrm{~mm}$ ). The beaker was washed with cyclohexane and the washings were poured through the thimble. The thimble was placed in a Soxhlet extraction apparatus and its contents were extracted in cyclohexane for 24 hours or until the wash solvent was clear. The thimble was next air dried for 6 hours and then dried over night under vacuum at $130^{\circ} \mathrm{C}$. After cooling in a desiccator, the thimble and its contents were weighed and the weight of cyclohexane insoluble residue was recorded. A portion of the cyclohexane insoluble material was next transferred to a tared alundum thimble $(32 \times 80)$ and extracted in toluene, dried in the same manner as above, and the weight of the toluene insoluble residue was recorded. Finally the sample was extracted in pyridine by the same procedure to obtain the weight of pyridine insolubles. 
Conversions wire calculated on an MAF coal + residuum basis according to the formula:

$$
\% \text { conversion }=\frac{\mathrm{g} \text { mf coal }+ \text { residuum }-\mathrm{g} \text { insol. prod. residue }}{\mathrm{g} \text { maf coal }+\mathrm{g} \text { residuum }} \times 100
$$

As the residuum material is partially soluble in cyclohexane and almost totally soluble in toluene and pyridine, substantial "conversion" is observed for the unreacted feedstock. However, this definition does have the desirable feature of approaching $100 \%$ when all organic matter is solubilized.

The catalyst for these experiments was the Amocat $1 \mathrm{~A}$ (CoMo/Alumina) employed in the hydrotreating studies and discussed in Section II and III. Physical properties are compiled in Table 1 . The catalyst was presulfided with $\mathrm{CS}_{2} /$ heavy mineral oil according to the procedure of Table 10. After presulfiding, creosote oil only is fed to the uitit to displace the mineral oil and to help take the edge off the catalyst. During this period reaction conditions are maintained at $750^{\circ} \mathrm{F}, 2000 \mathrm{psig}$, WHSV $=1$ and $\mathrm{H}_{2}$ treat rate $=5000$ scf/bbl. After about 20 hours of hydrotreating creosote oil, the reactor is brought to $800^{\circ} \mathrm{F}$, coal paste is cut in, and the unit is set to the desired operating conditions. At the completion of a rin, the coal paste feed is cut off, and the unit is allowed to process creosote oil overnight to wash solids and heavy residue materials from the reactor.

The used catalysts were routinely Soxhlet extracted in tetrahydrofuran under an argon atmosphere, air dried, and finally vacuum dried at $105^{\circ} \mathrm{C}$. A portion of the used extracted catalyst is then fired in a muffle furnace at $500^{\circ} \mathrm{C}$ to obtain the loss on ignition and the percent catalyst recovery. 


\section{Results}

A brief description of the ZTJ series of coal liquefaction runs is presented in Table 26. As indicated, the first four runs were plagued with plugs primarily in the inlet and outlet lines to the reactor. Problems were also experienced with the extractions. Beginning with Run ZTJ06, operation of the reactor was generally satisfactory. As a whole this series of runs established the effects of solvent/coal ratio, space velocity, stirrer speed and temperature on conversion level so that a set of conditions could be selected for the deactivation run. Two successiul deactivation runs were completed, Runs ZTJ06 and ZTJ09; however, the extractions were considered to be unreliable with the former. Run ¿i'J08 provided information on thermal conversion. Finally, regenerated catalyst from two ten day runs was evaluated in Run ZTJ14.

\section{Run ZTJ01:}

The ZTJ01 runs were conducted at nominal $800^{\circ} \mathrm{F}, 2000$ psig, a Weight Hourly Space Velocity (WHSV) of $1 \mathrm{gm} \mathrm{coal} / \mathrm{hr} / \mathrm{gm}$ catalyst and a Hydrogen Treat Rate (HTR) of 4000 scf/bbl of coal paste plus makeup solvent. The solvent to coal ratio was varied from $4: 1$ initially to $3: 1$ and finally to $2: 1$.

A run summary is presented in Table 27. The first balance period, ZTJ01-01, was completed with creosote oil feed. Coal paste was cut in at this point and the makeup solvent rate was adjusted to give a solvent (creosote oil + residuum) to coal (as received) ratio of 4:1. Two balance periods, Runs ZTJ01-02 and ZTJ01-03, were completed at these conditions with no operability problems. After completion of Run ZTJ03-03 the makeup solvent rate was lowered to give a nominal 3:1 solvent to coal ratio. A plug developed soon 
Table 26. Description of ZTJ Run Series

\begin{tabular}{|c|c|c|c|}
\hline $\begin{array}{l}\text { Run } \\
\text { ID }\end{array}$ & $\begin{array}{c}\text { Duration } \\
\text { (hrs) }\end{array}$ & Purpose & Remarks \\
\hline ZTJ01 & 115 & Effect of Solvent/Coal Ratio & Plugged in Inlet \\
\hline ZTJ02 & 71 & Effect of Solvent/Coal Ratio & Plugged in Outlet \\
\hline ZTJ03 & 7 & Effect of Space Velocity & Plugged \\
\hline ZTJ04 & 4 & Effect of Space Velocity & Plugged in Inlet \\
\hline ZTJ05 & 97 & Effect of Space Velocity & Temperature Controller Failed \\
\hline ZTJ06 & 241 & Deactivation Run & Unreliable Extractions \\
\hline ZTJ07 & 73 & Thermal Run & Unreliable Extractions \\
\hline ZTJ08 & 73 & Thermal Run & Successful \\
\hline ZTJ09 & 245 & Deactivation Run & Successful \\
\hline ZTJ10 & 48 & Effect of Stirrer Speed & $\mathrm{H}_{2}$ Leak \\
\hline ZTJ11 & 245 & Effect of Stirrer Speed & Successful \\
\hline ZTJ12 & 73 & Effect of Temperature & Successful \\
\hline ZTJ13 & 73 & Effect of Temperature & Successful \\
\hline ZTJ14 & $331^{(1)}$ & Regenerated Catalyst Run & Successful \\
\hline
\end{tabular}

(1) This run employed used, regenerated catalyst from Runs ZTJ06 and ZTJ09. 
Table 27

Run ZTJ01 Summary, 5.0045 gm Amocat 1A

Run Summary:

Yield Period No.

Yicld Period Length, hr

A:crage Temperature, $F$

Average Pressure, psig

Sitirrer Speed, rpm

Makcup Solvent Feed Rate, gm $/ \mathrm{hr}$

Coal Paste Rate, $\mathrm{gm} / \mathrm{hr}$

Residence Tïme, hr

$\begin{array}{cc}1 & 2 \\ 4.0 & 4.0 \\ 796 & 811 \\ 1995 & 1997 \\ 1205 & 1205 \\ 10.13 & 14.92 \\ 0.000 & 9.996 \\ 5.701 & 2.409\end{array}$

3

4.0

802

1991

1205

15.08

9.996

2.394

Space Velocities:

(iM Coal/Hr/GM Cat

(iM Dry Coal/Hr/GM Cat

GM MAF Coal/Hr/GM Cat

GM MAF Coal/Hr/CC Cat

I. $\mathrm{B} \mathrm{MAF} \mathrm{Coal} / \mathrm{Hr} / \mathrm{CUFT}$ Cat

Solvent/Coal Wt Ratios:

(iM CO/GM Coal

GM CO+Resid/GM Coal

(iM CO/GM Dry Coal

(iM CO+Resid/GM Dry Coal

(iM CO/GM MAF Coal

(IM CO+Resid/GM MAF Coal

$\mathrm{H}_{2}$ Trcat Rate, L(SIP)/Hr

$\mathrm{II}_{2}$ Treat Rate, SCF/BBL

Iixit Gas Ratc, L(STP)/Hr

Cumulative Quanitites:

Ilours on Catalyst

Wt Makcup Solvent/Wt Cat

WI Resid/Wt Cat

Wt Coal/Wt Cat

()verall Material Balance ${ }^{\circ}$ Wt\%

0.000

0.000

0.000

0.000

0.000

0.999
0.756
0.707
0.391
34.48

0.999

0.756

0.707

0.391

34.48

$\begin{array}{cc}4 & 5 \\ 4.0 & 4.0 \\ 802 & 801 \\ 1976 & 1991 \\ 1205 & 1205 \\ 10.22 & 10.15 \\ 9.996 & 9.996 \\ 2.997 & 3.008\end{array}$

0.999

0.756

0.707

0.391

34.48

0.999

0.756

0.707

0.391

34.48

$\begin{array}{ccccc}\text { N/A } & 3.653 & 3.683 & 2.712 & 2.697 \\ \text { N/A } & 3.986 & 4.016 & 3.046 & 3.031 \\ \text { N/A } & 4.829 & 4.868 & 3.585 & 3.566 \\ \text { N/A } & 5.269 & 5.309 & 4.026 & 4.006 \\ \text { N/A } & 5.161 & 5.203 & 3.832 & 3.811 \\ \text { N/A } & 5.632 & 5.674 & 4.303 & 4.282 \\ & & & & \\ 8.18 & 15.90 & 15.90 & 12.53 & 12.53 \\ 4920 & 4042 & 4017 & 3961 & 3977 \\ 4.75 & 12.34 & 12.75 & 9.60 & 10.31\end{array}$

Y'iclds (TOT Feed Basis):

Carbon Monoxide, Wi\%

Carbon Dioxide, Wt\%

llydrocarbon Gases $\left(C_{1}-C_{4}\right)$, Wi\%

Slurry Product, $\mathrm{Wt} \%$

44.5

85.5

0.0

0.0

95.3

12.34

12.75

9.60

10.31

$\mathrm{I}_{2}$ Consumption (TOT Feed Basis), Wt\%

0.00

0.00

1.81

97.1

68.4

153.6

7.1

21.3

92.4

225.9

116.4

278.6

140.4

15.1

22.8

327.5

45.4

68.4

30.8

92.5

101.2

100.7

101.2

101.1

4.27

0.08

0.00

1.80

101.7

2.26

0.10

1.96

100.8

2.15

0.11

0.06

2.50

100.9

0.10

0.09

100.7

Conversions (MAF Coal + Resid Basis):

$\%$ Cyclohexane Soluble

\% Toluene Soluble

N/A

91.8

93.6

N/A

94.9

92.2

93.8

95.3

2.25

2.13

- Does not include $\mathrm{NH}_{3}, \mathrm{H}_{2} \mathrm{~S}$ and $\mathrm{H}_{2} \mathrm{O}$ in exit gas. 
afterwards, but the plug was broken by lowering the accumulator pressure to $1500 \mathrm{psi}$ for a brief period. Two balance periods, Runs ZTJ01-04 and 2'TJ01-05, were completed at the 3:1 ratio, and the makeup solvent rate was again lowered to a nominal 2:1 solvent to coal ratio. Operation was initially smooth at those conditions, but a plug developed overnight and the unit was shut down the next morning.

Inspection of the reactor contents after cooling revealed that the liquid was of low viscosity and little solid matter remained inside the vessel. The catalyst basket and screens were clean. However, the plug which formed in the inlet line had to be drilled out. The arrangement of the inlet manifold was such that hydrogen was contacted with coal paste prior to the introduction of creosote oil. It was surmised that the hydrogen may have stripped volatiles from the coal paste thus forming a plug. In subsequent runs the creosoie oil was injected into the feed line before the hydrogen.

Overall material balances are quite good. Note should be made of the fact that our extraction procedures were not quite worked out during the early liquefaction runs. In contrast to the procedure described above, the contents of the accumulator were washed directly into the extraction thimble, i.e. without dilution, using cyclohexane. Some material was observed to ooze through the thimble, and consequently the solvent conversions reported in Table 27 may be a bit high.

\section{Run ZTJ02:}

The objectives of this run were the same as those of the previous ilin. Startup was identical to that of Run ZTJ01 except that the solvent:coal ratio was set at 2:1 upon introduction of coal paste. Operation was good for two days on coal paste; however, the 
unit plugged on the third day. The reactor was under observation when the plug first formed and after several unsuccessful attempts to break the plug by lowering accumulator pressure the unit was shut down. While cooling the reactor, the stirrer froze due to solids buildup in the bearings. Solids were also present in the reactor and around the catalyst basket. Plugs had formed in both the inlet and outlet lines. The presence of solids in the reactor and the absence of same in the previous run suggests that the initial plug may have formed in the outlet line. The outlet plug was hard and had to be drilled out.

A run summary is provided in Table 28. Again, material balances are good. The same extraction procedures were used as in Run ZTJ01, so the conversions may again be somewhat high.

\section{Run ZTJ03:}

Several modifications were made to the unit after Run ZTJ02. The insulation on the bottom of the reactor was removed to eliminate the possibility that a hot spot may have caused plugging of the outlet line. Secondly the feed manifold was modified to permit mixing of the hydrogen and creosote oil before combining with the coal paste. Finally a high pressure cut off switch was added to sense the pressure increase that accompanies plug formation so that the unit will shut down automatically.

This was to have been a repeat of Run ZTJ02 but at a higher WHSV of $2 \mathrm{gm}$ $\mathrm{coal} / \mathrm{hr} / \mathrm{gm}$ catalyst. Unfortunately the reactor plugged only seven hours after the introduction of coal paste. The reactor was clean upon inspection, and neither the inlet nor the outlet line was severely plugged. The precise point of plugging could not be ascertained. No balance periods were completed for this run. 
Table 28

Run ZTJ02 Summary, 5.0028 gm Amocat 1A

Run Summary:

Yicld Period No.

Yield Period Length, hr

Average Temperature, $\mathbf{F}$

Average Pressure, psig

Stirrer Speed, rpm

Makcup Solvent Feed Rate, gm/hr

Coal Paste Rate, $\mathrm{gm} / \mathrm{hr}$

Residence Time, hr

$\begin{array}{ccc}1 & 2 & 3 \\ 4.0 & 6.0 & 6.0 \\ 799 & 804 & 803 \\ 1992 & 1994 & 1996 \\ 1205 & 1205 & 1205 \\ 9.75 & 4.97 & 5.08 \\ 0.000 & 9.996 & 9.996 \\ 5.921 & 4.122 & 4.088\end{array}$

Space Velocities:

GM Coal/Hr/GM Cal

GM Dry Coal/Lr/GM Cat

GM MAF Coal//Ir/GM Cat

GM MAF Coal/Hr/CC Cat

LB MAF COal/Hr/CUFI Cat

$\begin{array}{lcc}0.100 & 0.999 & 0.999 \\ 0.100 & 0.756 & 0.756 \\ 0.1000 & 0.707 & 0.707 \\ 0.1100 & 0.391 & 0.391 \\ 0.1000 & 34.49 & 34.49\end{array}$

Solvent/Coal Wt Ratios:

GM CO/GM Coal

GM CO+Resid/GM Coal

GM CO/GM Dry Coal

GM CO+Resid/GM Dry Coal

GM CO/GM MAF Coal

GM CO + Resid/GM MAF Coal

$\mathrm{II}_{2}$ Treat Rate, $\mathrm{L}(\mathrm{SIP}) / \mathrm{Hr}$

$\mathrm{II}_{2}$ Treat Rate, SCF/BBL

Exit Gas Rate, L(STP)/Hr

$N_{/}^{\prime} A$

$N / A$

$N / A$

$N / A$

N/A

N/A

B.18

5.109

1.74

1.660

1.994

2.194

2.635

2.345

2.817

1.683

2.017

2.225

2.666

2.378

2.850

Cumulative Quanitites:

Hours on Catalyst

Wt Makeup Solvent/Wt Cat

Wt Resid/Wt Cat

Wt Coal/Wi Cat

$\begin{array}{ll}9.22 & 9.22\end{array}$

$4009 \quad 3975$

$6.21 \quad 6.86$

Overall Material Balance', Wi\%

0.0

102.9

47.6

59.5

101.3

Yields (TOT Feed Basis):

Carbon Monoxide, Wt\%

0,00

0.12

0.14

0.00

1.91

0.10

0.16

Ilydrocarbon Gases $\left(C_{1}-C_{4}\right)$, Wt\%

101.1

3.57

4.02

Slurry Product, Wt\%

3.62

2.91

2.48

Conversions (MAF Coal + Resid Basis):

$\%$ Cyclohexane Soluble

$\%$ Toluene Soluble

$\%$ Pyridine Soluble

N/A

84.8

85.7

N/A

87.1

87.4

N/A

89.2

89.6

- Does not include $\mathrm{NH}_{3}, \mathrm{H}_{2} \mathrm{~S}$ and $\mathrm{H}_{2} \mathrm{O}$ in exit gas. 


\section{Run ZTJ04:}

This was to have been a repeat of the failed Run ZTJ03, but again the reactor plugged in the inlet forcing termination before a balance period could be completed.

\section{Run ZTJ05:}

It was apparent at this point that a more drastic action was needed to solve the plugging problem. A new reactor inlet was drilled to the side of the central inlet port. (The central inlet port had served the dual role of thermocouple port and feed inlet by means of a heat exchanger tee arrangement.) The new inlet inside diameter was increased from $1 / 4$ inch to $3 / 8$ inch. But more importantly perhaps, air was directed to the inlet and outlet lines to provide cooling. Plugging problems were greatly reduced after this modification.

Three balance periods were completed after introduction of coal, Table 29. Run ZTJ05-01 operated at a coal WHSV of 1; whereas, the space velocity was doubled for Runs ZTJ05-02 and ZTJ05-03. The reactor temperature controller failed after the third balance period and the unit had to be shut down.

\section{Run ZTJ06:}

Except for an elevated temperature during the 9th balance period, the unit operated smoothly. The ten day run was completed, and the unit was shut down as planned. The run summary is presented in Table 30.

Unfortunately, the extractions were not as successful. The accumulator contents were erroneously washed in cyclohexanone instead of cyclohexane. Although the extractions were conducted in the correct sequence with the correct solvents (cyclohexane, toluene and 
Table 29

Run ZTJ05 Summary, 5.0001 gm Amocat 1A

Run Summary:

Yicld Period No.

Yield Poriod Length, hr

Average Temperature, $\mathrm{F}$

Averago Pressure, psig

Siltrer Speed, rpm

Makcup Solvent Rate, $\mathrm{gm} / \mathrm{hr}$

Coal Paste Rate, $\mathrm{gm} / \mathrm{hr}$

Residence Time, hr

$\begin{array}{ccc}1 & 2 & 3 \\ 4.0 & 2.0 & 2.0 \\ 801 & 801 & 801 \\ 1989 & 1980 & 2002 \\ 120.5 & 1205 & 120.5 \\ 10.00 & 20.40 & 20.10 \\ 10.01 & 20.02 & 20.02 \\ 3.030 & 1.499 & 1.511\end{array}$

Space Velocities:

GM Coal/Hr/OM Cat

(IM Dry Coal/Hr/GM Cat

(IM MAP Coal/Hr/GM Cat

CIM MAF Coal/IIr/CC Cat

LB MAP Coal/Hr/CUFI Cat

Solvent/Coal Wt Ratios:

(JM CO/GM Coal

GM CO/GM Dry Coa!

CiM CO+Resid/GM Dry Coal

GM CO/GM MAF COII

II, 'Treat Rate, L(SIP)/Hr

$\mathrm{II}_{2}$ 'Treal Rate, SCF/BBBL

lixit Cas Ratc, L(STP)/Hr

Cumulative Quantitles:

Ilours on Catalyst

WI Makcup Solvent/Wt Cat

WI Resid/Wi Cat

Wt Coal/Wt Cat

Overall Material Balance', Wi\%

Yields (TO'T Iced Basis):

Carton Monoxide, Wt\%

Carbon Dloxide, Wt\%

Ilydrocarbon Gases $\left(\mathrm{C}_{1}-\mathrm{C}_{4}\right)$, Wt\%

Slurry Product, WI\%

$\mathrm{H}_{2}$ Consumption (IO'T reed Basis), W/\%

Converstons (MAY Coal + Resid Babin):

Wi\% Cyclohexane Soluble

WI\% Toluene Soluble

- Does not include $\mathrm{NH}_{3}, \mathrm{H}_{2} \mathrm{~S}$ and $\mathrm{H}_{2} \mathrm{O}$ in exit gas.

$\begin{array}{ll}88.8 & 87.3 \\ 89.0 & 87.5 \\ 90.0 & 89.5\end{array}$


Table 30

Run ZTJ06 Summary, 5.0022 gm Amocat 1A

Run Summary:

Yicid Period No.

Yileld Period length, hr

Average 'Temperature, $F$

Average Pressure, psig

stirrer Speed, rpm

Makeup Solvent Rate, gm/hr

Coal Paste Rate, gm/hr

Residence 'l'lme, hr

$\begin{array}{cc}1 & 2 \\ 2.0 & 2.0 \\ 799 & 801 \\ 2000 & 2000 \\ 120.5 & 1205 \\ 19.85 & 20.20 \\ 20.02 & 20.02 \\ 1.521 & 1.507\end{array}$

3

- 2.0

801

2000

1205

20.30

20.02

1.503

\section{4}

2,0

801

2010

120.5

20.35

20.02

1.501

Space Velocities:

(iM Coal/Hr/GM Cat (iM Dry Conl/Hr/GM Cal (IM MAIi Coal/HIr/GM Cat (iM MAli Coal/Hr/CC Cal

l.1) MAI Coal/Hr/CUMT Cat

$\begin{array}{rr}2.001 & 2.00 \\ 1.514 & 1.51 \\ 1.416 & 1.41 \\ 0.783 & 0.783 \\ 48.89 & 48.89\end{array}$

2.001

1.514

1.416

0.783

48.89

\subsection{1}

1.514

1.416

0.78 .3

48.89

$$
\begin{aligned}
& 2 .(x) 1 \\
& 1.514 \\
& 1.416 \\
& 0.78 .3 \\
& 48.89
\end{aligned}
$$

Solvent/Coal WI Ratlos:

(iM CO/GM Coal

(iM CO+Resld/GM Coal

(iM CO/GM Dry Coal

(iM CO+Resid/GM Dry Coal

(IM CO/CMM MAF Coal

GM CO+Resid/GM MAF' Coal

$\begin{array}{ll}2.650 & 2.685 \\ 2.983 & 3.018 \\ 3.503 & 3.549 \\ 3.944 & 3.990 \\ 3.744 & 3.793 \\ 4.215 & 4.265\end{array}$

\subsection{5}

\subsection{8}

3.562

4.003

3.808

4.279

2.700

3.033

$2 .(6,6)$

3.569

$2 . \% 3$

4.010

3.516

3.957

$3.815 \quad 3.758$

$\mathrm{II}_{2}$ Ireal Rutc, L(SIP)/Hr

25.05

$\mathrm{II}_{2}$ I'real Rate, SCF/BBL.

Iixit Cas Ratc, I,(SIP)/Hr

4021

25.05

25.05

4.286

4.229

16.51

3985

3974

$25.05 \quad 25,05$

$3969-4011$

Cumulative Quantities:

Ilours on Catalyst"

WI Makcup Solvent/Wt Cat

WI Resid/WI Cat

WI Coal/Wt Cat

Overall Material Balance', Wt\%

Yiclds (I'O'I Feed Basis):

Carbon Monoxide, Wi\%

Carbon Dioxide, Wi\%

llydrocarbon Gases $\left(C_{1}-C_{4}\right), W 1 \%$

100.2

Conversions (MAF Coal + Resid Basis):

Wi\% Cyclohexane Soluble

WI\% Toluene Soluble

WI\% Pyridine Soluble

-. Does not include $\mathrm{NH}_{3}, \mathrm{I}_{2} \mathrm{~S}$ and $\mathrm{H}_{2} \mathrm{O}$ in exit gas.

- Prehydrotreating Run Hours: 20 
Table 30 (continued)

Run ZTJ06 Summary, 5.0022 gm Amocat 1A

Run Summary:

Yield Period No.

Yicld Period Length, hr

Average Temperature, $\mathbf{F}$

Average Pressure, psig

Stirrer Speed, rpm

Makcup Solvent Rate, gm/hr

Coal Paste Rate, gm/hr

Residence Time, hr

$\begin{array}{cc}6 & \\ 2.0 & \\ 800 & 8 \\ 2000 & 2000 \\ 1205 & 1205 \\ 20.30 & 20.1 \\ 20.02 & 20 \\ 1.503 & \end{array}$

$7 \quad 8$

8
2.0

801

801

2010

1205

20.25

20.15

20.02

20.02

1.505

9

10

2.0

2.0

$812-801$

$2000 \quad 1990$

$1205 \quad 1205$

$20.20 \quad 19.60$

$20.02 \quad 20.02$

Space Velocities:

(iM Coal/Hr/GM Cat

GM Dry Coal/Hr/GM Cat

GM MAF Coal/Hr/GM Cat

(iM MAF Coal/Hr/CC Cat

LIB MAF Coal/Hr/CUF' Cat

2.001

1.514

1.416

0.783

48.89

\subsection{1}

1.514

1.416

0.783

48.89

\subsection{1}

1.514

1.416

0.783

48.89

1.507

1.531

Solvent/Coal Wt Ratlos:

(IM CO/GM Coal

CiM CO+Resid/GM Coal

(JM CO/GM Dry Coal

GM CO+Resld/GM Dry Coal

GM CO/GM MAF Coal

GM CO+Resid/GM MAF Coal

$\mathrm{H}_{2}$ Ireat Rate, $\mathrm{I}(\mathrm{STP}) / \mathrm{Hr}$

$\mathrm{II}_{2}$ 'Treal Rate, SCF/BBL

25.05

lixil Gas Rate, $\mathrm{L}(\mathrm{SIP}) / \mathrm{Hr}$

Cumulative Quantities:

25.05

Ilours on Catalyst"

Wt Makeup Solvent/Wt Cat

Wt Resid/Wt Cat

WI Coal/Wt Cat

Overall Material Balance', Wi\%

143.1

618.6

93.6

280.9

102.7

Yields (TOT Feed Basis):

Carbon Monoxide, WI\%

Carbon Dioxide, Wt\%

llydrocarbon Gases $\left(C_{1}-C_{4}\right)$, Wt\%

Slurry Product, Wt\%

$\mathrm{II}_{2}$ Consumption (TOT Feed Basis), Wt\%

Conversions (MAF Coal + Resid Basis):

Wt\% Cyclohexane Soluble

Wi\% Toluene Soluble

Wt\% Pyridine Soluble

- Does not include $\mathrm{NH}_{3}, \mathrm{H}_{2} \mathrm{~S}$ and $\mathrm{H}_{2} \mathrm{O}$ in exit gas.

- Prehydrotreating Run Hours: 20

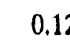

0.37

1.36

103.4

2.24

74.0

81.4

73.6
81.7 
pyridine), the initial washing in cyclohexanone no doubt solubilized some cyclohexane insoluble material.

While the product conversions are of questionable validity, the analysis of the used catalyst was in no way affected.

\section{Run ZTJ07:}

This was a thermal run at $800^{\circ} \mathrm{F}, 2000 \mathrm{psig}$, a solvent/coal weight ratio of $3: 1$, a hydrogen treat rate of $4000 \mathrm{scf} / \mathrm{bbl}$ and at feedrates corresponding to a WHSV of 2 . The catalyst was however replaced with an equal volume of $3 \mathrm{~mm}$ diameter glass beads. The usage of the incorrect wash solvent was actually discovered during this run, hence no workup of the data was attempted.

\section{Run ZTJ08:}

This was a repeat of the thermal Run ZTJ07. Problems with the wash solvent and the extractions were remedied. Three balance periods were completed, and the results recorded in Table 31 may be considered reliable.

\section{Run ZTJ09:}

Run ZTJ09 was a deactivation run at nominal $800^{\circ} \mathrm{F}, 2000$ psig, HTR $=4000$ $\mathrm{scf} / \mathrm{bbl}, \mathrm{WHSV}=2$ and a solvent/coal weight ratio of 3 . This was a repeat of Run ZTJ06. The unit operated smoothly for the entire ten balance periods. No problems were experienced with the extractions. The run summary is provided in Table 32. Overall material balances were within the range $98 \cdot 102 \%$. 


\section{Table 31}

Run ZTJ08 Summary, Thermal Run With 14.6363 GMS 3mm Glass Beads The Same Solid Volume as 4.9987 GMS of Amocat 1A Catalyst

\begin{tabular}{|c|c|c|c|}
\hline \multicolumn{4}{|l|}{ Run Summary: } \\
\hline Yleld Period No. & 1 & 2 & 3 \\
\hline Yicld Period Length, hr & 2.0 & 2.0 & 2.0 \\
\hline Average Temperature, $\mathrm{F}$ & 800 & 800 & 796 \\
\hline Average Pressure, psig & 2000 & 2000 & 1990 \\
\hline Stirrer Speed, rpm & 1205 & 1205 & 1205 \\
\hline Makcup Solvent Rate, gm/hr & 20.40 & 20.25 & 20.30 \\
\hline Coal Paste Rate, $\mathrm{gm} / \mathrm{hr}$ & 20.02 & 20,02 & 20,02 \\
\hline Residence Time, hr & 1.499 & 1.505 & 1.503 \\
\hline \multicolumn{4}{|l|}{ Solvent/Coal Wi Ratios: } \\
\hline GM CO/GM Conl & 2.705 & 2.690 & 2.695 \\
\hline GM CO+Resid/GM Coal & 3.038 & $3.02,3$ & 3,028 \\
\hline GM CO/GM Dry Coal & 3.576 & 3.556 & 3.562 \\
\hline GM CO + Resid/GM Dry Coal & 4,016 & 3.997 & 4,003 \\
\hline GM CO/GM MAF COal & 3.822 & 3,800 & 3,808 \\
\hline GM CO' Resid/GM MAF Coal & 4.293 & 4.272 & 4.279 \\
\hline $\mathrm{II}_{2}$ Treat Rate, L(SIP)/Hr & 25.05 & 25.05 & 25.05 \\
\hline $\mathrm{HI}_{2}$ Treat Rate, SCF/BBL & 3964 & 3979 & 3974 \\
\hline Lxit Gas Rate, L(SIP)/Hr & 25.09 & 25.47 & 25.75 \\
\hline Cumulative Hours on Catalyst & 21.5 & 46.0 & 68.9 \\
\hline Overall Material Balance ${ }^{\circ}, \mathrm{W} l \%$ & 98.5 & 98.1 & 97.8 \\
\hline \multicolumn{4}{|l|}{ Yields (TOT Feed Basis): } \\
\hline Carbon Monoxide, Wi\% & 0.14 & 0.15 & 0.15 \\
\hline Carbon Dioxide, WI\% & 1.01 & 1.05 & 1.05 \\
\hline Ilydrocartion Gases $\left(\mathrm{C}_{1}-\mathrm{C}_{4}\right), \mathrm{W}_{1} \%$ & 0.82 & 0.79 & 0.76 \\
\hline Slurry Product, Wt\% & 97.5 & 96.9 & 96.5 \\
\hline $\mathrm{II}_{2}$ Consumption (IO'T Feed Basis), Wt\% & 1.09 & 0.98 & 0.83 \\
\hline \multicolumn{4}{|l|}{ Conversions (MAF Coal + Resid Basis): } \\
\hline Wi\% Cyclohexane Soluble & 41.2 & 42.0 & 38.7 \\
\hline Wt\% T'oluene Soluble & $\$ 6.7$ & 58.8 & 52.3 \\
\hline Wi\% Pyridine Soluble & 64.9 & 64.4 & 61.7 \\
\hline
\end{tabular}

\footnotetext{
Does not include $\mathrm{NH}_{3}, \mathrm{H}_{2} \mathrm{~S}$ and $\mathrm{H}_{2} \mathrm{O}$ in exit gas.
} 
Table 32

Run ZTJ09 Summary, 5.001 gms Amocat 1A

RuII Summary:

Ylald puriod No,

Yickl Poriod length, hr

Avorago Temperalure, $"$

Average Mrossure, psig

Silirer Speod, rpm

Makcup Solvent Rato, gm/ hr

(cal Paste Rate, gm/hr

Residence 'Ilme, his

Sipace Volocitles:

(IM C.oat/ $/ \mathrm{Hr} / \mathrm{CIM}$ Cat

(IM I)ry Coal/IIr/CMM Cat

(IM MAI Coal/1Ir/CIM Cal

(IM MAIi Conl/Hr/CC Cal

l.1) MAli Coal/lltr/C.UFl Cal

Siolvent/Coal Wt Ratlos:

(IM CO/OM Coal

(iM CO + Rosid/OM Coal

(iM CO/CIM Dry Coal

(IM COC + Resid/GM Dry Coal

(iM $(C) /$ GM MAY Coal

(iM (C) + Resid/GM MAl' Coal

$\mathrm{II}_{2}$ 'Ireat Rute, I.(SIP)/IIr

II Ireal Rate, SCW/BBL.

I'xil (Jas Rate, l,(SIP)/IIr

C'umblative Quantilies:

Ilours on Calalyst"

WI Makcup Solvent/Wt Cal

WI Residl/WI Cat

WI Conl/Wi Cat

Oucrall Malerial Balance', WI\%

Yickds ('IO'T' ficed Basls):

Carbon Monoxide, Wi\%

Carbon Dioxlde, WI\%

Iyclrocarton Cases $\left(C_{1}-C_{4}\right), W 1 \%$

Sllurry Producl, Wi\%

$\mathrm{II}_{2}$ Consumplion (TO'T liced Basls), WI\%

(onversions (MAF Conl + Resid l3asis):

WI\% C'ycluhexane Soluble

WI\% l'oluene Soluble

WI\% Pyridine Soluble

- Does nol include $\mathrm{NII}_{3}, \mathrm{H}_{2} \mathrm{~S}$ and $\mathrm{H}_{2} \mathrm{O}$ In exil gas.

" Prehydrotrealing Run Hlours: 19

\begin{tabular}{|c|c|c|c|c|}
\hline 1 & 2 & 3 & 4 & .5 \\
\hline 2.0 & 2,0 & 2,0 & 2.0 & 2,0 \\
\hline 802 & 801 & 8012 & 802 & 790 \\
\hline $1 \times 90$ & 1990 & $19 \times 0$ & $20(X)$ & {$[(x)$} \\
\hline 1205 & 1205 & 1205 & 1205 & 120.5 \\
\hline 20,40 & 20,40 & 20,35 & 20,30 & 20.20 \\
\hline 20.02 & 20,02 & 20,02 & 20,02 & 20,02 \\
\hline 1.499 & 1.490 & 1.501 & 1.50 .3 & $1.50 \%$ \\
\hline
\end{tabular}

$\begin{array}{ccccc}2.001 & 2.001 & 2.001 & 2.001 & 2.001 \\ 1.514 & 1.514 & 1.514 & 1.514 & 1.511 \\ 1.416 & 1.416 & 1.416 & 1.416 & 1.416 \\ 0.783 & 0.783 & 0.78 .3 & 0.78 .3 & 10.78 .3 \\ 48.91 & 48.91 & 48.91 & 48.91 & 18.91\end{array}$

2.705

3,038

3.576

4.016

3.822

4,293

25.05

3964

18.47

24.5

137.0

15.9

47.6

100.4

0.13

0.16

1.29

101.4

2.50)

81.0

84,6

88.4
2.705

3.038

3.576

4.016

3.822

4.293

25.05

3064

19.43

49.5

2.37 .9

34.2

102.5

100.2

0.15

0.33

1.37

100.9

2.50

78.3

80.3

83.8
2.700

$3,03,3$

3.569

4.010

$3,81.5$

4.286

25.05

$3(0)$

20.68

73.0

3.32 .2

49.7

149.0

100.2

97,0

429,6

65.5

$1 \%, 4$

$1(12.1$
2.6855

3,018

3.541

$3,5(0)$

3.793

4.261

25,015

3985

21.53

121.0

527.1

81.1

243.4

101.4 
Table 32 (continued)

Run ZTJ09 Summary, $5.001 \mathrm{gms}$ Amocat 1A

Run Sunimary:

Ylold Poriod No,

Yleld l'orlod Longth, hr

Avorago 'I'omporature, II

Averago Prosuture, psilg

Sillrror Spood, rpm

Mukoup Solvent Rato, gm/ hr

Coul Pasio Rulo, gm/hr

Rosidenco 'Ilme, hr

$\begin{array}{cc}6 & 7 \\ 2.0 & 2.0 \\ 7 \% 6 & 801 \\ 2000 & 2000 \\ 1205 & 1205 \\ 20.20 & 20.25 \\ 20.02 & 20.02 \\ 1.507 & 1.505\end{array}$

8

- 2.0

801

2000

1205

20.30

20.02

1.503

9

2.0

803

1990

1205

20.55

20,02

1.494

10

2.0

804

$1 \% 0$

120.5

20,40

20,02

1,490

Spaco Volocilles:

(IM Coal/11r/CMM Cal

(IM Dry Coal/Hr/OM Cal

(IM MAP' Coal/Hr/CIM Cat

(IM MAI' Coal/11r/CC Cal

IB MAP Coal/Hr/CUIT' Cal

1.416

0.783

48.91

\subsection{1}

1.514

1,416

0.783

48.91

2.001
1.514
1,416
0,783
48,91

2.001

1.514

1,416

$0,78.3$

48,91

2.001

1.514

1.416

0.783

48.91

Solvont/Cosal WI Rullos:

(IM CO/OM Coal

CIM CO+Resid/CMM Coal

(IM CO/CIM Dry Coal

(IM CO+Reuld/OM Dry Coral

GM CO/OM MAP COAI

CM CO+ Resid/CM MAFi Coal

$\mathrm{II}_{2}$ 'Ireat Halo, L.(STP)/IIr

II $_{2}$ 'Ireat Rato, SCW/IJBII.

Iixli Clas Rale, I.(SIP)/IIr

C'umulatlve Quanillies:

Ilours on Catalyst"

WI Makoup Solvent/WI Cat

Wi Resid/Wi Cat

WI Coal/Wt Cal

Overall Mulorial Balanco', WI\%

Ylelds (I'O'I Pend Basis);

Carbon Monoxido, WI\%

Carbon Dioxido, Wi \%

Ilydrocartoon Clases $\left(\mathrm{C}_{1}-\mathrm{C}_{4}\right)$, Wi\%

Slurry Producl, Wt\%

$\mathrm{II}_{2}$ Consumption ('TO'I' Fecd Basis), WI\%

Convorsions (MAl' Cosal + Resid Basis):

Wi\% Cyclohexano Soluble

Wi $\%$ 'olueno Soluble

WI\% Pyridino Solublo

- Does not linclude: $\mathrm{NI}_{3}, \mathrm{H}_{2} \mathrm{~S}$ and $\mathrm{H}_{2} \mathrm{O}$ in exit gas.

" Prehydrotranting Run Hours: 19
101,9

102,1

98.7

99.1 


\section{Run ZTJ10:}

The purpose of Run ZTJ10 was to test for possible effects of stirrer speed on conversion. Run conditions were again $800^{\circ} \mathrm{F}, 2000 \mathrm{psi}, 4000 \mathrm{scf} / \mathrm{bbl}, \mathrm{H}_{2}$ treat rate coal WHSV $=2$ and solvent $/$ coal weight ratio $=3: 1$. Only one balance period on coal was completed. The stirrer speed was set at $1650 \mathrm{rpm}$. The results are reported in Table 33 . Shortly after the completion of this balance period, or 48 hours into the run, a leak developed in a valve in the hydrogen reservoir. This forced a sinutdown of the unit.

\section{Run ZTJ11:}

Run conditions were the same as the previous Run ZTJ10. Operation seemed normal during the first four balance periods on coal. On the fifth day during balance period ZTJ11-05 the reactor temperature dropped suddenly from $801^{\circ} \mathrm{F}$ to $795^{\circ} \mathrm{F}$. The shell temperature was raised just slightly at the end of the balance period to bring the temperature back to $800^{\circ} \mathrm{F}$. Similar observations were made on the sixth and seventh days. In addition a momentary halt of the stirrer was observed on the seventh day when the feed to the accumulators was switched. belt dressing was applied to the stirrer drive and no further seizing of the stirrer occurred. However, operation of the impeller seemed noisier than usual. The unit was nursed through the entire ten balance periods and the results are compiled in Table 34.

Inspection of the reactor contents at run termination revealed that the catalyst basket was badly coked. The catalyst particles were cemented together. About two thirds of the annular space surrounding the basket was also plugged. 
Table 33

Run ZTJ10 Summary, 5.0004 gms Amocat 1A

Run Summary:

Yicld Poriod No. 1

Yleld Period Length, hr

Average 'T'emperature, $P$

801

Average Pressure, psig

2000

Silrror Speed, rpm

1650

Makoup Solvent Rate, $\mathrm{gm} / \mathrm{hr}$

20.25

Coal P'aste Rate, gm/hr

20.02

Residence Time, hr

Space Velocities:

GM Coal/Hr/GM Cat 2,001

GM Dry Coal// Ir/GM Cat

1.514

(IM MAP Coal/Hr/GM Cat

1.417

(iM MAF Coal/ $\mathrm{Hr} / \mathrm{CC}$ Cat

0.783

L.13 MAF Coal/Hr/CUIT Cat

48.91

Solvent/Coal Wt Ratlos:

GM CO/GM Coal

CiM CO+Resid/GM Coal 3.023

(IM CO/GM Dry Coal $\quad 3.556$

GM CO+Resid/GM Dry Coal $\quad 3.997$

GM CO/GM MAF Coal $\quad 3.800$

GM CO+Resid/GM MAli Coal $\quad 4.272$

$\mathrm{H}_{2}$ 'Ireat Rate, L(SIP)/Hr $\quad 25.05$

$\mathrm{H}_{2}$ 'l'real Rate, SCF/BBL 3979

Lxil Gas Rate, L.(STP)/Hr

Cumulative Quantities:

Ilours on Catalyst"

24.8

Wi Makeup Solvent/Wt Cat $\quad 136.4$

Wi Resid/Wt Cat $\quad 16.3$

Wi Coal/Wt Cat $\quad 49,0$

Overall Material Balance', Wi\% $\quad 100.7$

Ylelds (TO'T Feed Basis):

Carton Monoxide, Wt\%

Carton Dioxide, Wt\% $\quad 0.15$

Hydrocarbon Gases $\left(\mathrm{C}_{1}-\mathrm{C}_{4}\right), \mathrm{W} \%$

$\begin{array}{lr}\text { Slurry Product, WI\% } & 101.7\end{array}$

$\mathrm{H}_{2}$ Consumption (T'O'T Feed Basis), Wt\% 2.39

Conversions (MAF Coal + Resid Busis):

W1\% Cyclohexane Soluble $\quad 78,8$

Wi\% Toluene Soluble $\quad 82.5$

WI\% Pyridine Soluble $\quad 86.7$

- Does not include $\mathrm{NH}_{3}, \mathrm{H}_{2} \mathrm{~S}$ and $\mathrm{H}_{2} \mathrm{O}$ in exit gas.

" Prehydrotreating Run Hours: 19 
Table 34

Run ZTJ11 Summary, 5.0013 gms Amocat 1A

Run Summary:

Yield Period No.

Yicld Period Length, hr

Average Temperature, $F$

Average Pressure, psig

Slirrer Speed, rpm

Makcup Solvent Rate, gm/hr

Coal Paste Rate, $\mathrm{gm} / \mathrm{hr}$

Residence Time, hr

$\begin{array}{cc}1 & 2 \\ 2.0 & 2.0 \\ 802 & 801 \\ 2000 & 1990 \\ 1650 & 1650 \\ 20.25 & 20.30 \\ 20.02 & 20.02 \\ 1.505 & 1.503\end{array}$

3

$\begin{array}{cc}4 & 5 \\ 2.0 & 2.0 \\ 803 & 801 \\ 2000 & 2000 \\ 1650 & 1650 \\ 20.40 & 20.30 \\ 20.02 & 20.02 \\ 1.499 & 1.503\end{array}$

Space V'elocities:

GM Coal/Hr/GM Cat

GM Dry Coal/Hr/GM Cat

GM MAF Coal/Hr/GM Cat

GM MAF Coal/Hr/CC Cat

L.B MAF Cog!/Hr/CUFT Cat

Solvent/Coal Wt Ratios:

GM CO/GM Coal
GM CO+Resid/GM Coal
GM CO/GM Dry Coal
GM CO + Resid/GM Dry Coal
GM CO/GM MAF Coal
GM CO+ Resid/GM MAF Coal

$\mathrm{II}_{2}$ Treat Rate, I(STP)/Hr

$\mathrm{II}_{2}$ Treat Rate, SCF/BBL

Exit Gas Rate, L(STP)/Hr

Cumulative Quantities:

Ilours on Catalyst"

WI Makeup Solvent/Wt Cat

WI Resid/Wt Cat

Wi Coal/Wt Cat

Overall Material Balance', Wt\%

Yiclds (TOT Feed Basis):

Carbon Monoxide, Wt\%

Carbon Dioxide, Wi\%

Hydrocarbon Gases $\left(\mathrm{C}_{1}-\mathrm{C}_{4}\right)$, Wt\%

Slurry Product, Wt\%

$\mathrm{I}_{2}$ Consumption (TOT Peed Basis), Wi\%

Conversions (MAF Coal + Resid Basis):

Wt\% Cyclohexane Soluble

Wt\% Toluene Soluble

Wt\% Pyridine Soluble

82.4

85.5

88.2

- Does not include $\mathrm{NH}_{3}, \mathrm{H}_{2} \mathrm{~S}$ and $\mathrm{H}_{2} \mathrm{O}$ in exit gas.

"Prehydrotreating Run Hours: 19 
Table 34 (continued)

Run ZTJ11 Summary, 5.0013 gms Amocat 1A

Run Summary:

Yield Period No.

Yicld Period Length, hr

Average Temperalure, if

Average Pressure, psig

Stirrer Speed, rpm

Makeup Solvent Rate, $\mathrm{gm} / \mathrm{hr}$

Coal Paste Rate, $\mathrm{gm} / \mathrm{hr}$

Residence Time, hr

$\begin{array}{ccc}6 & 7 & 8 \\ 2.0 & 2.0 & 2.0 \\ 799 & 799 & 802 \\ 1990 & 2010 & 2020 \\ 1650 & 1650 & 1650 \\ 19.45 & 20.20 & 20.10 \\ 20.02 & 20.02 & 20.02 \\ 1.53 \% & 1.507 & 1.51\end{array}$

Space Velocities:

GM Coal/Hr/GM Cat

GM Dry Coal/Hr/GM Cat

GM MAF Coal// Ir/GM Cat

GM MAF Coal/Hr/CC Cat

L.B MAF Coal/IIr/CUFT Cat

Solvent/Coal Wt Ratios:

GM CO/GM Coal

GM CO+Resid/GM Coal

GM CO/GM Dry Coal

GM CO+Resid/GM Dry Coal

GM CO/GM MAF Coal

GM CO+Resid/GM MAF Coal

$\mathrm{II}_{2}$ 'Ireat Rate, L(SIT)/Hr

$\mathrm{II}_{2}$ Treat Rate, SCF/BBL

Lixit Gas Rate, L(STP)/Hr

Cumulative Quantities:

IIours on Catalyst"

Wt Makeup Solvent/Wt Cat

WI Resid/Wt Cat

Wt Coal/Wt Cat

Overall Material Balance', Wt\%

Yiclds (TO'T Feed Basis):

Carbon Monoxide, Wt\%

Carbon Dioxide, W1\%

Ilydrocarbon Gases $\left(\mathrm{C}_{1}-\mathrm{C}_{4}\right)$, Wt\%

Slurry Product, $\mathrm{W}_{\mathrm{t}} \%$

$\mathrm{II}_{2}$ Consumption (TOT Feed Basis), Wt\%

Conversions (MAF Coal + Resid Basis):

Wi\% Cyclohexane Soluble

WI\% Toluene Soluble

WI\% Pyridine Soluble

- Does not include $\mathrm{NH}_{3}, \mathrm{H}_{2} \mathrm{~S}$ and $\mathrm{H}_{2} \mathrm{O}$ in exit gas.

- Prehydrotreating Run Hours: 19

\begin{tabular}{|c|c|c|c|c|}
\hline 2.610 & 2.685 & 2.675 & 2.690 & 2.685 \\
\hline 2.943 & 3.018 & 3.008 & 3.023 & 3.018 \\
\hline 3.450 & 3.549 & 3.536 & 3.556 & 3.549 \\
\hline 3.891 & 3.990 & 3.977 & 3.997 & 3.990 \\
\hline 3.688 & 3.793 & 3.779 & 3.801 & 3.793 \\
\hline 4.159 & 4.265 & 4.250 & 4.272 & 4.26 .5 \\
\hline 25.05 & 25.05 & 25.05 & 25.05 & 25.05 \\
\hline 4064 & 3985 & 3995 & 3979 & 3985 \\
\hline 19.52 & 21.15 & 27.83 & 26.10 & 26.18 \\
\hline & • & & & \\
\hline 144.5 & 168.5 & 199.0 & 216.5 & 241.0 \\
\hline 104.7 & 89.8 & 43.5 & 113.9 & 212.4 \\
\hline 94.8 & 110.3 & 132.4 & 143.9 & 159.9 \\
\hline 284.4 & 330.7 & 397.1 & 431.6 & 479.5 \\
\hline 104.6 & 99.6 & 99.6 & 103.6 & 101.3 \\
\hline 0.00 & 0.00 & 0.00 & 0.00 & 0.00 \\
\hline 0.52 & 0.65 & 0.94 & 0.96 & 0.98 \\
\hline 1.15 & 1.12 & 0.82 & 0.89 & 0.90 \\
\hline 105.9 & 100.0 & 98.6 & 103.0 & 100.4 \\
\hline 2.56 & 2.17 & 0.71 & 0.92 & 0.86 \\
\hline 58.2 & 55.6 & 50.2 & 40.0 & 46.0 \\
\hline 68.3 & 67.4 & 63.2 & 50.9 & 58.9 \\
\hline 78.6 & 71.7 & 69.6 & 58.5 & 65.2 \\
\hline
\end{tabular}

2.001

1.514

1.416

0.783

48.90 


\section{Runs ZTJ12 and ZTJ13:}

The purpose of these two runs was to investigate the effect of temperature on conversion. Since run conditions, especially temperature, sometimes stray from target conditions, a correction to the conversions is needed. Run ZTJ12 was a short run of 73 hours on catalyst and at a temperature of $790^{\circ} \mathrm{F}$; whereas, Run ZTJ13 was also a 73 hour run but at the higher temperature of $810^{\circ} \mathrm{F}$. Both runs were at the nominal $2000 \mathrm{psig}$, coal WHSV of 2, HTR of $4000 \mathrm{scf} / \mathrm{bbl}$ and solvent/coal ratio $=3$. Operability was good during both runs. Run summaries are compiled in Tables 35 (Run ZTJ12) and 36 (Run ZTJ13).

\section{Run ZTJ14:}

The used catalyst from Runs ZTJ06 and ZTJ09 was extracted and an equal portion of each was combined and fired overnight (16 hours) in a muffle furnace at $500^{\circ} \mathrm{C}$ to burn coke off the catalyst. A charge of 6.41 grams (equivalent to 5.0 grams of deposit free catalyst) was then loaded into the reactor and a total of three balance periods was completed on the used "regenerated" catalyst. The run summary is provided in Table 37.

\section{Analysis and Discussion}

In Runs ZTJ01 and ZTJ02 the solvent/coal ratio was varied as temperature $\left(800^{\circ} \mathrm{F}\right)$, pressure (2000 psi), coal weight hourly space velocity $(1 \mathrm{~g} / \mathrm{hr} / \mathrm{g})$ and hydrogen treat rate (4000 scf/bbl) were held constant. Conversions are compared in Table 38 for solvent/coal weight ratios in the range $2: 1$ to $4: 1$. Higher solvent/coal ratios appear to enhance the conversions somewhat. Perhaps coal fragments are better dispersed in the presence of increased solvent, and this may serve to reduce retrograde reactions. The lower overall 
Table 35

Run ZTJ12 Summary, 5.0025 gms Amocat 1A

Run Summary:

Yicld Period No.

Yleld Period length, hr

Average Temperature, $F$

Average Pressure, psig

Stirrer Speed, rpm

Makeup Solvent Rate, $\mathrm{gm} / \mathrm{hr}$

Coal Paste Rate, gm/hr

Residence 'Time, hr

Spacc Velocities:

GM Coal/Hr/GM Cat

GM Dry Coal/Hr/GM Cat

GM MAF Coal/Hr/GM Cat

GM MAF Coal/Hr/CC Cat

L,B MAF Coal/Hr/CUFT Cat

$\begin{array}{ccc}1 & 2 & 3 \\ 2.0 & 2.0 & 2.0 \\ 789 & 789 & 790 \\ 2000 & 2000 & 2000 \\ 1205 & 1205 & 1205 \\ 20.35 & 20.20 & 20.25 \\ 20.02 & 20.02 & 20.02 \\ 1.501 & 1.507 & 1.505\end{array}$

Solvent/Coal W/ Ratios:

GM CO/GM Coal

GM CO + Resid/GM Coal

GM CO/GM Dry Coal

GM CO+Resid/GM Dry Coal

GM CO/GM MAF Coal

GM CO + Resid/GM MAF Coal

$\begin{array}{cc}2.001 & 2.001 \\ 1.513 & 1.513 \\ 1.416 & 1.416 \\ 0.783 & 0.783 \\ 48.89 & 48.89\end{array}$

$\mathrm{H}_{2}$ Treat Rate, L(STP)/IIr

$\mathrm{H}_{2}$ Treat Rate, SCF/BBL

Exil Gas Rate, L(STP)/Hr

Cumulative Quantities:

$\begin{array}{lll}25.05 & 25.05 & 25.05\end{array}$

$3969 \quad 3985 \quad 3979$

$\begin{array}{lll}18.85 & 19.08 & 20.37\end{array}$

IIours on Catalyst"

Wt Makcup Solvent/Wt Cat

Wt Resid/Wt Cat

Wt Coal/Wt Cat

Overall Material Balance', WI\%

24.5

132.2

16.4

49.1

100.7

Yiclds (IOT Feed Basis):

Carbon Monoxide, Wt\%

Carbon Dioxide, Wt\%

Hydrocarbon Gases $\left(C_{1}-C_{4}\right), W t \%$

Slurry Product, Wt\%

$\mathrm{H}_{2}$ Consumption (TO'T Feed Basis), Wt\%

Conversions (MAP Coal + Resid Basis):

Wt\% Cyclohexane Soluble

Wt\% Toluene Soluble

Wt\% Pyridine Soluble

- Does not include $\mathrm{NH}_{3}, \mathrm{H}_{2} \mathrm{~S}$ and $\mathrm{H}_{2} \mathrm{O}$ in exit gas.

- Prehydrotreating Run Hours: 19
77.8

83.7

85.9

$\begin{array}{ccc}0.00 & 0.00 & 0.00 \\ 0.15 & 0.19 & 0.32 \\ 1.24 & 1.29 & 1.41 \\ 102.0 & 102.8 & 101.7 \\ & & \\ 2.60 & 2.58 & 2.26\end{array}$


Table 36

Run ZTJ13 Summary, 5.0017 gms Amocat 1A

Run Summary:

Yield Period No.

Yield Period Length, hr

Average 'I'emperature, $P$

Average Pressure, psig

Slirrer Speed, rpm

Makcup Solvent Rate, gm/hr

Coal Paste Rate, gm/hr

Residence Time, $\mathrm{hr}$

$\begin{array}{ccc}1 & 2 & 3 \\ 2.0 & 2.0 & 2.0 \\ 810 & 810 & 811 \\ 2000 & 2000 & 2000 \\ 1205 & 1205 & 1205 \\ 20.30 & 20.35 & 20.30 \\ 20.02 & 20.02 & 20.02 \\ 1.503 & 1.501 & 1.503\end{array}$

Space Velocities:

GM Coal/Hr/GM Cat

GM Dry Coal/Hr/GM Cat

(GM MAF Coal/Hr/GM Cat

(iM MAF Coal/Hr/CC Cat

I.B MAF Coal/Hr/CUFI Cat

2.001

1.514

1.416

0.783

48.90

2.001

1.514

1.416

0.783

48.90

2.001

1.514

1.416

0.783

Solvent/Coal Wi Ratios:

(iM CO/GM COAI

GM CO+Resid/GM Coal

(iM CO+Resid/GM !)ry Coal

GM CO/GM MAF Coal

4.279

$\mathrm{II}_{2}$ 'Ireat Rate, L(STP)/Hr

$\mathrm{II}_{2}$ 'lreat Rate, SCF/BBL

I'xit Gas Rate, L(SIP)/Hr

Cumulative Quantities:

IIours on Catalyst"

WI Makeup Solvent/Wt Cat

Wt Resid/Wt Cat

Wi Coal/Wt Cat

Overall Matcrial Balance', Wt\%

100.7

Yiclds (IOT Ficed Basis):

Carbon Monoxide, Wi\%

Carbon Dioxide, Wi\%

llydrocarbon Gases $\left(\mathrm{C}_{1}-\mathrm{C}_{4}\right)$, Wt\%

100.7

101.0

Slurry Product, Wt\%

$\begin{array}{rrr}0.00 & 0.00 & 0.00 \\ 0.17 & 0.21 & 0.29 \\ 1.96 & 1.92 & 1.99 \\ 101.2 & 101.1 & 101.2 \\ & & \end{array}$

$\mathrm{H}_{2}$ Consumption (TOT Feed Basis), W1\%

Conversions (MAF Coal + Resid Basis):

WI\% Cyclohexane Soluble

WI\% Toluene Soluble

WI\% Pyridine Soluble

-. Does not include $\mathrm{NH}_{3}, \mathrm{H}_{2} \mathrm{~S}$ and $\mathrm{H}_{2} \mathrm{O}$ in exit gas.
82.1

87.6

89.7

$\begin{array}{ll}82.4 & 77.6 \\ 86.1 & 83.6 \\ 89.3 & 87.7\end{array}$


Table 37

Run ZTJ14 Summary, 5.0031 (Deposit-Free) gms Spent Amocat 1A

Run Summary:

Yicld Period No,

Yicld Period length, hr

Average Temperature, $P$

Average Pressure, psig

Stlrer Speed, rpm

Makeup Sotvent Rate, $\mathrm{gm} / \mathrm{hr}$

Coal Pasle Rate, gm/hr

Residence Time, hr

$\begin{array}{ccc}1 & 2 & 3 \\ 2.0 & 2.0 & 2.0 \\ 802 & 801 & 800 \\ 1990 & 2000 & 2000 \\ 1205 & 1205 & 1205 \\ 20.40 & 20.30 & 20.35 \\ 20.02 & 20.02 & 20.02 \\ 1.499 & 1.503 & 1.501\end{array}$

Space Velocities:

(IM Coal $/ \mathrm{Hr} / \mathrm{GM} \mathrm{Cat}$

(IM Dry Coal/Hr/GM Cat

GM MAI Coal/Hr/GM Cat

(IM MAF Coal/Hr/CC Cat

L,B MAY' Coal/Mr/CUPI Cat

Solvenl/Coal Wi Ratios:

GM CO/GM Coal
GM CO+Resid/GM Coal
GM CO/GM Dry Coal
GM CO+Resid/GM Dry Coal
GM CO/GM MAF Coal
GM CO+Resid/GM MAP Coal

H, Treal Rate, L(STP)/Hr

11 , Treat Ralc, SCF/BBL.

Lixit Gas Rate, $L(S T P) / I I r$

Cumulative Quantities:

Ilours on Catalyst"

WI Makeup Solvent/WI Cat

WI Resid/WI Cat

WI Coal/Wi Cat

Overall Material Balance', W $\%$

Yiclds (l'O'T Feed Basis):

Carton Monoxide, WI\%

Cartion Dioxide, W1\%

Hydrocarton Gases $\left(C_{1} \cdot C_{4}\right), W_{1} \%$

Slurry Product, WI\%

$\mathrm{H}_{2}$ Consumption (TOT Feed I

Conversions (MAF Coal + Resid Basis):

WI\% Cyclohexane Soluble

$W_{1} \%$, Toluene Soluble

WI\% Pyridine Soluble

- Does not include $\mathrm{NH}_{3}, \mathrm{H}_{2} \mathrm{~S}$ and $\mathrm{H}_{2} \mathrm{O}$ in exit gas.

"Prehydrolreating Run Hours: 19

$\begin{array}{lll}2.705 & 2.695 & 2.700 \\ 3.038 & 3.028 & 3.033 \\ 3.376 & 3.562 & 3.569 \\ 4.016 & 4.003 & 4.010 \\ 3.822 & 3.808 & 3.815 \\ 4.293 & 4.279 & 4.286 \\ & & \\ 25.05 & 25.05 & 25.05 \\ 3464 & 3974 & 3969 \\ 26.00 & 25.55 & 25.69\end{array}$

$\begin{array}{rrr}25.0 & 49.0 & 73.0 \\ 135.6 & 233.3 & 330.9 \\ 16.5 & 32.2 & 47.8 \\ 49.6 & 96.5 & 14.3 .4\end{array}$

$\begin{array}{lll}101.5 & 101.8 & 101.4\end{array}$

$\begin{array}{ccc}0.00 & 0.00 & 0.00 \\ 0.99 & 1.04 & 1.08 \\ 1.55 & 1.53 & 1.43 \\ 100.0 & 100.4 & 100.0 \\ & & \\ 0.94 & 1.04 & 0.98\end{array}$

$\begin{array}{lll}42.4 & 42.6 & 40.1 \\ 66.1 & 65.8 & 63.7 \\ 72.4 & 70.2 & 67.9\end{array}$


Table 38. Effect of Solvent/Coal Ratio on Conversion $800^{\circ} \mathrm{F}, 2000 \mathrm{psig}, 4000 \mathrm{scf} / \mathrm{bbl}$ $1.0 \mathrm{gm} \mathrm{coal} / \mathrm{hr} / \mathrm{gm}$ catalyst, $1205 \mathrm{rpm}$

$\begin{array}{lccc}\text { Solvent/Coal Ratio } & 4: 1 & 3: 1 & 2: 1 \\ \text { Residence Time, hr } & 2.4 & 3.0 & 4.1 \\ \text { Catalyst Service, gm/gm } & 21 & 68 & 2.3 \\ \text { CC6 Conversion, \% } & 91.8 & 88.7 & 84.8 \\ \text { Toluene Conversion, \% } & 93.6 & 90.9 & 87.1 \\ \text { Pyridine Conversion, \% } & 94.9 & 92.5 & 89.2\end{array}$


residence time (computed as reaction volumetric hold up divided by total feedrate) at the higher solvent/coal ratios is evidently not an overriding factor. A solvent/coal weight ratio of 3:1 was selected for base operating conditions primarily because of convenience. The unit ran smoothly, and the product accumulators had sufficient capacity to accommodate the $3: 1$ ratio.

All the conversions in Table 38 are higher than desired, since it is difficult to observe changes in catalyst activity at the $90 \%$ conversion level and above. The effect of coal weight hourly space velocity is evident from the data of Table 39. Initial conversion levels at a coal WHSV of $2 \mathrm{gm} / \mathrm{hr} / \mathrm{gm}$ appear suitable, and deactivation of the catalyst is readily observed. Accordingly a coal WHSV of 2 was selected for the base operating conditions.

As discussed in Section III-B-3 the liquid holdup in the reactor with a five gram catalyst charge is about $53 \mathrm{~cm}^{3}$, and thus thermal reactions will almost certainly play a role in coal conversion. The extent of thermal conversion was studied by replacing the catalyst with an equal volume of glass beads (Run ZTJ08). The results are reported in Table 40. Clearly the thermal conversions are very much lower than the overall (catalytic + thermal) conversions of Table 39. This further reinforces the selection of the coal WHSV of 2 for base operating conditions. The catalytic effect is readily observed, and yet conversions are not approaching the $90-100 \%$ level.

In principal, the stirrer speeds corresponding to incipient fluidization and particle carryover can be calculated from the correlations of Section III-A-2. However, practical application of these correlations requires that the viscosity of the reaction mixture be known, and this is difficult to obtain with a high degree of accuracy. A sample of liquefaction 
Table 39. Effect of Space Velocity on Conversion

$800^{\circ} \mathrm{F}, 2000 \mathrm{psig}, 4000 \mathrm{scf} / \mathrm{bbl}$

3:1 solvent/coal ratio, $1205 \mathrm{rpm}$

$\begin{array}{lcccccc}\text { Coal WHSV, gm/hr/gm } & 1.0 & & 2.0 \\ \text { Residence Time, } \mathrm{hr} & 3.0 & & 1.5 & \\ \text { Catalyst Service, gm/gm } & 68 & & 48 & 103 & 243 \\ \text { CC6 Conversion, \% } & 88.7 & 81.0 & 78.3 & 66.0 \\ \text { Toluene Conversion, \% } & 90.9 & 84.6 & 80.3 & 73.1 \\ \text { Pyridine Conversion, \% } & 92.5 & 88.4 & 83.8 & 81.7\end{array}$


Table 40. Thermal Conversions

$800^{\circ} \mathrm{F}, 2000 \mathrm{psig}, 4000 \mathrm{scf} / \mathrm{bbl}, 2 \mathrm{gm} / \mathrm{hr} / \mathrm{g}$ (equiv.)

$3: 1$ solvent/coal ratio, $1205 \mathrm{rpm}$

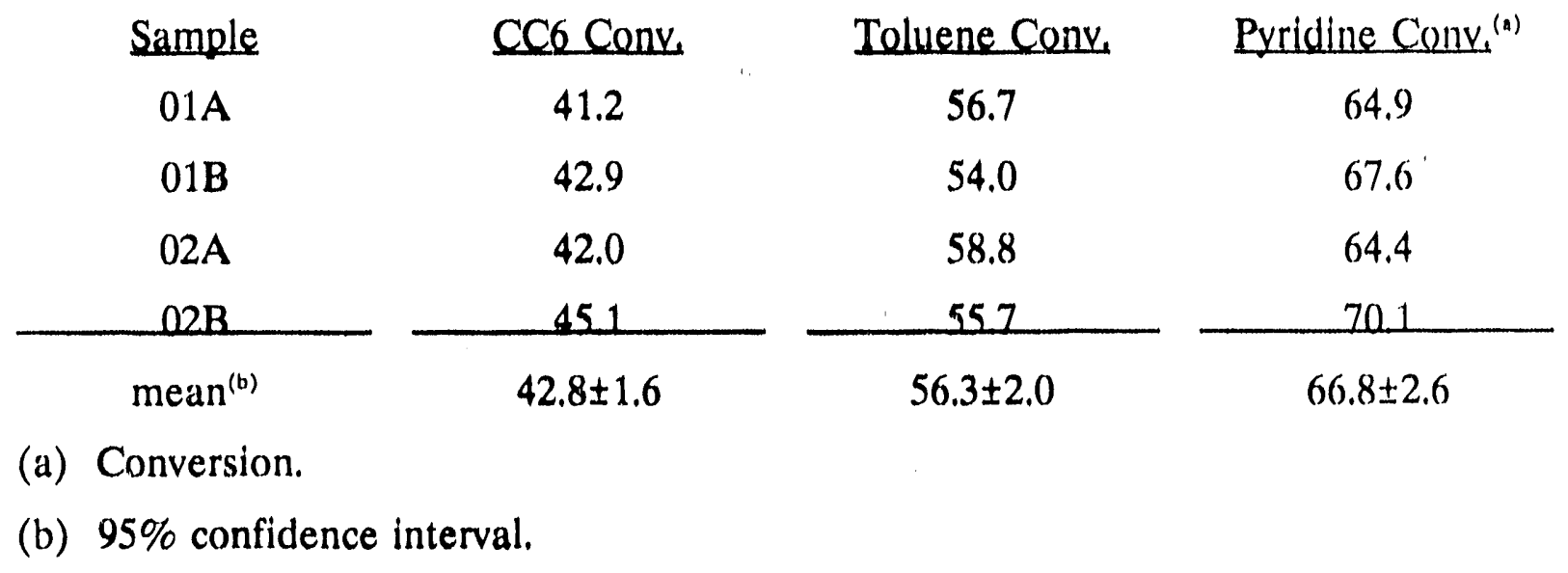


product from Run ZTJ09 was taken between 4.33 and $480 \mathrm{gm}$ coal processed/gm catalyst, 'This material was filtered through Whatman no, 1 filter paper, and its viscosilty was measured in a Ruska Mod. 1602-830) rolling ball viscometer over temperatures ranging from $77^{\circ} \mathrm{F}$ to $300^{\circ} \mathrm{F}$. The results are complled in Table 41. Extrapolation of these data using the modifled Doolittle equation (51) ylelded a viscosity of $0.9 \mathrm{cp}$ at $8(0) 0^{\circ} \mathrm{F}$. Using this value, the stirrer speed at inciplent fluldization, $S_{1}$, was calculated to be $1200 \mathrm{rpm}$ using Eq. (11). Furthermore the stirrer speeds corresponding to full bed expansion $\left(S_{2}\right)$ and cavitation $\left(S_{3}\right)$ were calculated from Eqs, (13) and (12), respectively. Their values are $S_{2}=2155$ and $S_{3}$ $=2329$. Since $S_{2}<S_{3}$, the bed should expand to the limit.

Unfortunately the accuracy of these stirrer speed calculations is greatly shadowed by the presence of solld particles in the reaction mixture and the fact that the viscosity had to be extrapolated over a wide temperature range. It was felt that nonfiltered material might serve to make the reaction mixture more viscous than the filtrate, and thus the measured viscosity would likely be low. As a consequence the critical stirrer speeds would likely be lower than calculated. The stirrer speed of $1205 \mathrm{rpm}$ was selected for base operating conditions because: 1 . it is equivalent to the calculated stirrer speed at Incipient fluidization, $S_{1}$, which is probably somewhat low and 2 , the recycle ratio from Figure 26 is over one thousand. Also, this stirrer speed had been used successfully in the hydrotreating runs, and in the coal liquefaction runs there was no tendency for the catalyst particles to agglomerate or become cemented to one another. 
Table 41. Viscosity of Coal Liquefaction Product ${ }^{(n)}$

\begin{tabular}{cc} 
Temperature ('F) & Viscosity irid \\
\hline 77 & 26.31 \\
100 & 17.72 \\
125 & 12.07 \\
150 & 9.09 \\
175 & 7.23 \\
200 & 5.57 \\
250 & 4.28 \\
300 & 2.86 \\
\hline
\end{tabular}

(a) Filtered product with catalyst service between 433 and $480 \mathrm{gm}$ coal/gm catalyst from ZTJ09. 
However, because of the uncertainty in the calculated stirrer speeds, it was decided 10 conduct a deactivation run at $1650 \mathrm{rpm}$ (Run ZTJ11) for comparison with the (leactivation run at $1205 \mathrm{rpm}$ (Run ZTJ09). Except for the differences in stirrer speed, conditions were identical in these two runs.

As already discussed, operabillty problems were experienced during Run ZTJ11, and the reactor was badly coked at run termination. Solubility conversions for the two runs are compared in Figures 43 to 45 . The results are essentially equivalent early in the run, but Weactivation at the higher stirrer speed appears more pronounced until ultimately thermal levels are attained consistent with the end of run coking of the catalyst basket.

It is surmised that the catalyst bed may have been forced against the top basket screen at the 1605 stirrer speed. Agitation would be restricted, and ultimately solids would lill the voids between catalyst particles, the particles would become cemented to one incther, the bed would plug, and circulation would be lost. It is also possible that cavitation of the impeller could be a problem at the higher stirrer speeds. Similar losses of circulation were observed in the cold model study at high stirrer speeds.

On the basis of these results, the set of base operating conditions of Table 42 has been deduced. Operation of the unit is smooth at these conditions and conversion levels are reasonable. Perhaps it should be noted that the conditions are not as severe as typical II-Coal (52) and Wilsonville (53) conditions. However, our base conditions are not out of line with bench scale operations at Amoco $(8,9)$ and the Pittsburgh Energy Technology Center (54), Table 43. Note, however, the greatly reduced catalyst charge to our reactor. 


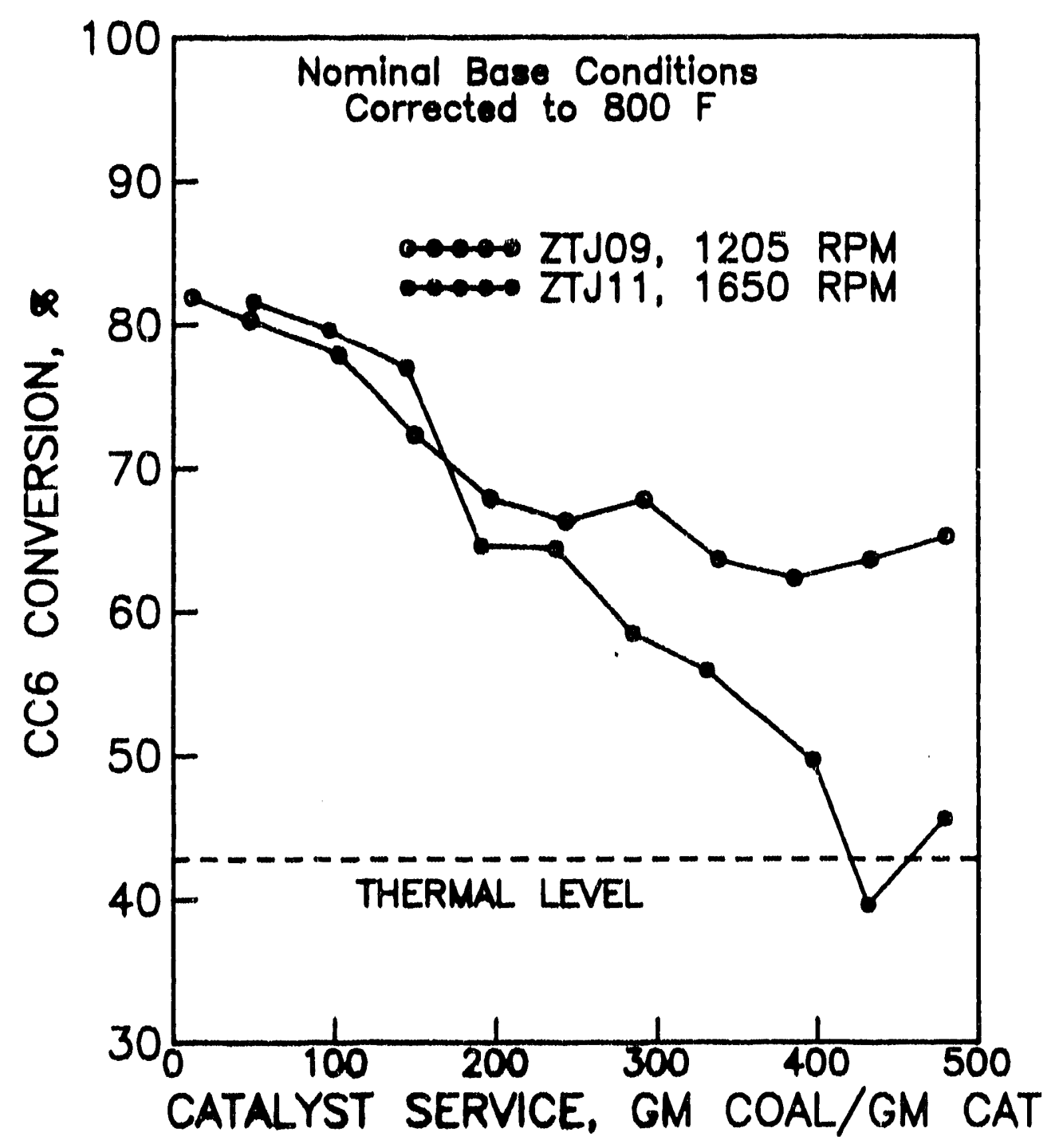

Figure 43. Effect of stirrer speed on cyclohexane conversions. $T=800^{\circ} \mathrm{F}, \mathrm{P}=2000 \mathrm{psig}$, $\mathrm{HTR}=4000 \mathrm{SCF} / \mathrm{BBL}$, Coal WHSV $=2$, Solvent $/$ Coal wt. ratio $=3$. 


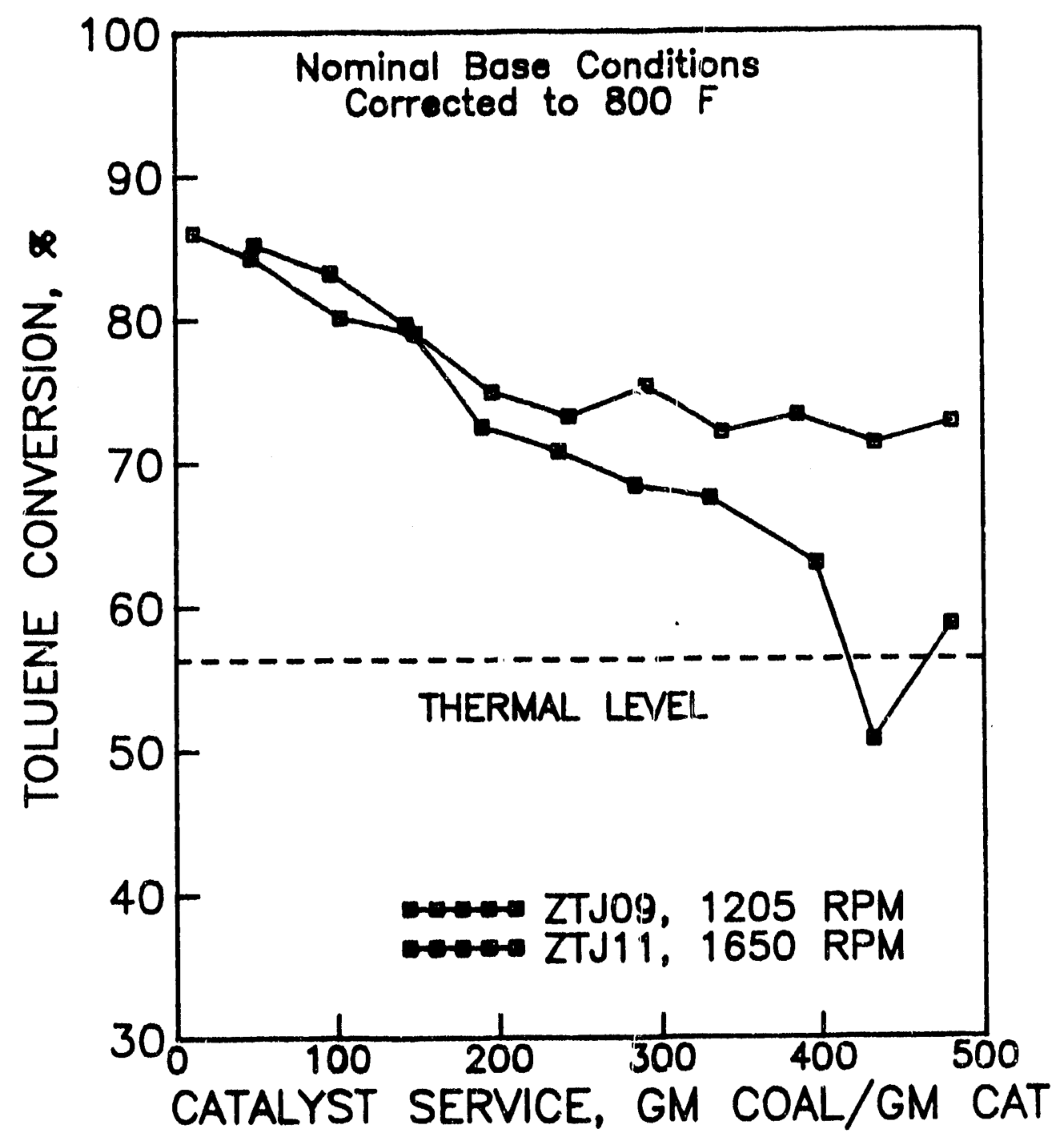

Figure 44. Effect of stirrer speed on toluene conversions. $\mathrm{T}=800^{\circ} \mathrm{F}, \mathrm{P}=2000 \mathrm{psig}$, HTR $=4000 \mathrm{SCF} / \mathrm{BBL}$, Coal WHSV $=2$, Solvent $/$ Coal wt. ratio $=3$. 


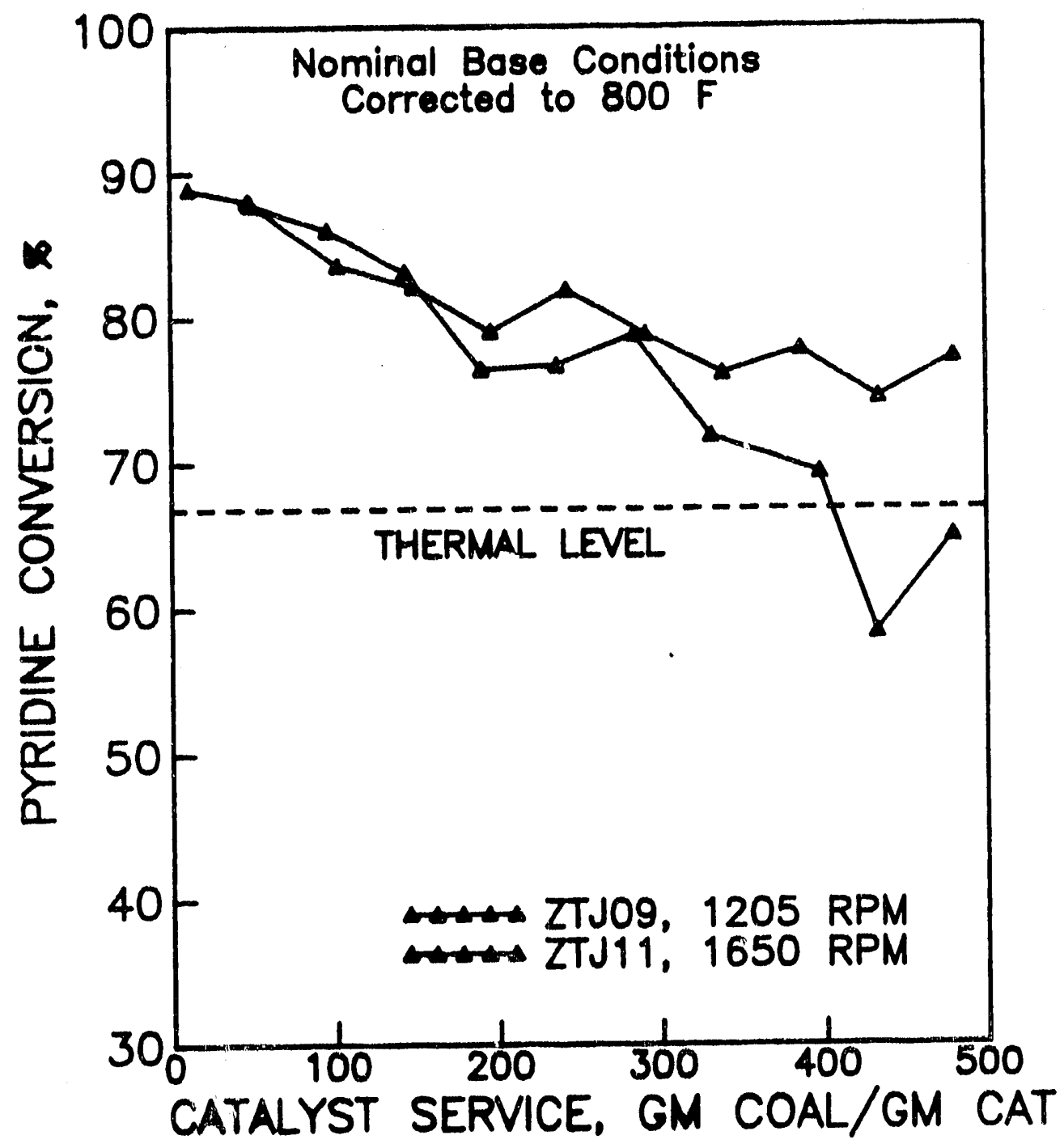

Figure 45. Effect of stirrer speed on pyridine conversions. $\mathrm{T}=800^{\circ} \mathrm{F}, \mathrm{P}=2000 \mathrm{psig}$, $\mathrm{HTR}=4000 \mathrm{SCF} / \mathrm{BBL}$, Coal WHSV $=2$, Solvent $/$ Coal wt. ratio $=3$. 
Table 42. Base Operation Conditions

Catalyst charge, gm 5

Temperature, ${ }^{\circ} \mathrm{F} \quad 800$

Pressure, psi 2000

Hydrogen treat rate, scf/bbl $\quad 4000$

Solvent/coal wt. ratio $\quad 3: 1$

Coal WHSV 2.0

Coal Space Velocity, $\mathrm{gm} / \mathrm{hr} / \mathrm{cm}^{3} \quad 1.10^{(1)}$

Residence time, hr $\quad 1.5$

Stirrer speed, rpm 1205

(1) based on catalyst bulk density of $0.55 \mathrm{gm} / \mathrm{cm}^{3}$ 
Table 43. Amoco's and PETC's Operating Conditions

\begin{tabular}{lccc} 
& \multicolumn{2}{c}{ Amoco } & PETC \\
& Mild & Severe & \\
Catalyst charge, gm & 60 & 60 & 60 \\
Temperature, ${ }^{\circ} \mathrm{F}$ & 800 & 825 & 825 \\
Pressure, psi & 2000 & 2000 & 2000 \\
Hydrogen treat rate, scf $/ \mathrm{bbl}$ & 2750 & 3500 & 4000 \\
Solvent/coal wt. ratio & $4: 1$ & $3: 1$ & $3: 1$ \\
Coal space velocity, $\mathrm{gm} / \mathrm{hr} / \mathrm{cm}^{3(1)}$ & 1.33 & 1.79 & 1.65 \\
Residence time, $\mathrm{hr}$ & 0.80 & 0.73 & 0.75 \\
\hline
\end{tabular}

(1) based on catalyst bulk density of $0.55 \mathrm{gm} / \mathrm{cm}^{3}$. 
On occasions the reactor temperature will differ from the set point temperature by a few degrees, and in such cases it is desirable to make an adjustment to the product yields to bring them back to the target temperature of $800^{\circ} \mathrm{F}$. The effect of temperature on solubility conversions was investigated in Runs ZTJ12 and ZTJ13. Conversions at three different times on stream are listed in Table 44. Both temperature and time on stream clearly have an effect on the conversions, but the purpose of this analysis is to obtain an expression for the temperature dependence only. It will be assumed that the temperature effect is the same regardless of catalyst service. The limited data do not justify any other conclusion.

The data in Table 44 were fit to an Arrhenius type expression:

$$
\ln X=1000 B / T+A
$$

for each solubility classification. The intercept, $A$, was allowed to vary between each time on stream grouping, but a common slope was assumed. The slopes obtained from the regression are:

Table 45

Temperature Correction Factors

\begin{tabular}{ll} 
& $\mathrm{B}\left({ }^{\circ} \mathrm{K}\right)$ \\
\cline { 2 - 2 } Cyclohexane & -4.207 \\
Toluene & -1.800 \\
Pyridine & -1.820
\end{tabular}


Table 44. Effect of Temperature and Time on Stream $(\mathrm{P}=2000 \mathrm{psi}, \mathrm{Coal} \mathrm{WHSV}=2, \mathrm{HTR}=4000 \mathrm{scf} / \mathrm{bbl}, \mathrm{st} . \mathrm{spd} .=1205)$

\section{@ 24.5 HRS}

\begin{tabular}{|c|c|c|c|}
\hline & \multicolumn{3}{|c|}{$\%$ Conversion } \\
\hline$T(F)$ & $\underline{\mathrm{CC} 6}$ & TOL & PYD \\
\hline 789 & 77.8 & 83.7 & 85.9 \\
\hline 802 & 81.0 & 84.6 & 88.4 \\
\hline 810 & 82.1 & 87.6 & 89.7 \\
\hline \multicolumn{4}{|l|}{ (11) $49.5 \mathrm{hrs}$} \\
\hline & \multicolumn{3}{|c|}{$\%$ Conversion } \\
\hline$T(F)$ & $\mathrm{CC6}$ & TOL & PYD \\
\hline 789 & 75.8 & 82.1 & 84.9 \\
\hline 801 & 78.3 & 80.3 & 83.8 \\
\hline 810 & 82.4 & 86.1 & 89.3 \\
\hline \multicolumn{4}{|l|}{ @ 73.0 HRS } \\
\hline & \multicolumn{3}{|c|}{ of Conversion } \\
\hline $\mathrm{T}(\mathrm{F})$ & $\mathrm{CC6}$ & TOL & PYD \\
\hline 790 & 65.9 & 79.8 & 83.9 \\
\hline 802 & 73.0 & 79.3 & 82.4 \\
\hline 811 & 77.6 & 83.6 & 87.7 \\
\hline
\end{tabular}


These values were then used to correct all measured conversions, $X_{T}$, to the target temperature of $800^{\circ} \mathrm{F}\left(699.8^{\circ} \mathrm{K}\right)$ using the relation:

$$
X_{800}=X_{T} \exp [B(1000 / 699.8-1000 / T)]
$$

The crude nature of this correction is justified by the fact that the correction is always small. Only rarely did the actual temperature deviate from the target temperature by more than a couple of degrees.

In Run ZTJ09 reaction conditions were held constant at the base operating conditions of Table 42, and the solubility conversions were monitored as a function of time on catalyst service. The conversions have all been corrected to the $800^{\circ} \mathrm{F}$ target temperature, and the results are plotted in Figure 46. Deactivation is clearly substantial, especially during the first $200 \mathrm{gm} / \mathrm{gm}$ catalyst service. The deactivation is more gradual later in the run. Similar results are normally observed in the processing of petroleum streams where the initial deactivation can be attributed to coke laydown on the catalyst. Note that the catalyst is still quite active at run termination. End of run conversions are significantly higher than the corresponding thermal conversions.

As discussed earlier, the Run ZTJ06 data are of questionable validity due to the use of an incorrect solvent (cyclohexanone) in washing the reactor contents into the product beaker. As a consequence, the cyclohexane conversions for Run ZTJ06 are significantly higher than was observed during Run ZTJ09. However, the toluene and pyridine conversions for the two runs compare very favorably as shown in Figures 47 and 48. Evidently cyclohexanone solubilizes very little material that is insoluble in toluene. 


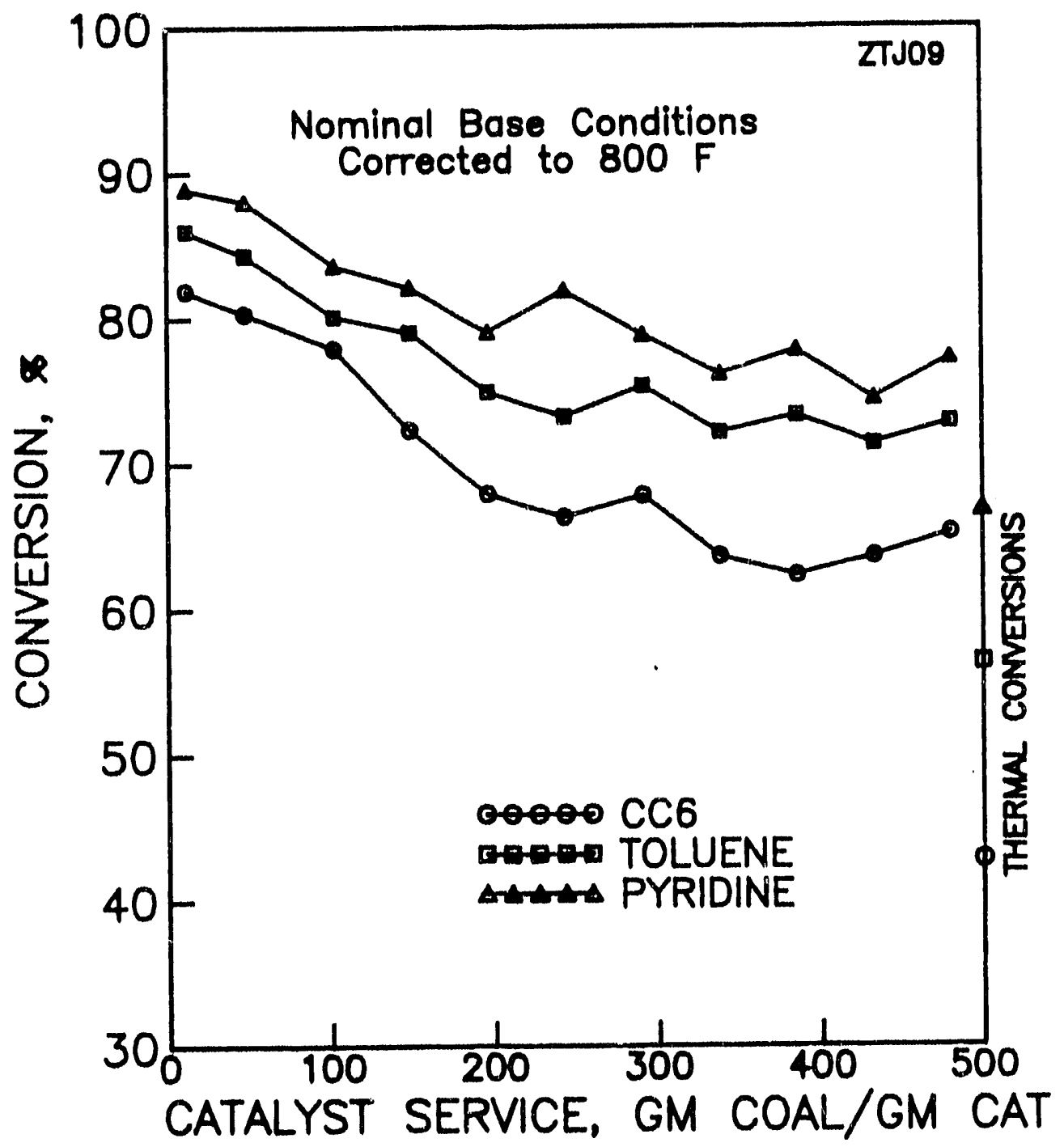

Figure 46. Deactivation run for Amocat 1A catalyst at the operating conditions of Table 42. 


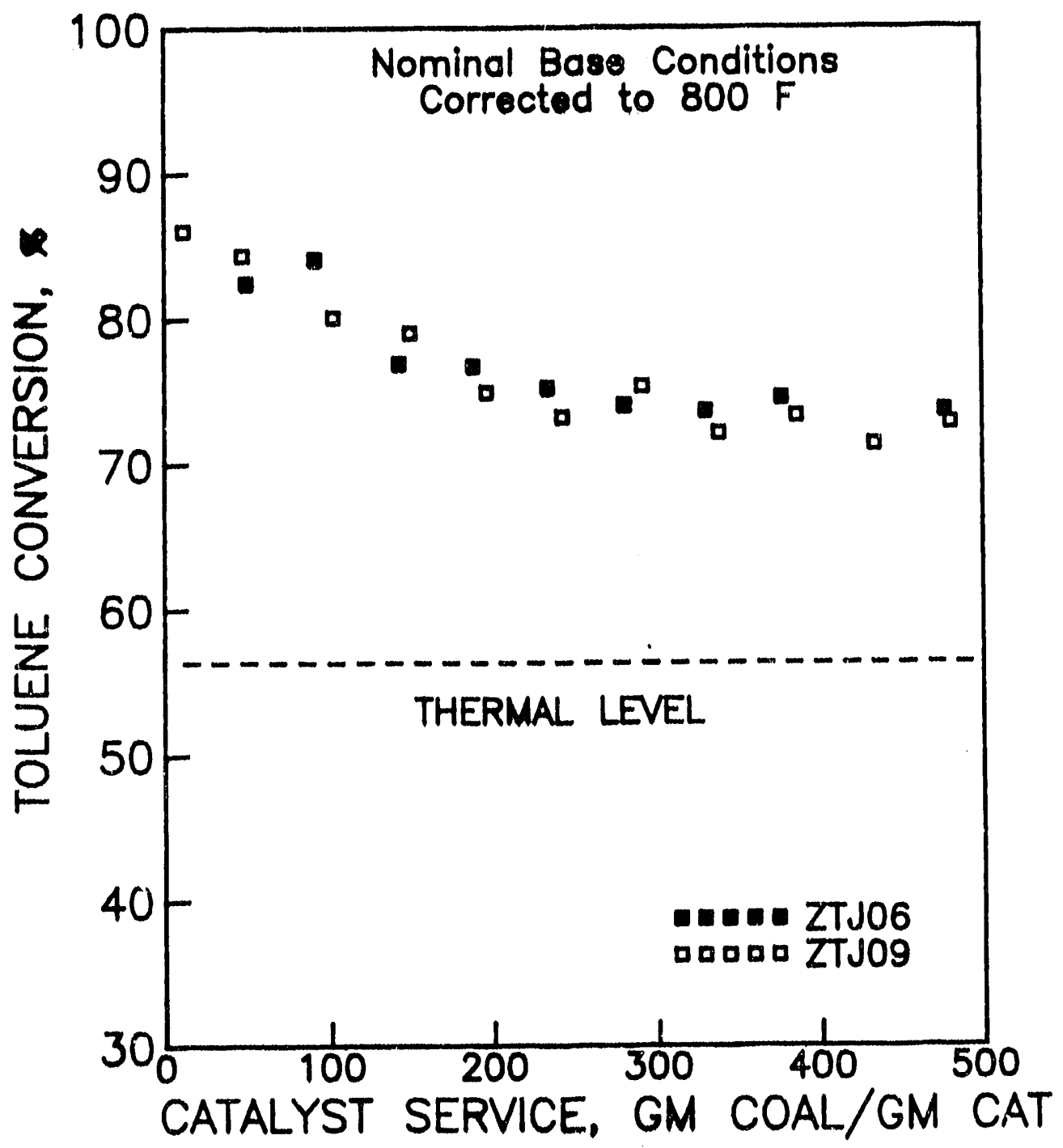

Figure 47. Comparison of Runs ZTJ06 and ZTJ09 deactivation curves for toluene conversion. Table 42 run conditions. 


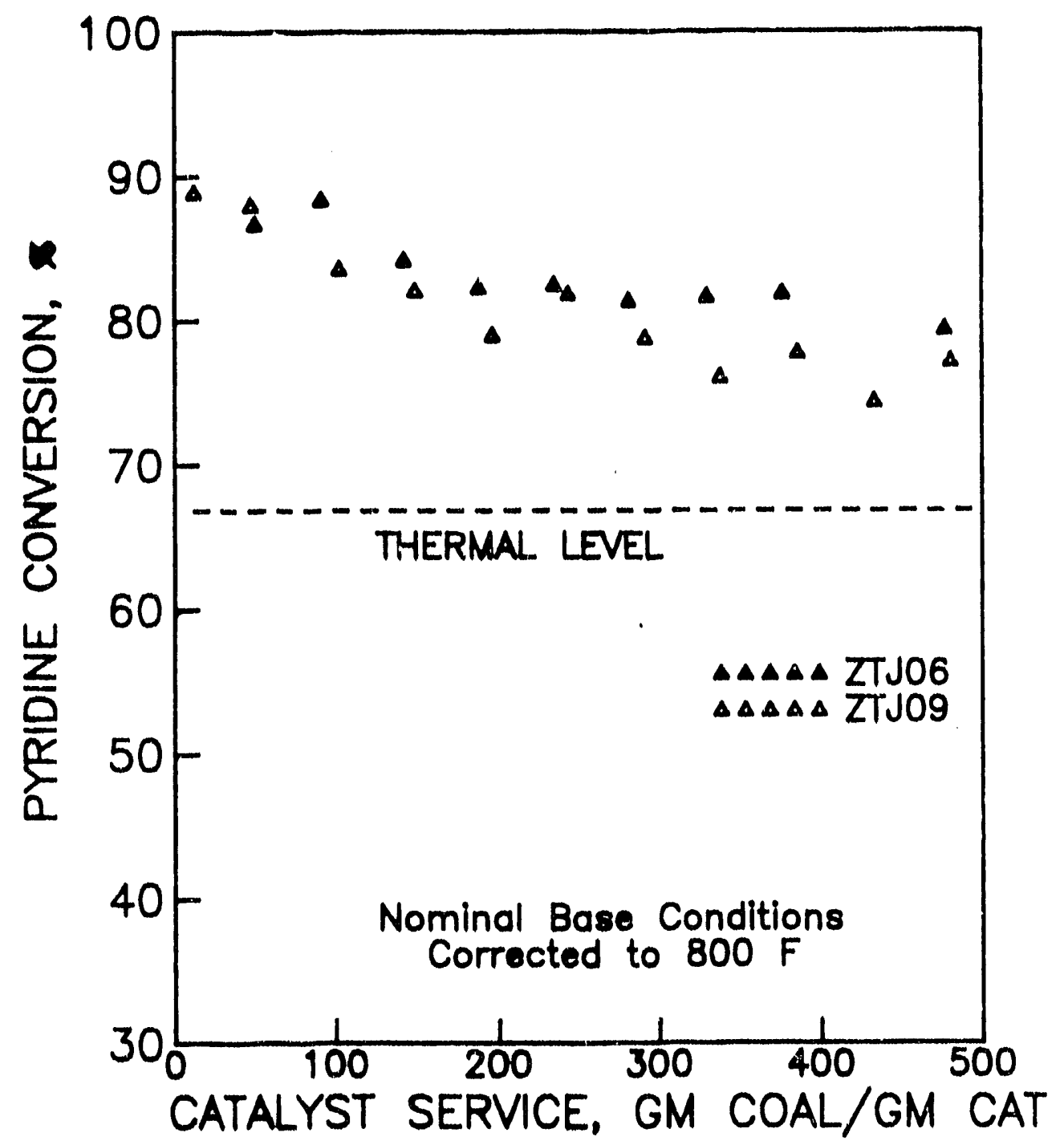

Figure 48. Comparison of Runs ZTJ06 and ZTJ09 deactivation curves for pyridine conversion. Table 42 run conditions. 
Roughly equal portions of used catalyst from Runs Z'TJ(0) and Z'TJOS were "regenerated" by firing overnlght (16 hours) in a muffle furnace at $5(0)^{\circ} \mathrm{C}$. Difflculty was expeitenced in burning the carbon off the catalyst. The external surface of the particles remained black after the firing, and while a few particles when broken into pleces, exhibited the characteristic blue color of CoMo/alumina, most were black through the interior as well. Some had black centers surrounded by blue. These observations strongly suggest that oxygen either does not penetrate the particle during firing, or when it does the combustion reaction is mass transfer controlled.

Nevertheless the regenerated catalyst was charged to the reactor for a short deactivation run at base conditions. The results are plotted in Figure 49. The used catalyst activities all lie substantially below the end of run activities for the fresh catalyst. Cyclohexane and pyridine conversions are near thermal levels. Evidently the regeneration process imparted significant damage to the catalyst. The problems experienced in burning coke off the catalyst suggest that sintering of some as of yet unknown material at or near the outer surface of the particles may have been responsible.

The loss on ignition and catalyst recovery are presented in Table 45. The entries for Runs ZTJ02 and ZTJ11 are probably not very meaningful since the reactor was badly plugged in both cases. Consequently it was difficult to separate noncatalytic solids and residues from the catalyst charge. Conditions varied from run to run, but those runs of shorter duration tended to exhibit a higher loss on ignition and a lower recovery percentage than did the longer duration runs, Runs ZTJ06 and ZTJ09 in particular. Coke burnoff was evidently more complete on the shorter duration runs. The high percent recoveries for the 


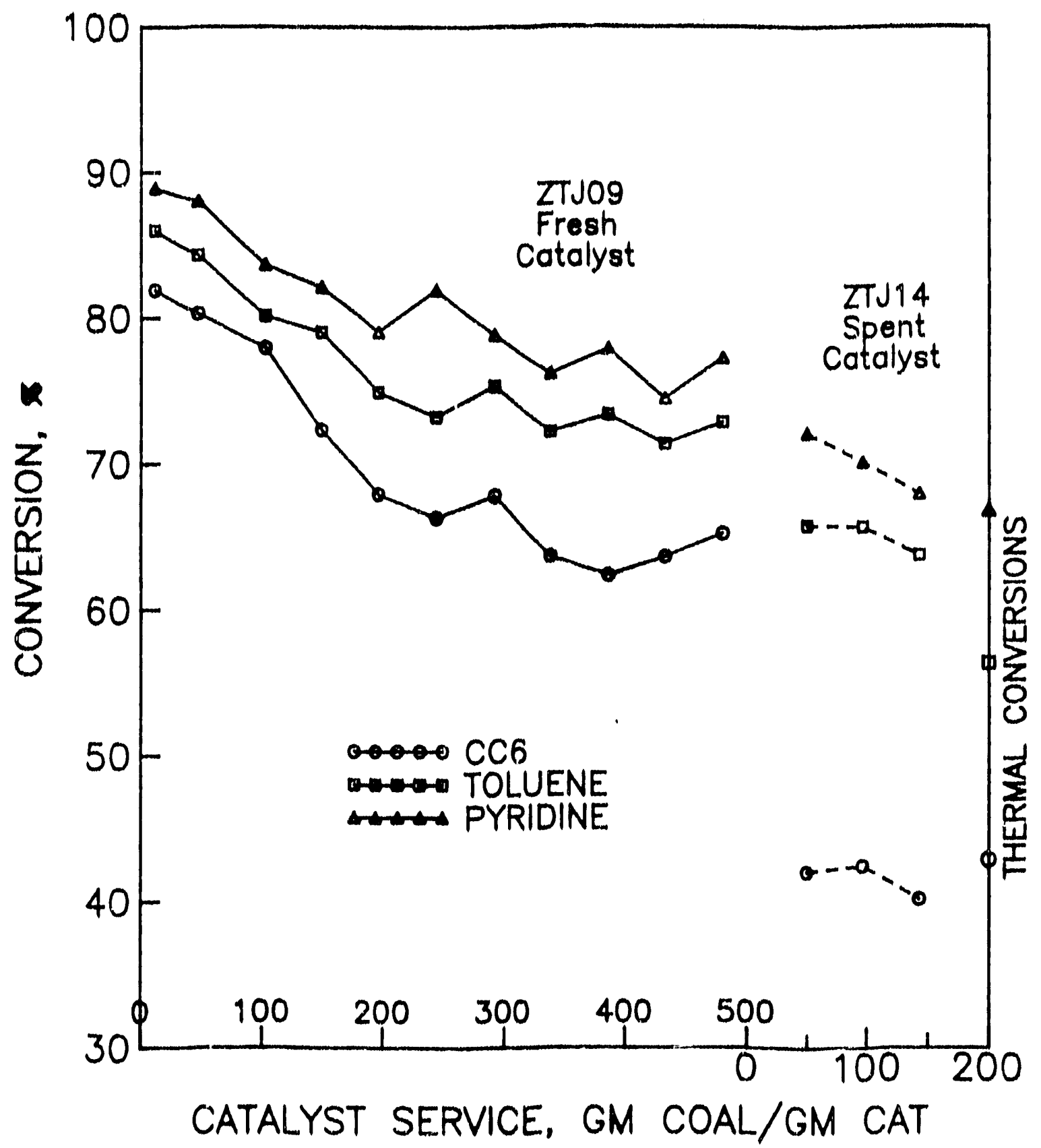

Fïgure 49. Comparison of "regenerated" and fresh catalyst results. Table 42 run conditions. 


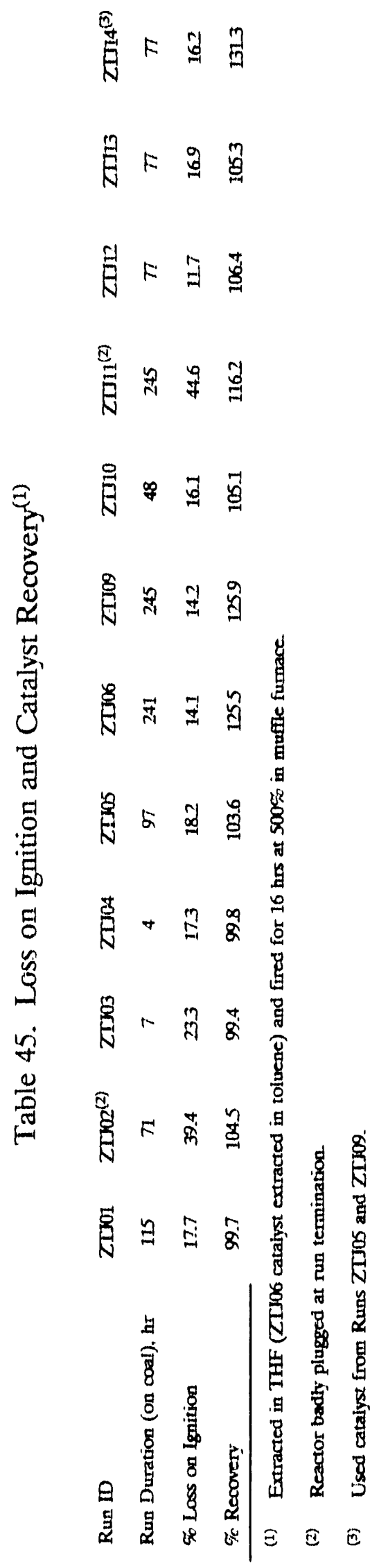


ZTJ06 and ZTJ09 catalysts are probably due to a combination of incomplete burnoff of coke and higher metals deposition by comparison to the other catalysts. Samples of the ZTJ09 catalyst have been submitted to an outside laboratory for metals and $\mathrm{C} / \mathrm{H}$ analyses, but the results are not available as of this writing.

Samples of used ZTJ06 catalyst were analyzed at the Western Research Institute using the scanning electron microscope for Energy Dispersive X-ray Analysis (EDXA). The catalyst sample was mounted on a carbon sample stub with pliobond glue and carbon sputter coated. An EDXA spectrum from the center of the catalyst particle is plotted in Figure 50. This should be compared with the EDXA spectrum from the outside surface of the particle, Figure 51. The presence of substantial amounts of calcium in the coating is clear and unmistakable; whereas, only a trace of calcium is present in the catalyst interior. Sulfur is also evident in the coating and not in the interior. However, this distinction is not as clear since sulfur and molybdenum peaks overlap. The presence of calcium on the exterior of the used catalyst particles is consistent with the substantial amount of calcium in the coal ash, Table 24. Amoco workers observed large crystals of a calcium salt on spent catalysts that had been used to process Illinois No. 6 coal (55). The crystals occurred predominantly within 50 microns of the exterior surface and they were composed of calcium and sulfur in a close to 1:1 stoichiometric ratio.

With the evidence mounting for a sinterable layer of a calcium containing material on the external surface of the used catalyst particles, the diameters of 60 used and extracted catalyst particles were measured with a micrometer. These measurements were compared with similar measurements on 60 randomly selected fresh catalyst particles. The difference 


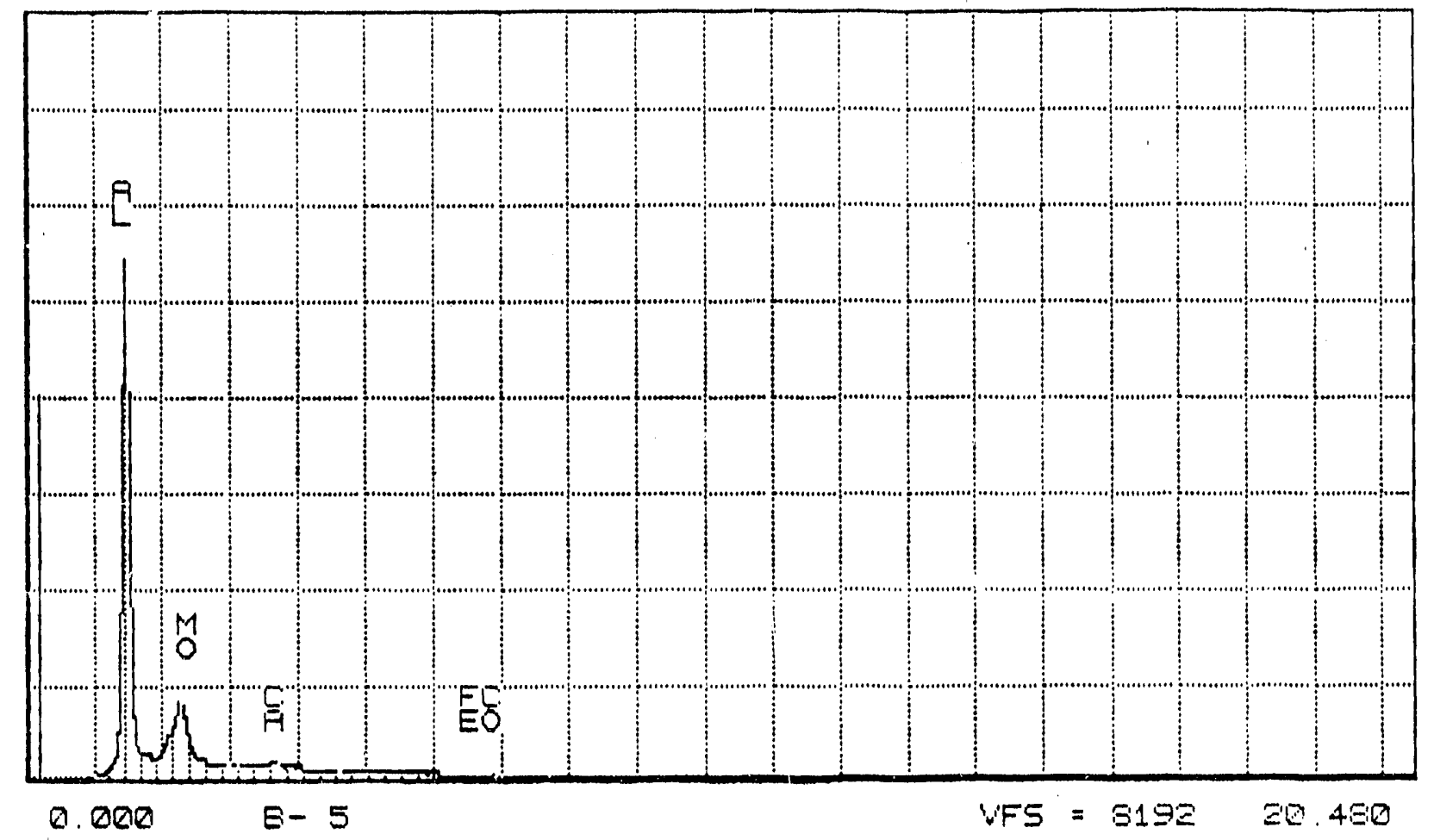

Figure 50. EDXA spectrum from the center of used catalyst from Run ZTJ06.

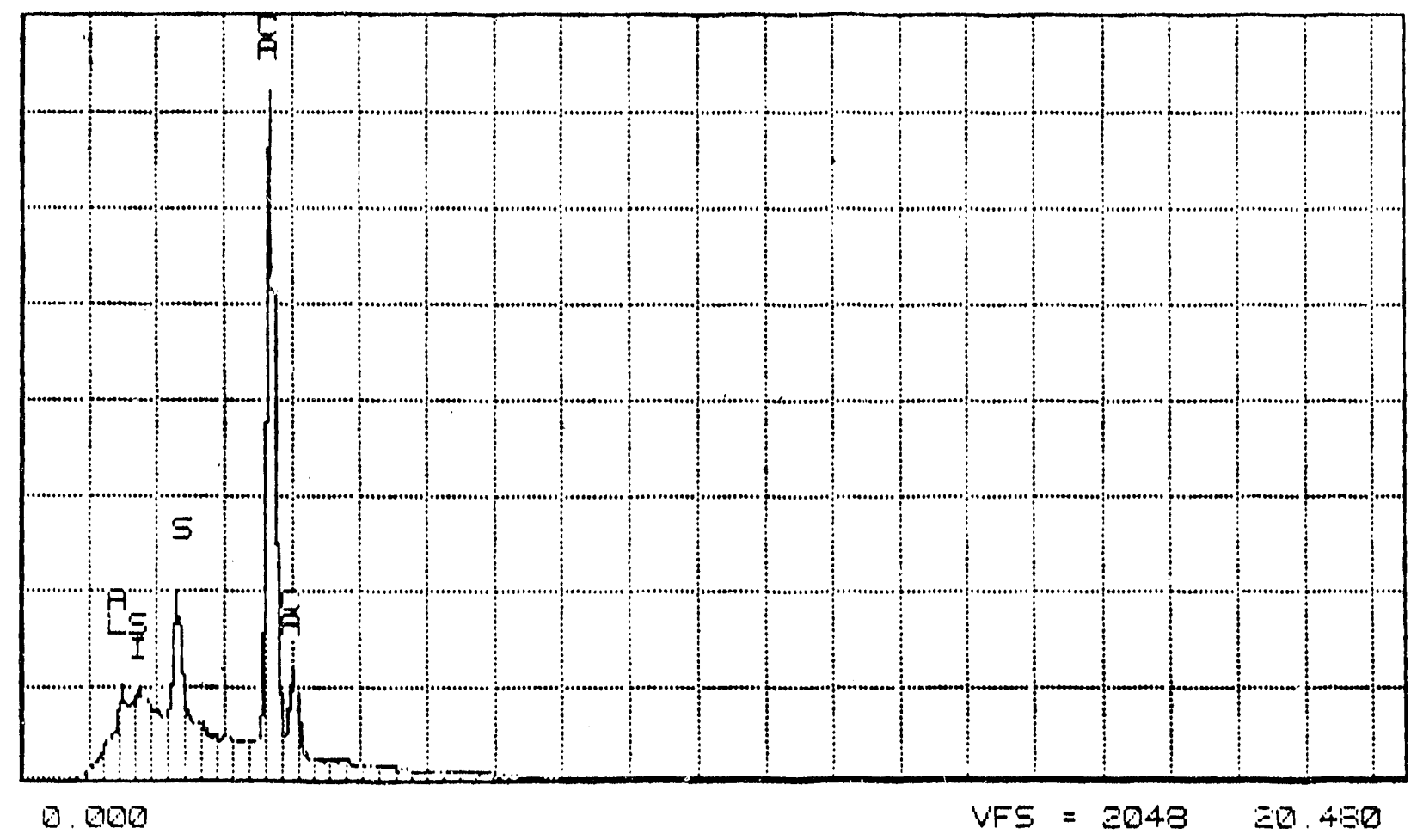

Figure 51. EDXA spectrum from the external surface of used catalyst from Run ZTJ06. 
in diameters was compared with a two sample t-test. The mean diameters of the used catalyst was significantly larger than that of the fresh catalyst. At the $95 \%$ level of significance, the thickness of the "rind" layer was found to be

$$
8=18.65 \pm 5.37 \mu m
$$

Work is underway to characterize the internal pore structure of the used catalysts.

\section{Conclusions}

The extrusion of a coal paste via a high pressure syringe pump provides a convenient means of introducing coal into the reactor. The ISCO pump with a modified head assembly served well in this application. Early problems with plugging were due mainly to hot spots at the entrance and exit of the reactor. This problem was avoided by directing cooling air on the inlet and outlet fittings. A set of base operating conditions was identified that gives reasonable solubility class conversions with the benchmark Amocat 1A catalyst. A deactivation run at base conditions (Run ZTJ09) will provide a basis for comparison with other catalyst preparations. Regeneration of the used Amocat 1A catalyst was unsuccessful, and in fact served to further deactivate the catalyst. Evidence points to the formation of an approximately $19 \mu \mathrm{m}$ thick rind on the exterior of the catalyst particles. Major components of this layer are calcium and perhaps sulfurs. When heated to $500^{\circ} \mathrm{C}$, this material appears to sinter to form a barrier preventing ready access of oxygen to the particle interior. This barrier may also be responsible for the poor activity of the regenerated catalyst. 


\section{EVALUATION OF NOVEL CA'TALYST PREPARATIONS FOR DIRECT COAL LIQUEFACTION}

With the completion of the CCLM and establishment of a set of base operating conditions as described in the previous section, attention was next turned to the preparation and testing of novel catalysts. Obvious cardidates for further investigation are the alkali and alkaline earth promoted CoMo/Alumina catalysts. The results presented in Section II of this report demonstrated that a Ca-promoted Amocat 1A catalyst was as effective as the unpromoted catalyst for HYD and furthermore that the Ca-promoted catalyst coked to a much lesser extent. See Figure 8 and Tabls 6.

Another catalyst which has generated some recent interest among petroleum refiners is a catalyst marketed by Idemitsu Kosan Co., Ltd., for resid hydrocracking (R-HYC). The unique feature of this catalyst is that it contains an FeY zeolite and is reported to exhibit a high hydrocracking activity and a high selectivity to middle distillates when processing petroleum residuum streams.

The information generated to date with both of these catalysts is preliminary in nature. Further work is underway to characterize the spent catalysts in terms of carbon and metals deposits and pore structure. Idemitsu must give their permission to perform any analysis on zeolite content or zeolite structural integrity. In order to meet the final report deadline it is necessary therefore that only partial results can be reported at this time. More details will be available in the future in the dissertations by P.D. Jacobs and T. Zhang, and perhaps in literature publications stemming from this work.

It must be stressed that this work is continuing. The successful development of the CCLM puts us in a unique position to evaluate gram quantities of catalyst under actual 
continuous coal liquefaction conditions. In our unit we have excellent control over temperatures (isothermal operation) and the extent of mixing (perfectly mixed) while simulating ebullated bed operation. This is normally not the case in large pilot plant operations. Future work will concentrate on additional preparations suggested by our earlier experience in testing catalysts for hydrotreating coal derived liquids (29).

\section{A. Ca-MODIFIED AMOCAT-1A}

A calcium loaded Amocat-1A catalyst was prepared by loading the otherwise finished catalyst with calcium nitrate by the incipient wetness technique as described in Section II. The calcium loading corresponded to 0.9 moles $\mathrm{Ca} /$ mole $\mathrm{Mo}$, or approximately $5.7 \% \mathrm{CaO}$. This loading is sufficient to just extinguish the high temperature acid site peak in the tbutylamine TPD spectrum, Figures 5 and 6 .

\section{Run PMT01:}

This was a deactivation run at the base operating conditions of Table 42. Operation was smooth for the entire run duration and the unit was shut down as planned after the 10th yield period ( 245 hours on catalyst). The run summary is provided in Table 46.

The results from this run after corrections for small deviations from the target temperature of $800^{\circ} \mathrm{F}$ are plotted in Figure 52. The catalyst is still active at run termination. These results are compared with similar results for the untreated Amocat $1 \mathrm{~A}$ catalyst (Run ZTJ09) in Figures 53, 54 and 55. No dramatic differences are evident in the performance of these two catalysts. There appears to be an improvement in the toluene 
Table 46

Run PMT01 Summary, 5.5178 gms Amocat 1A-Ca Modified

Run Summary:

Yicld Period No.

Yicld l'eriod Length, hr

Average 'I'mperature, $F$

Average Pressure, psig

Sitirer Speed, rpm

Makeup Solvent Rate, $\mathrm{gm} / \mathrm{hr}$

Coal Paste Rate, $\mathrm{gm} / \mathrm{hr}$

Residence 'Time, $\mathrm{hr}$

Spacc Velocities:

(iM Coal/Hr/GM Cat

(iM Dry Coal/Hr/GM Cat

(iM MAF Coal/Hr/GM Cat

(iM MAI Coal/Ir/CC Cal

I.13 MAr Coal/IIr/CUFT Cat

Solvent/Coal Wt Ratios:

GiM CO/GM Coal

(iM CO+Resid/GM Coal

GM CO/GM Dry Coal

(iM CO+Resid/GM Dry Coal

(iM CO/GM MAF Coal

(iM CO+Resid/GM MAF Coal

$\mathrm{II}_{2}$ Treat Rate, $\mathrm{L}$ (STP)/Hr

$\mathrm{II}_{2}$ Treat Ratc, SCF/BBL

Lixil (ias Rate, L.(STP)/IIr

Cumulative Quantilics:

Ilours on Catalyst"

WI Makcup Solvent/Wt Cat

WI Resid/Wt Cat

WI Coal/Wt Cat

()verall Matcrial Balance', Wt\%

Yiclds ('TOT Feed Basis):

Carbon Monoxide, Wi\%

Carbon Dioxide, Wi\%

Ilydrocarbon Gases $\left(\mathrm{C}_{1}-\mathrm{C}_{4}\right)$, Wi $\%$

Slurry Product, W1\%

$\mathrm{I}_{2}$ Consumption (TO'T Feed Basis), Wi\%

Conversions (MAF Coal + Resid Basis):

Wt $\%$ Cyclohexane Soluble

WI\% Toluene Soluble

WI\% Pyridine Soluble

.. Does not include $\mathrm{NH}_{3}, \mathrm{H}_{2} \mathrm{~S}$ and $\mathrm{H}_{2} \mathrm{O}$ in exit gas.

- Prehydrotreating Run llours: 15

$\begin{array}{ccccc}1 & 2 & 3 & 4 & 5 \\ 2.0 & 2.0 & .2 .0 & 2.0 & 2.0 \\ 804 & 801 & 801 & 799 & 802 \\ 1990 & 2000 & 2000 & 2000 & 2000 \\ 1205 & 1205 & 1205 & 1205 & 1205 \\ 20.35 & 20.30 & 20.35 & 20.35 & 20.35 \\ 20.02 & 20.02 & 20.02 & 20.02 & 20.02 \\ 1.501 & 1.503 & 1.501 & 1.501 & 1.501\end{array}$

$\begin{array}{ccccc}2.002 & 2.002 & 2.002 & 2.002 & 2.002 \\ 1.514 & 1.514 & 1.514 & 1.514 & 1.514 \\ 1.417 & 1.417 & 1.417 & 1.417 & 1.417 \\ 0.783 & 0.783 & 0.783 & 0.783 & 0.783 \\ 48.92 & 48.92 & 48.92 & 48.92 & 48.92\end{array}$

2.700

3.033

3.569

4.010

3.815

4.286

25.05

3969

17.96

25.0

133.6

16.7

50.1

102.1

0.00

0.27

1.73

103.2

2.82

79.5

85.8

88.4
2.695

3.028

3.562

4.003

3.808

4.279

25.05

3974

19.9

2.700

3.033

3.569

4.010

3.815

4.286

25.05

3969

21.00

73.1

329.3

48.2

144.4

100.0

100.8

0.00

0.31

1.73

101.2

2.38

78.6

84.7

87.7
64.2

80.6

85.0
0.00

0.43

1.88

99.8

2.14
2.700

3.033

3.569

4.010

3.815

4.286

25.05

3969

21.61

97.0

426.6

63.8

191.2

99.3

100.3

0.00

0.51

1.86

98.6

0.59

2.00

99.7

1.71

1.90

64.3

66.4

77.2

80.0 
Table 46 (continued)

Run Summary:

Y'icld Period No.

Yicld Period Length, hr

Average Temperature, $\mathbf{F}$

Average Pressure, psig

Stirrer Speed, rpm

Mukcup Solvent Rate, $\mathrm{gm} / \mathrm{hr}$

Coal Paste Rate, gm/hr

Residence Time, hr

Run PMT01 Summary, 5.5178 gms Amocat 1A-Ca Modified

Space Velocities:

GM Coal/Hr/GM Cal

GM Dry Coal/Hr/GM Cat

GM MAF Coal $/ \mathrm{Hr} / \mathrm{GM}$ Cat

GM MAF Coal/1/r/CC Cat

L.B MAF Coal/Hr/CUFT Cat

6

2.0

801

2000

1205

18.90

20.02

1.560

7
2.0
798
2010
1205
18.60
20.02
1.573

8

2.0

802

2000

1205

18.90

20.02

1.560

9

2.0

801

2000

1205

19,90

22.20

1.444

10

2.0

801

190

1205

19.90

20.02

1.51)

Solvent/Coal W/ Ratios:

GM CO/GM Coal

GM CO + Resid/GM Coal

(jM CO/GM Dry Coal

GM CO+Resid/GM Dry Coal

GM CO/GM MAF Coal

GM CO + Resid/GM MAF Coal

2.002

1.514

1.417

0.783

48.92

2.002

1.514

1.417

0.783

48.92

2.002
1.514
1.417
0.783
48.92

2.220

1.679

1.571

0.869

54.25

2,002

1.514

1.417

0.783

48.92

$\mathrm{H}_{2}$ Treat Rate, L(STP)/Hr

11 , Treat Rate, SCF/BBL,

Iixit Gas Rate, I.(STP)/Ir

Cumulative Quantities:

IIours on Catalyst"

Wt Makeup Solvent/Wt Cat

WI Resid/Wt Cat

Wi Coal/Wt Cat

Yields (TOT Feed Basis):

Carbon Monoxide, Wt\%

Carbon Dioxide, Wi\%

Hydrocarbon Gases $\left(C_{1}-C_{4}\right)$, Wt\%

$\mathrm{H}_{2}$ Consumption (TOT Feed Basis), Wt\%

Conversions (MAF Coal + Resid Basis):

WI\% Cyclohexane Soluble

WI\% Toluene Soluble

- Does not include $\mathrm{NH}_{3}, \mathrm{H}_{2} \mathrm{~S}$ and $\mathrm{H}_{2} \mathrm{O}$ in exit gas.

i. Prehydrotreating Run Hours: 15

... No gas analysis. 


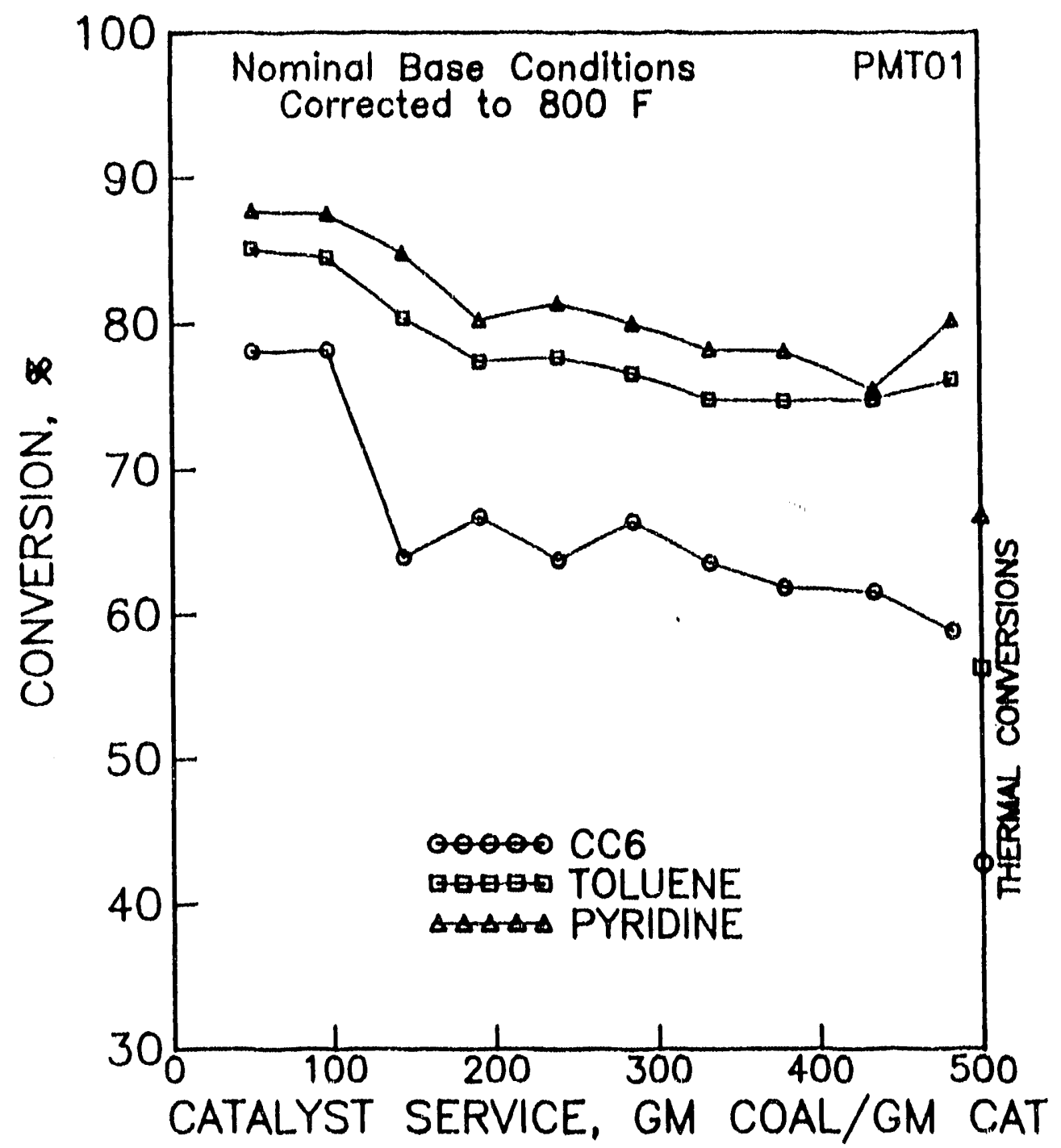

Figure 52. Deactivation run for Ca-modified Amocat $1 \mathrm{~A}$ catalyst at the operating conditions of Table 42 . 


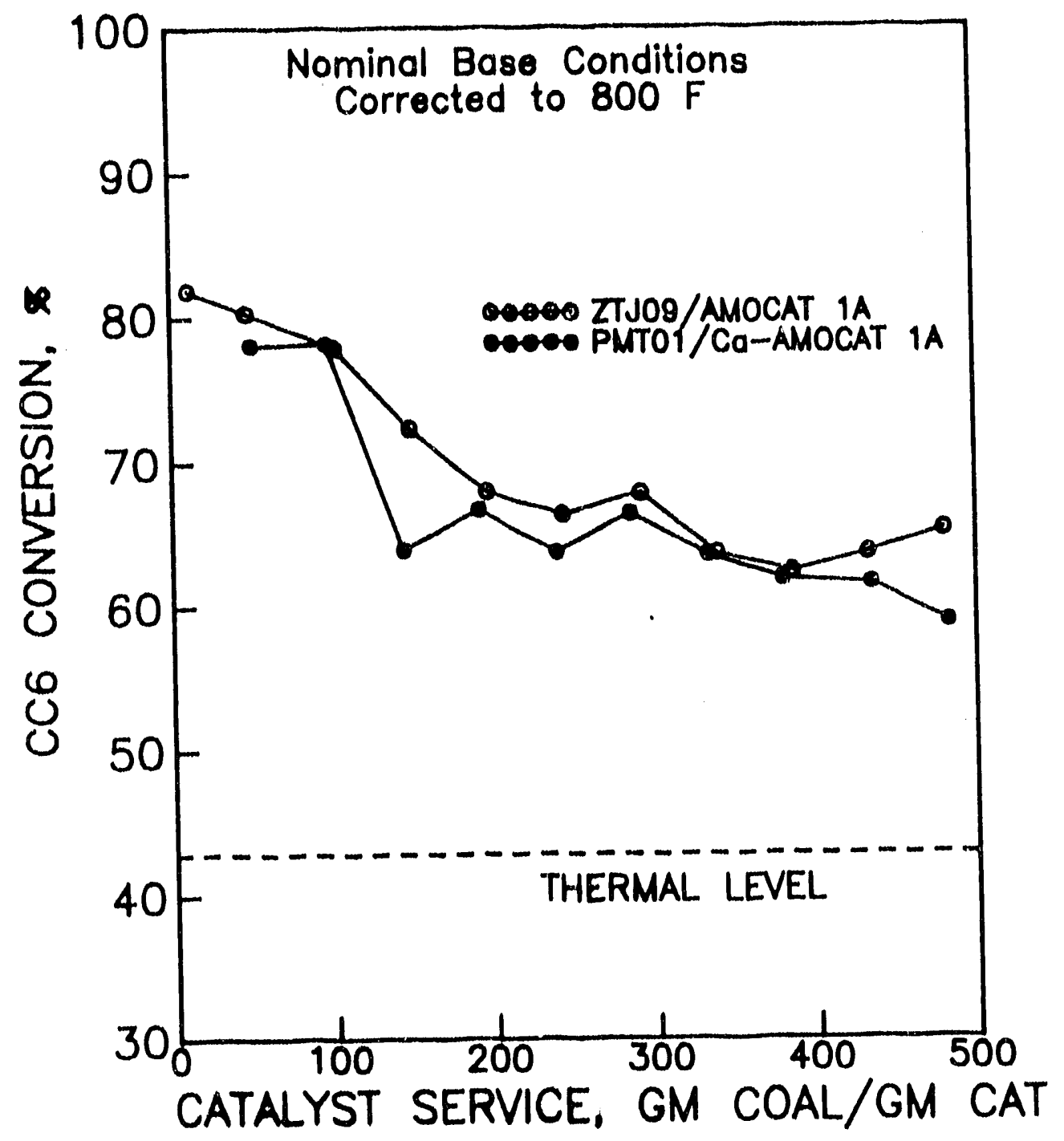

Figure 53. Comparison of Ca-modified and unmodified Amocat 1A catalysts for cyclohexane conversion. Table 42 run conditions. 


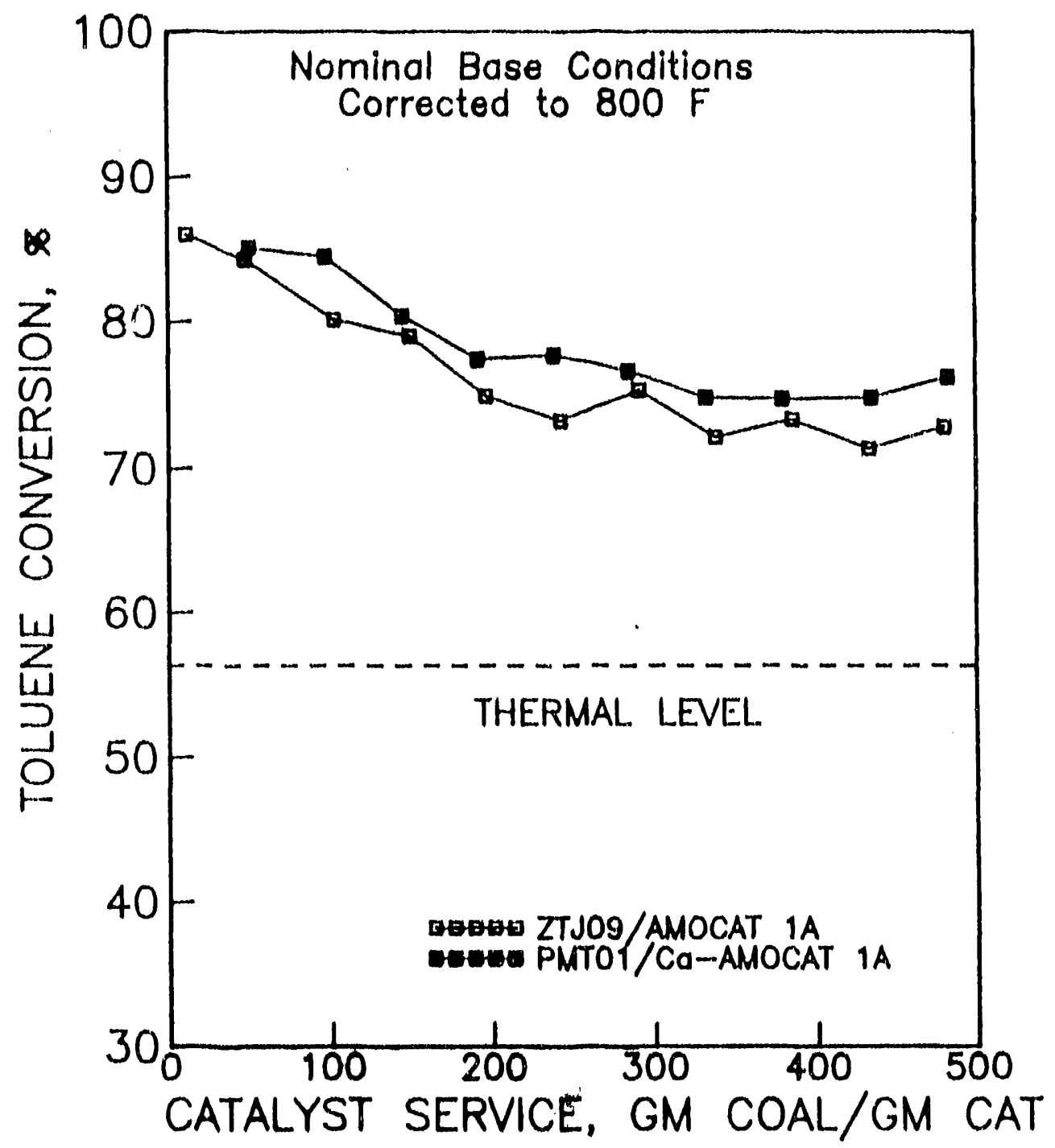

Figure 54. Comparison of Ca-modified and unmodified Ainocat 1A catalysts for toluene conversion. Table 42 run conditions. 


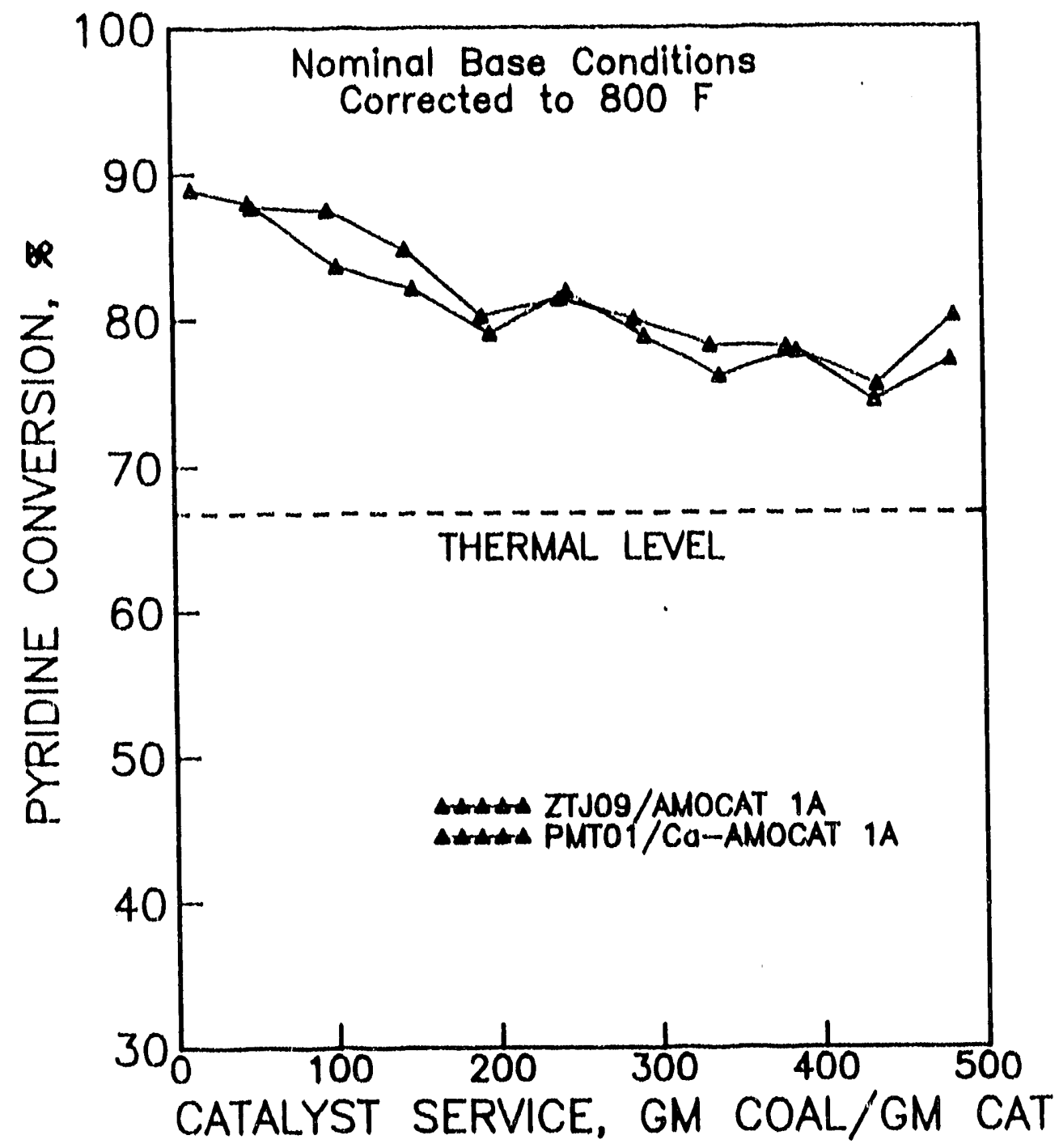

Figure 55. Comparison of Ca-modified and unmodified Amocat 1A catalysts for pyridine conversion. Table 42 run conditions. 
conversions due to the calcium promotion, but the improvements if any are slight, and they may be within experimental uncertainty.

It remains to be determined if coke depositions are reduced by the calcium modification as was observed in the hydrotreating work, Section II. Loss on ignition of the spent catalyst was $5.65 \%$ and the percent catalyst recovery was $136.0 \%$. It may be that the accumulation of calcium rich deposits on the external surface of the catalyst is a principal cause of deactivation, and that this mechanism would not be altered by the calcium modification. Amoco has agreed to perform an electron microprobe analysis for calcium and other metals on both the Ca-modified and unmodified spent catalysts. Pore structural analyses are also in progress. Once these data and the $\mathrm{C} / \mathrm{H}$ analytical data are available it may be possible to make an assertion about the principal cause or causes of deactivation in both of these catalysts.

\section{B. IDEMITSU R-HYC (FeHY/CoMo/ALUMINA)}

Information pertaining to the development and usage of R-HYC is available in several literature sources. The catalyst has been used commercially as a partial replacement of conventional resid desulfurization catalysts in order to convert heavy residues to smaller hydrocarbons (56). The FeHY zeolite is prepared by treating $\mathrm{NH}_{4} \mathrm{Y}$ with ferric nitrate solution, and the catalyst is most active in the presence of hydrogen sulfide $(57,58)$. When a Kuwait atmospheric residue was hydrocracked over the R-HYC catalyst, the hydrocracking activity increased very gradually upon increasing the temperature from $400 \%$ to $410^{\circ} \mathrm{C}$, and no decline in activity was observed for the 1500 hour run duration (59). In contrast, the HDS activity increased immediately and then declined throughout the remainder of the run. 
It was argued that dehydrogenation and graphitization of the carbon residues at the higher temperature exposed acid sites on the external surface of the zeolite crystals. These external protonic sites are believed to be active in residuum processing. Depending upon the method of preparation, several types of Fe species are observed. The active species are believed to be small $\mathrm{Fe}^{3+}$ containing clusters bonded to the zeolite framework $(60,61,62)$.

\section{Run IKC01:}

Run IKC01 was a deactivation run at the conditions of Table 42. The R-HYC catalyst was in the form of $1 / 16$ inch trilobe extrudates. It consists of an FeHY zeolite incorporated into CoMo/Alumina. The information provided by Idemitsu is quite limited, Table 47.

Operation of the unit proceeded smoothly. However, by the end of the 6th balance period it was evident that the catalyst had deactivated to near thermal levels and the run was terminated. The run summary is presented in Table 48.

Results for Run IKC01 are plotted in Figure 56. While initial activities are high, the deactivation is clearly rapid and severe. Near thermal levels are achieved by a catalyst service of approximately $200 \mathrm{gm} / \mathrm{gm}$. The R-HYC catalyst performance is compared with that of the Amocat 1A catalyst in Figures 57, 58, and 59. While there may be some improvement in activity early in the run, any advantages claimed for the Idemitsu catalyst are quickly lost.

The pore size distribution in the micropore (external to the zeolite) and mesopore range is critical to the performance of a coal liquefaction catalyst. The optimum micropore range appears to be in the neighborhood of $120 \mathrm{~A}$ diameter to allow for accumulation of 
Table 47. Idemitsu R-HYC Catalyst Propertles

$\begin{array}{ll}\text { Carrier } & \text { Iron Supported Zeolite - Alumina } \\ \text { Supported Metal } & \text { Co - Mo } \\ \text { Shape } & \text { Trilobe Extrudate } \\ \text { Size } & 1 / 16^{\prime \prime} \text { Diameter } \\ \text { Apparent Bulk Density }(\mathrm{g} / \mathrm{ml}) & 0.5 \\ \text { Compact Bulk Density }(\mathrm{g} / \mathrm{ml}) & 0.6 \\ \text { Surface Area }\left(\mathrm{m}^{2} / \mathrm{g}\right) & 430 \\ \text { Crush Strength }(\mathrm{kg} / \mathrm{mm}) & 1.0\end{array}$


Table 48

\section{Run IKC01 Summary, 5.0015 gms Idemitsu Kosan Catalyst}

Run Summury:

Ylate Period No,

Ylold Period Length, hr

Average 'Tomperature, it

Average Pressure, psig

Silirrer Speed, rpm

Makeup Solvent Ratc, $\mathrm{gm} / \mathrm{hr}$

Coal l'asto Rate, gm/hr

Residence 'Ilime, hr

Space Volocities:

CM Coal/Hr/CMM Cat

(IM Dry Coal/1Ir/GM Cat

CM MAl Coal/Hr/GM Cat

(IM MAI Coal/IIr/CC Cat

I.13 MAl' Coal/Hr/CUFI' Cat

Solvent/Coal Wt Rutios:

(IM CO/GM Coal

(iM CO+Resid/CM Coal

GM CO/GM Dry Coal

GM CO+Resid/CMM Dry Coal

GiM CO/GM MAP Coal

GM CO+Resid/GM MAF Coal

II, Treat Ratc, L.(SIT)/IIr

$\mathrm{II}_{2}$ I'reat Rate, SCV/nBL

I.xil Gas Ratc, L.(SIT)/Hr

Cunulative Quantities:

Ilours on Catalysi."

Wi Makeup Solvent/Wt Cat

Wi Resid/Wi Cat

WI Coal/Wi Cat

Ovcrall Material Balance', WI\%

Yiclds (I'OT Fecd Basis):

Carbon Monoxide, Wi\%

Carbon Dloxide, Wt\%

Ilydrocarbon Gases $\left(\mathrm{C}_{1}-\mathrm{C}_{4}\right)$, Wt\%

Slurry Product, Wt\%

$\mathrm{H}_{2}$ Consumption (T'O'T Fecd IBasis), Wt\%

Conversions (MAP Coal + Resid Basis):

Wt\% Cyclohexane Soluble

Wt\% I'oluene soluble

WI\% Pyridine Soluble

- Does not inctude $\mathrm{NH}_{3}, \mathrm{H}_{2} \mathrm{~S}$ and $\mathrm{H}_{2} \mathrm{O}$ in exil gas.

"Prehydrotreating Run Ilous:s: 19

$\begin{array}{cc}1 & 2 \\ 2.0 & 2.0 \\ 802 & 801 \\ 1990 & 2000 \\ 910 & 910 \\ 20.00 & 20.35 \\ 20.02 & 20.02 \\ 1.51 .5 & 1.501\end{array}$

3

- 2.0

800

2000

910

20.05

20.02

1.513

$\begin{array}{ccccc}2.001 & 2.001 & 2.001 & 2.001 & 2.001 \\ 1.514 & 1.514 & 1.514 & 1.514 & 1.514 \\ 1.416 & 1.416 & 1.416 & 1.416 & 1.416 \\ 0.783 & 0.783 & 0.783 & 0.783 & 0.783 \\ 48.90 & 48.90 & 48.90 & 48.90 & 48.90\end{array}$

$\begin{array}{lllll}2.665 & 2.700 & 2.670 & 2.5(00 & 2.245 \\ 2.998 & 3.033 & 3.003 & 2.893 & 2.579 \\ 3.523 & 3.569 & 3.529 & 3.384 & 2.968 \\ 3.964 & 4.010 & 3.970 & 3.825 & 3.409 \\ 3.765 & 3.815 & 3.772 & 3.617 & 3.172 \\ 4.236 & 4.286 & 4.243 & 4.088 & 3 .(44.3 \\ & & & & \\ 25.05 & 25.05 & 25.05 & 25.05 & 25.05 \\ 4006 & 3969 & 4000 & 4119 & 4502 \\ 21.31 & 22.61 & 23.33 & 25,04 & 25.21\end{array}$

34.3

173.9

23.2

69.5

100.9

$\begin{array}{rr}0.00 & 0.00 \\ 0.27 & 0.33 \\ 1.79 & 1.79 \\ 101.0 & 100,0\end{array}$

2.05

81.3

87.1

88.6
56.0

253.7

37.2

111.6

100.4

100,0

1.71

78.8
84.4
86.6

73.5

324.5

48.8

146.4

102.6
97.0

417,0

64.3

$193.0^{\circ}$

104,3

0.00

1,05

1.73

103.2

1.25

44.9

67.5

72.7
121,0

508.2

79.9

239.5

102.8
5

2.0
$7 y 4$

2010

15.80

20,02

1.703
48.90 
Table 46 (continued)

Run PMT01 Summary, 5.5178 gms Amocat 1A-Ca Modified

Run Summary:

Yield Period No.

Yield Period Length, hr 2.0

Average 'Temperature, $\mathrm{F} \quad 799$

Average Pressure, psig $\quad 1990$

Stirrer Speed, rpm $\quad 910$

Makeup Solvent Rate, $\mathrm{gm} / \mathrm{hr} \quad 20.25$

Coal Paste Rate, $\mathrm{gm} / \mathrm{hr} \quad 20.02$

Residence Time, hr $\quad 1.505$

Space Velocities:

GM Coal/Hr/GM Cat

(iM Dry Coal/Hr/GM Cat $\quad 1.514$

GM MAr Coal/Hr/GM Cat $\quad 1.416$

GM MAF Coal $/ \mathrm{Hr} / \mathrm{CC}$ Cat $\quad 0.783$

LB MAF Coal/Hr/CUIT Cat $\quad 48.90$

Solvent/Coal Wt Ratios:

GM CO/GM Coal $\quad 2.690$

GM CO + Resid/GM Coal $\quad 3.023$

GM CO/GM Dry Coal $\quad 3.556$

GM CO+Resid/GM Dry Coal 3.997

GM CO/GM MAF Coal $\quad 3.800$

(iM CO+Resid/GM MAF Coal $\quad 4.272$

$\mathrm{H}_{2}$ I ics Rate, L(STP)/Hr $\quad 25.05$

$\mathrm{II}_{2}$ Treat Rate, SCF/BBL

Exit Gas Rate, L(STP)/Hr $\quad 26.23$

Cumulative Quantitics:

IIours on Catalyst ". 145.5

Wt Makeup Solvent/Wt Cat $\quad 599.0$

Wt Resid/Wt Cat $\quad 96.3$

Wt Coal/Wt Cat 288.7

Overall Material Balance', Wt\% $\quad 103.0$

Yiclds (TO'T Feed Basis):

Carbon Monoxide, Wt\% $\quad 0.00$

Carbon Dioxide, Wt\% 1.23

Ilydrocarbon Gases $\left(C_{1}-C_{4}\right), W_{t} \% \quad 1.73$

Slurry Product, Wt\% 101.3

$\mathrm{H}_{2}$ Consumption (TO'T Feed Basis), Wt\% 0.95

Conversions (MAF Coai + Resid Basis):

Wi\% Cyclohexane Soluble $\quad 39.4$

WI\% Toluene Soluble $\quad 60.6$

Wt\% Pyridine Soluble $\quad 65.0$

- Does not include $\mathrm{NH}_{3}, \mathrm{H}_{2} \mathrm{~S}$ and $\mathrm{H}_{2} \mathrm{O}$ in exit gas.

-* Prehydrotreating Run Hours: 19 


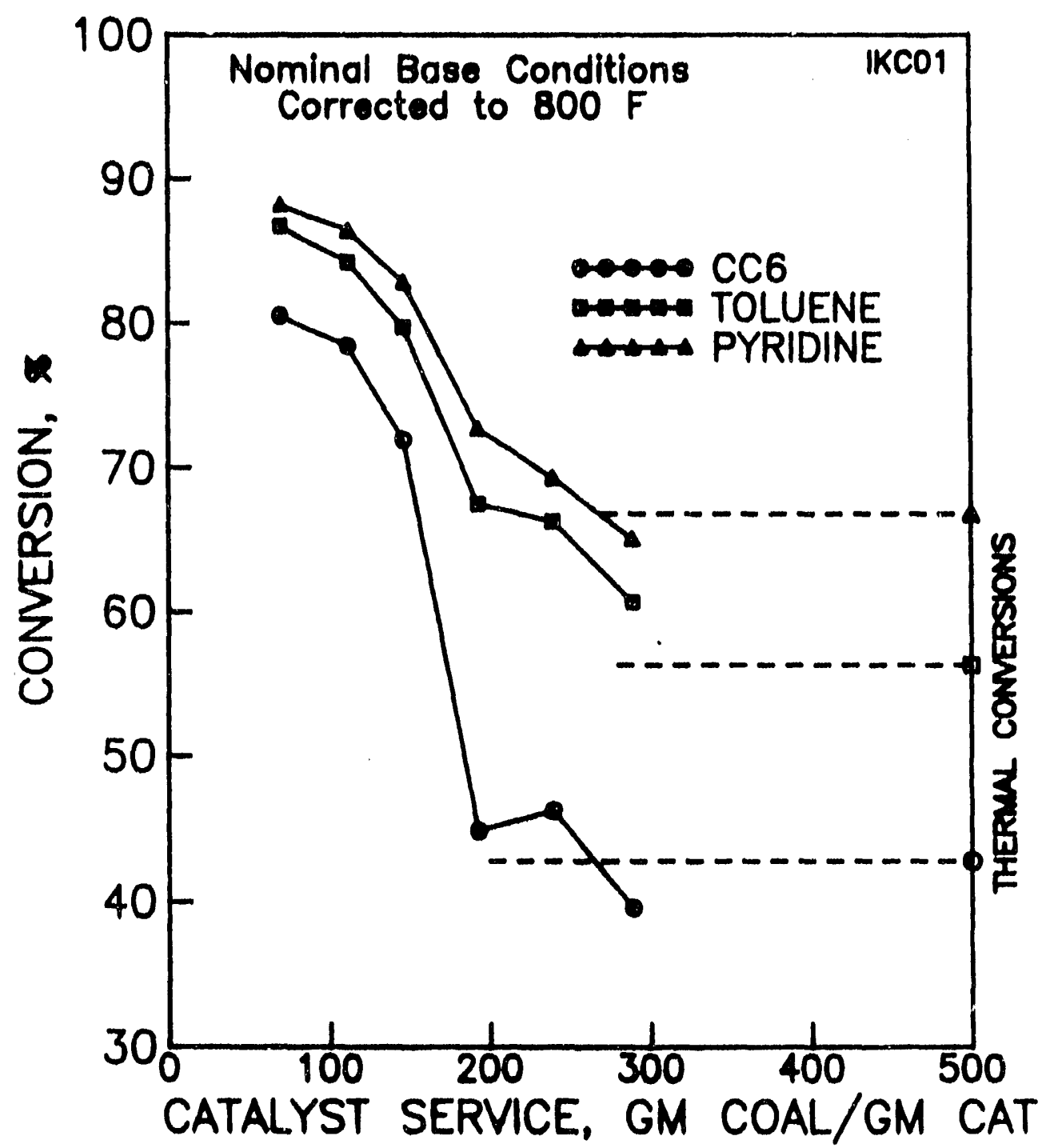

Figure 56. Deactivation run for Idemitsu Kosan R-HYC catalyst at the operating conditions of Table 42 . 


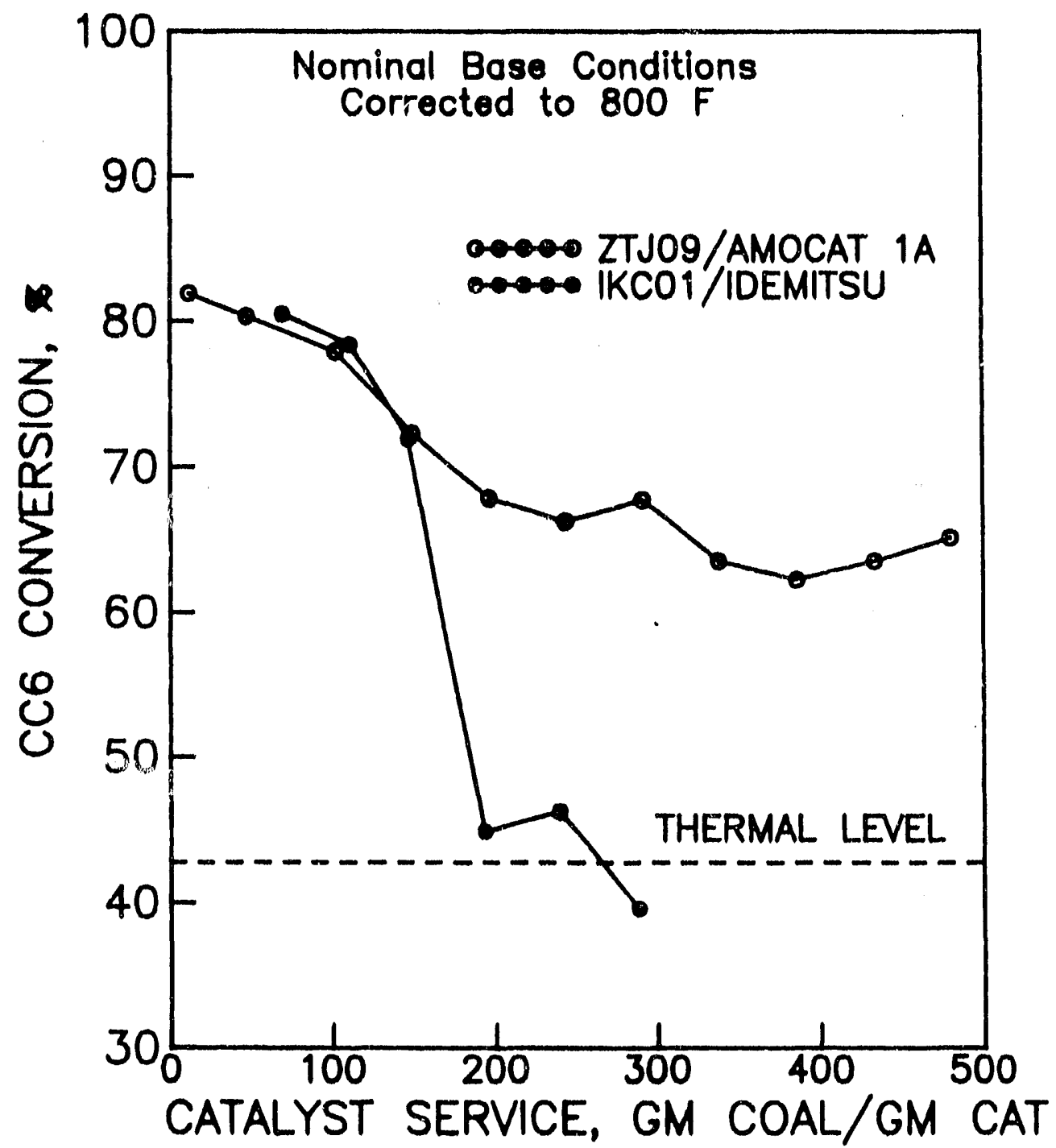

Figure 57. Comparison of Idemitsu R-HYC and Amocat 1A catalysts for cyclohexane conversion. Table 42 run conditions. 


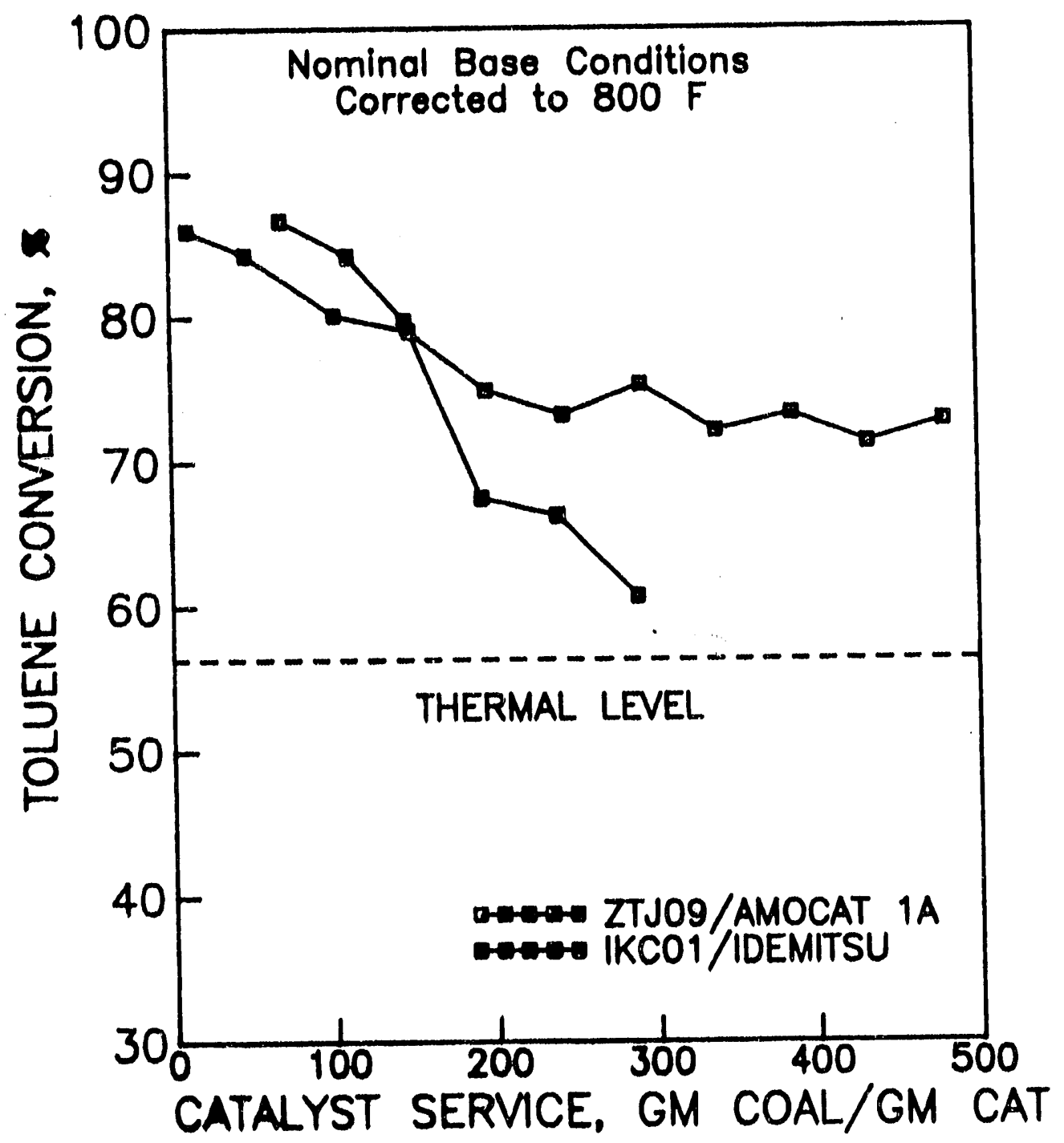

Figure 58. Comparison of Idemitsu R-HYC and Amocat 1A catalysts for toluene conversion. Table 42 run conditions. 


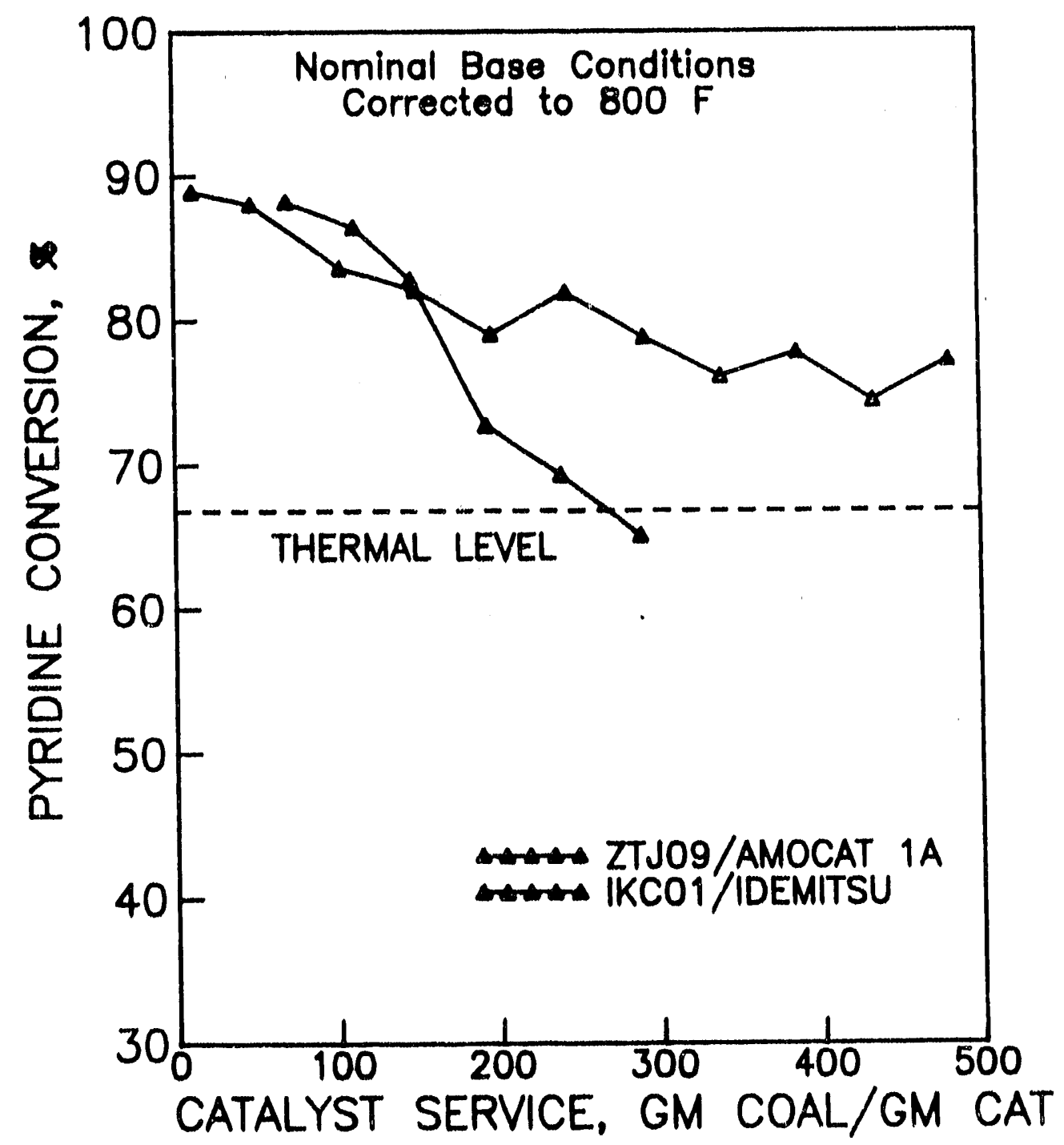

Figure 59. Comparison of Idemitsu R-HYC and Amocat 1A catalyst for pyridine conversion. Table 42 run conditions. 
carbonaceous material without blocking the pores $(8,9,40,43)$. Since the Idemitsu catalyst was not designed for coal liquefaction applications, it may well be that the pore structure is not optimum for this application. Further collaboration with Idemitsu is needed to obtain structural information on their catitgst. Also, we have recently submitted samples of filtered liquefaction products from both runs for GC simulated distillation analysis to ascertain whether any advantage in boiling point distribution can be realized with the zeolite containing catalyst. Because of the critical importance of hydrogen sulfide on activation of the FeHY zeolite, it might be worthwhile to repeat the run with added $\mathrm{H}_{2} \mathrm{~S}$.

\section{CONCLUSIONS}

Two catalysts have been successfully compared with the benchmark Amocat $1 \mathrm{~A}$ catalyst under actual coal liquefaction conditions for ten days run duration. The addition of percentage quantities of calcium to Amocat $1 \mathrm{~A}$ does not appear to help or hinder performance. The Idemitsu R-HYC catalyst performed well early in the run but deactivated quickly. In both cases, much analytical work has yet to be done to understand the cause or causes of deactivation. 


\section{LITERATURE REFERENCES}

1. Spencer, D., EPRI Jour., 12 (1), 40 (198\%).

2. Petrakis, L. and D.W. Grandy, Fuel, 59, 227 (1980.

3. Petrakis, L., Grandy, D.W. and G.L. Jones, Fuel, 61, 21 (1982).

4. Cronauer, D.C., Jewell, D.M., Shah, Y.T., Modi, R.J. and K.S. Seshadri, Ind. Eng. Chem., Fund., 18, 368 (1979).

5. Abichandani, J.S., Wieland, J.H., Shah, Y.T., and D.C. Cronauer, AIChE Jour., 30, 295 (1984).

6. Abichandani, J.S., Wieland, J.H., Shah, Y.T., and D.C. Cronauer, AIChE Jour., 30, 304 (1984).

7. Tsai, M.C. and S.W. Weller, Fuel Proc. Technol., 2, 313 (1979).

8. Bertolacini, R.J., Gutberlet, L.C., Kim, D.K., and K.K. Robinson, "Catalyst Development for Coal Liquefaction", rept., EPRI AF-1084, June, 1979.

9. Kim, D.K., Bertolacini, R.J., Forgac, J.M., Pellet, R.J., Robinson, K.K., and C.V. McDaniel, "Catalyst Development for Coal Liquefaction", rept. EPRI AF-1233, November 1979.

10. Wu, W.R.K. and H.H. Storch, "Hydrogenation of Coal and Tar", U.S. Dept. of Interior, Bur. of Mines Bull. 633, 1968.

11. Kageyama, Y.; Masuyama, T. Proc. 1985 Int. Conf. Coal Sci., 157-160 (1985).

12. Kelly, J.F.; Kriz, J.F.; Ternan, M. Canadian Pat. No. 1,121,293, April 6, 1982.

13. Kelly, J.F.; Ternan, M. Can. J. Chem. Eng., 57, 726-733 (1979).

14. Muralidhar, G.; Massoth, F.E.; Shabtai, J. J. Catal., 85, 44-52 (1984).

15. Kovach, S.M.; Castle, L.J.; Bennett, J.V. Ind. Eng. Chem., Prod. Res. Dev., 17, 62-67, (1978).

16. Kordulis, Ch.; Lycorghiotis, A.; Voliotis, S.; Pomonis, P. Appl. Catal., 15, 301-315 (1985). 
17. Shimada, H.; Sato, T.; Yoshimura, Y.; Nishijima, A.; Matsuda, M.; Kohakahara, T.; Sato, K. Sekiyu Gakkaijhi, 31, 227-232 (1988).

18. Martinez, N.P.; Mitchell, P.C.N., Chem. Uses of Molybdenum, Proc. Int. Conf., 3rd, $1979,105-110$ (1979).

19. Kordulis, C.; Voliotis, S.; Lycourghiotis, A. J. Less-Common Met., 84, 187-200 (1982).

20. Kordulis, Ch.; Voliotis, A.; Lycourghiotis, A.; Vattis, D. Appl. Catal., 11, 179-193 (1984).

21. Kantschewa, M.; Delannay, F.; Jeziorowski, N.; Delgado, E.; Eder, S.; Ertl, G.; Knozinger, H. J. Catal., 87, 482-496 (1984).

22. Kettmann, V.; Balgavy, P.; Sokol, L. J. Catal., 112, 93-106 (1988).

23. Kordulis, C.; Voliotis, S.; Lycourghiotis, A. J. Less-Common Met., 85, 275-84 (1982).

24. Boorman, P.M.; Kriz, J.F.; Brown, J.R.; Ternan, M. Chem. Uses of Molybdenum, Proc. Int. Conf., 4th, 1982, 192-196 (1982).

25. O'Young, C.-L. J. Phys. Chem., 93, 2016-2018 (1989).

26. Baker, J.R.; McCormick, R.L.; Haynes, H.W. Jr. Ind. Eng. Chem. Res., 26, 1895-1901 (1987).

27. Satterfield, C.N. AIChE Jour., 21, 209-288 (19.75).

28. Koros, R.J. Chem. React. Eng., Proc. Int. Symp., 4th 1976, $372-381$ (1976).

29. Haynes, H.W., Jr., "Improved Catalysts for Coal Liquefaction", Final Rept., U.S.D.O.E., DOE/PC/70812-13, April 1988.

30. Kiviat, F.E. and L. Tetrakis, J. Phys. Chem., 77, 1232 (1973).

31. Segawa, K. and W.K. Hall, J. Catal., 76, 133 (1982).

32. Boorman, P.M., Kydd, R.A., Sarbak, Z. and A. Somogyvari, J. Catal., 96, 115 (1985).

33. Baker, J.R., M.S. Thesis, Univ. of Wyoming, May 1986.

34. Sivasanker, S., Ramaswany, A.V. and P. Ratvasamy, 3rd Int. Conf. on Chem. and Uses Molybdenum, 98 (1979). 
35. Suarez, W., Dumesic, J.A. and C.G. Hill Jr., J. Catal., 94, 408 (1985).

36. Boorman, P.M., Kydd, R.A., Sarbak, Z. and A. Somogyvari, J. Catal., 100, 287 (1986).

37. Hou, P. and H. Wise, J. Catal., 78, 469 (1982).

38. Lipsch, J.M.J.G. and G.C.A. Schuit, J. Catal., 15, 179 (1969).

39. Boorman, P.M., Kydd, R.A., Sarbak, Z. and 1. Somogyvari, J. Catal., 106, 544 (1987).

40. McCormick, R.L., "The Influence of Support on the Performance of Molybdenum Sulfide Catalysts Used to Hydrotreat Coal Liquids", Ph.D. Thesis, University of Wyoming, December 1987.

41. Ternan, M. and Brown, J.R., Fuel, 61, 1110 (1982).

42. Sajkowski, D.J., Pacheco, M.A., Fleisch, T.H. and B.L. Meyers, Proc. 9th Intl. Congr: Catal., 1, 223-229 (1988).

43. McCormick, R.L., King, J.A., King, T.R. and H.W. Haynes, Jr., Ind. Eng. Chem. Res., 28, 940-947 (1989).

44. McCormick, R.L., Baker, J.R., Haynes, H.W. Jr., and R. Malhotra, Energy Fuels, 2, 740-743 (1988).

45. Mahoney, J.A., Robinson, K.K. and E.C. Myers, CHEMTECH, 8, 758-763, (1978).

46. Mahoney, J.A. NATO Advs. Study Just. Ser., Ser. E: Appl. Sci. - No. 52, p. 487-513, A.E. Rodrigues, J.M. Calo, N.H. Sweed, Eds., Sijthoff Noordhoff, Rockville, MD, 1981.

47. Holloway, P.H. Sandia Lab. [Rep.], SAND 78-0056, August, 1978.

48. Yoshimura, Y., Hayamizu, K., Sato, T., Shimada, H., and A. Nishijima, Fuel Proc. Technol., 16, 55-69 (1987).

49. Song, G.-H., Bavarian, F., Fan, L.-S., Buttke, R.D. and L.B. Peck, Can. J. Ch. E., 67, 265.275 (1989).

50. Hallie, H., Oil \& Gas Jour., p. 69, Dec. 20, (1982).

51. Doolittle, A.K. J. .4ppl. Phys. 1951, 22, 1471-1475.

52. Thomas, M.G. and D.G. Sample, Fuel, 60, 145 (1981). 
53. Schindler, H.D., Chen, J.M., Peluso, M., Moroni, E.C. and J.D. Potts, "The Integrated Two-Stage Liquefaction Process", pap. 56, 1981 Ann. Mtg. of A.I.Ch.E., New Orleans, Nov. 8-12, 1981.

54. Polinski, L.M., Stiegel, G.J. and R.E. Tischer, "1980 Status Review", DOE/PETC/ TR-81-2, June, 1980.

55. Tait, A.M., Swanson, A.J., Pacheco, M.A. and W.C. Rovesti, "Multistage Coal Liquefaction Catalyst Development", Final Rept. EPRI RP 2561-02, June, 1989.

56. Sue, H. and M. Fujita, Oil \& Gas Jour., 51-56, May 26, 1986.

57. Hidaka, S., Iino, A., Nakai, S., Shimakawa, H., Mibuchi, T. and K. Nita, Ketjen Catalysts Symposium, pap. H-9, 1986.

58. Hidaka, S., Iino, A., Nita, K., Maeda, Y. and K. Morinaga, Proc. 7th Int. Zeolite Conf., IM-2-5, 329-336 (1986).

59. Nita, K., Nakai, S., Stidaka, S., Mibuchi, T., Shimakawa, H., II, K.-I. and K. Inamura, Stud. Surf. Sci. Catal. 34, 501-511 (1987).

60. Hidaka, S., Iino, A., Mibuchi, T., Nita, K. and N. Yamazoe, Chem Lett., 1213-1216 (1986).

61. Hidaka, S., Iino, A., Gotoh, M., Ishikawa, N., Mibuchi, T. and K. Nita, Appl. Catal. 43, 57-69 (1988).

62. Hidaka, S., lino, A., Nita, K., Morinaga, K. and N. Yamazoe, Bull. Chem. Soc. Jpn. $61,3169-3174$ (1988).

63. Tauster, S.J., Pecoraro, T.A. and R.R. Chianelli, J. Catal. 63, 515 (1980).

64. Tauster, S.J. and K.L. Riley, J. Catal. 67, 250 (1981).

65. Tauster, S.J. and K.L. Riley, J. Catal. 70, 230 (1981).

66. Parekh, S.S. and S.W. Weller, J. Catal. 47, 100 (1977).

67. Zmierczak, W.; Muralidhar, G. and F.E. Massoth, J. Catal. 77, 432 (1982).

68. Burch, R. and A. Collins, Appl. Catal. 17, 273 (1985).

69. Reddy, B.M.; Chary, K.V.R. and V.S. Subrahmanyam, J. Chem. Soc., Faraday Trans. 1, 81, 1655 (1985). 
7). Bodrero, T.A. and C.H. Bartholomew, J. Catal. 84, 145 (1983).

71. Mears, D.E. and R.C. Hansford, J. Catal. 9, 125 (1967).

72. Gosselink, J.W.; Schaper, H.; de Jonge, J.P. and W.H.J. Stork, Appl. Catal. 32, 337 (1987).

73. Segawa, K.-I. and W.K. Hall, J. Catal. 77, 221 (1982).

74. Valyon, J.; Schneider, R.L. and W.K. Hall, J. Catal. 85, 277 (1984).

75. Millman, W.S.; Segawa, K.-I.; Smrz, D. and W.K. Hall, Polyhedron 5, 169 (1986).

76. Zmieerczak, W.; Qader, Q. and F.E. Massoth, J. Catal. 106, 65 (1987). 


\section{APPENDIX I \\ TEMPERATURE PROGRAMMED DESORPTION/CHEMISORPTION APPARA'TUS}

A schematic of the Temperature Programmed Desorption/Chemisorption apparatus is shown in Figure A1. In 'TPD operation for acid sites characterization, helium carrier palsses through a series of sample valves where it may be diverted through a number of devices before it ultimately exits through the sample side of a thermal conductivity detector. With the valves in the position indicated in the figure the pure helium carrier passes through the sample holder (SH) in a temperature programmed oven. By switching Valve $\perp$ an $\mathrm{NH}_{3} / \mathrm{He}$ mixture is passed over the catalyst and breakthrough is observed by means of the detector. Upon returning Valve 1 to its original position, pure helium again flows over the catalyst and ultimately base line is reestablished with $\mathrm{NH}_{3}$ preadsorbed on the catalyst. Upon raising the temperature in a linear fashion, two peaks are normally observed - a low temperature peak due to physically adsorbed $\mathrm{NH}_{3}$ and a high temperature peak due (o) chemisorbed $\mathrm{NH}_{3}$ (acid-base interaction). By a similar manipuation of Valve 2 the same experiment can be conducted with organic bases which are liquids at ambient conditions such as tert-butylamine or pyridine. Valve 3 is a dosing valve which can be used to pass a known volume of butane, for example, into the detector for calibration purposes. The caltalyst can be sulfided in silu by switching Valve 4 . With this arrangement the sulfiding gas never passes through the detector where it may damage the filaments.

A fundamental problem in catalysts is to identify the specific surface area or dispersion of active component on the support. With this in mind, we have also designed the apparatus of Figure $\mathrm{A} 1$ for chemisorption studies in the pui.e or continuous flow mode. 


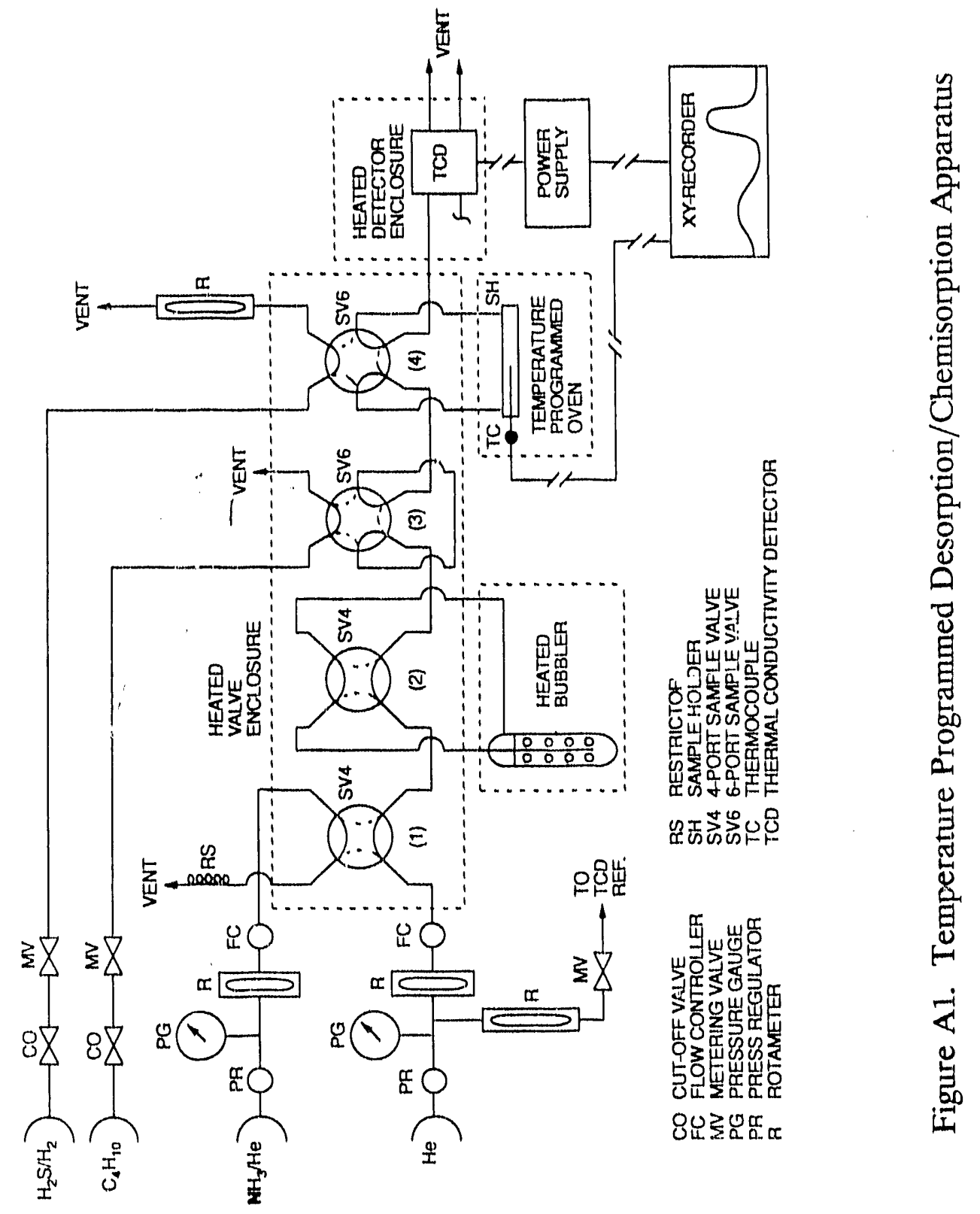


reasonable correlations with HDS activity $(63-65,72)$ while others have been less successful $(67,68)$. The popular usage of thiophene HDS as a model reaction may be partly responsible (72). Of paramount importance to our work is the observation that hydrogenation activity correlates well with $\mathrm{O}_{2}$ chemisorption, and this has been observed for sulfided molybdenum, promoted and unpromoted, on a variety of catalyst supports $(6 i, 69)$. The primary function of a coal liquefaction catalyst is to hydrogenate.

Other probe molecules are of interest. Hall and coworkers $(73,74,75)$ in an IR study demonstrated that NO adsorbed selectively on the molybdenum phase of molybdenaalumina catalysts. Carbon dioxide was found to adsorb selectively on the alumina portion of the catalyst. Massoth and coworkers used this fact to determine the $\mathrm{MoS}_{2}$ coverage on sulfided molybdena alumina catalysts (76).

\section{RESULTS}

Some results exploring the usage of various organic bases in acid sites characterization will now be presented. As an aid to discussion, it is helpful to have an indication of relative basicity of the organic basis that have been investigated. Table $\mathrm{A} 1$ lists the basicity constants in aqueous solution of several organic bases. The order of increasing basic strength is from top (pyridine) to bottom (piperidine) in the table.

In the first series of experiments, the effect of preadsorption temperature on the pyridine TPD spectra was investigated. The catalyst in these experiments was silica-alumina $\left(45 \% \mathrm{Al}_{2} \mathrm{O}_{3}, 53 \% \mathrm{SiO}_{2}\right.$ ) obtained from the Alfa Division of Ventron Corporation. It was ground to $20 / 40$ mesh size and pretreated in air overnight at $500^{\circ} \mathrm{C}$ before loading approximately one gram into the sample tube. The purge gas (helium) flowrate was 60 
reasonable correlations with HDS activity $(63-65,72)$ while others have been less successful $(67,68)$. The popular usage of thiophene HDS as a model reaction may be partly responsible (72). Of paramount importance to our work is the observation that hydrogenation activity correlates well with $\mathrm{O}_{2}$ chemisorption, and this has been observed for sulfided molybdenum, promoted and unpromoted, on a variety of catalyst supports $(67,69)$. The primary function of a coal liquefaction catalyst is to hydrogenate.

Other probe molecules are of interest. Hall and coworkers $(73,74,75)$ in an IR study demonstrated that NO adsorbed selectively on the molybdenum phase of molybdenaalumina catalysts. Carbon dioxide was found to adsorb selectively on the alumina portion of the catalyst. Massoth and coworkers used this fact to determine the $\mathrm{MoS}_{2}$ coverage on sulfided molybdena alumina catalysts (76).

\section{RESULTS}

Some results exploring the usage of various organic bases in acid sites characterization will now be presented. As an aid to discussion, it is helpful to have an indication of relative basicity of the organic basis that have been investigated. Table A1 lists the basicity constants in aqueous solution of several organic bases. The order of increasing basic strength is from top (pyridine) to bottom (piperidine) in the table.

In the first series of experiments, the effect of preadsorption temperature on the pyridine TPD spectra was investigated. The catalyst in these experiments was silica-alumina $\left(45 \% \mathrm{Al}_{2} \mathrm{O}_{3}, 53 \% \mathrm{SiO}_{2}\right)$ obtained from the Alfa Division of Ventron Corporation. It was ground to $20 / 40$ mesh size and pretreated in air overnight at $500^{\circ} \mathrm{C}$ before loading approximately one gram into the sample tube. The purge gas (helium) flowrate was 60 
Table A1. Basicity Constants of Some Organic Bases

\begin{tabular}{lc}
\multicolumn{1}{c}{ Compound } & $\mathrm{K}_{\mathrm{o}}$ \\
Pyridine & $1.78 \times 10^{-9}$ \\
2,6-Lutidine & $5.12 \times 10^{-8}$ \\
Ammonia & $1.76 \times 10^{-5}$ \\
Methylamine & $3.70 \times 10^{-4}$ \\
t-Butylamine & $4.84 \times 10^{-4}$ \\
Triethylamine & $1.02 \times 10^{-3}$ \\
2,6-Lupetidine & $1.17 \times 10^{-3}$ \\
Piperidine & $1.33 \times 10^{-3}$
\end{tabular}


$\mathrm{cm}^{3} / \mathrm{min}$ and the temperature program rate was $20^{\circ} \mathrm{C} / \mathrm{min}$. The results are plotted in Figure A2. Physical adsorption is extensive at the low preadsorption temperatures, but there is no evidence of a high temperature peak indicative of an acid sites interaction.

These results are in sharp contrast to results obtained for the very strong base, piperidine, Figure A3. A distinctive high temperature peak was observed in the region 400$450^{\circ} \mathrm{C}$. Clearly there are acid sites on the silica-alumina too weak to interact with pyridine, but which interact strongly with piperidine. One can only speculate, but the shoulder on the high temperature peak may be due to a decomposition product. This feature is more pronounced at higher preadsorption temperatures.

TPD spectra for several organic bases, all preadsorbed at $120^{\circ} \mathrm{C}$, are plotted in Figure A4 for comparison. Piperidine, 2,6-lupetidine and triethylamine all exhibit definite high temperature interactions and all have similar basicities as shown in Table A1. Ammonia exhibits a high temperature peak, but at a lower temperature by comparison. Correspondingly, the basicity of ammonia is lower. Pyridine, the weakest base exhibits no high temperature interaction. Thus the results plotted in Figure A4 appear to conform roughly to expectations gleaned from the data of Table A1.

As exception, however, is provided by t-butylamine. The data of Figure A4 are replotted in Figure A5 for comparison with the t-butylamine TPD results. As expected from its strong basicity, t-butylamine does exhibit a high temperature peak. But the desorption temperature is lower than that of the much weaker base ammonia. Previous work has shown that t-butylamine does not simply desorb from these catalysts, but decomposes prior to desorption (44). The decomposition is probably acid catalyzed. These results suggest 


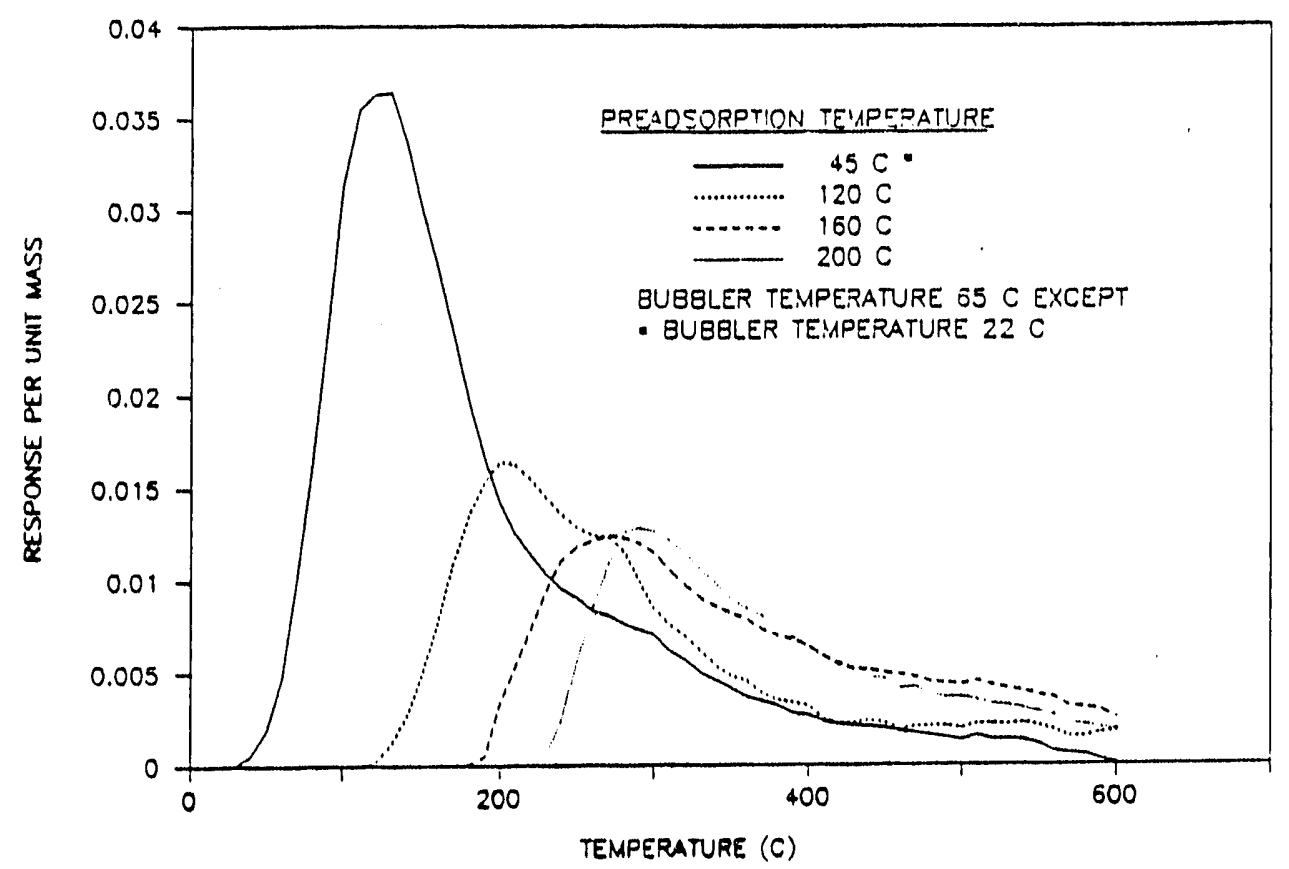

Figure A2. Effect of preadsorption temperature on pyridine TPD. Silica-alumina catalyst.

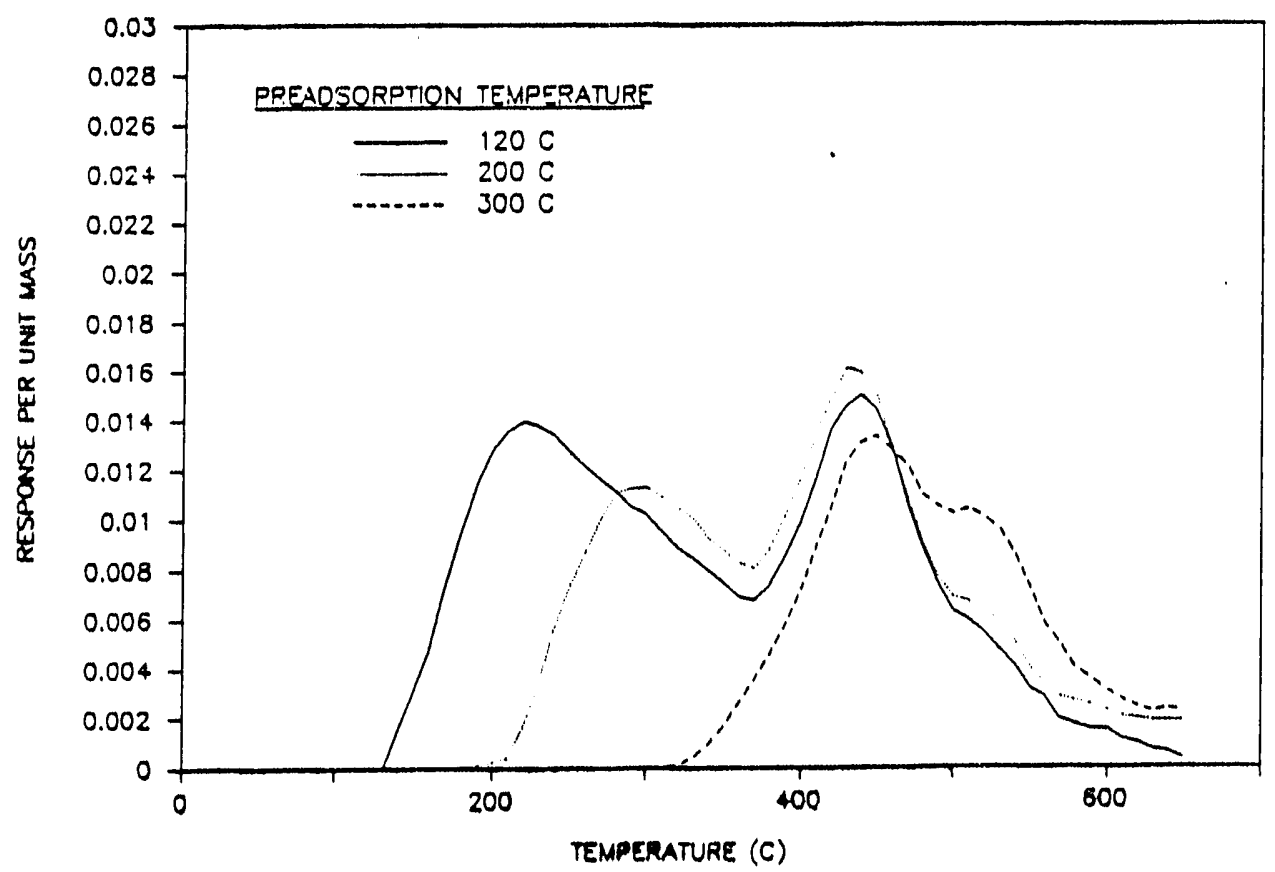

Figure A3. Effect of preadsorption temperature on piperidine TPD. Silica-alumina catalyst. 


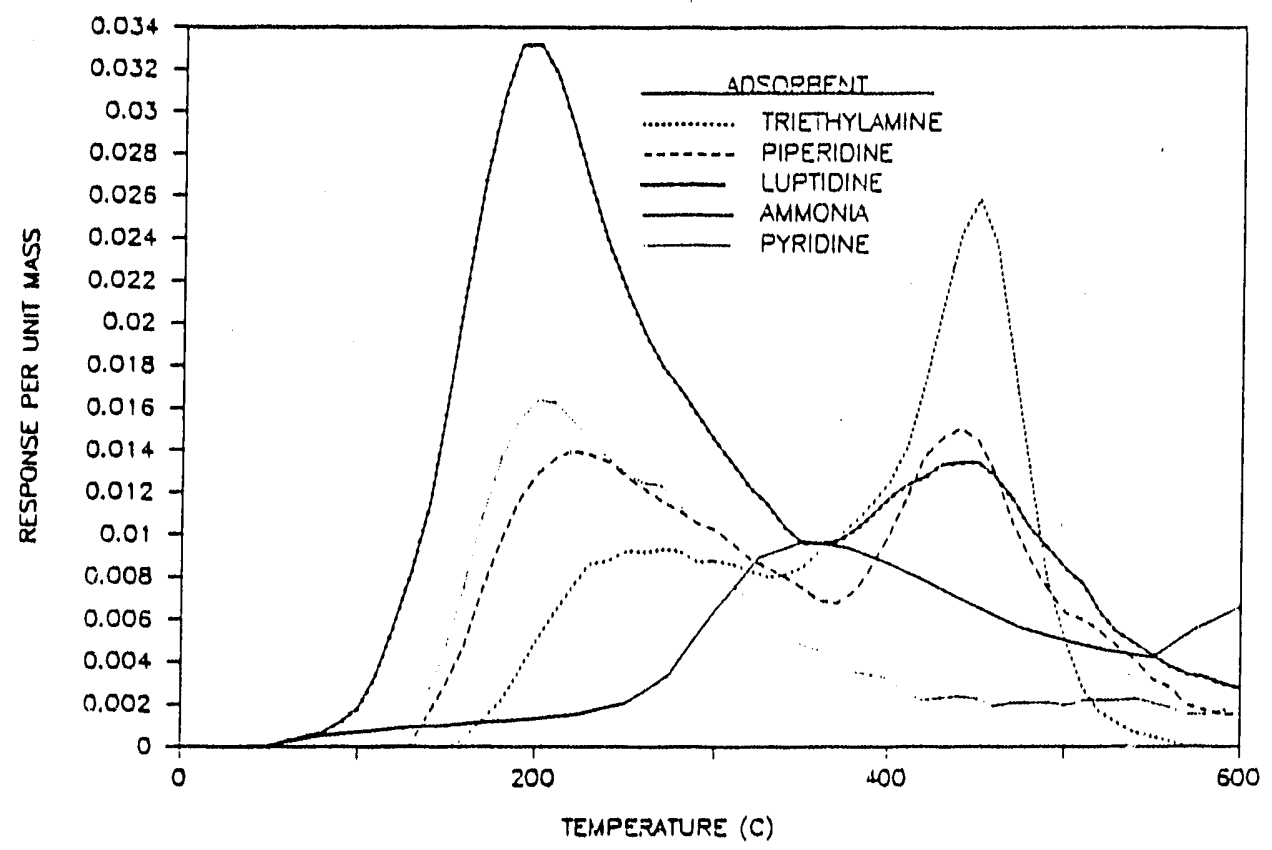

Figure A4. TPD spectra for several organic bases on silica-alumina. Preadsorption temperature $=120^{\circ} \mathrm{C}$.

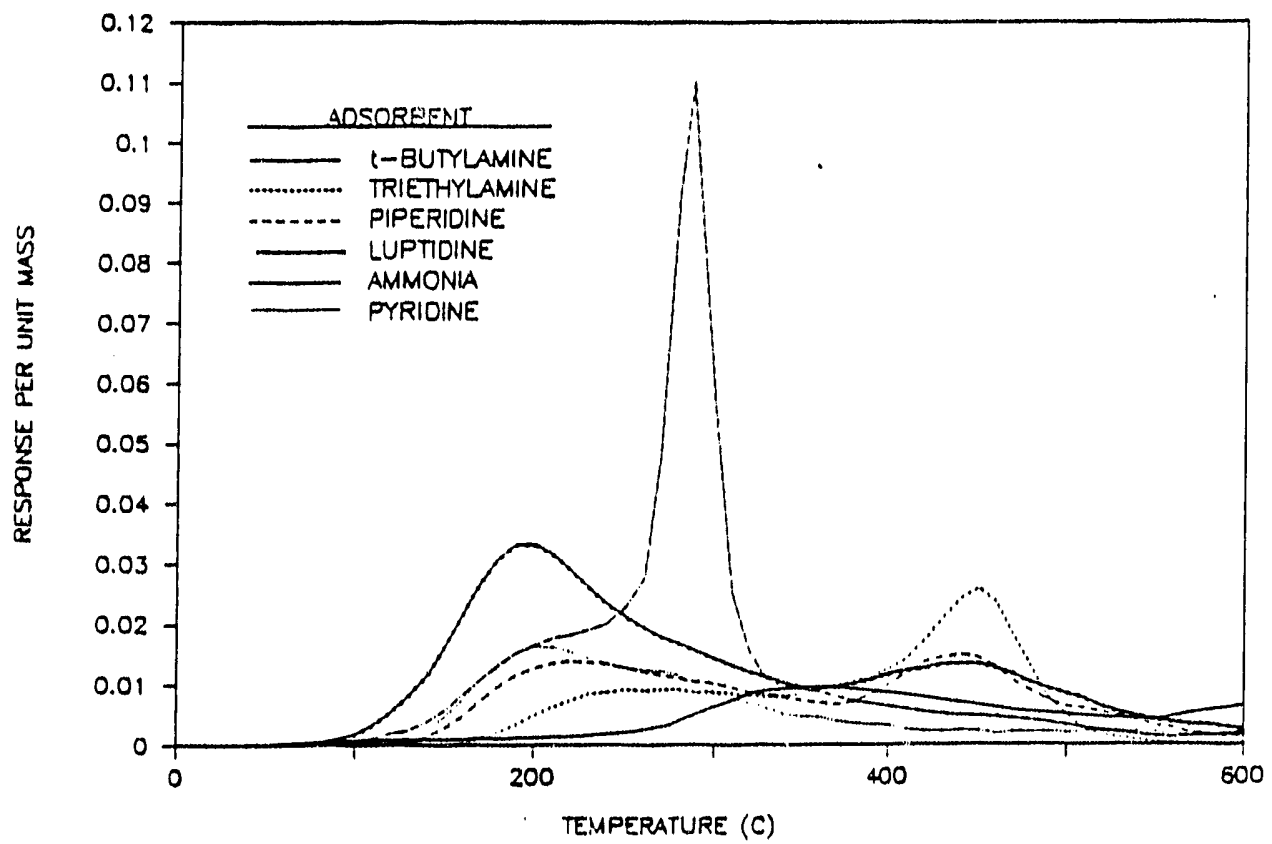

Figure A5. TPD spectra for several organic bases on silica-alumina compared with tbutylamine. Preadsorption temperature $=120^{\circ} \mathrm{C}$. 
that triethylamine, lupetidine and piperidine may desorb largely as the parent amine, and may therefore be used as a probe for acid site strength. Further confirmation is needed, however. 

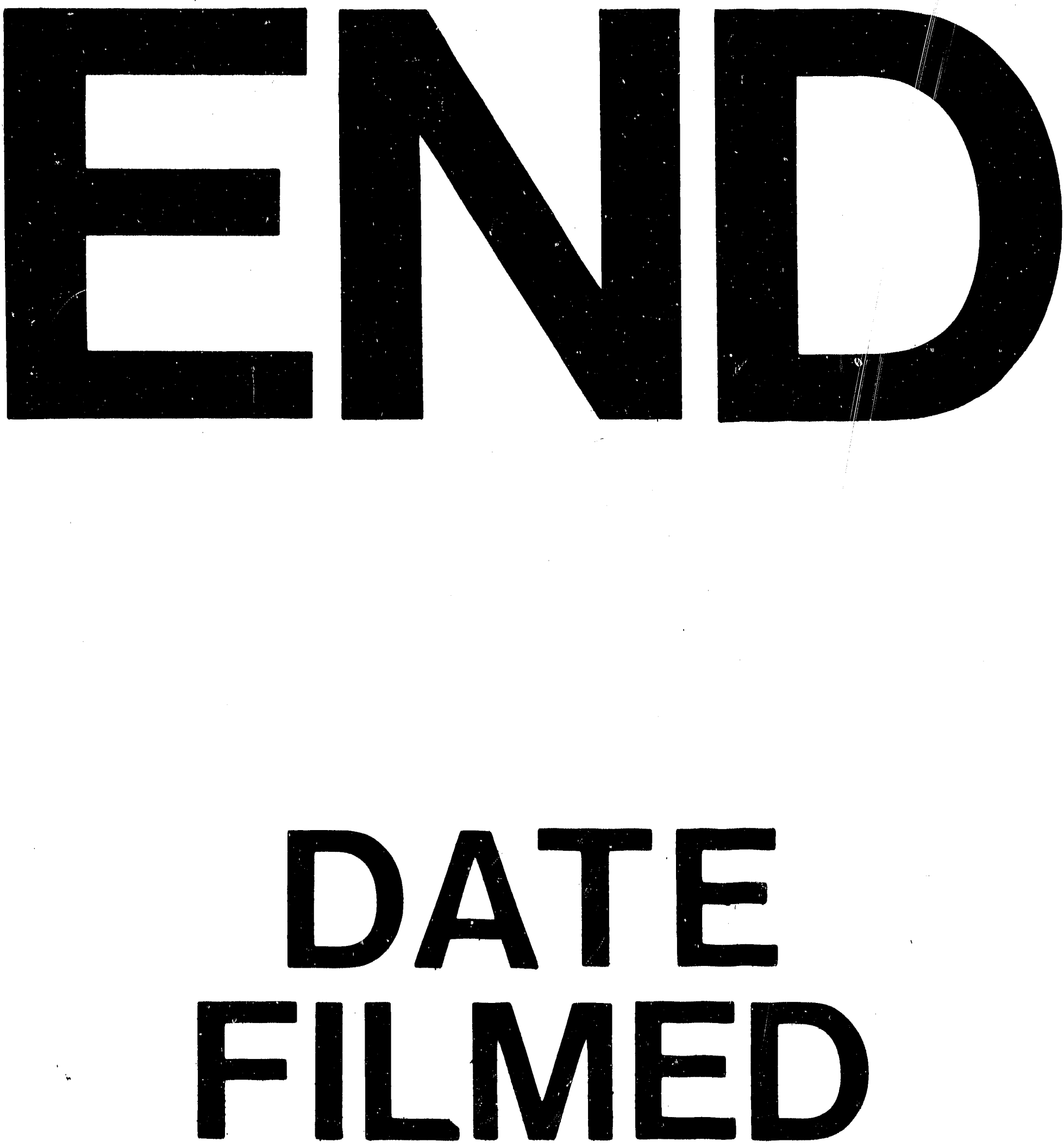

1

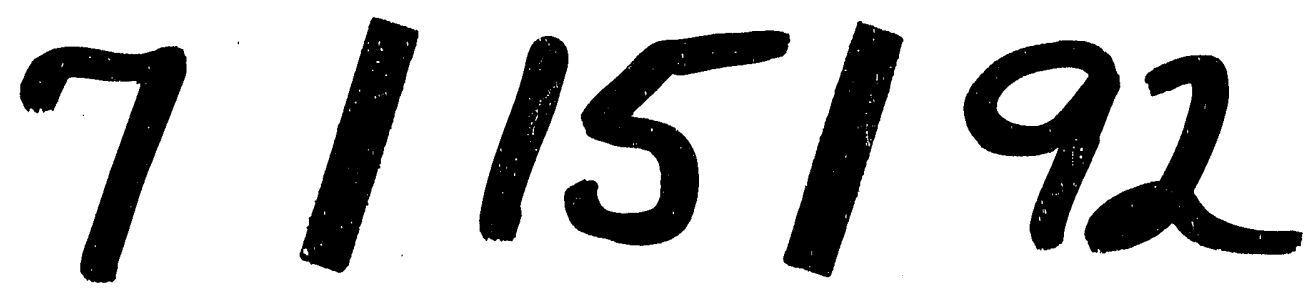




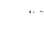

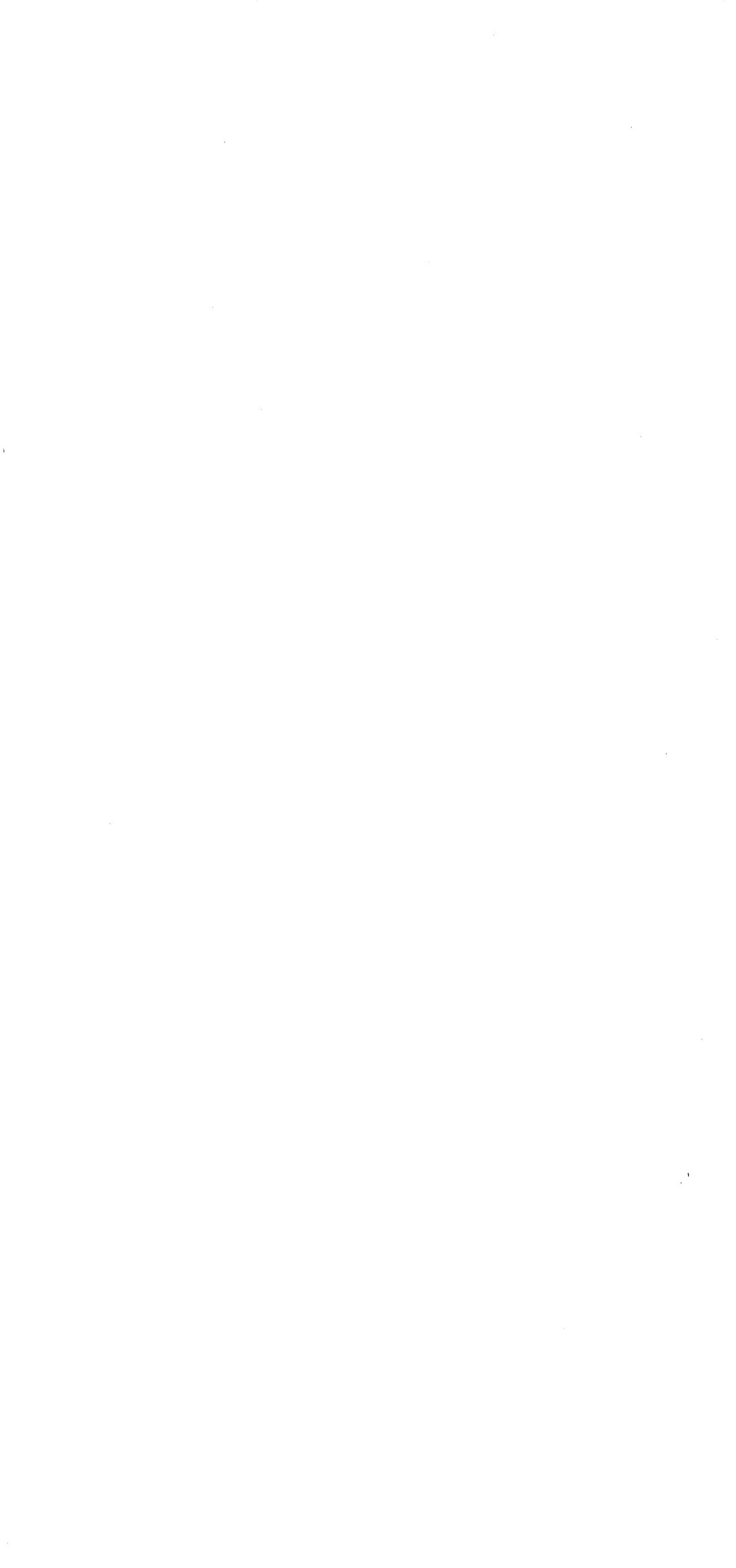

